\title{
MOLECULAR ION PHOTOFRAGMENT SPECTROSCOPY
}

\author{
Sanford Will Bustamente \\ Materials and Molecular Research Division \\ Department of Chemistry \\ Lawrence Berkeley Laboratory \\ University of California \\ Berkeley, California 94720 \\ Nowe mber 1983
}

\section{DISCIAAIMER}

\begin{abstract}
This report was prepared as an account of work sponsored by an agency of the United States Government. Neither the United States Government nor any agency thereof, nor any of their employees, makes any warranty, express or implied, or assumes any legal liability or responsibility for the accuracy, completeness, or usefulness of any information, apparatus, product, or process disclosed, or represents that its use would not infringe privately ownod rights. Reference herein to any specific commercial product, process, or service by trade name, trademark, manufaciurer, or otherwise does not necessarily constitute or imply its endorsement, recommendation, or favoring by the United States Government or any agency thereof. The views and opinions of authors expressed herein do not necessarily state or reflect those of the United Slates Government or any agency thereof.
\end{abstract}

This work was supported by the Director, Office of Energy Research, Office of Basic Energy Science, Chemical Sciences Division of the U.S. Department of Energy under Contract No. DE-AC03-76SF00098.

\section{NOTICE}

PORTIONS OF TMIS REPOBT ARE ILLEGIBLE. it has been repisduced from the best available copy to permit the broadest possible ayailability.

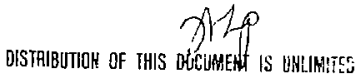


This report was done with support from the Department of Energy. Any conclusions or opinions expressed in this repor represent solely those of the author(s) and not necessarily those of The Regents of the University of California, the Lawrence Berkeley Laboratory or the Department of Energy.

Referenoe to a company or produce name does not imply approval or recommendation of the product by the University of Califormia or the U.S. Department of Energy tc the exclusion of athers that may be suitable. 


\section{MOLECULAR ION PHOTOFPAGMENT SPECTROSCOPY \\ Materials and Molecular Research Division Department of Chemistry Lawrence Berkeley Laboratory University of California \\ Berkeley, CA 94720}

Sanford Will Bustamente

\section{ABSTRACT}

A new molecular ion photofragment spectrometer is described which features a supersonic molecular beam ion source and a "radio frequency octapole ion trap interaction region. This unique combination aliows several techniques to be applied to the problem of detecting a photon absorption event of a molecular ion. In particular, it may be possible to obtain low resolution survey spectra of exotic molecular ions by using a direct vibrational predissociation process, or by using other more indirect detection methods. The use of the spectrometer is demonstrated by measuring the lifetime of the $\mathrm{O}_{2}^{+}\left({ }^{4} \pi_{4}\right)$ metastable state which is found to consist of two main components: the ${ }^{4} \pi_{5 / 2}$ and ${ }^{4} \pi_{-1 / 2}$ spin components having a long lifetime $(-129 \mathrm{msec}$.) and the $4_{3 / 2}$ and ${ }^{4} \pi_{1 / 2}$ sp in components having a short lifetime $(\sim 6 \mathrm{msec}$.). 


\section{ACKNOWLEDGEMENTS}

I would like to thank Professor Yuan T. Lee for his tolerance over the years. Also, I would like to thank Lee group members, present and past, for any assistance they may have rendered. Of special mention are Lee Carlson, who worked with me during the early days of this project, Dieter Gerlich, who designed the radiofrequency ion traps used in the spectrometer, and Frances Houle, who took most of the supersonic ion source data. In addition, I would like to thank Cydney Ramos for punching computer cards for me and for helping me assembie the final version of the octapole ion trap. Lisa Yeh and Mitchio Okumura, two swell guys who have taken over the ion spectroscopy project, are wished the best of luck.

Many thanks are extended to the Technical Information Department of LBL. Especially Shirley Ashley and Diana Morris for providing prompt, professional service.

Much appreciation is expressed to Mitchio, Lisa, and Alec wiodtke for their kindness, friendship, and assistance during my last weekends here at Berkeley. Bird, Lizard, Beetleman, and the Dog will be well remembered. But far above all, the Rambus family will always stand as the most meaningful and the most remembered part of my graduate school jears.

This work was supported by the Director, Office of Energy Research, Office of Basic Energy Science, Chemical Sciences Division of the U.S. Department of Energy under Contract No. DE-AC03-76SF00098. 
TABLE OF CONTENTS

ABSTRACT...........................

ACKNOHLEDGEMENTS........................ iv

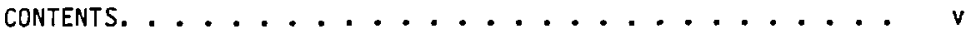

I. INTRODUCTION: CONSEQUENCE SPECTROSCOPY ........ 1

References................... 21

Figure Caption. .................. 23

Figure...................... 24

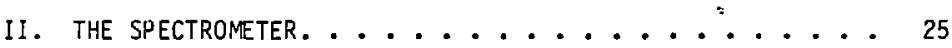

A. The ion source. ............... 25

?. The sector magnet ............... 34

C. The quadrupole lens pair. ......... 35

D. The quadrupole field deflector. ........ 37

E. The RF octapole trap............ 39

F. The QMF and detector.............. 45

G. The light source. ............ 46

H. Data acquisition and control......... 46

I. Performance ................. 47

References............... 48

Figure Captions............... 50

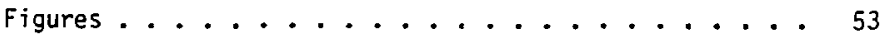

III. PHOTOFRAGMENTATION OF $\mathrm{O}_{2}^{+}$: THE LIFETIME

OF the a $a^{4}$ Metastable state ........... 88

A. Introduction. ............... 88

B. Experimental. ............. 90 
vi

C. Results and discussion. ............. 93

э. Conclusion. .................... 98

References...................... 99

Figure Captions ................ 102

Figures . . . . . . . . . . . . 104

IV. APPENDIX: DATA ACQUISITION PROGRAM ......... 116 


\section{INTRODUCTION: CONSEQUENCE SPECTROSCOPY}

Spectroscopy in the traditional sense is the measurement of those wavelengths of the electromagnetic spectrum at which molecular or atomic species will absorb or emit radiation. From detailed measurements one can infer energy levels and from these one can obtain a distinct picture of the potential energy surfaces influencing the motions of the atoms within a molecular species and how these atoms are arranged geometrica?ly in space. For nonreactive neutral species, spectroscopy can be just a matter of getting a sample of the species in question, shining light through the sample and making one or both of two basic measurements: one can measure the amount of light getting through the sample as a function of wavelength (the absorption spectrum) or one can measure the fluorescence from the sample. These measurements can be conducted with ease. By the astute application of lasers, with their well known properties, one may produce extremely high resolution spectra (the discussion here being limited to the gas phase spectroscopy of molecular and atomic srecies). But when speaking of the spectroscopy of molecular ions in this context, one finds that even at the most basic level, spectral information is quite limited. As for neutrals, knowing the spectroscopy of molecular ions would lead to the characterization of the potential energy surfaces of the ion and to its geometry. Knowing these facts about the ion can also lead to a better underjtanding of the neutral species the ion is derived from, as was the case in atomic spectroscopy. 
The presence of gas phase ions in flames, plasmas, electrical discharges, planetary atmospheres and interstellar clouds as well as their more common existence in liquids and solids has made their spectroscopy a valued resource to many scientists. With the spectra of an ion known, its presence in outer space can be evaluated and its influence in the chemistry of interstellar space and the atmospheres of planets (like Earth) can be modelled more accurately. In the laboratory, knowledge of the potential energy surfaces of jons in experiments measuring ion-molecule reactions in a state-to-state determination is, of course, vital.

The molecular ion $\mathrm{CH}^{+}$was detected spectroscopicalty in space some forty years ago(1) and for years stood as the only known absorption spectrum of a molecular ion. In the last ten years, however, there has been a virtual revolution in the field of ion spectroscopy. New sensitive techniques(2) along with laser light sources have been applied with gratifying success. About sixty ions have been studied with techniques which yielded at least rotational resolution. (2f) But this fact can be placed somewhat in perspective when one learns that to this date the structure of the common ion $\mathrm{CH}_{5}^{+}$has not been spectroscopically determined and that the high resolution spectra of $\mathrm{H}_{3} \mathrm{O}^{+}$was reported only very recently by Saykally et al. (3) With these facts in mind, we set out to build a spectrometer which would help fill in the void found in gas phase molecular ion spectroscopy by using a technique which would be more generally applicable than the methods used by existing instruments. 
The difficulty.

Why is the gas phase spectroscopy of molecular ions so difficult? We11, to put the relative difficulties somewhat in perspective, let us consider taking the infrared spectrum of $\mathrm{HCl}$ gas at room temperature. Suppose one fills some sample cell with 1 torr of $\mathrm{HCl}$ gas. With very little trouble, shen, one has a sample density of $-3 \times 10^{-16}$

particles $/ \mathrm{cm}^{3}$ of essentially one species, with a well defined themal population distribution to accomplish one's measurements with. One may generate an absorption spectrum with ease.

Now that one has the infrared spectrum of $\mathrm{HCl}$ neutral, it would be nice to have the spectrum of $\mathrm{HCl}^{+}$say, to be able to make all the comparisons one would like. Putting aside all the details of how the following condition is actually arrived at, we now have a container with electrons whizzing about creating $\mathrm{HCl}^{+}$from the neutral $\mathrm{HCl}$ gas originally in the container. But in addition to the two species above, orie also has other neutral and ionic species-a veritable zoo of charged and uncharged species. So here at the start our spectroscopy is complicated by the fact that we have a mixture in our container, rather than just a single species as in the neutral case. This conditicn is exacerbated by the fact that ion-molecule reactions are among the fastest of chemical reactions. Thes, the $\mathrm{HCl}^{+}$created tend to be short lived because they recombine with electrons found in their environment, react with other species present, or find their way to a container surface and thereby annihilating themselves. This al i leads to ion densities in typical experimental arrangements of $10^{4}$ to $10^{8}$ 
ions $/ \mathrm{cm}^{3}$. Note that the best case here is down by a factor of $10^{8}$ from our 1 torr sample of $\mathrm{HCl}$ neutral. of the $\mathrm{HCl}^{+}$that is created in this hodgepodge one has to put up with an additional ofstacle: because their envircilirent is generally hot, and because of the mechanism by which they are created, their population is partitioned among a large number of translational, rotational, and vibrational states, and perhaps even long lived electror: $:$ states. In short one does not have a 1 Torr sample of $\mathrm{HC}^{+}$gas to work with. What one does have is a sample so diiute and dirty that spectroscopy irecomes a very difficult, if not impossible, task.

The problems in trying to do spectroscopy on molecular ions in the gas phase have been mentioned above. What course shou?d be taken if one wants to succeed in overcoming these problems? Many approaches have been taken, several very similar to ours. The following discussion will develop our approach to the problem of gas phase molecular ion spectroscopy, with particulai interest in the infrared region, and concurrently will outline some detection techniques which have been tried by us and others or that cou?d possibly be used with some success.

A pure sample.

The first problem to be taken care of is the "hodgepodge" which exists in most ien sources. That is, we want only one molecular ion species in our "sample bottie," i.e. our interaction region. Thus, no matter what our source of ions is, the source must be followed by some 
sort of mass filter which allows only the ion of interest through into the interaction region. We ther have a nice pure sampie of a known species to work with. How this situation is maintained will be adiressed later.

Once the ions are in the interaction region they encounter a flux of photons from a light source and if the energy of these photons is equal to the spacing of sme allowed transition in the ion, photon absorption by the ions will take place. Here comes the part where "technique" is written in large letters: How does one tell whether or not the molecular ions have absorbed any of the incident photons? Hell, one searches for possible consequences of the adsorption process and then chooses the one best suited as a datection technique under the prevailing circumstances. At this point I wish to emphasize that the following is not intended to be, by any means, a comprehensive ruiew of the techniques used in gas phase molecular ion spectroscopy. Rather, it is just a bare bones sampling of the techniques, to sonewhat acquaint the reader with the field. Details may be gathered froin the references found at the end of this chapter.

Absorption and emission.

At the beginning of this chapter, two standerd spectroscopic techniques were mentioned: absorption and emission. Direct absorption measurements are generally riut practical in molecuisu ion spectroscopy. For example, suppose one has 10,000 ions of species $A^{+}$in an interaction region through which is passed an infrared light pulse 
containing $10^{16}$ photons $(\sim 1 \mathrm{mj} / \mathrm{pulse}$ at $3.5 \mu)$. And suppose one ion in 100 absorbs a photon, i.e. 100 photons were absorbed by îhe sample. One can easily see that there is no way that this absorption loss will be measured in a photon pulse containing $10^{16}$ photons originally. However, although uncommon, there are experimental arrangements which make the above technique possible. For example, in 1974, a direct microwave measurement of $\mathrm{CC}^{+}$through the plasma of a $\mathrm{DC}$ glow discharge was accomplished by Dixon and Woods (4) yielding very high resolution spectra. While the source provided a greater-than-average ion density $\left(\sim 10^{10}\right.$ ion $\left./ \mathrm{cm}^{3}\right)$, the spectra of the ions were quite weak. Therefore lise of sensitive modulation methods and computer signal averaging are required to make the measurements possib?e. More recently the technique of velacity-modulation absorption spectroscopy developed by Saykally et al. (5) has been successful in observing the spectra of several ions with high resolution in the infrared. Emission and fluorescence studies of molecular ions in the visible and near ultraviolet parts of the spectrum is feasible, but difficult because of low ion number density. Unfortunately, in the infrared region of the spectrum, lack of detectors with extremely high sensitivity, coupled with the long lifetimes of vibrationally excited states, make tnis method impractical.

Laser magnetic resonance (2f) has also been successfully applied to the study of molecular ions. However, since this technique, applies only to paramagnetic species, it is not as general as one would like. 
Also the spectroscopy is complicated by the required presence of a magnetic field and by the fact the plasma source used in such experimerits usually produces a mixture of ions which is vibrationally very hot. The technique does, however, yield nice high resolution data.

Ions are charged.

Most of the methods described above do not make any use of the fact that ions, by their defining characteristic, are charged species. The charged quality is of course the root of the difficulty in attempting their spectroscopy, but one may in turn use this apparently baneful characteristic to great advantage and thus overcone some of the shortcomings involved. One attribute of ions is that they can be detected with efficiencies close to unity. Thus if the "consequence" to be measured pertained to ion counting, rather than photon counting as above, one could possibly achieve the very high sensitivity necessary to combat the problem of low ion density.

Consider again the 10,000 ions in an interaction region in their ground state and call them species $A^{+}$. Suppose that in the ground state species $A^{+}$will not react with the neutral barkground species $B$, which is also in the interartion region, but if $A^{+}$absorbs an IR photon, it will then react with $B$ to give products $C^{+}$and 0 , according to the following reaction: 


$$
\begin{array}{ll}
A^{+}+B-1-1 \rightarrow & \text { ground state does not react } \\
A^{+}+h \nu \longrightarrow A^{+\star} & \text { absorption } \\
A^{+\star}+B \longrightarrow C^{+}+D & \text { exited state reacts. }
\end{array}
$$

Furthermore, suppose that in some way all the ions can be guided to a mass filter which transmits only species $\mathrm{C}^{+}$to an ion detector having near unit counting efficiency. Now before the light pulse passes through the interaction region, all the $A^{+}$are in the.jr ground state. This implies there will be no reaction, and thus no $\mathrm{C}^{+}$production. If the ions were to be sent on towards the detector, no counts would result. After the light pulse passes through, $100 \mathrm{~A}^{+}$ions are no longer in their ground state (using the same figures as beforæ) and may now react with species $B$ to form $C^{+}$and $D$. Now senting the ions forward through the mass filter would result in approximately 100 counts being registered $\left(100 \mathrm{C}^{+}\right.$product). These 100 counts are attributed to the absorption events. Here we have a case where by using ion counting, one can detect virtualiy every absorption event which took $p$ lace in this very small sample of ions.

The types of reactions which may be used in schemes such as the one above are:
(1) charge exchange
$\mathrm{A}^{+}+\mathrm{B} \rightarrow \mathrm{A}+\mathrm{B}^{+}$
(2) collision induced dissociation

$$
\mathrm{A}^{+}+\mathrm{B} \rightarrow \mathrm{C}^{+}+\mathrm{D}+\mathrm{B}
$$
(3) proton transfer

$$
\mathrm{AH}^{+}+\mathrm{B} \longrightarrow \mathrm{A}+\mathrm{BH}^{+}
$$


and (4) other reactions where mass $A$ \& mass $C$

$\mathrm{A}^{+}+\mathrm{B} \longrightarrow \mathrm{C}^{+}+\mathrm{D}$.

The situation described above is of course the ideal case with no $\mathrm{C}^{+}$being produced when the light is off and all $\mathrm{C}^{+}$produced when the light is on being caused by the absorption events. There are numerous examples which approach this ideal. But more generally one may expect that the lower state will have a reactive cross section comparable to the upper state and of course the species $A^{+}$in the interaction region may well be spread over several states initially. Thus, when the $\mathrm{A}^{+}$absorbs photons, only a change in the amount of $\mathrm{C}^{+}$produced will be seen; but this percentage change is still very much larger than the percentage of photons lost to the sample. Thus, in most cases the detection process is more difficult than the ideal flip-in experiment, but is still very doable.

Charge exchange was the detectio- scheme used by Wing et al. (6) who were the first to observe the infrared spectrum of a molecular ion, specifically $\mathrm{HO}^{+}$. After the $\mathrm{HD}^{+}$had interacted with a laser beam, it was passed through a target gas $\left(\mathrm{Ar}, \mathrm{N}_{2}\right.$, or $\mathrm{H}_{2}$ ) and the surviving $\mathrm{HO}^{+}$exiting the target region was measured by a Faraday cup. Since the charge exchange process occurring in the target gas region is a function of the vibrational state of the $\mathrm{HD}^{+}$, smali changes in the beam current $(-3 \mathrm{ppm})$ were observed when on resonance. Carrington et al. (7) also used the charge exchange technique to detect electronic absorptions in the molecular ion $\mathrm{CO}^{+}$and used the reactive cross section method in observing a single rotational line of $\mathrm{H}_{2} \mathrm{O}^{+}$. (2f) 
Photodetachment.

Photodetachment is a technique applicable to negative ions. (2e) The technique hinges on the fact that absorption of a photon with energy above some limit will cause the ejection of an electron from the ion, thus creating a neutral species:

(5) $A^{-}+h v \rightarrow A+e^{-}$

Here one monitors the decrease of the $\mathrm{A}^{-}$parent ion as a function of wavelength. This results in data with more noise than a flop-in experiment since one is often times observing small changes in the parent ion count rate caused by the photodetachment process. This would be like detecting the decrease in the parent ion $A^{+}$rather than detecting the appearance of $\mathrm{C}^{+}$product in the ideal chemical reaction technique considered earlier.

Photofragmentation.

Dunbar says in his review(2b) "photodissociati.n spectroscopy relies on the truism that before an ion can dissociate, it must absorb a photon." Photofragmentation is another one of the possible consequences of an ion absurbing a photon, but it is a very important one in the field of molecular ion spectroscopy. Photofragmentation offers extremely high detection sensitivity because one detects the daughter ion fragment formed in the process 
(6) $A^{+}+h v \rightarrow B^{+}+C$

just as one would detect the $\mathrm{C}^{+}$product ion in the chemical reaction scheme discussed before. But in photofragmentation all one needs in the interaction region is the species being studied. There is no need for a neutral reaction partner. So one always has an "ideal" case as Tong as the vacuum in the interaction region is good enough to prevent ion-molecule reactions, now unwanted, from occurring. The success or failure of the photofragmentation detection method rest mainly in the properties of the ion under study. Are the potential energy surfaces of the ion placed so that upon absorption of a photon of a particular snergy, fragmentation will occur?

Electronic transitions leading to direct dissociation or predissociation have now been used extensively tu obtain the photofragment spectra of gas phase molecular ions both large and small. When conditions are right, as for the $0_{2}^{+}\left({ }^{4} \Sigma_{g}^{-} \leftarrow-{ }^{4} \pi_{u}\right)$ bands, photofragment spectroscopy with fast ion beam techniques yield very high resolution spectra which are unsurpassed by other techniques. The photofragment spectrometer at SRI International is one of the most sophisticated fast ion beam instruments, ${ }^{(8)}$ and it can be operated in several modes (e.g.. optical-optical double reasonance has been performed on $\left.\mathrm{O}_{2}^{+}\right)^{(9)}$ yielding a remarkable quantity of detailed information on the $\mathrm{O}_{2}^{+}$quartet potentials. 
Vibrational Predissociation.

Vibrational predissociation has not been used as a detection scheme in molecular ion studies. This is simply because, unlike optical transitions which pump a considerable amount of energy into a molecule, vibrational transitions in infrared $\left(400-4000 \mathrm{~cm}^{-1}\right)$ typically do not have enough energy to initiate fragmentation. But there are exceptions. Some ions produced by electron impact ionization are highly vibrationally excited. To the extent that some levels populated are near a dissociative channei of the ion, absorption of an IR photon can induce fraginentation of the ion.

Clusters, or van der Waals molecules, are chemical species which are held together by weak bonds; usually about one tenth the energy of a! IR photon. In the case of neutral van der Waals complexes, vibrational predissociation has been observed and has been used as a spectroscopic \pm 001 to generate the spectra of molecular clusters: (10)

$$
\left(\mathrm{C}_{6} \mathrm{H}_{6}\right)_{2}+\mathrm{h}_{v} \longrightarrow 2 \mathrm{C}_{6} \mathrm{H}_{6}
$$

\section{Lasers.}

Just as one may take advantage of the great sensitivity afforded by ion detection schemes to help overcome the low number densities typically found in gas phase ion spectroscopy, so has the advent of the laser as a common spectroscopic light source been invaluable in the study of molecular ions. The laser, with its well known beam 
qualities, makes it possible to achieve high photon fluxes through the ion interaction region, thus helping to compensate for the low ion number densities one has to work with.

One should not take a cavalier attitude when it comes to the design or selection of the laser light source. There are numerous factors which must be kept in mind in this regard. One simple feature which should not be overlooked in evaluating the effectiveness of the light source is its linewidth relative to that of the molecular transition one is expecting to excite. Serious deviations in the expected signal-to-noise can result if this is not considered. For example, say the laser produces lots of IR photons $\left(\sim 10^{16}\right.$ per pulse), but that the spectral width of the pulse is $-1 \mathrm{~cm}^{-1}$ while the transition of the molecular ion has a total width of -0.01 $\mathrm{cm}^{-1}$. In this case, because of the spectral width mismatch, only $\sim 1$ percent of the laser energy will be resonant with the transition. It becomes obvious that one should tajlor the laser's characteristics so as to optimize the desired resolution and signal of the particular measurement being made.

Design goals.

One desired condition in the spectroscopy of molecular ions is to have a pure sample. Hence, it is desirable to use a mass filter following the ion source. In addition several detection schemes have been outlined. Before making any further statements about how the 
spectrosccpy is to be accompiished, one should state what the desired goals are for the spectrometer. These design goals should be within the limits set by experimental practicability.

What is it that we want to accomplish in this fieid where practically any piece of information is a new piece of information? Our primary objective was to have a generally applicable technique able to generate survey infrared spectra of gas phase molecular ions. High resolution spectroscopy was relegated to subsequent investigations. That is, once one has a low resolution spectra of an ion, ther une can go back and use techniques that yield higher resoluxion, but that would have been impractical to use as a survey method.

Thus, our primary aim is to do survey (low resolution) infrared spectroscopy of ions in a general fashion. Clearly, it would be nice to have a sample of cold ions-ions in their ground electronic and vibrational siat-. This would make the spectrum generated easier to interpret and would give information concerning the lower levels of the ground electronic state, informaition generally difficult to ontain for ions. If one had enough resolution to resolve rotational structure, then moments of inertia could be calculated, yielding structural information. Of the techniques mentioned previously, which would give the ability to observe the infrared absorption process directly with the required high sensitivity so necessary for success Well, vibrational predissociation is a likely cendidate, but what about having cold ions and the desired generality of the scheme 
The molecular beam mentality.

our research grolip is heavily into molecular beams. As a consequence, solutions to many prublems are viewed with a certain molecular beam mentality, which many times is quiti fruitful. In this case, the knowledge that with molecular beams one can easily make very cold clusters of various compositions, made the idea of vibratiunal predissociation of neutral and ionic van der Waals complexes a natural.

The idea goes like this. Suppose one wants to get the infrared spectrum of the molecular ion $\mathrm{M}^{+}$. What one does is form the van der Waals species $M^{+} \cdots x$, where $x=$ He or $A r$. The binding energy of this complex is bound to be quite low, undoubtedly much lower than the energy of an inf rared photon $\left(400-4,000 \mathrm{~cm}^{-1}\right)$. (12) Once we have formed this species, things are a snap. The selected compiex is deposited into the interacton region, which is a region of ultra high vacuum thus minimizing collisional dissociation of the weakly bond complex by neutrals. While in the interaction region, the ions are bathed with a healthy pulse of IR photons. If the wavelength is correct, the $M^{+} \cdots \times$ complex will absorb a photon. The energy absorbed will rattle around the complex until enough is transferred to the weak bond to cause its rupture,

$$
M^{+} \cdots x+h_{v} \rightarrow M^{+}+x(h y=I R) \text {. }
$$

So here we have a method which promises to be general (so long as the complex can be made) nd which uses vibrational predissociation to directy view the absorption process. Very high sensitivity would be 
achieved by mass selective ion counting. A spectrum would be generated by counting the $\mathrm{M}^{+}$product as a function of the infrared wavelength, which is scanned.

Drawbacks.

The scheme looks good. Much could be learned about the $\mathrm{M}^{+} \cdots \mathrm{X}$ complex itself and about the $\mathrm{M}^{+}$ion, if all worked out well. But, as hinted at above, barriers exist which might preverit our goal from being achieved. For one thing no proven source for generating lots of the $M^{+} \cdots x$ complex exist. The end result may be that we will have very few complexes to work with-much liss than typically found in ion spectroscopy. But it should be easier to generate ion clusters of the type $(M)_{n}^{+}$or the protonated $(M)_{n} \mathrm{H}^{+}$species with which one could perform vibrational predissociation experiments if the cluster size is large enough:

$$
(M)_{n}^{+}+h_{v} \rightarrow(M)_{n-1}^{+}
$$

The number of ion clusters may be so low that the number of ions illuminated by a light beam with $1 \mathrm{~cm}^{2}$ cross section, crossing at right angles to the ion beam, would be quite a bit less than one. To help mitigate the problem of having extremely few ions, a coaxial light source, slow-ion-beam arrangement was decided upon. Thus, in an ultra high vacuum environment, slowly moving ions travel througr: a long interaction region through whic: light sulse propogates. This 
configuration provides good spatia! overlap of the ions with the light source and increases the number of ions in the interaction region per -Tight pulse.

In addition to the need for a good ion beam-light beam overlap, one also needs all ions (targets and fragments) to be guided to the detector. A radio frequency (RF) ion guide can accomplish this task quite efficiently. And as an added bonus, by placing ion mirrors at either end of the ion guide, one can trap the ions within the guide. Having an $\mathrm{RF}$ ion trap for an interaction region proves beneficial in other respects. With the trap one need not worry about the time it takes for the vibrational predissociation event to take place. One just keeps the excited complex trapped until the bond rupture takes place, then feeds the products to the detector. Experience gained from the vibrational predissociation of neutrals indicates that these times are short, and thus are of no practical concern.

If one is working with ions which are vibrationally or electronically hot, one may use the trap as a cooling tank. Not only could one possibly use this method to get the spectrum of the relaxed ion, but one could also measure the radiative lifetimes of various excited states. One excellent use of the ion trap is to guide reactant ions and their products through a background gas and finally to the detector in schemes which fall under the "chemical reaction" category discussed earlier. A machine in our group uses this "guided ion 
technique" t,o measure total cross sections in ion-molecule reactions. (11) Having an RF ion trap for the interaction region is very convenient.

Let us get back to the draw backs of using $M^{+} \cdots \times$ complexes in our spectroscopy scheme. The spectrum we are after is that of the $\mathrm{if}^{+}$ion, but what we are generating is the spectrum of the complex. Now this in itself is of interest, since it gives us structural information of the complex and possibly the time scale for the predissociation. However, the intent is to study the of $\mathrm{M}^{+}$ion. The situation here is not too bad. Although the rotational structure of the tr asitions would be expected to be characteristic of the complex as a whole, the vibrational stru ture shculd be essential?y that of $\mathrm{M}^{+}$alone. Furthermore, as stated before, once one has found the wavelength regions where the $\mathrm{M}^{+}$ion absorbs by using the survey method, perhaps one can return to the problem with a high resolution technique, and acquire the rotational structure of the uncomplexed ion.

Roundup.

Here the essential qualities of a spectrometer capable of acquiring the low resolution infrared spectrum of a molecular ion $\mathrm{M}^{+}$ by directly observing the vibrational predissociation products of the related van der Waals ion $M^{+} \cdots x(X=H e, A r)$, are stated. The basic requirements are:

1) An ion source region with high pumping speed and high throughput capability able to support the gas loads created by the 
supersonic molecular heam source used to form the cold $\mathrm{M}^{+} \cdots \times$ type van der Waals molecular ions.

2) A mass filter following the ion source so that one may select the species placed into the interaction region. The filter should provide good ion-beam quality and luminosity.

3) An ultra high vacuum interaction region shoulc provide a clear through shot for the light scurce and should support slawly moving ions over a long straight path so that good spitial overlap between the ion beam and light beam can be achieved. The ion optics here must be $a b$ ? e to guide all ions, parents and fragients, to the final sections of the spectrometer.

4) After the interaction region comes a second mass filter which allows one to select which mass the ion detector views. This gives the high sensitivity, low background detection necessary for success.

5) One needs an ion detector with low inherent dark count and reasonably fast response time.

6) And finally, a necessary component which is physically separate from the above, but is an integral part of the spectrometer system, is the light source. Without the advantages rendered by a good inirared laser light source, the project would be doomed. Lots of photons are needed to help overcome the lack of ion density.

A functional block diagram of the spectrometer is shown in Fig. 1. The success of the instrument as an infrared molecular ion spectrometer of general utility depends on the successful operation of the following three components: 
1) the ion source producing $M^{+} \cdots \times$ complexes.

2) the ion trap used to achieve adequate ion-laser spatial overlap and to guide all ions to the detection stage.

3) the infrared laser light source.

If any of the three fails, then the spectrometer becomes just a run-of-the-mill tandem mass spectrometer capable of low resolution photofragment spectroscopy. 


\section{REFERENCES}

1. W. S. Adams, Astrophys. J. 93, 11 (1941).

2. (a) G. Herzberg, Rev. Chem. Soc. 25, 201 (1971).

(b) R. Dunbar, "Ion Photodissociation," in Kinetics of Ion-Molecule Reactions, edited by P. Ausloos, Plenum Press, New York (1979).

(c) J. Moseley and J. Durup, "Fast Ion Beam Photofragment Spectroscopy," Ann. Rev. Phys. Chem. 32, 53 (1981).

(d) L. Andrews, "Spectroscopy of Molecular Ions in Noble Gas Matrices," Ann. Rev. Phys. Chem. 30, 79 (1979).

(e) R. R. Cordeman and W. C. Lineberger, "Negative Ion Spectroscopy," Ann. Rev. Phys. Chem. 30, 347 (1979).

(f) R. J. Saykally and R. C. Woods, "High Resolution Spectroscopy of Molecular Ions," Ann. Rev. Phys. Chem. 32, 403 (1981).

(g) Molecular Ions: Geometric and Electronic Structures, edited by G. J. Berkowitz and K. O. Groeneveld, Proc. NATO Advanced Study Institute, Sep. 1980, Plenum, New York (1983).

3. M. H. Begemann, C. S. Gudeman, J. Pfaff, and R. J. Saykally, Phys. Rev. Lett. 51, 554 (1983).

4. T. A. Dixon and R. C. Woods, Phys. Rev. Lett., 34, 61 (1975).

5. C. S. Gudeman, M. H. Begemann, J. Pfaff, and R. J. Saykally, J. Chem. Phys. 78, 5837 (1983).

6. W. H. Wing, G. A. Ruff, W. E. Lamb, and J. J. Spezeski, Phys. Rev. Lett. 36,1488 (1976).

7. A. Carrington and P. J. Sarre, Molec. Phys. 33, 1495 (1977). 
8. B. A. Huber, T. M. Miller, P. C. Cosby, H. D. Zeman, R. L. Leon, 3. T. Moseley and J R. Peterson, Rev. Sci. Instrum. $\underline{48}, 1306$ (1977).

9. P. C. Cosby and H. Helm, J. Chem. Phys., 76, 4720 (1982).

10. M. F. Vernon, "Molecular Beam Scattering," Chap. 2, Ph.D. Thesis, University of California, Berkeley, CA (1983).

11. S. L. Anderson, "The Effect of Vibrational Excitation on the Dynamics of Ion-Molecule Reactions," Ph.D. Thesis, University of California, Berkeley, CA (1981).

12. D.L. Cooper and S. Wilson, Molec. Phys. 44, 161 (1981). 


\section{FiguRE CAPTION}

Fig. 1. A functional block diagram of the molecular ion photofragment spectrometer using a tandem mass fitter configuration and an ion guide interaction region. 


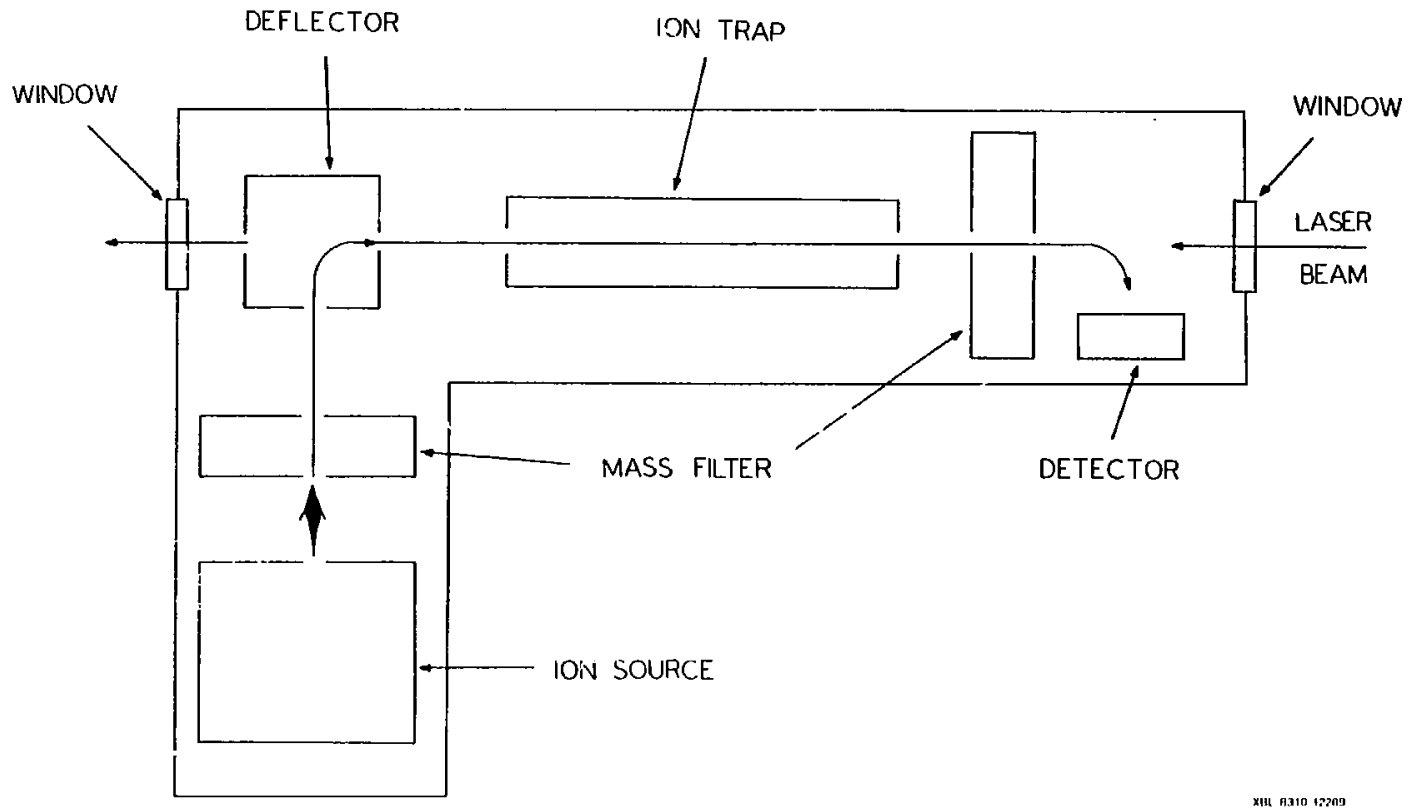

Figure 1 


\section{THE SPECTROMETER}

In Chapter I the general description of the spectrometer we wished to construct was laid out. It was to be a low resolution infrared photofragment spectrometer of general applicability. This chapter will take a look at what was actually built in the attempt to resch our design goals.

\section{A. The Ion Source}

On first seeing our spectrometer, one is apt to ask "why in the heck is the darn thing so big?" The answer is two-fold. first, some parts are large because they are just remakes of existing beam designs found in our group or are surplus items, such as the large sector magnet used as the first mass filter. Second, and more importantly, the source region is large because it has to accommodate not only conventional ion sources, such as electron impact ior. zers, duoplasmatrons, etc., but also the high pressure expansion beam source. The molecular beam source operates at abcut one atmosihere through a $100 \mu \mathrm{m}$ diameter orifice creating a large demand on the system's pumping speed and throughput capabilities. The spectrometer must have sufficient differential pumping to maintain the interaction region at about $10^{-12}$ atmospheres when the nozzle is operating at 1 atmosphere. The ion source is mounted in Region I of the spectrometer (see Fig. 1). This region is pumped by a high speed 10 inch diffusion pump (Varian VHS-10) charged with Convalex-10 pump oil, as are the other 
two diffusion pumps used on the spectrometer. This pump is trapped by a liquid nitrogen cooled chevron baffle in order to minimize the backstreaming of oil into the ion source region. Metal surfaces must be kept free of oil, so that surface charge build up will not be a problem. If the throughput from this region is large, the diffusion pump is backed by a $1501 \mathrm{sec}^{-1}$ Roots blower. This combination can maintain the high pumping speeds and throughputs which are necessary when the supersonic beam source is employed.

Region II of the source (see Fig. 1) contains the lens system (Fig. 2) used to accelerate and focus the ions issuing from the ion source. Deflection plates steer the ion beam either to a quadrupole mass spectrometer for source optimization or to the sector magnet which selects the ion mass sent on into the interaction region. Region II is pumped by a liquid nitrogen trapped, six inch diffusion pump (Varian M-6). This region should have pressures below $10^{-5}$ torr when the supersonic source is being used.

The supersonic ion beam source to be described is basically an atmospheric pressure ionizer(1) used in mass spectrometry, except that here the intent is to form clusters, or van der Waals complexes of some $p a^{r}$. inlar species $M^{+}$. The working idea is to form a weak plasma at pressures of about one atmosphere by using the b-rays of some radioactive element, usualiy $63_{\mathrm{Ni}}$ or ${ }^{3} \mathrm{H}$. Because high temperature bakeouts are often needed to clean out the nozzle system, $63_{\mathrm{Nj}}$ is perhaps the better choice, but we bought ${ }^{3} \mathrm{H}$ foils opting for the higher activity available from tritiated foils. As Fig. 3 
shows, the radioactive foil, curled to form a cylinder, is placed in a small tube so that it is near the nozzle orifice. The gas mixture to be ionized is fed in through the inlet tube until it fills the nozzle cavities. If the vent line of the nozzle is closed, the only flow of gas is through the orifice placed near the foil's active region. If the vent line is opened, one may have a controlled flow of gas above that which flows out the orifice, so that one may dictate the amount of time the volume of gas remains in the region of the radioactive foil. This extra flow can mitigate the effects of unwanted side reactions.

The light plasma, formed within the nozzle by the B-particles acting on the gaseous species, gives rise to a complicated array of ion chemistry. One wants the b-particles to interact with some carrier gas directly, to form ions and excited states, and then subsequenty to have these ions and/or metastable species interact more softly with the species one really wants ionized, but not torn to bits. For example, suppose one wants to ionize species $M$ by using the above scheme. One would whip up a mixture of say 99 percent argon and 1 percent species $M$, and then send it down the tube to meet its foil. Within the foil's volume, the s-particles would, by chance, interact with the argon atoms directly, forming $\mathrm{Ar}^{+}$and $\mathrm{Ar}^{*}$ (metastable state). These two species would then interact with M via collisions within the light plasma :

$$
\begin{aligned}
& B+A r \longrightarrow A r^{+}+2 e \\
& B+A r \longrightarrow A r^{*}+e
\end{aligned}
$$




$$
\begin{aligned}
& \mathrm{Ar}^{+}+\mathrm{M} \longrightarrow \mathrm{M}^{+}+\mathrm{Ar} \\
& \mathrm{Ar}^{*}+\mathrm{M} \longrightarrow \mathrm{M}^{+}+\mathrm{Ar}+\mathrm{e}
\end{aligned}
$$

Process (3) is simply a charge exchange reaction and process (4) is termed Penning ionization. Ideally these would be the only processes occurring within the plasma. The light plasma consisting of charged species $\mathrm{M}^{+}$, e, and $\mathrm{Ar}^{+}$would expand into the vacuum along with the neutrals Ar and $M$ to form the supersonic molecular beam. One would then adjust parameters such as temperature and stagnation pressure to optmize the formation of the desired van der Waals ion, which might be $M^{+} \cdot$ Ar in this case. If enough of the complex is made, then the fun part begins. What color light makes it fall apart again

But things are somewhat more compicated than outlined above. The complication arises because ion-molecule reactions, as stated earlier, are very fast, and so the charge can be passed from one species to another. The positively charged species found in the plasma, referred to as the terminal ions, are those which are the most stable. Water seems to be present in any vacuum system, so given sufficient time, one usually ends up with the terminal ions being $\mathrm{H}_{3} \mathrm{O} \cdot\left(\mathrm{H}_{2} \mathrm{O}\right)_{n}^{+}$ ions, where $n$ range from zero to surprisingly large numbers. This distribution of water cluster ions depends on the temperature, the water concentration, other species present, and the time giver to react. (1a) Thus, it becomes more clear why it is desirable to be able to bake out the sy'stem, control the temperature, and by using the extre low via the vent tube, to control the residence time of the 
plasma in the foil region. The ion spectrum one gets in a particular case is difficult to predict because of the wide variety of ionization routes available. These can be characterized as follows:

$$
\begin{aligned}
& A^{*}+B \longrightarrow(A B)^{+}+e \\
& A^{\star}+B \longrightarrow B^{+}+A+e \\
& A^{ \pm}+B \longrightarrow A+B^{ \pm}
\end{aligned}
$$

$$
A+B+e \longrightarrow A^{-}+B
$$$$
A B+\mathrm{e} \longrightarrow \mathrm{A}^{-}+\mathrm{B}
$$

$$
\mathrm{AH}^{+}+\mathrm{B} \longrightarrow \mathrm{A}+\mathrm{BH}^{+}
$$$$
\mathrm{A}^{-}+\mathrm{BH} \longrightarrow \mathrm{AH}+\mathrm{B}^{-}
$$$$
\mathrm{A}^{+}+\mathrm{BC} \longrightarrow \mathrm{A}+\mathrm{B}^{+}+\mathrm{C}
$$$$
A+B^{ \pm}+C \longrightarrow A B^{ \pm}+C
$$$$
\mathrm{MCl}+\mathrm{O}_{2}^{-} \longrightarrow \mathrm{MO}^{-}+\mathrm{OCl}
$$

associative ionization

Penning ionization

charge transfer

electron attachment

proton transfer

deprotonation

dissociative charge transfer

clustering

substitution

Let's consider again the action of this type of source on a gas mixture composed of argon and the species $M$ we wish to ionize. In particular say the mixture is 95 percent $\mathrm{Ar}$ and 5 percent $\mathrm{O}_{2}$ (used because it was on hand). Then a realistic scheme representing the primary positive ion chemistry in the foil region of the nozzle would be the following:

$$
\begin{aligned}
& B+\mathrm{Ar} \longrightarrow \mathrm{Ar}^{+}+2 \mathrm{e} \\
& \mathrm{B}+\mathrm{Ar} \longrightarrow \mathrm{Ar}^{*}+\mathrm{e} \\
& \mathrm{Ar}^{+}+2 \mathrm{Ar} \rightarrow \mathrm{Ar}_{2}^{+}+\mathrm{Ar}
\end{aligned}
$$




$$
\begin{aligned}
& \mathrm{Ar}^{+}+\mathrm{O}_{2} \rightarrow \mathrm{O}_{2}^{+}+\mathrm{Ar} \\
& \mathrm{Ar}^{+}+\mathrm{H}_{2} \mathrm{O} \rightarrow \mathrm{H}_{2} \mathrm{O}^{+}+\mathrm{Ar} \\
& \mathrm{Ar}^{+}+\mathrm{H}_{2} \rightarrow \mathrm{ArH}^{+}+\mathrm{OH} \\
& \mathrm{Ar}^{\star}+\mathrm{H}_{2} \mathrm{O} \rightarrow \mathrm{H}_{2} \mathrm{O}^{+}+\mathrm{Ar}+\mathrm{e} \\
& \mathrm{H}_{2} \mathrm{O}^{+}+\mathrm{O}_{2} \longrightarrow \mathrm{O}_{2}^{+}+\mathrm{H}_{2} \mathrm{O} \\
& \mathrm{H}_{2} \mathrm{O}^{+}+\mathrm{H}_{2} \mathrm{O} \rightarrow \mathrm{H}_{3} \mathrm{O}^{+}+\mathrm{OH}_{3} \\
& \mathrm{H}_{3} \mathrm{O}^{+}+\mathrm{H}_{2} \mathrm{O} \rightarrow \mathrm{Ar} \longrightarrow \mathrm{H}_{3} \mathrm{OH}_{2} \mathrm{O}^{+}+\mathrm{Ar}
\end{aligned}
$$

Reactions similar to (23) would lead to clusters of the type $\mathrm{H}_{3} \mathrm{O} \cdot\left(\mathrm{H}_{2} \mathrm{O}\right)_{n}^{+}$with the distribution of $\mathrm{n}$ being highly dependentas noted before-on the temperature, the water concentration, other impurity species present, and the time given to react. Of course clustering of the various species with each other will be taking place also, not to mention the adided complication of other impurity species found in the nozzle.

The prototype nozzle shown in Fig. 3 was designed to discover the influence of gas flow, nozzle aperture size, nozzle-skimmer acceleration gradients, nozzle-skimmer distance, and gas mixture on the ion spectrum produced by the nozzle. In addition we hoped to learn whether the pumping capabilities met the demands of the source. The tests which were carried out using this nozzle were very preliminary in nature-just to get an inkling of whether the idea would work and how one might set up to study the nozzle more systematically. Unfortunately, in the following years, the time was never found to return to characterize the nozzle well. In short, the ion mass 
spectra presented here, which display the effects of varying some of the various parameters mentioned above, are not of good quality. Nevertheless the spectra are presented to show that one does have some control over the cluster types and the cluster distribution produced by this ion source, giving hope that one may be able to optimize the production of a particular ion cluster.

The first ion mass spectra to be presented show how an extra flow of gas (that is in addition to the flow of gas through: the nozzle orifice) can change the product ion distributions. Figure 4 shows how an additionaj flow can eliminate the production of ions derived from an impurity. In this case the impurity is ethanol which was used as a cleaning solvent. The flow is enough to remove the ethanol clusters from the speritrum, but it changes the water cluster distribution minimally. In Fig. 5 a more drastic fiow is used anc in addition to suppressing the ethanol clusters, the water cluster distribution is radically altered. Sometimes extra flow through the foil region does not bring a benefit. For example, if one were trying to produce the van der Waals ion $\mathrm{Ar} \cdot \mathrm{H}_{3} \mathrm{O}^{+}$, then having less residence time in the foil region would seem to be a definite disadvantage. Figure 6 shows that extra flow results in the disappearance of the $\mathrm{Ar} \cdot \mathrm{H}_{3} \mathrm{O}\left(\mathrm{H}_{2} \mathrm{O}\right)_{n}^{+}$ type clusters from the mass spectrum.

One would like the ions which leave the nozzle to go through the skimmer orifice and into Region II of the source, but of course only a fraction of the total ion flux makes it through. To increase the number of ions which pass through this orifice, an electric field is 
established between the nozzle and the skimmer to accelerate the ions towards the skimmer. But there are consequences to this procedure. Figure 7 shows that there is a decrease in average cluster size with increasing accelerating electric field. This shift in cluster size may be understood by recognizing that the acceleration takes place in a region of high pressure. Thus, the clusters may be fragmented by colliding with neutrals which are present in the beam. Another possibility is that ions are pulled away from the expansion zone where, via three body collisions, the clusters are becoming larger. But one must also add focusing effects to the above. It may be that there is a shift in ion mass transmission through the skimmer orifice as the electric field gradient is changed.

Although the ion mass spectra seen so far were taken as a mixture of $\mathrm{Ar} / \mathrm{O}_{2}$ was fed into the source, one does not see any $\mathrm{O}_{2}^{+}$in Figs. $4,5,6$ or 7 . Figure 8 is included to show that with the addition of heat (nozzle tip $100^{\circ} \mathrm{C}$ ) and extra flow one can produce the $\mathrm{O}_{2}^{+}$ion. Thus, one may conclude that with a source of this type, c.e does have a handle on what is produced by it. Hopefully, there is enough control to generate the prerequisite quantity of the species needed for spectroscopy.

A good case.

Suppose that the species that one is trying to create is $\mathrm{Ar}^{-} \mathrm{H}_{3} \mathrm{O}^{+}$. Figure 9 shows the ion spectrum generated from the Ar/O $\mathrm{O}_{2}$ gas mixture discussed before, but with various parameters 
adjusted to optimize the generation of the $\mathrm{Ar}^{-} \mathrm{H}_{3} \mathrm{O}^{+}$ion. If the spectrum shows all the masses being produced under the conditions, then the $\mathrm{Ar} \cdot \mathrm{H}_{3} \mathrm{O}^{+}$peak comprises about 25 percent of the total ion flux. That is about as good as one might expect to achiev: for the production of a van der Waals ion. If the total ion flux from the nozzle is $5 \times 10^{8}$ ion $\sec ^{-1}(-50 \mathrm{mC} i$ tritiated foil) then one would have $-1.2 \times 10^{8}$ ion $\mathrm{sec}^{-1}$ of $\mathrm{Ar}^{-} \mathrm{H}_{3} \mathrm{O}^{+}$. Assuming an efficiency of $10^{-5}$ (that is one ion in $10^{5}$ survives the skimmer, Region II collisions with neutrals, and all the ion optics), one gets $\sim 1.2 \times 10^{3}$ ion $\mathrm{sec}^{-1}$ arriving at the interaction region. It takes about $1 \mathrm{msec}$ for the ions to traverse the interaction region, so at any given time one has about one $\mathrm{Ar} \cdot \mathrm{H}_{3} \mathrm{O}^{+}$to work with. This is less than originaliy expected and is unacceptable.

Ten to one hundred times this many jons are needed in the interaction region to have a workable experiment. What went wrong The original error was in over estimating the number of B-particles that could be delivered per second into the ionization volume by the tritiated foil. Tritiated foils were chosen because they are available with higher activities than are the ${ }^{63} \mathrm{Ni}$ foils. The error made was that the quoted activities of the various foils were converted directly to B-particles $\sec ^{-1}$ withou: considering the correction necessary for saturation due to seli-absorption. This cost about a factor of 20 in the ion flux estimates and may spell doom for the experiment as presently configured. Some improvement may be realized by using ${ }^{63_{\mathrm{Ni}}}$ foils which are bakeable and yield $\beta$ particles which are more energetic than those produced by ${ }^{3}$. 


\section{B. The Sector Magnet: momentum analysis}

The jons which are extracted from the source are accelerated to a given potential, focused, and sent on to Region III by the action of the ion optics in Region II. Region IiI, shown schematically in Fig. 10, is maintained at $2 \times 10^{-8}$ torr by a liquid nitrogen baffled, 4 inch diffusion pump (Varian VHS 4). Ions of differing masses trave? together until encountering the magnetic field of the sector magnet. The magnetic field is arranged to be perpendicular to the ion trajectories. Each ion type, all having the same average kinetic energy, is forced to travel in a circular path by the influence of the magnetic field. The radius of the circular path followed by a particular ion is proportional to the momentum of the ion and thus to the square ront of the ion's mass. Therefore, if only a limited range of curvatures are allowed to be transmitted (by using physical beam stops), one has a mass separator. In this case, since the energy and transmitted radius is fixed, one selects which ion mass gets passage by setting the value of the magnetic field.

The magnet used is a $60^{\circ}$ sector. It is situated so that the ions enter the sector region with trajectories perpendicular to the pole piece and exit with trajectories perpendicular to the exit pole boundary if their radius of curvature is $8 \mathrm{in.}$ while in the magnetic field. Ions traveling through the magnetic sector in this fashion are focused in the radial direction but experience no focusing in the direction parallel to the magnetic field. This poses a serious problem, because if the ion beam approaches the mass filter with an 
expanding circular cross section, lack of $z$ direction focusing in the sector would result in a substantial loss of ions-something which cannot be endured in the van der Waals ion experiment.

The sector magnet was chosen as a mass separator in part for its excellent beam quality, but to work well it must also exhibit adequate resolution and high transmission. Usually, the resolution is obtained by proper use of slits and lenses (other factors being constant). However, this would only add to the losses mentioned above unless the lens corrects for the lack of $z$ focusing. One wants a method which will satisfy the resolution requirements and at the same time, increase, rather than decrease, ion transmission efficienciej.

\section{The Quadrupole Lens Pair}

The focusing properties of an electrostatic quadrupole lens pair (QLP) has these fesired qualities. The QLP consists of a double set of four rods each creating an electrostatic quadrupole field. The orientation of one quadrupole field is rotated $90^{\circ}$ from that of the other. The QLP will transform a rectangular ion beam entering it into one which is parallel in one plane and is converging in the other, thus focusing the ions onto a line (see Fig. 11). This result is excellent because focusing to a line will enhance the mass seperator's resolution, and having a wedge-shaped beam means that no 2 direction focusing is required; thus, losses in the sector magnet can be reduced. The QLP'S characteristics have been detailed by several authors. (2) It is enough to say here that the characteristics of the 
lens are ideally suited for use with magnetic mass separators. (3) Our mass spectrometer uses no mechanical slits within Region III. (The only apertures are those used to establish the differential pumping regions.) Instead, one QLP is used at the entrance to transform the beam into a wedge and another used at the exit is to transform it back to a collimated beam. One added feature of the QLP is that it can be operated with pole voltages offset symetrically to act as beam deflectors without loss of focusing. This is quite conven ient.

Figure 12 shows the improvement afforded by the QLP's action. The resolution goes from $M / \Delta M=85$ with the QLP's off to $M / \triangle M=150$ with them on. The ion count rate is improved by 16 fold with the use of the QLPS. These mass spectra were taken using an ion energy of only 350 ev. The resolution at this energy is rather poor, but is typically good enough for our purpcses for $M / e<100$. The resolution can be greatly improved by increasing the ion energy should the need arise. The present condition is tolerated because (1) it is quite adequate for experiments being done and (2) raising the ion energy would require a slight modification of the quadrupole mass filter used down stream of the interaction region.

When leaving Region III the ions pass through a small tube which serves to limit conductance between Region III, which is held at $\sim 2 \times 10^{-8}$ torr, and Region IV, which is usually $\sim 2 \times 10^{-9}$ torr or less under operating conditions. Region IV (see Fig. 13) is pumped by a $220 \mathrm{lsec}^{-1}$ ion pump. It contains the ion-laser interaction region 
and the ion photofragment detection system. Both Regions III and IV are designed to be bakeable.

The discussion in Chapter I pointed out that one of the design objectives of the srectrometer was to have a "clear through" shot for the light beam. This wruld make alignment less of a problem, especially when using infrared light. Because of our configuration, reaching this objective necessitated bending the ion beam. Electrostatic deflection was selected to accomplish this jot since one voltage setting would track all masses ransmitted by the sector magnet. There are several types of electrostatic def?ectors in common use, but most of them will not allow the ion beam to be merged with a light beam without having holes in one or more of the electrodes. The presence of these holes disturbs the electric field within the deflector and thus its operating characteristics. If a wire mesh is used over the hole to preserve the electric field, then the light beam may produce unwanted side affects when it strikes the mesh.

\section{The Quadrupole Filzld Deflector}

There is, hoivever, a marvelous electrostatic deflector which is simple to build, has excellent deflection properties and provices an unobstructed merging path for the light and ion beams. The device is a two dimensional electrostatic quadrupole field deflector (QFD) which is detailed by Zeman. (4) If designed properly the QFD gives excellent beam quality. In the present case its full abilities in this regard were not needed and so a simplified design was used (see 
Figs. 13 and 14). Figure 15 shows the equipotentials calculated for the simple QFO used here. The grounded elements are used to terminate the fringing field extending from the electrodes. The hyperbolic electrodes are approximated by circular ones.

The figures which are presented (Figs. 16-21) show ion trajectories through a QFD and serve to display some of its characteristics. The trajectories are those for an ideal quadrupole field with a sharp cut off fringe field. Figure 16 shows the lowest energy solution for which ions execute a $90^{\circ}$ deflection. This solution is also the one with the least aberrations. The energy of the ions in this case is assigned the relative energy 1.00. Figure 17 shows the action of the QFD on a narrow beam of ions which is not monnenergetic and Fig. 18 shows a monoenergetic wide beam entering the deflector. Figure 19 has a converging monoenergetic beam entering the QFD. Figures 20 and 21 show : he trajectories of two higher order solutions (with relative energy 1.925 and 1.858 , respectively), which have aberrations making them unsuitable for this application; besides, the ions would strike the pole piece unless it were modified to provide the necessary clearance.

Slow them down.

Following the QFD the ions enter a constant gradient decelerator ${ }^{(5)}$ which has an einzel lens as a last stage. The ions are clowed down to about $5 \mathrm{eV}$ and then focused into the octapole RF trap with the einzel lens. 
E. The RF Octapole Trap

The octapole region is one of central importance to the spectrometer. It must contain all ions, parents and offspring, and deliver then to the final mass filter. In selecting an ion guide for this purpose, one must be aware of its functional limitations. For example, the most common ion guide used is the RF quadrupole. But this ion guide has strict initial conditions which must be met by the ions for them to te contained by the guide. (6) In our spectrometer an RF ion guide developed by Teloy and Gerlich ${ }^{(10)}$ is used because it is felt that their octapole imposes initial condition requirements which are less severe than those of the quadrupole guide. Thus, more ions are confined in the octapole guide. The octapole used consists of eight parallel, 20 inch long, $1 / 8$ inch diameter, molybdenum rods, equaliy spaced about a circle of 1/2 inch diameter (see Fig. 22). Alterna:e poles are connected to opposite ends of a coil so as to form a resonant circuit; the parallel rods foming the "capacitor" of the circuit. This paralle? LC circuit is excited inductively by a single loop of wire powered by an RF generator tuned to the resonant frequency of the tank. Molybdenum is the material used for the rods and the entrance and exit lenses of the octarole because of its ability to maintain uniform surface potentials. (7) This is a must in applications using low energy charged particles. But if one must have an extensive lens system, the cost of using molybdenum can be sobering. pollard ${ }^{(8)}$ describes the fabrication of a less expensive, but completely satisfactory, lens system made of aluminum coated with 
molybdenum. For large systems this may be the preferred route to take. A detailed drawing st "sing how the eight rods are held in place at the ends of the guide is shown in Fig. 23. Only the topmost and bottommost rods are shown for clarity. The ends of the rods are rounded to minimize the tendency for arcing under the influence of the RF field. The machinable ceramic annulus, used for electrical isolation, is kept well away from the ion beam by use of stainless steel spacers. The entrance (exit) lens element controls the flow of ions into (out of) the octapole ion guide.

Trapped trajectories.

Based on Kapitza's analysis of classical mechanics in a fast

oscillating field, ${ }^{(9)}$ the average motion of a slow moving charged particle in an RF n-pole field is described by:

$$
m \frac{d^{2} \vec{r}}{d t^{2}}=-\vec{\nabla} v_{e f f}(r)
$$

where

$$
v_{\text {eff }}(r)=\frac{q^{2} E^{2}(r)}{4 \pi \omega^{2}}+q \phi_{s}(r)
$$

and $q$ is the charge of the particle, $E$ is the amplitude of the RF, $w$ is the angular frequency of the RF, $r$ is the smoothed distance from the axis of the trap to the ion, and $\phi_{s}$ is the electrostatic potential (see Fig. 22). The potential for an ideal octapole oscillatory field is given by 


$$
\phi(t)=\frac{V_{0}}{r_{0}{ }^{4}}\left(x^{4}+y^{4}-6 x^{2} y^{2}\right) \cos (\omega t+\theta)
$$

where any static component is neglected. This potential yields amplitudes for the $E$ field components and $E^{2}(r)$ as follows:

$$
E_{x}=-\frac{\partial \phi}{\partial x}=-\frac{4 v_{0}}{r_{0}}\left(x^{3}-3 x y^{2}\right)
$$

$$
\begin{aligned}
& E_{y}=-\frac{\partial \phi}{\partial y}=-\frac{4 V_{0}}{r_{0}{ }^{4}}\left(y^{3}-3 y x^{2}\right) \\
& E^{2}=E_{x}^{2}+E_{y}{ }^{2}=\frac{16 V_{0}^{2}}{r_{0}^{8}}\left(x^{2}+y^{2}\right)^{3}=\frac{16 V_{0}^{2}}{r_{0}{ }^{2}}\left(\frac{r}{r_{0}}\right)^{6}
\end{aligned}
$$

Thus, for an octapole field one has

$$
V_{\text {eff }}(r)=4 k\left(\frac{r}{r_{0}}\right)^{6},
$$

where

$$
k=\frac{q^{2} v_{0}^{2}}{m \omega^{2} r_{0}^{2}} .
$$

lin a similar fashion the effective potential for a quadrupole field is given by

$$
v_{\text {eff }}(r)=K\left(\frac{r}{r_{0}}\right)^{2}
$$

The effective potentials for an octapole and a quadrupole with the same $K$ value are shown in Fig. 24. It is immediately evident that the octapole field provides an effective potential which has higher walls 
than does the quadrupole field. As stated before, we believe that the octapole is better suited for "trapping" ions. Figure 25 shows the trajectory ( $x-y$ coordinates) for a singly charged ion in an octapole ion guide with $r_{0}=0.64 \mathrm{~cm}, \omega / 2 \pi=7.5 \mathrm{MHz}$, and $\mathrm{m}=32 \mathrm{amu}$. The trajectory is generated by integrating out the equations of motion and not by using any effective potential approximations. The trajectory shown follows the course of the ion over a 112 usec. period given an initial radial energy $\left(\varepsilon_{0}\right)$ of $\sim \mathrm{l}$ eV. If this ion had a z-axis (the axis of the trap) energy of $0.65 \mathrm{eV}$, then it would take -250 usec. to traverse the length of the octapole $(\mathrm{m} / \mathrm{e}=32)$, and would "bounce" of $\mathrm{f}$ the effective potential wall about 40 times during this time. Figure 26 shows the trajectories for singly charged ions with masses of 32 amu and 16 ans traveling with initial radial energies of $0.6 \mathrm{eV}$ and $0.3 \mathrm{eV}$, respectively. The octapole field parameters are $V_{0}=$ $200 \mathrm{~V}, \omega / 2 \pi=15 \mathrm{MHz}$, and $r_{0}=0.48 \mathrm{~cm}$. The trajectory is carried out for $20 \mu \mathrm{sec}$. for both ions. Figure 27 displays the probability of finding the ion of mass 32 at a reduced distance $r / r_{0}$ from the center of the ion guide, while Fig. 28 gives the radial energy proability distribution of the ion (with $\varepsilon_{0}=100$ ). Note that while the most piobable energy is the initial energy, the ion has radial energies substantially below and above its initial value for very significant amounts of time.

When using the octapole to confine ions one must always bear in mind that the equation describing its effective potential (Eq. 30) is valid only if the approximating conditions used in its derivation are 
met. (10) Also note that the effective potential is a function not only of the angular frequency, but also of the mass of the ion: ions of different mass coexisting in the ion guide will be governed by different effective potentials. This means that an octapole guide operating so as to guide a reactant ion, say $\mathrm{H}_{2}^{+}$, may fail to effectively confine the product mass created within the guide if the product is more massive than the reactant. For example, in the following reaction

$$
\mathrm{H}_{2}^{+}+\mathrm{O}_{2} \rightarrow \mathrm{D}_{2} \mathrm{H}^{+}+\mathrm{H},
$$

the product has greater mass than the reactant. One must ensure that the ion guide is operatirg with its parameters set so it will confine both species, or measurements made on the system will be misleading.

The octapole ion guide can also operate as an ion trap if ion "mirrors" cap the ends of the guide. Such an arrangement is used in our system. A neat way to observe the trapping effect is to lower the potential of the entrance mirror for a short length of time and then raise it again. Tris allows a bunch of ions into the trap. This bunch of ions can now be made to "bounce" back and forth in the ion guide by having the mirrors totally reflecting. But if no ions escape to the detector, one observes nothing. Now if the exit mirror is made partially transmitting, then every time the bunch of ions strikes it, some ions will pass through to be detected and the rest will be reflected back down the axis of the guide. The results of such a measurement (ion counts vs time) are shown in Fig. 29. Note that at the end of each round trip the transmitted peak becomes broader until 
a peak no longer exists and all one gets is a constant leakage of ions from the trap. At this point there is no longer any bunching in the trap: it is homogeneously filled with ions which have a broad kinetic energy distribution. This loss of bunching occurs because the "mirrors" are scattering the ions back into the guide in a diffuse manner. This transfers kinetic energy originally in the $z$ coordinate to the $x$ and $y$ coordinates until the energy is equally shared. This means that ions which have been stored in the trap for more than one millisecond become translationally very hot. This is a bad consequence in terms of the photofragment spectroscopy because of the large Doppler widths which result from it.

Another problem associated with sur octapole mirrors is that they leak ions out of the trap when they are not supposed to. The leaking ions are not escaping down the axis of the spectroneter since none reach the detector. They must be popping $:$ to the sides or slamming into metal surfaces. It seems though, that only ions above some critical kinetic energy leak out; for once these escape, the remainig ions are trapped efficiently. Figure 30 shows $\mathrm{O}_{2}^{+}$trapped out to $100 \mathrm{msec}$. Note that almost all the ions which will escape have done so by $50 \mathrm{msec}$. of trapping time. Figure 31 shows the trapping efficiency out to 5 minutes. This figure clearly demonstrates that after the initial loss of ions, the remaining ions are trapped very well indeed. Overall, the RF octapole ion guide works quite satisfactorily. The use of the guide as an ion trap may be made more efficient by carefully designing the mirrors at the ends of the 
octapole. These mirrors must be able to reflect the ions well whije not disturbing the effective potential created by the RF field.

Aside from the obvious assets of large ion-laser overlap, containment of all product ions, and the use of the trap to allow the relaxation of excited states, one may also use the trapping feature for temporal discrimination. That is, if the firing of the light source creates electronic noise or photon induced background in the detector, one may confine the meaningful light correlated products in the ion trap until the noise settles down--then allow the products to pass on to the detector. This capability is very advantageous to have since its application can increase the signal-to-noise ratio significantly.

F. The QMF and Detector

After the octapole ion guide has done its thing with the ions, they are extracted from the guide and focused into a commercially produced quadrupole mass filter (Extranuclear Laboratories, Inc.). The mass filter is set to transmit the laser correlated products to the final stage of the spectrometer in a typical flop-in type experiment. The ions which exit the quadrupole are directed towards a Daly(11) detector or a Ceratron (12) electron multiplier. The Ceratron, although having less gain then the Daly scheme, is convenient because both positive and negative ions can be detected by just changing the polarity of the power supplies. Both detectors were configured for pulse counting. 
5. The Light Source

The light source used with the spectrometer is based on a pulsed Nd:YAG (Quanta-Ray DCR) laser pump which produces if to $700 \mathrm{mj}$ (10 nsec. pulse duration) of 1.06 y radiat on. This fundamental can be doubled, tripled. or quadrupled with harmonic generating crystals. These harmonics are used either directly in the spectrometer or are used to pump a dye laser (quanta-Ray POL) to yield tunable visible radiatiol.. In addition, the 1.06 u light can be sent into an optical parametric oscillator(13) (OPO) thus producing tunable infrared $(\sim 1.5$ to $4.3 \mu)$ light.

H. Data Acquisition and Control

Many of the spectrometer functions are automated making long data tak:ng runs requiring many chancrs in instrumental parameters possible without much personal attention. A microcomputer (DEC LSI-11) performs the task of controlling these parameters and of collecting the data being generated. Communication between the computer and the spectrometer is accomplished via $\mathrm{A} 2 \mathrm{D}$ and $\mathrm{D} 2 \mathrm{~A}$ converters in the computer backplane, in addition to having a CAMAC crate interfaced to the computer. A programmable clock controls the trapping time of the octapole ion trap (see Fig. 32). Other accessories include a video terminal, a plotter, a DMA driven display scope, a printer and a floppy disk. The program used to operate the system is written in assembly language (see Appendix). It allows one to operate the sector magnet, the octapole ion trap, the quadrupole mass filter, and the laser via computer command. 
I. Performance: Photofragmentation in the Visible

The performance of the spectrometer was evaluated by observing the photofragmentation of some ions using visible light. This choice was made because with visible light one does not need a very weak bond to be present in the ion fo; photofragmentation to occur and so ions created by an electron inpact ionizer coild be used. Using the Nd:YAG pumped dye laser as the light source, $\mathrm{CH}_{3} \mathrm{I}^{+}, \mathrm{C}_{6} \mathrm{H}_{6}^{+}$and $\mathrm{O}_{2}^{+}$were photof ragmented.

First consider the $\mathrm{CH}_{3} \mathrm{I}^{+}$ion. This ion can dissociate yielding the $\mathrm{CH}_{3}^{+}$ion ${ }^{(14)}$ if it absorbs a photon with sufficient energy. Figure 33 shows the laser correlated $M / e=15$ product as a function of wavelength from 5000 to $5400 \AA$ sampled in $0.96 \AA$ steps. The structure seen is due to transitions to a bound upper state which subsequently leads to fragmentation. (14a) As another trial, the photofragmentation of $\mathrm{C}_{6} \mathrm{H}_{6}^{+}$was observed. In this case the dye laser was not frequency scanned; instead, the laser correlated mass spectrum was generated at a single frequency. Figure 34 shows the result. It is seen that at the laser intensity used, two daughter fragments are produced, $\mathrm{C}_{3} \mathrm{~h}_{3}^{+}$and $\mathrm{C}_{4} \mathrm{H}_{4}^{+}$, as a result of a multiphoton absorption process. (15) Finally, Fig. 35 shows the laser correlated product inass spectrum of $\mathrm{O}_{2}^{+}$being irradiated by $5100 \AA$ light. In each of these cases, the photofragmentation events were trivial to observe. But of these trials, only the photofragmentation of $\mathrm{O}_{2}^{+}$was studied in more detail; the results of the work on $\mathrm{O}_{2}^{+}$is the subject of Chapter III. 


\section{REFERENCES}

1. (a) E. C. Horning, D. I. Carroll, I. Ozidic, K. D. Haegele, M. G. Horning, and R. N. Stillwell, J of Chromatographic Sci. 12, 725 (1974).

(b) M. Mckeown and M. W. Siegel, American Laboratory, November (1975).

(c) M. W. Siegel and W. L. Fite, J Phys. Chem. 80, 2871 (1976).

(d) M. Armbruster, H. Haberland, and H. G. Schindler, Phys. Rev. Lett. 47, 323 (1981).

2. (a) H. A. Enge, Rev. Sci. Instrum. 30, 248 (1953).

(b) C. F. Giese, Rev. Sci. Instrum. 30, 260 (1959).

(c) C-S. Lu and H. E. Carr, Rev. Sci. Instrum. 33, 823 (1962).

(d) M. L. Vestal, "Crossed-Beam Studies of Ion-Molecule

Reactions" Ph.D. Thesis, University of Utah, 1975.

3. (a) E. T. Kinzer and H. Carr, Rev. Sci. Instrum. 30, 1132 (1959).

(b) S. Taya, I. Kanomatata, H. Hirose, T. Noda, and H. Matsuda, Int. J. Mass. Spect. and Ion Phys. 26, 237 (1978).

4. H. D. Zeman, Rev. Sci. Instrum. $\underline{48}, 1079$ (1977).

5. Ion Beams: with Application to Ion Imp iantation, R. G. Wilson and G. R. Brewer, John Wiley and Sons (1973).

6. P. H. Dawson and J. E. Fulford, Int. J. Mass. Spectra. and Ion Phys. 42, 195 (1982).

7. J. H. D. Eland, J. Phys. E.: Sci. Instrum. 11, 969 (1978). 
8. J. E. Pollard, "Photoelectron Spectroscopy of Supersonic Molecular Beams," Ph.D. Thesis, University of California, Berkeley, CA (1982).

9. Mechanics, L. D. Landau and E. Lifschitz, p. 93, Pergamon Press, Oxford, 1960.

10. E. Teloy and D. Gerlich, Chem. Phys. 4, 417 (1974).

11. R. N. Daly, Rev. Sci. Instrum. 31, 264 (1960).

12. S. Ehara, K. Wakino, H. Yamamoto, JEE, June, 1974.

13. (a) S. E Harris, Proc: IEEE 57, $2090^{\circ}$ (1969).

(b) R. L. Byer and R. L. Herbst, Top. Appl. Phys. 16, 81 (1977).

14. (a) S. P. Goss, D. C. McGilvery, J. D. Morrison and D. L. Smith, J. Chem. Phys. 75, 1820 (1981).

(b) S. P. Goss, J. D. Morrison, and D. L. Smith, J. Chem. Phys. 75, 757 (1981).

15. (a) P.N.T. Van Velzen and W. J. Van Der Hart, Chem. Phys. 61, 325 (1981).

(b) U. Boes 1, H. J. Neusser, and E. W. Schlag, J. Chem. Phys. 2, 4327 (1980). 


\section{FIGURE CAPTIONS}

Fig. 1. General schematic of source regions.

Fig. 2. The ion lens system following the ion source: (1) nozzle assembly, (2) skimer, (3) accelerating and focusing elements (4) and (5) ion beam deflectors.

Fig. 3. Detail of the supersonic nozzle ion source.

Fig. 4. Mass scans of ions produced by the nozzle source. The top scan is with a light extra flow of gas through the nozzle: the ethanol impurity peaks disappear with this extra flow.

Fig. 5. Two mass scans of ions produced by the nozzle source. The bottom scan is with no extra flow; the top is with a heavy flow. Impurities peaks disappear and water cluster distribution shifts downward with extra flow.

Fig. 6. Extra flow through the nozzle can produce unwanted rsults. The top mass scan taken with extra flow has no $\mathrm{Ar} \cdot\left(\mathrm{H}_{2} \mathrm{O}\right) \mathrm{n}^{\mathrm{H}^{+}}$clusters.

Fig. 7. The cluster size distribution from the nozzle source shifts to smaller average size as the electric field between the nozzle and the skimmer is increased.

Fig. 8. Illustration of the use of nozzle temperature and flow to enhance the quantity of $0_{2}^{+}$produced.

Fig. 9. Mass scans of nozzle source with parameters set to optmize the creation of $\mathrm{Ar} \cdot \mathrm{H}_{3} \mathrm{O}^{+}$.

Fig. 10. Schematic of Region III: the magnetic sector. 
Fig. 11. The quadrupole lens pairs (QLP) transforms a rectangular bean into a wedge-shaped beam.

Fig. 12. A comparison of mass spectra taken with the QLP on (top) and QLP off (bottom).

Fig. 13. Schematic of Region IV, the interaction region: (1) to Region III, (2) to window, (3) to ion detector, (4) quadrupole field deflector, (5) decelerator, (6) einzel lens (7) octapole trap, (8) quadrupole mass filter.

Fig. 14. A closer view of the quadr:-1pole field deflector.

Fig. 15. Calculated equipotentiais for the quadrupole field deflector. Fig. 16. Solution through the quadrupole field defler or with the. least aberration: relative ion energy of 1.00 .

Fig. 17. A narrow beam of ions which is not monoenergetic deflected by the QFD.

Fig. 18. A wide monoenergetic ion beam deflected by the QFD.

Fig. 19. A converging monoenergetic beam deflected by the QFD.

Fig. 20. A solution with a higher aberrations with a relative ion energy of 1.925 .

Fig. 21. A solution with higher aberrations with a relative ion energy of 1.858 .

Fig. 22. A cross section of the octapole trap: $r_{0}$ is the radius of the circle inscribed within the rods and $r$ is the distance of the ion from the origin. Also shown schematically is the tank coil and the exciter loop.

Fig. 23. A close up view of one end of the octapole assembly. 
Fig. 24. Effective potentials for an octapole and a quadrupole with the same dimensions, applied voltages, and the same ion mass.

Fig. 25. The trajectory of an ion in an octapole (transverse coordinates). The dotted circle has radius $r_{0}$.

Fig. 26. A comparison of the trajectories of a 16 amu ion and a 32 amu ion with initial radial energies of $0.3 \mathrm{eV}$ and $0.6 \mathrm{eV}$, respectively in an octapole; other parameters are the same in each case.

Fig. 27 . The relative probability of finding the 32 amu ion in Fig. 26 at position $r / r_{0}$.

Fig. 28. The relative probability of finding the 32 amu ion in Fig. 26 with energy $\varepsilon / \varepsilon_{0}$.

Fig. 29. The density of ions at the exit mirror of the octapole vs time when a sho:t pulse of ions is initially let into the trap.

Fig. 30. The number of $0_{2}^{+}$ions in the octapole trap as a function of time in $10 \mathrm{msec}$ steps out to $100 \mathrm{msec}$.

Fig. 31. The number of $0_{2}^{+}$ions in the octapole trap as a function of time in $500 \mathrm{msec}$. steps out. to 5 minutes.

Fig. 32. Block diagram of the computer and its accessories.

Fig. 33. Photofragmentation of $\mathrm{CH}_{3} \mathrm{I}^{+}$with detection of $\mathrm{CH}_{3}^{+}$as

a function of wavelength. Signal is sampled every $0.96 \AA$.

Fig. 34. Laser correlated mass spectrum of $\mathrm{C}_{6} \mathrm{H}_{6}^{+}$photofragmented by $5100 \AA$ light.

Fig. 35. Laser correlizied mass spectrum of $\mathrm{O}_{2}^{+}$photofragmented by $5100 A$ light. 
REGION

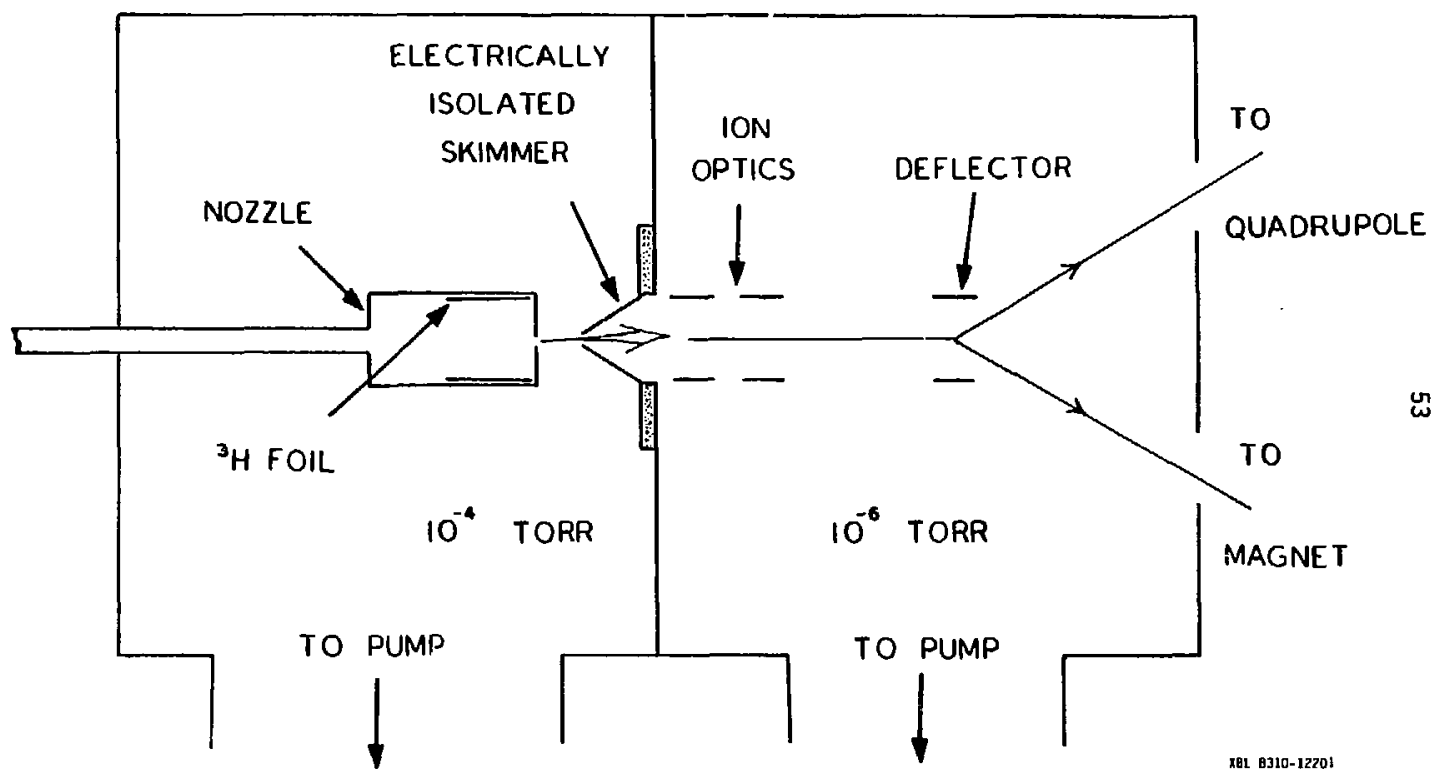

REEGION II

19310-1220

Figure i 


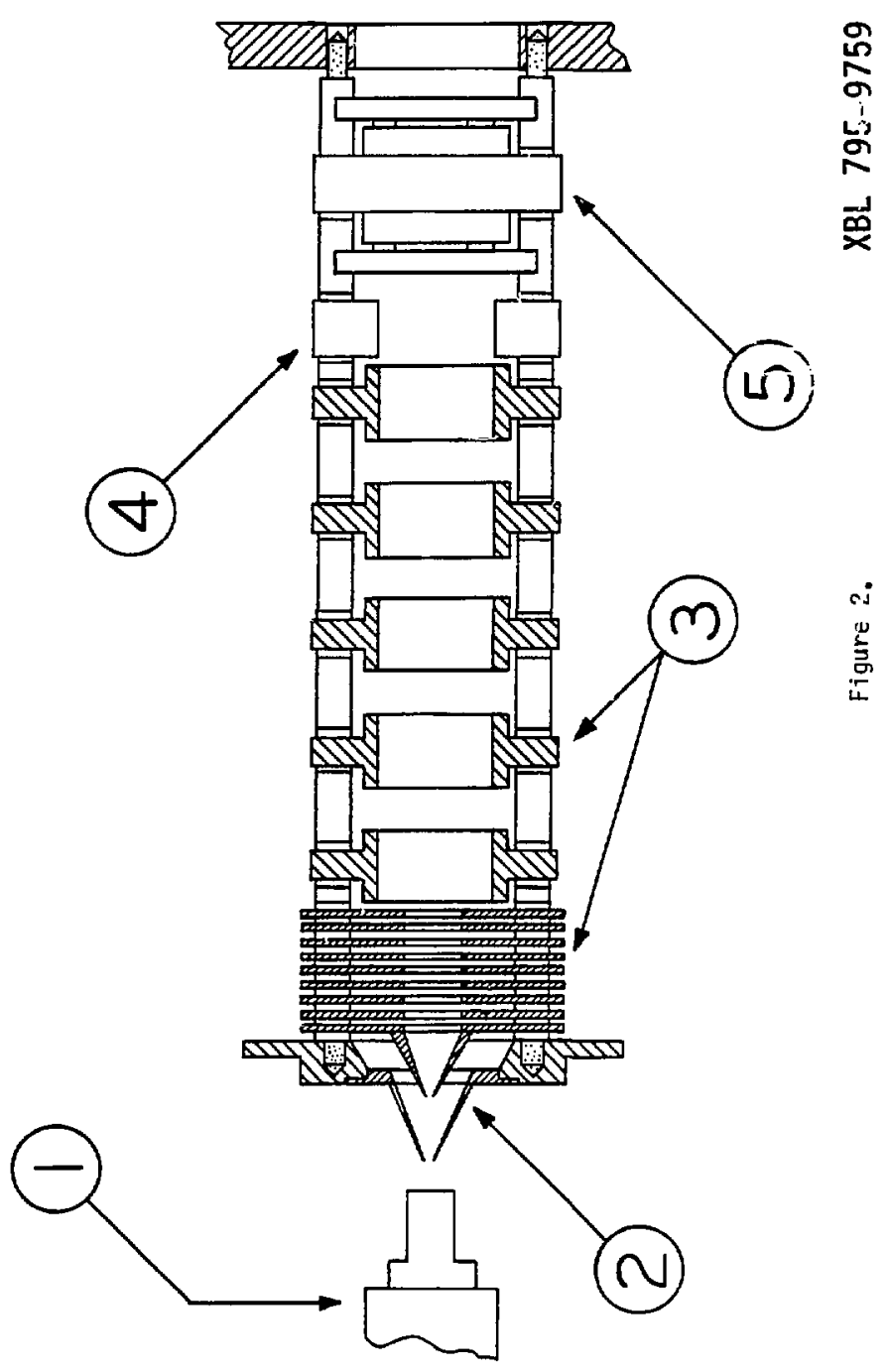



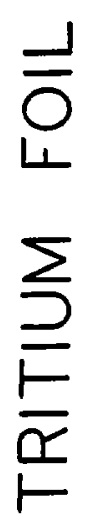
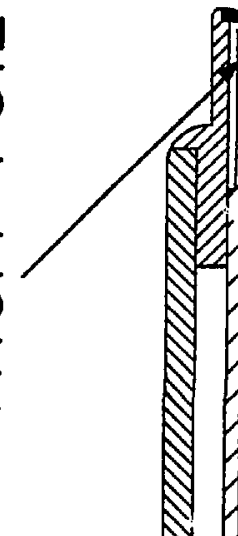

p.
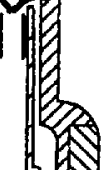

14
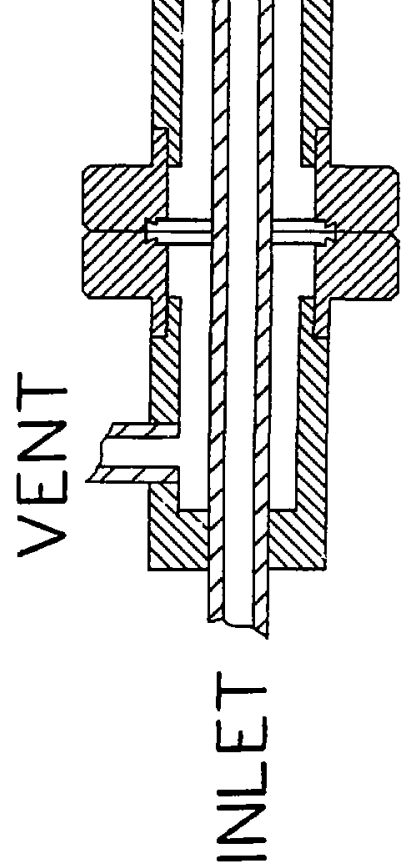

$$
\begin{aligned}
& \infty \\
& 0 \\
& 0 \\
& 1 \\
& 0 \\
& 0 \\
& 0 \\
& 0
\end{aligned}
$$

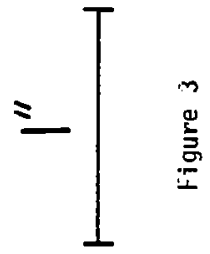




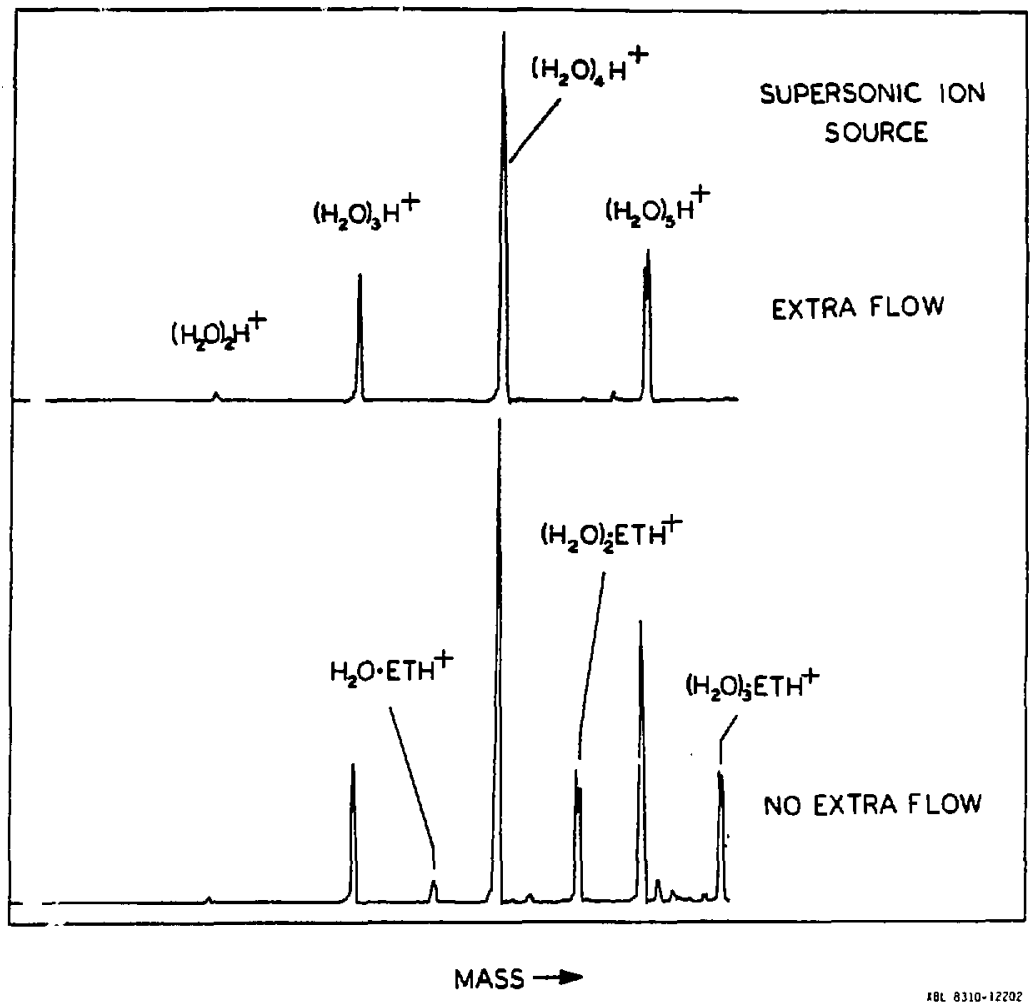

Figure 4 


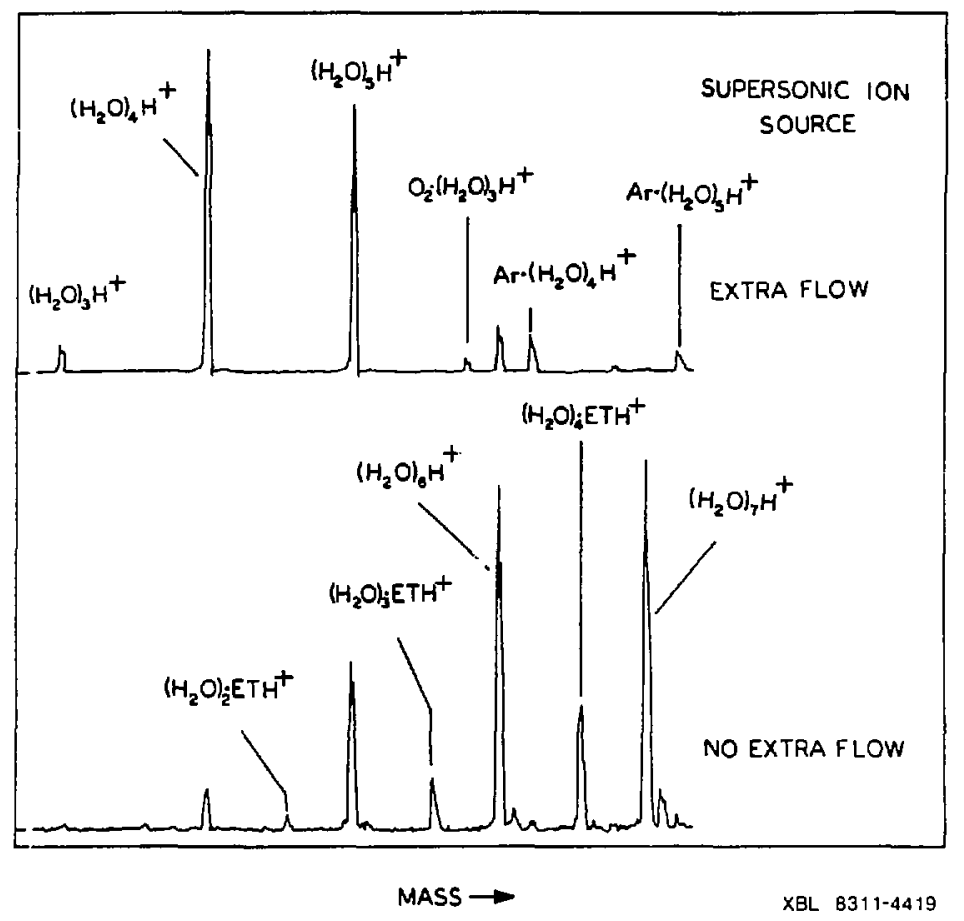

Figure 5 


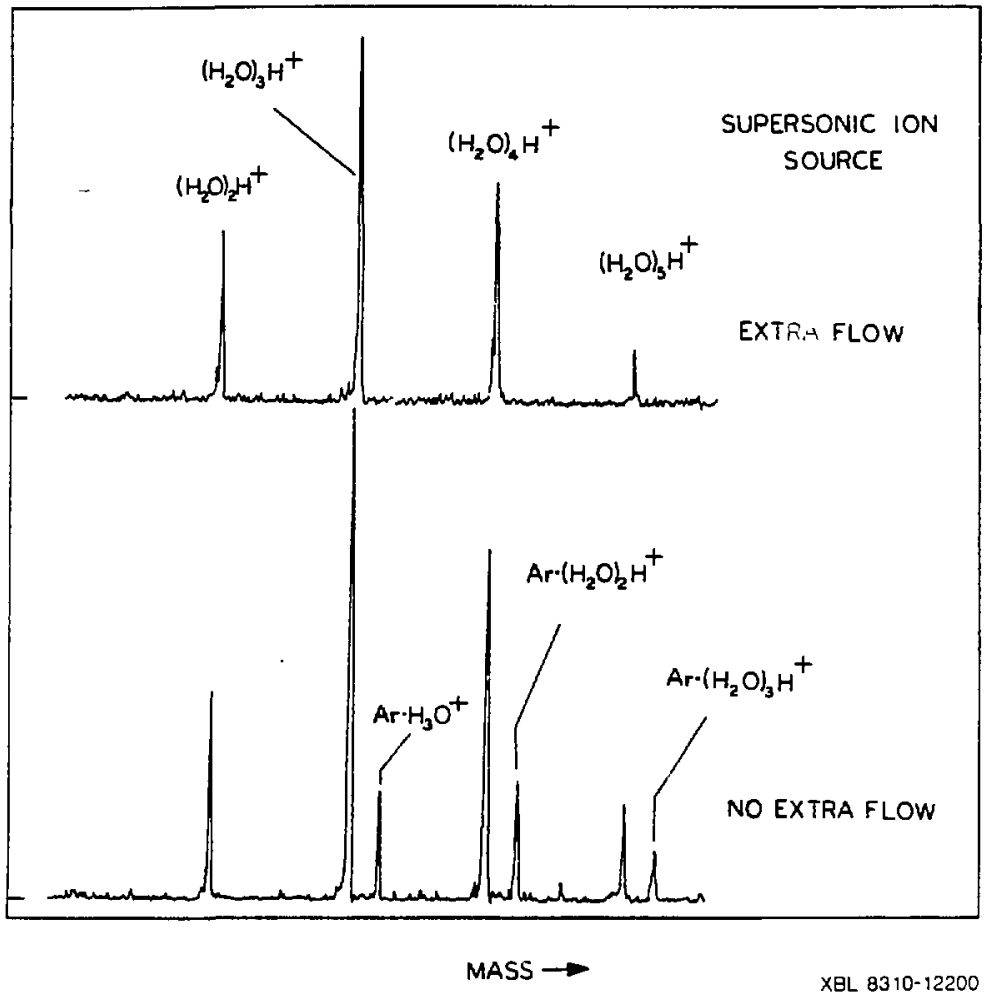

Figure 6 


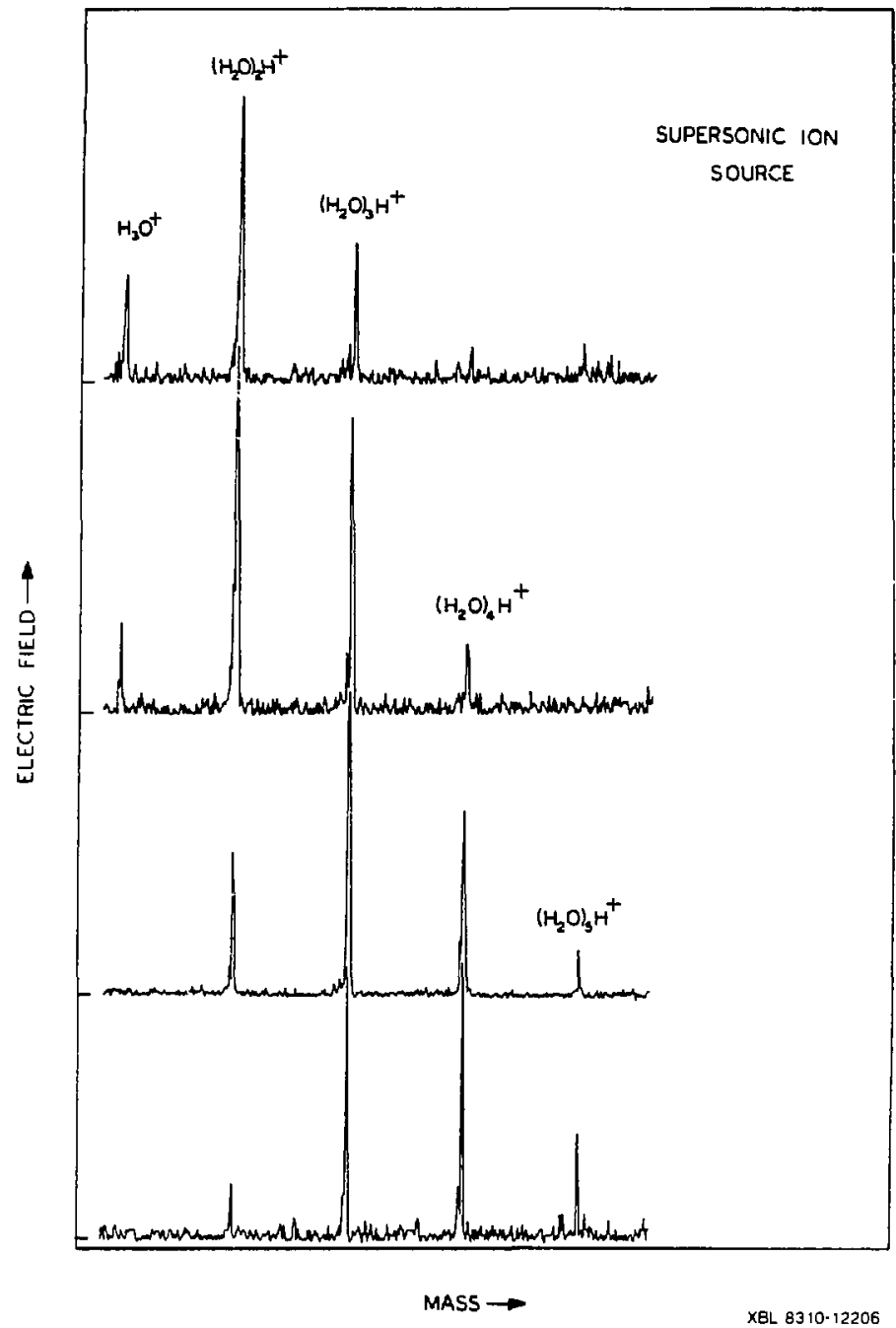

Figure 7 
60

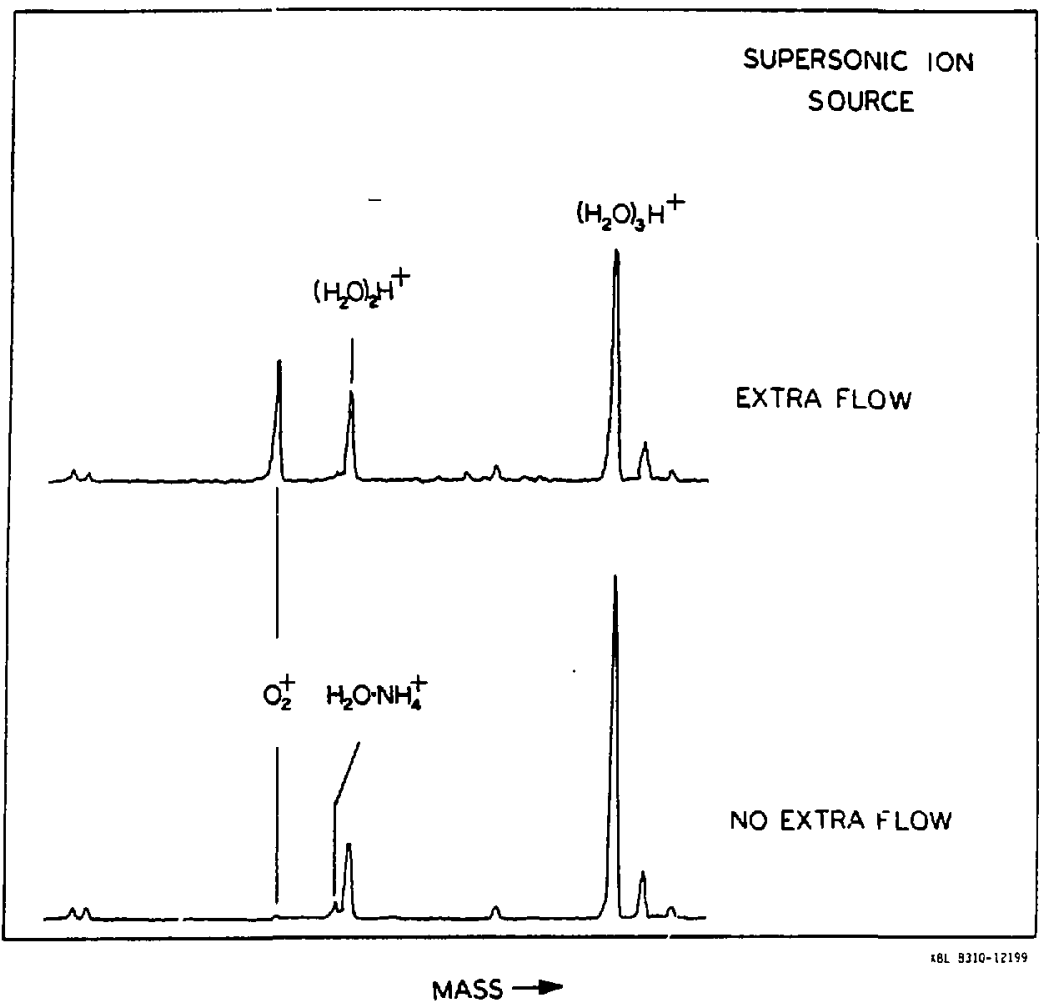

Figure 8 
61

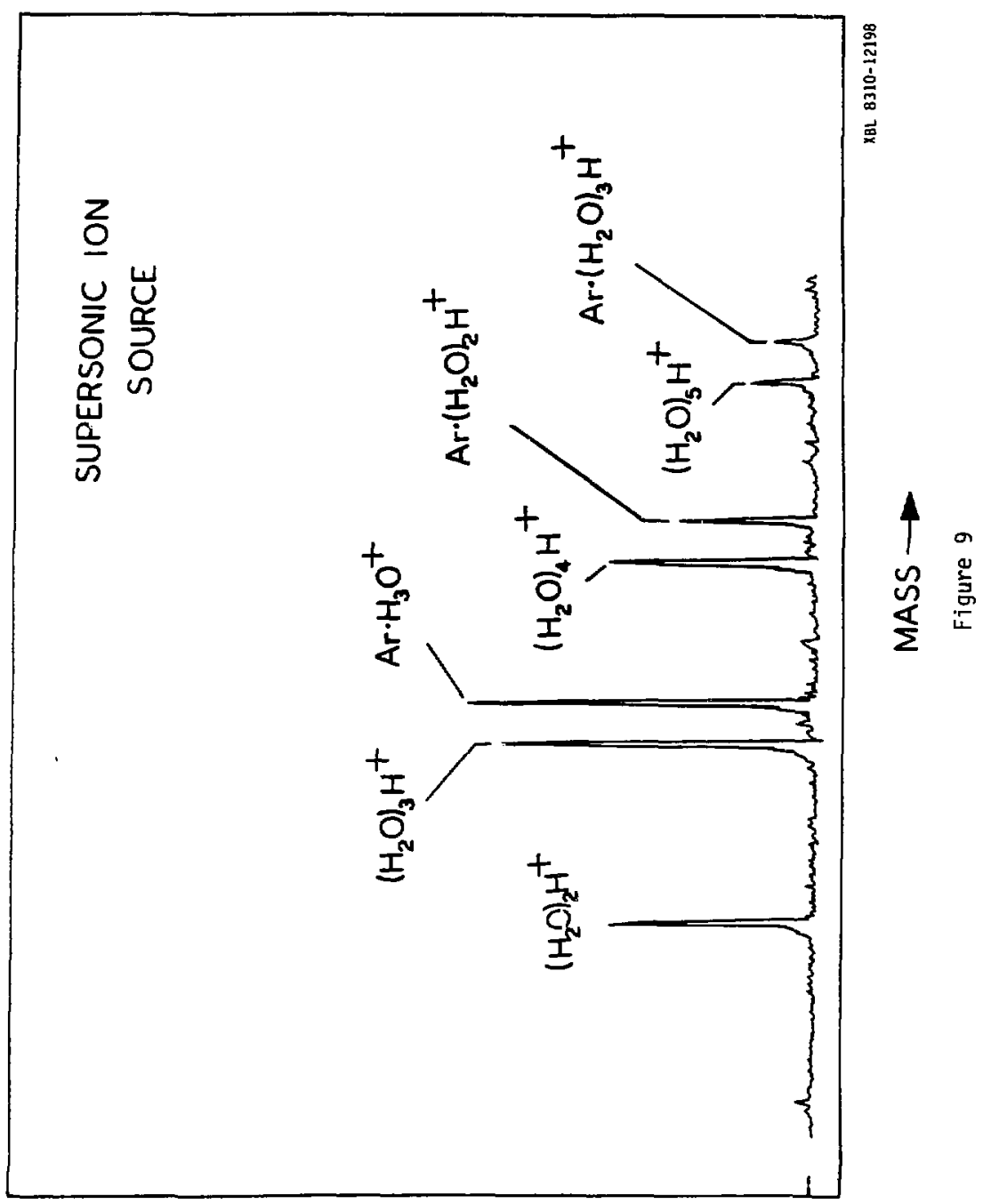


62

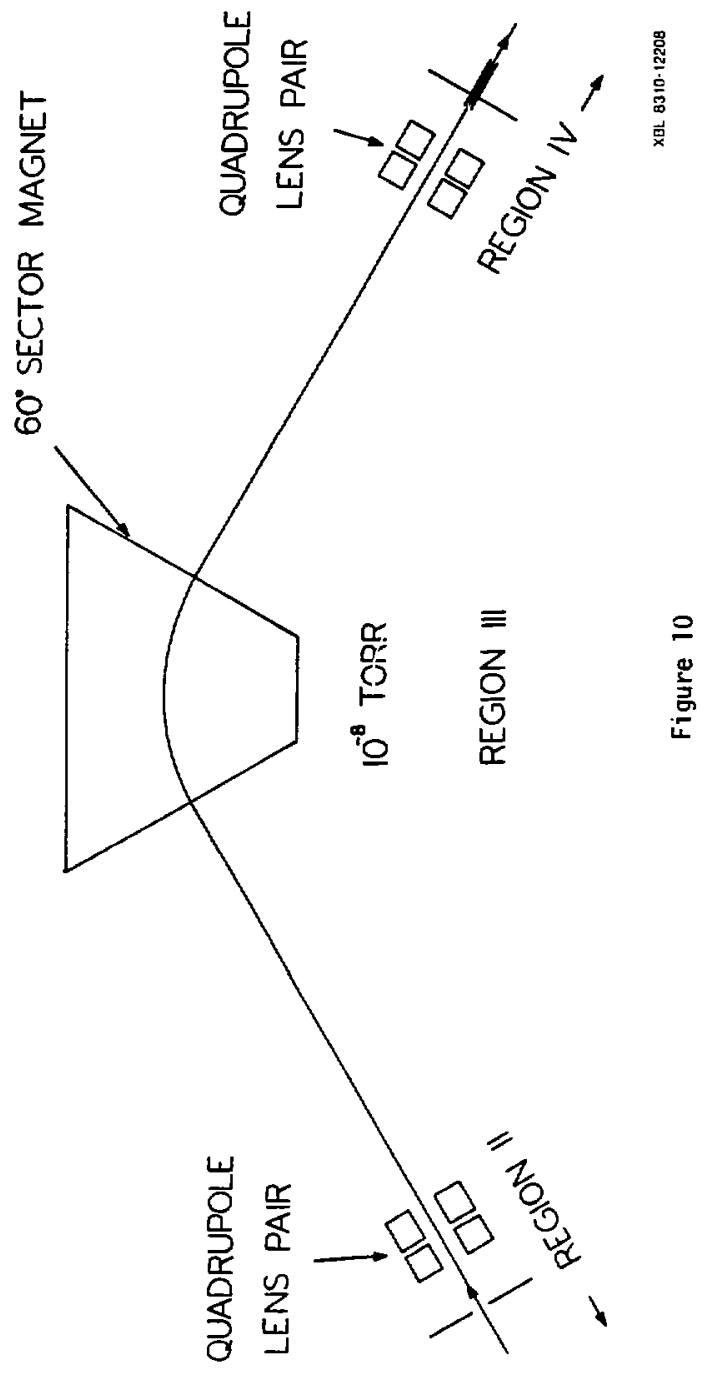



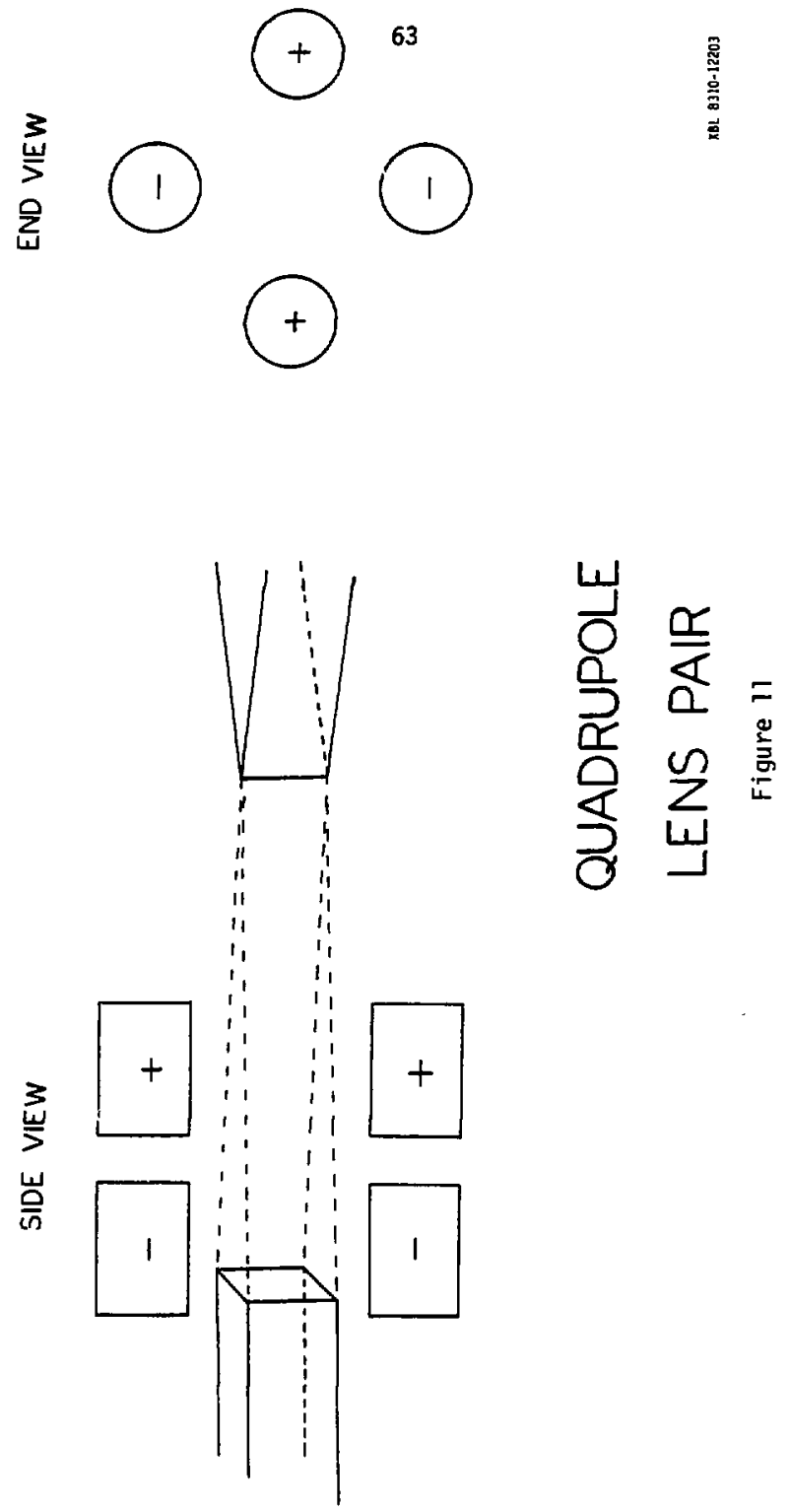


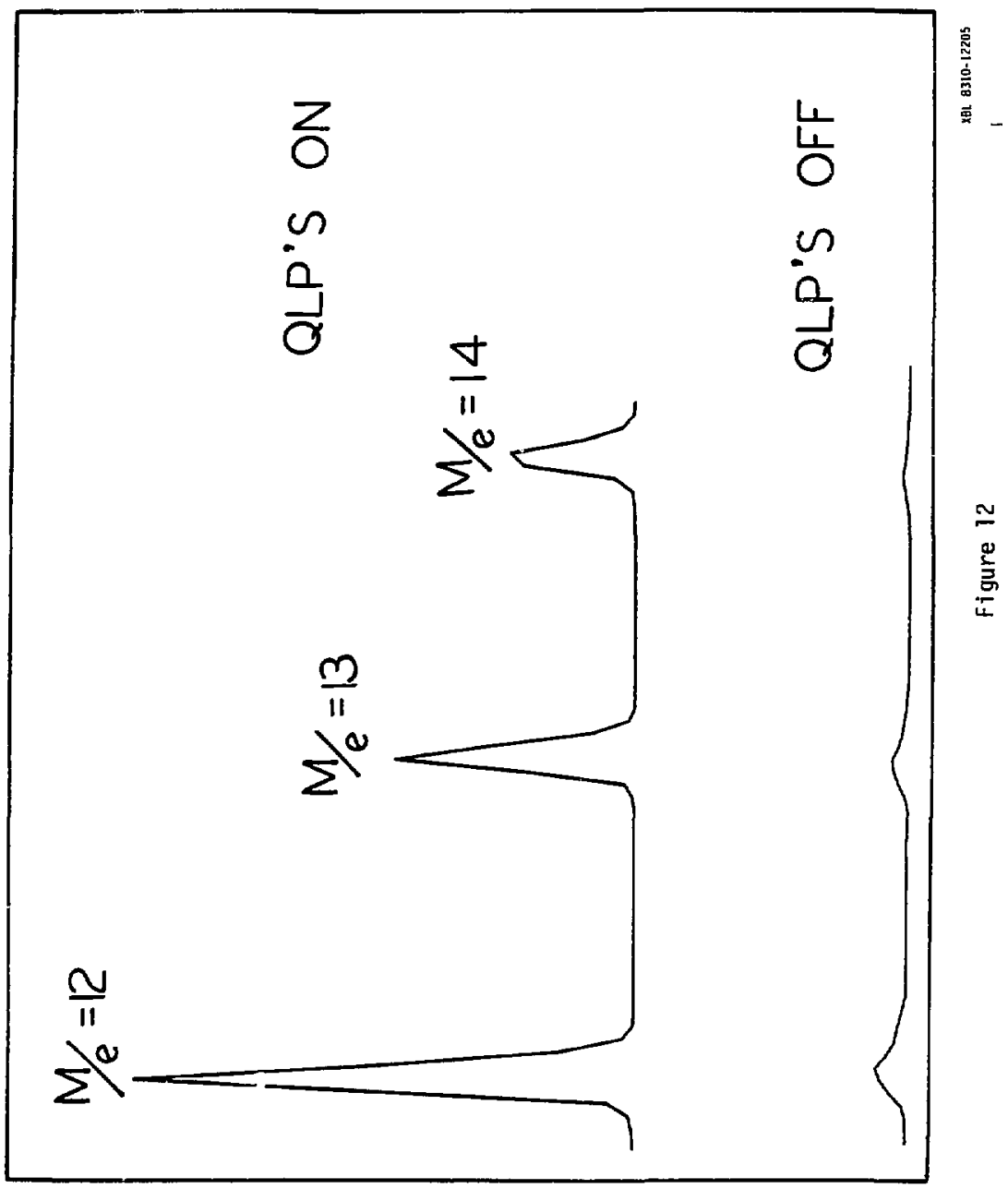




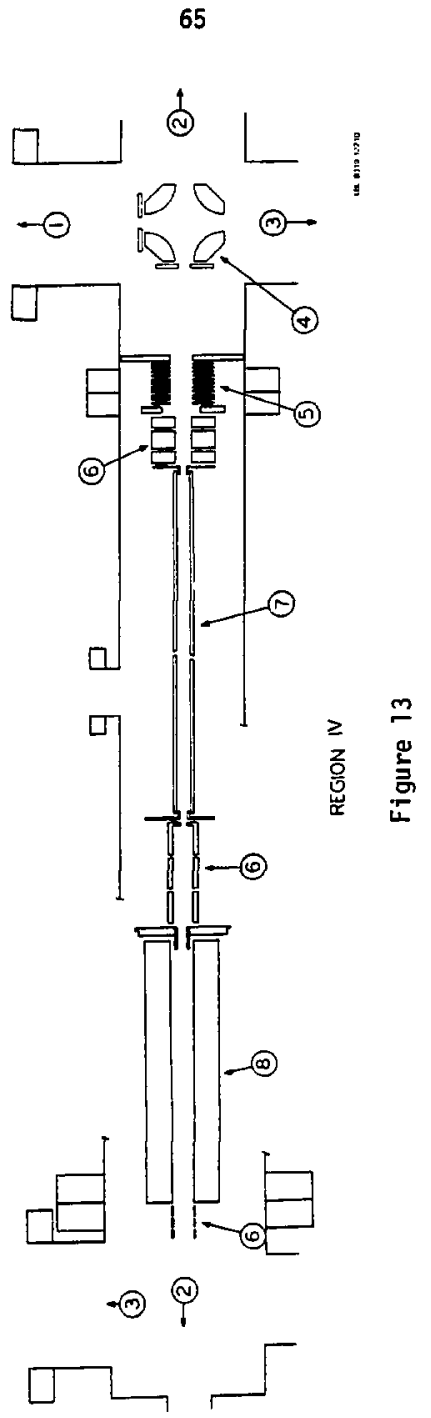




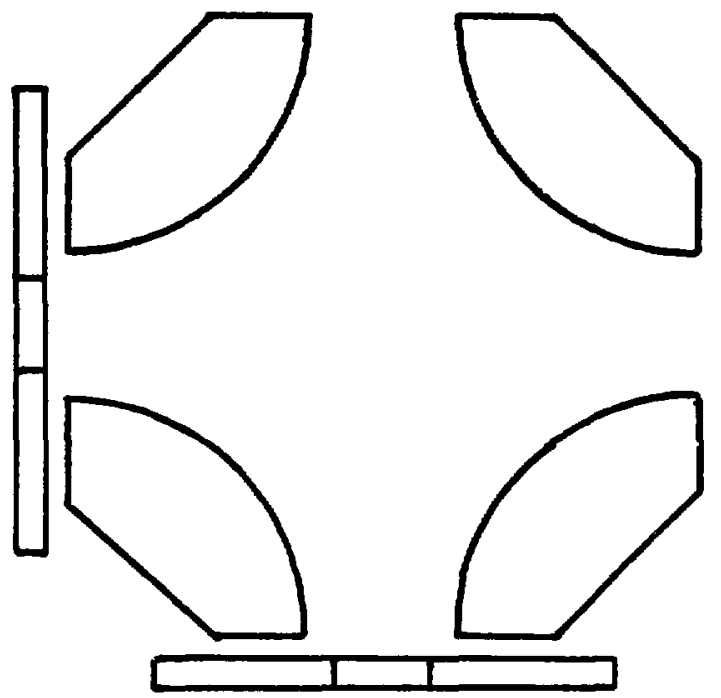

QUADRUPOLE FIELD
DEFLECT OR
xBL $8210-12196$

Figure 14 


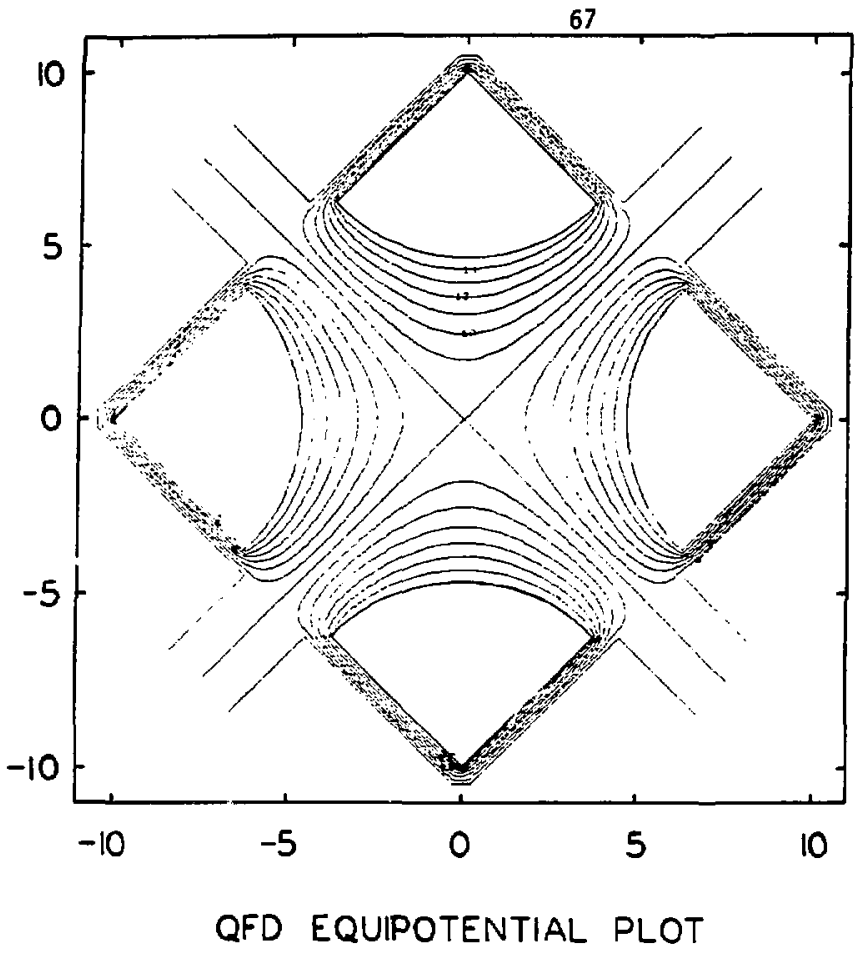

$$
\begin{aligned}
& \text { U-cont.juFs } \\
& 1 \text { - } 70 \text { 5T } \\
& 2 \text {-60.0\% } \\
& 3 \text { - } 58.005 \\
& 4-45.050 \\
& 5-3[.005 \\
& 6.20 .050 \\
& ?-10.005 \\
& \text { 2) } 0 \text {. } \\
& 910.000 \\
& 15 \quad 25.05 \\
& 11 \text { 30 ros } \\
& 12 \text { 4 } \\
& 13 \text { 5 } 13.005 \\
& 1465.000 \\
& \text { is } 70.950
\end{aligned}
$$

Figure 15 


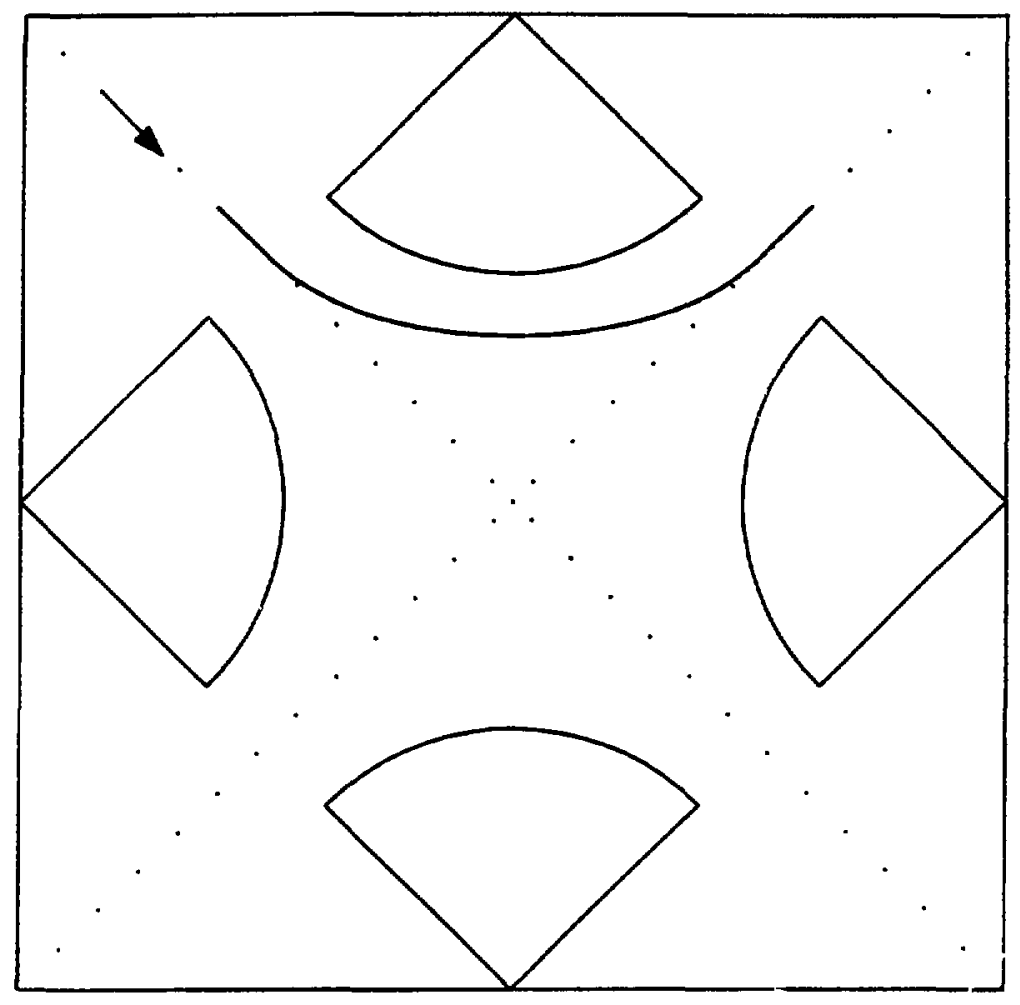

XBL $8310-12 ; 84$

Figure 16 


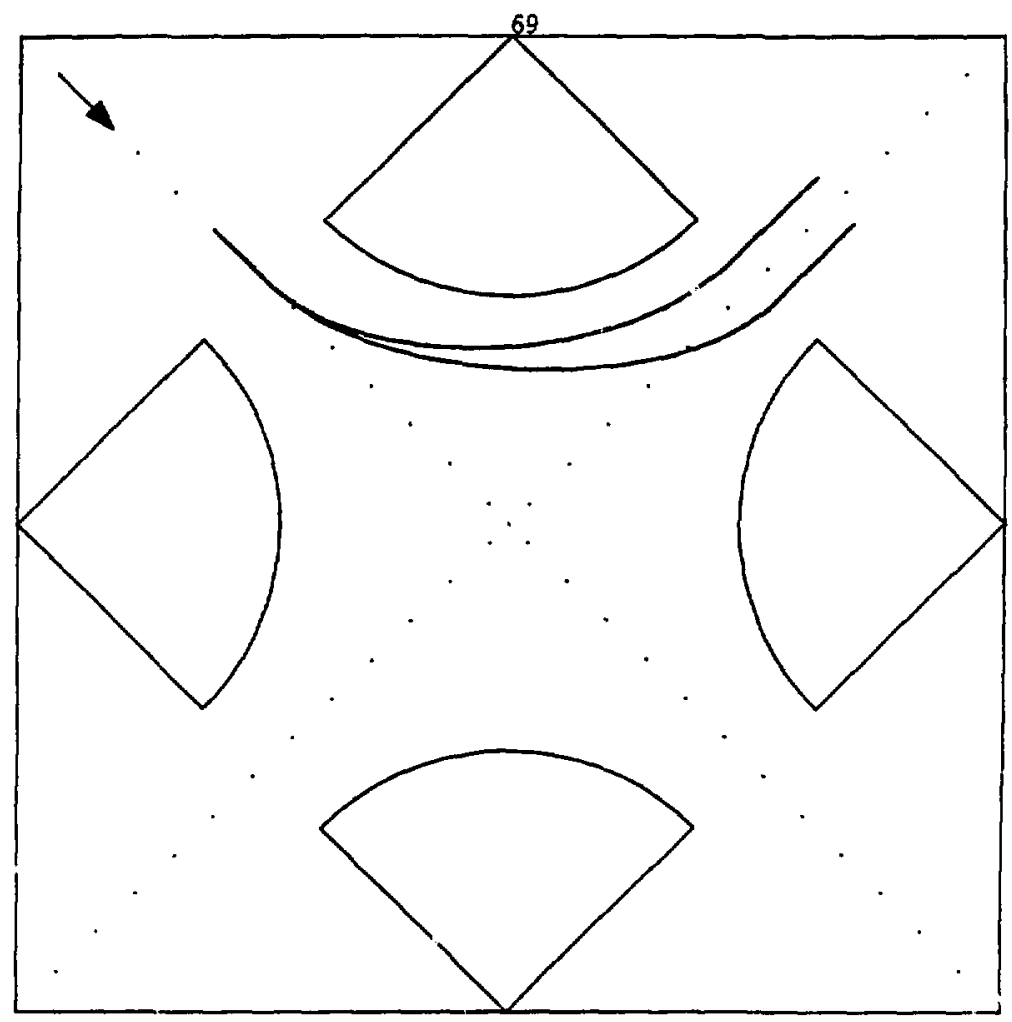

XBL 8310-12191

Figure 17 


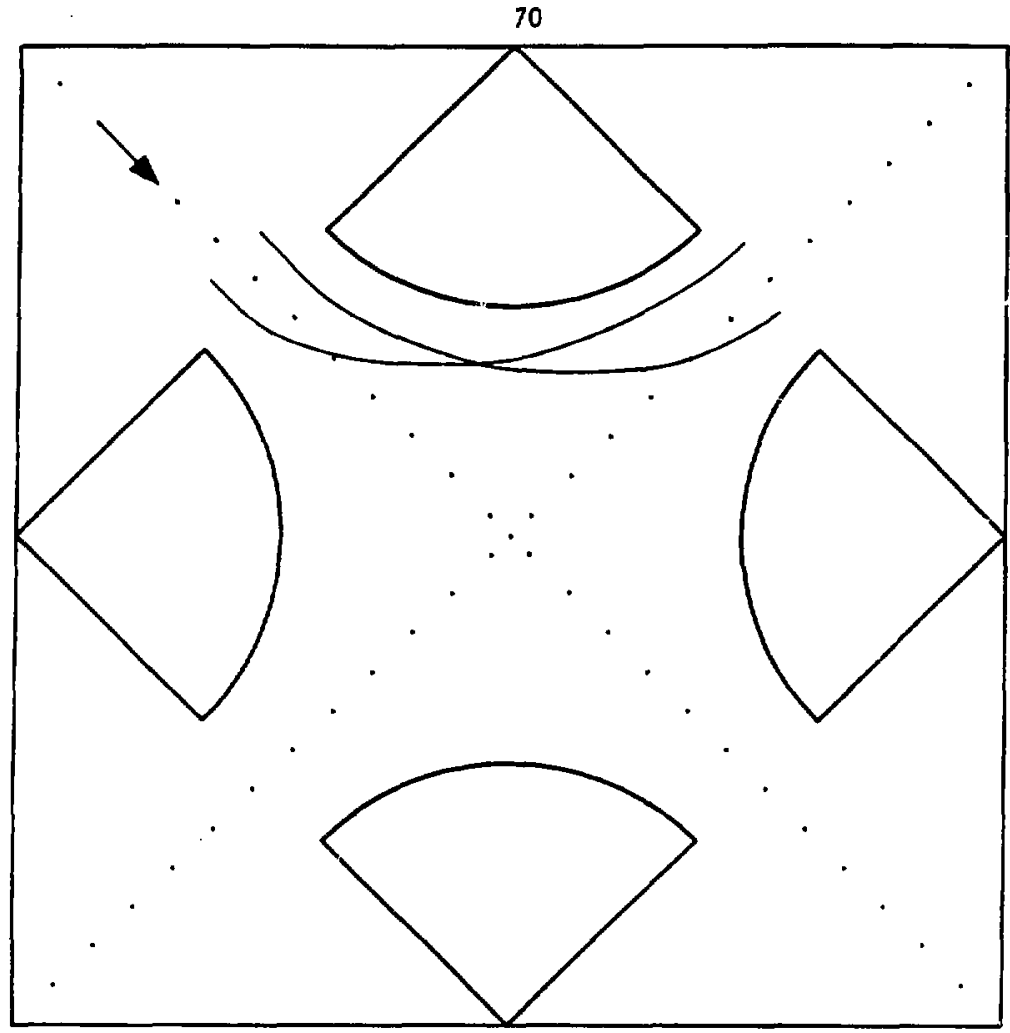

XBL 8310-12192

Figure 18 


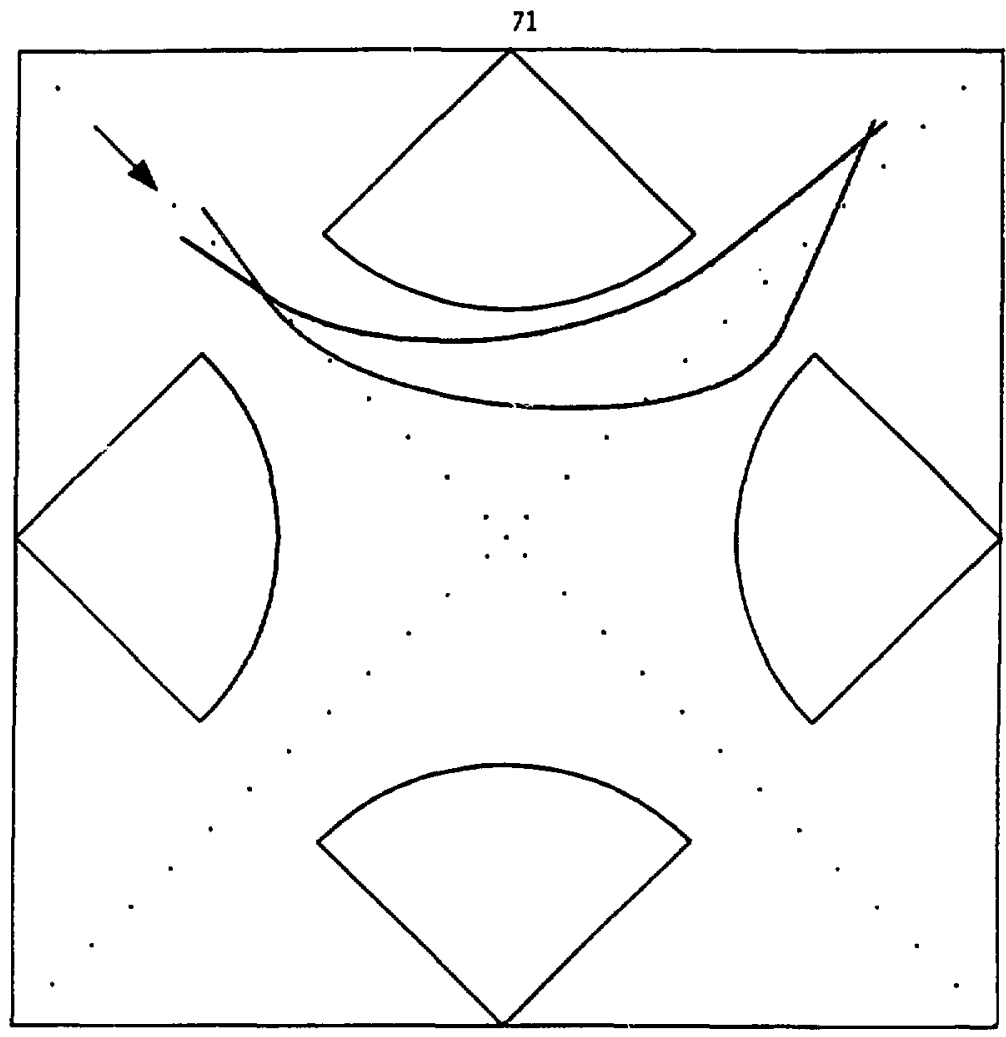

XBL 8310-12193

Figure 19 


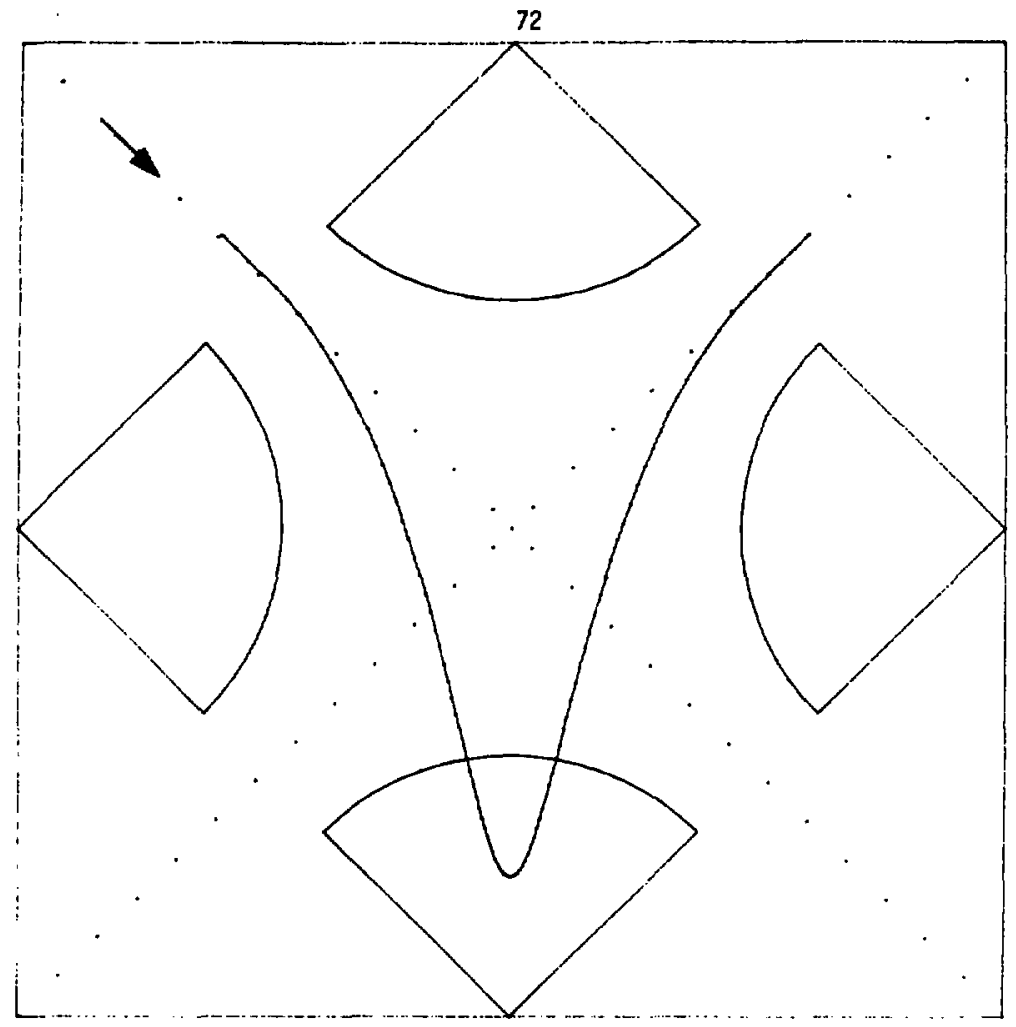

XBL 8310-12194

Figure 20 


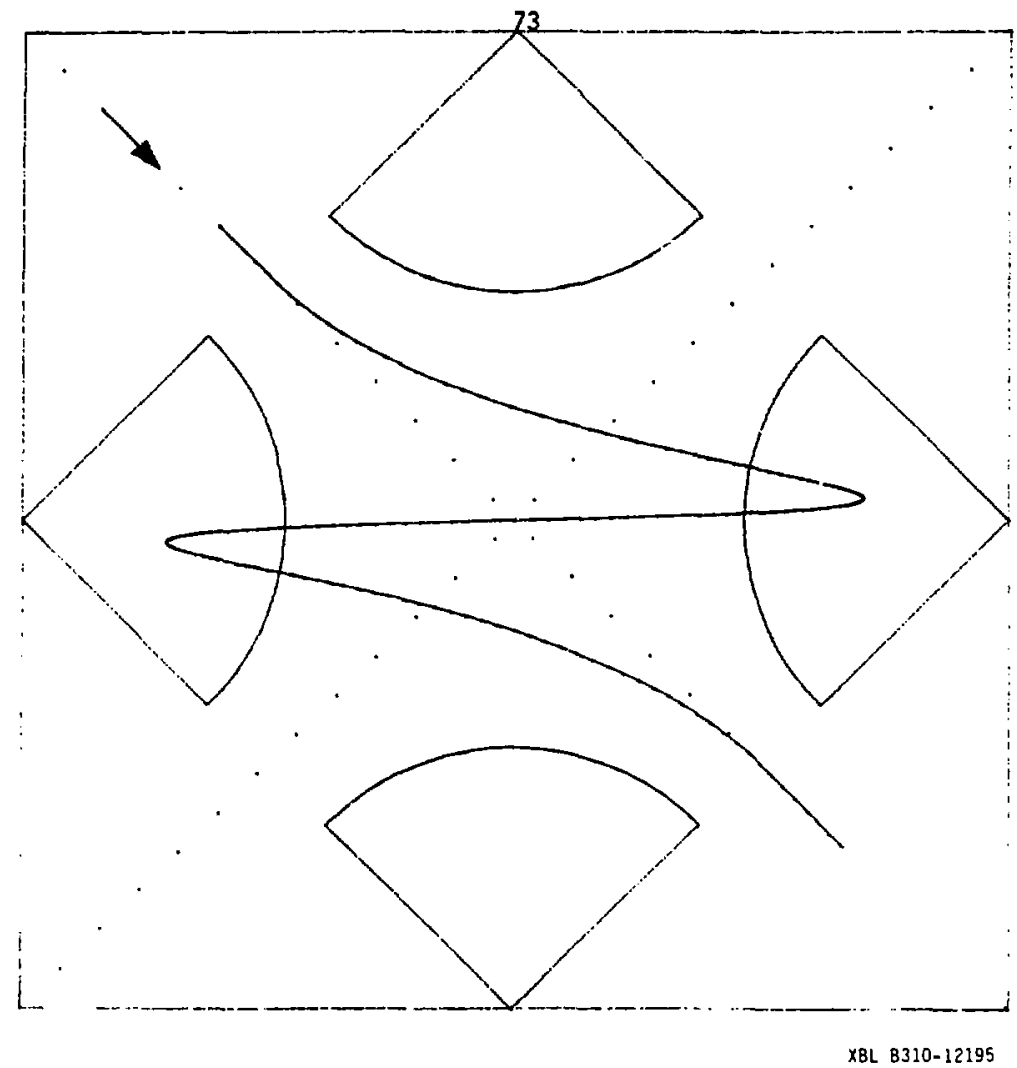

Figure 2] 

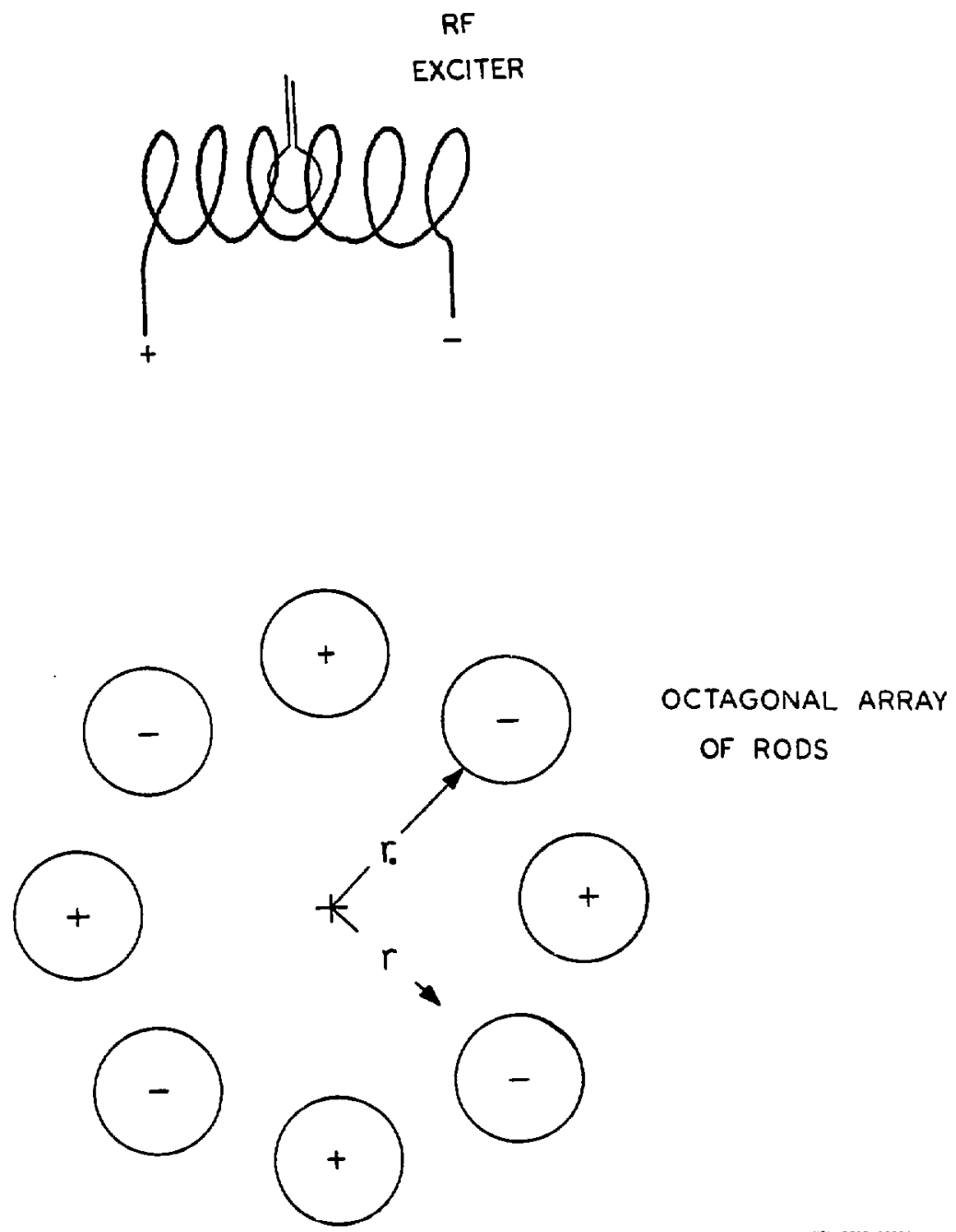

XBL $8310-12204$

Figure 22 
75

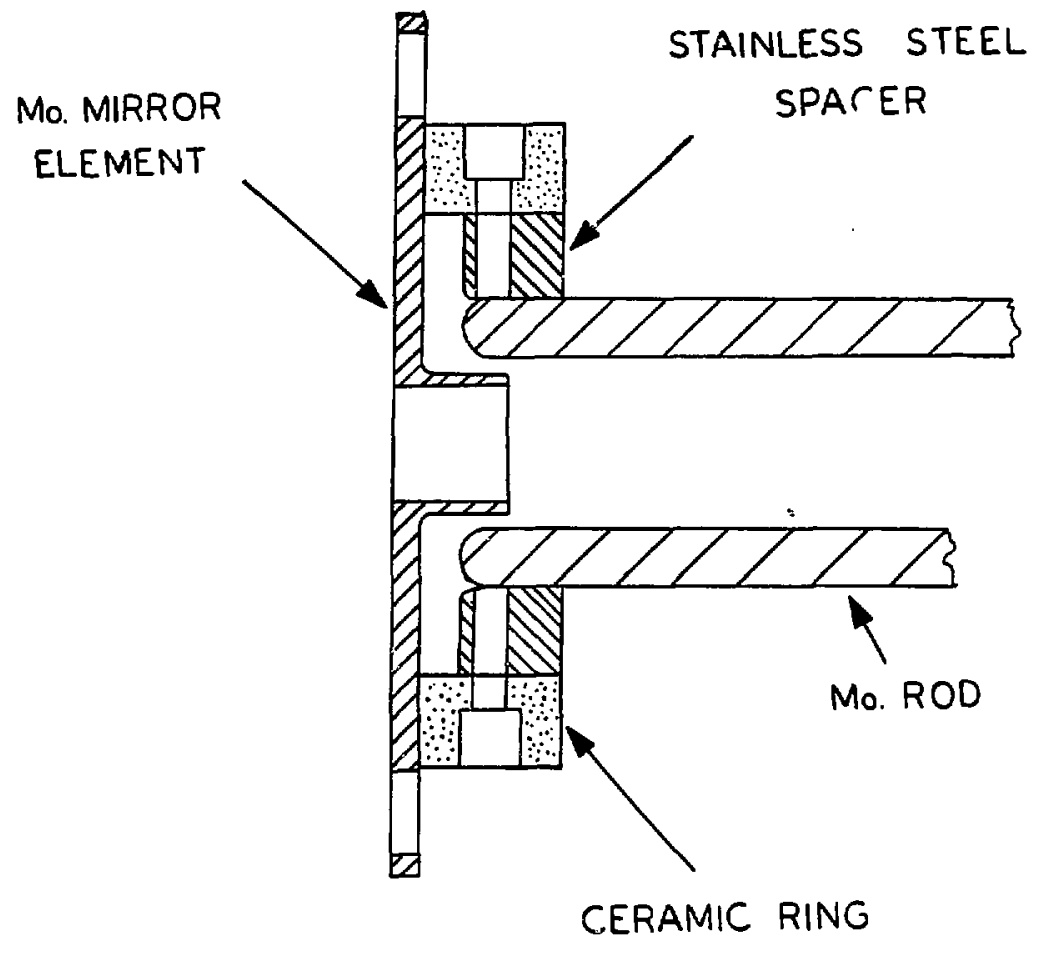

XBL $8310-12183$

Figure 23 


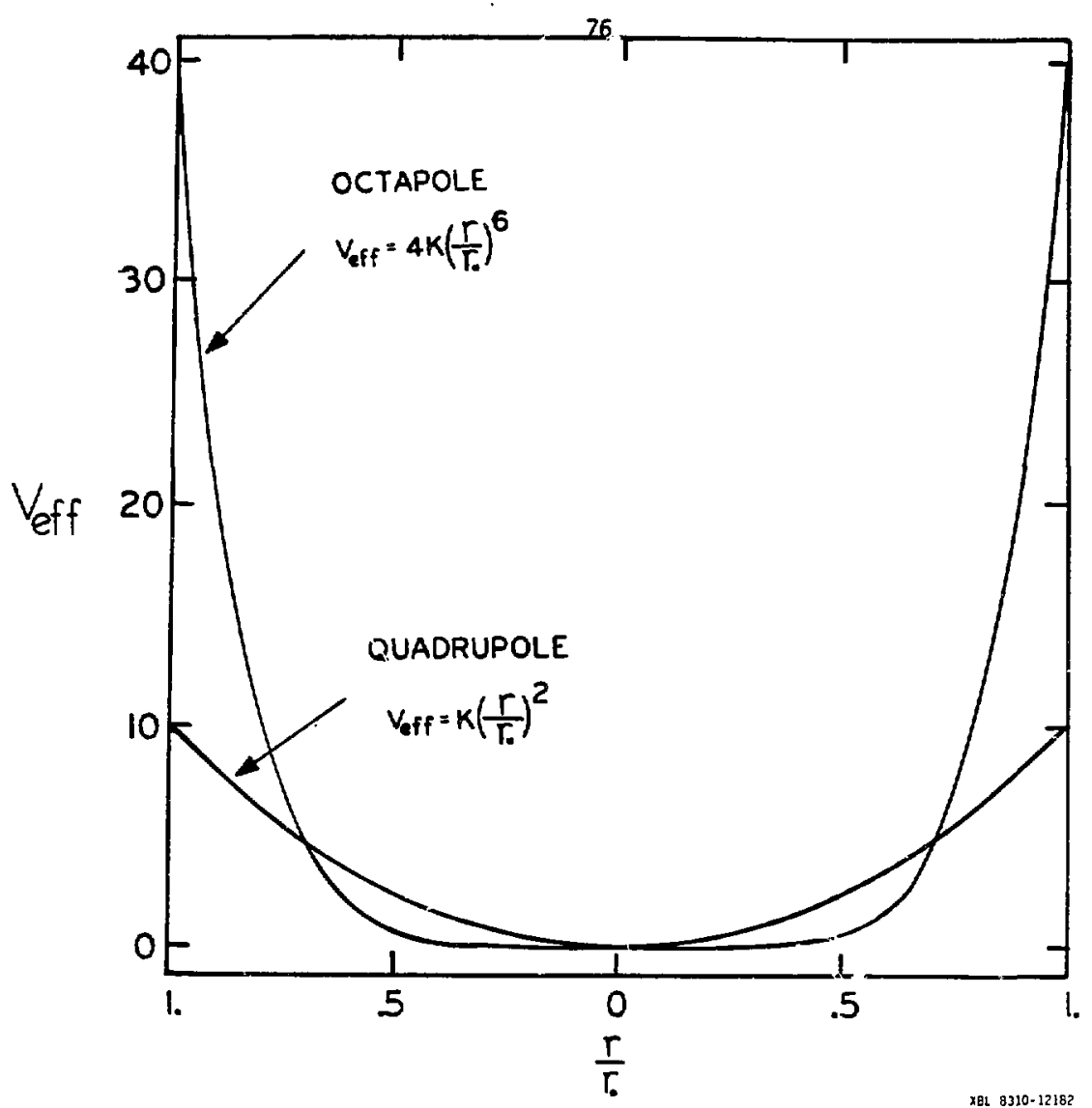

Figure 24 


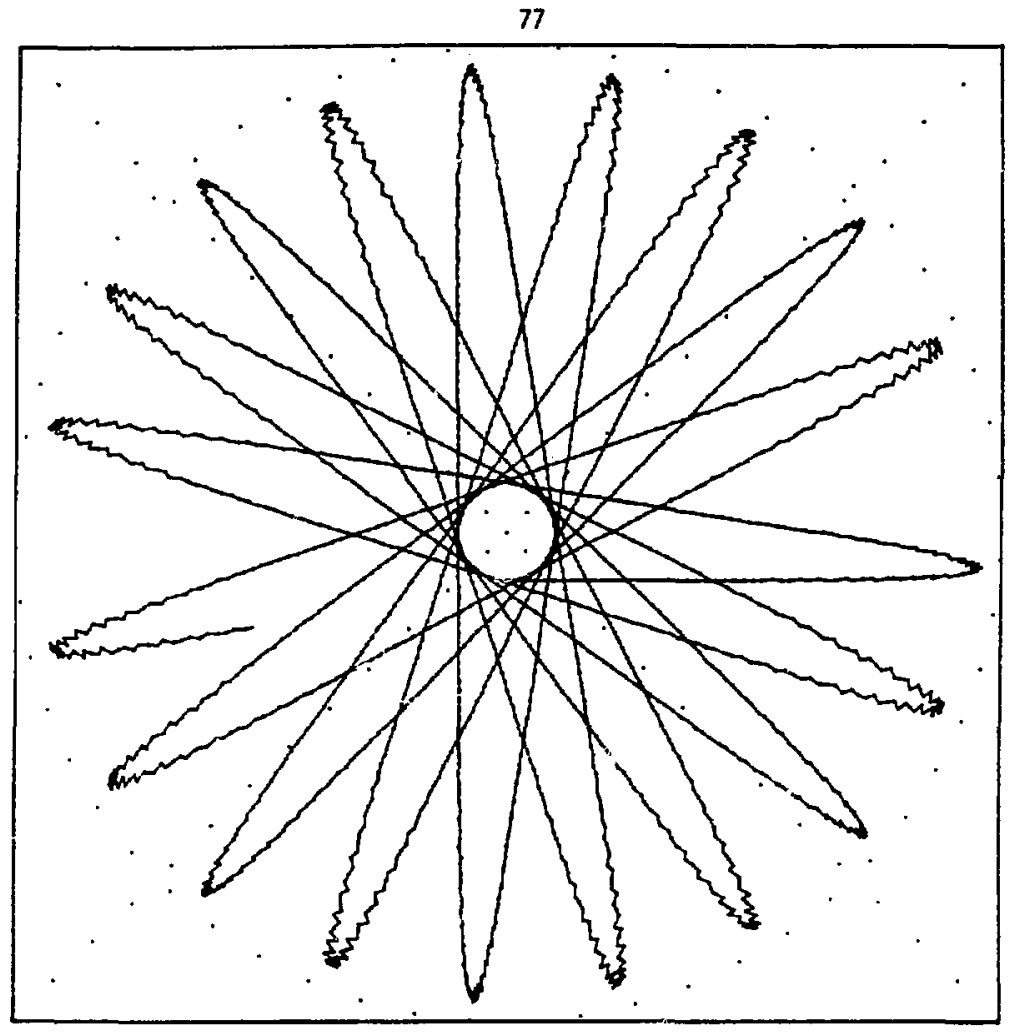

XBL $8310-12181$

Figure 25 
78
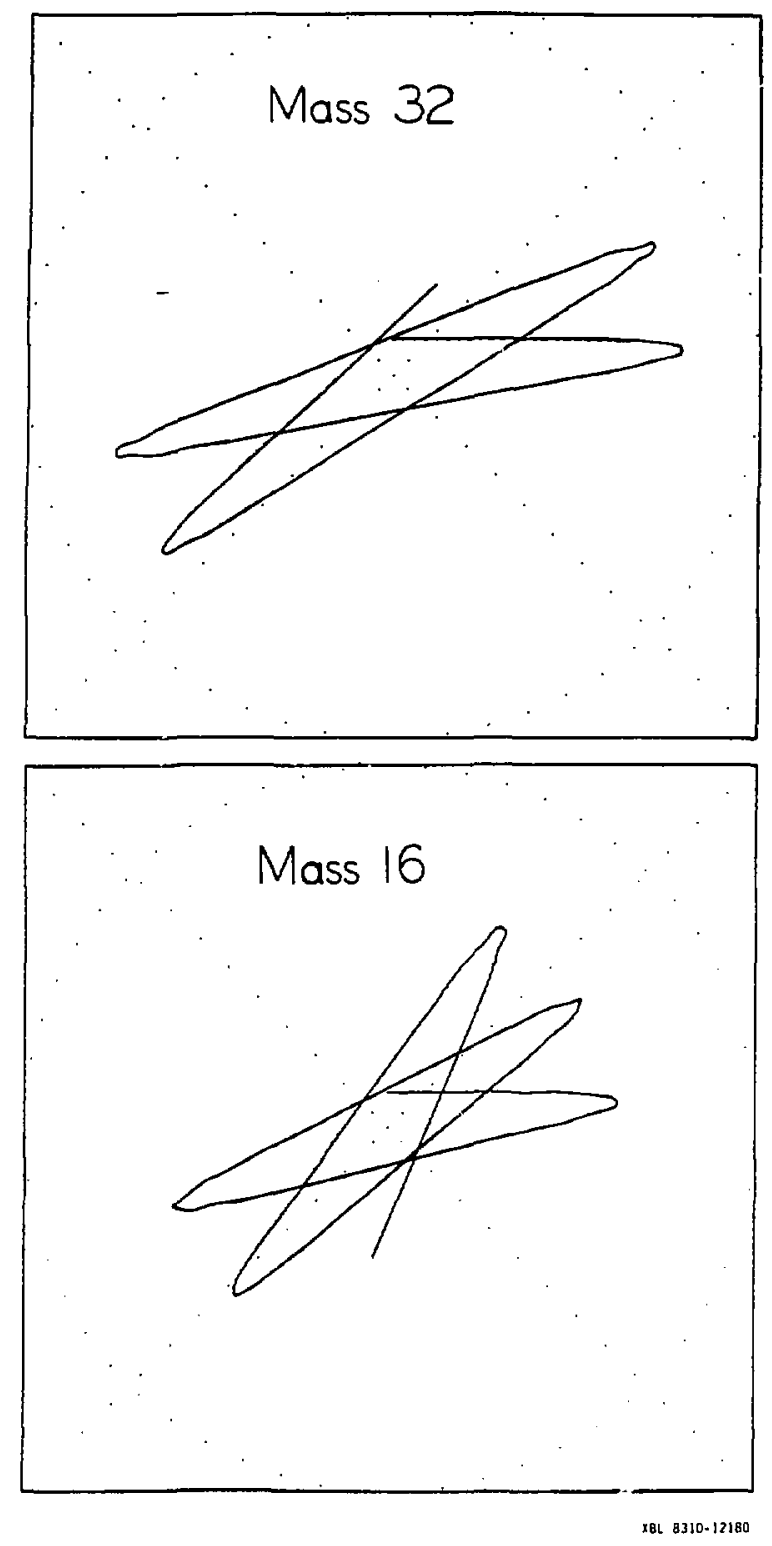

Figure 26 


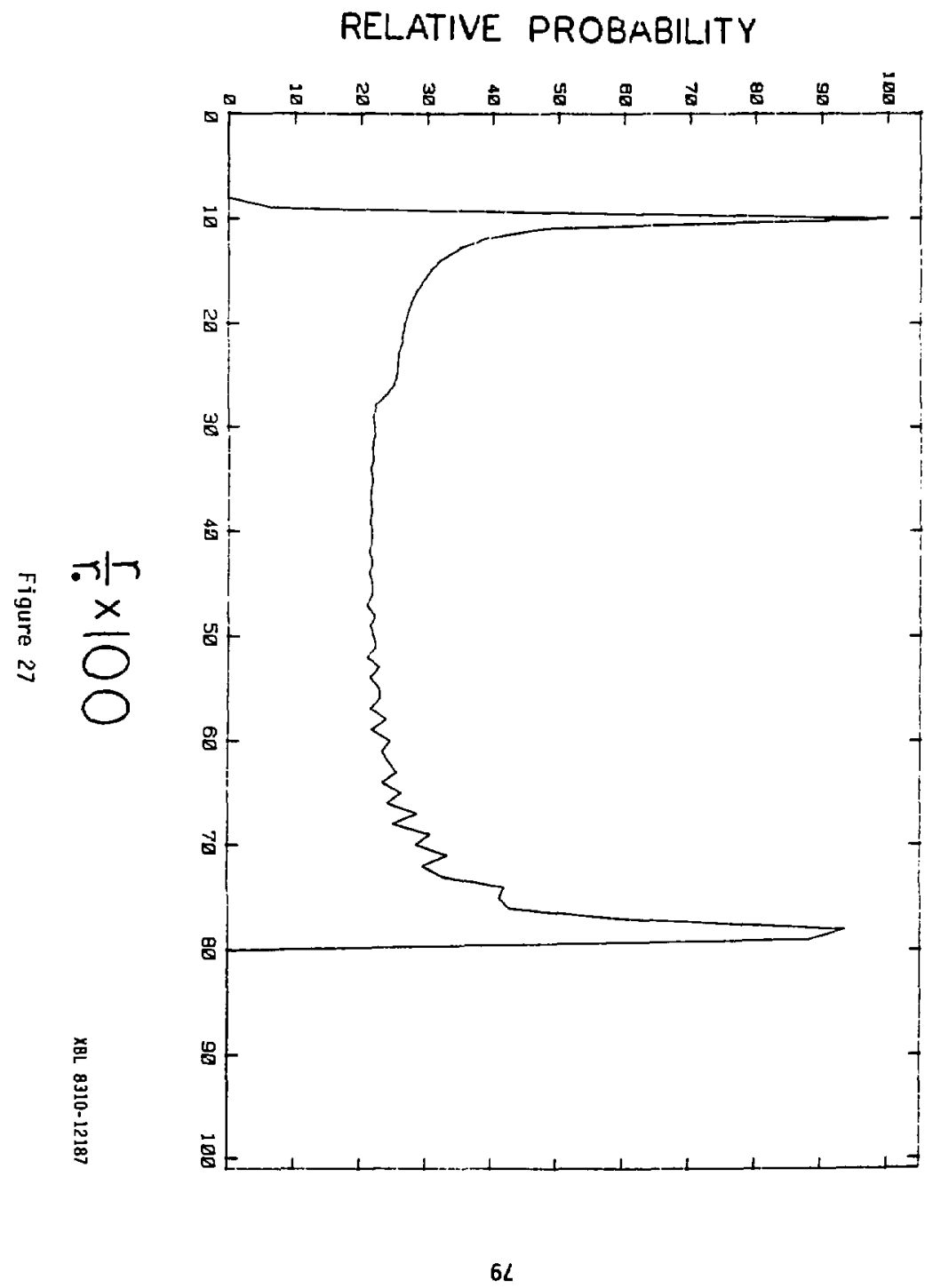


RELATIVE PROBABILITY

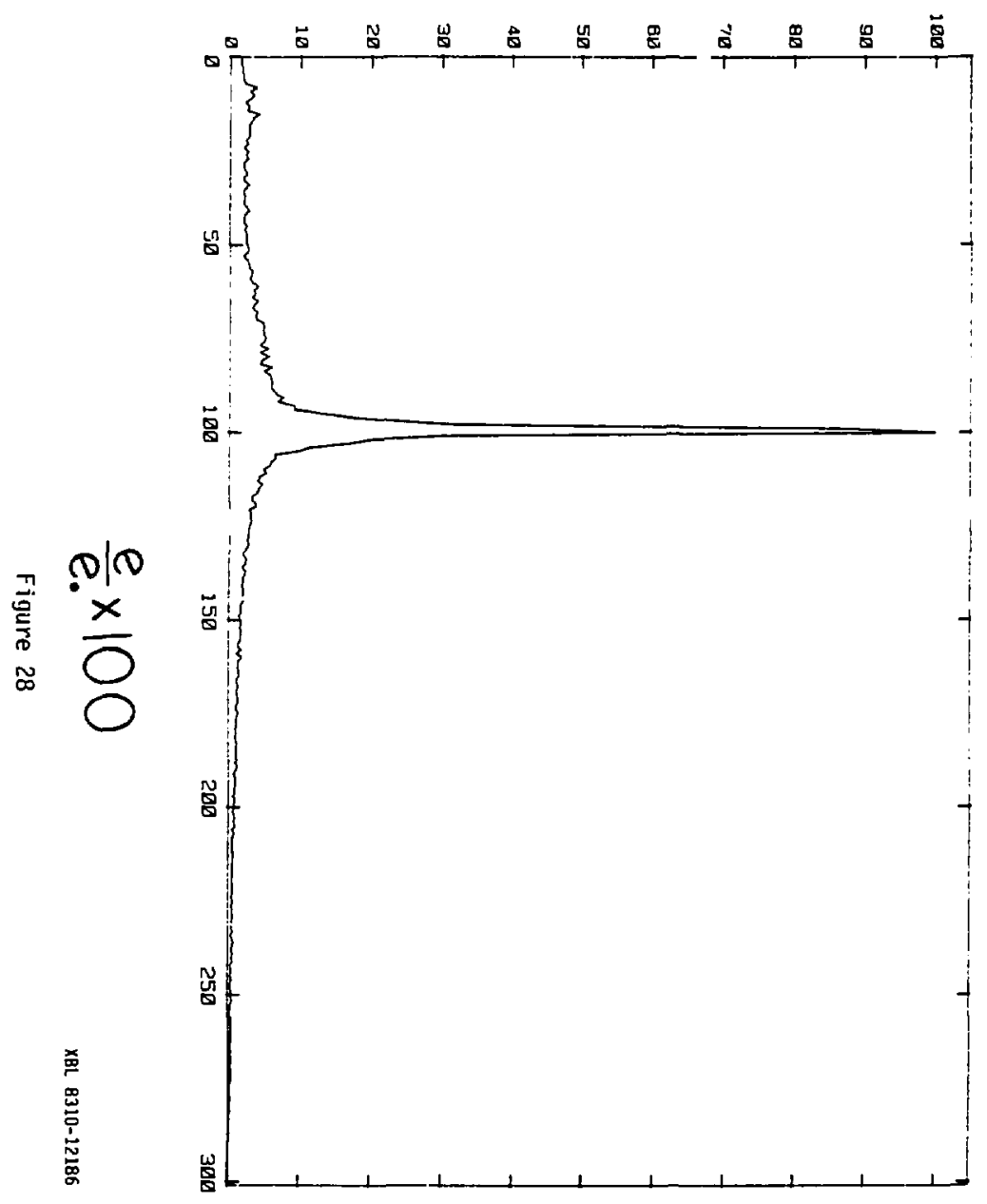


81

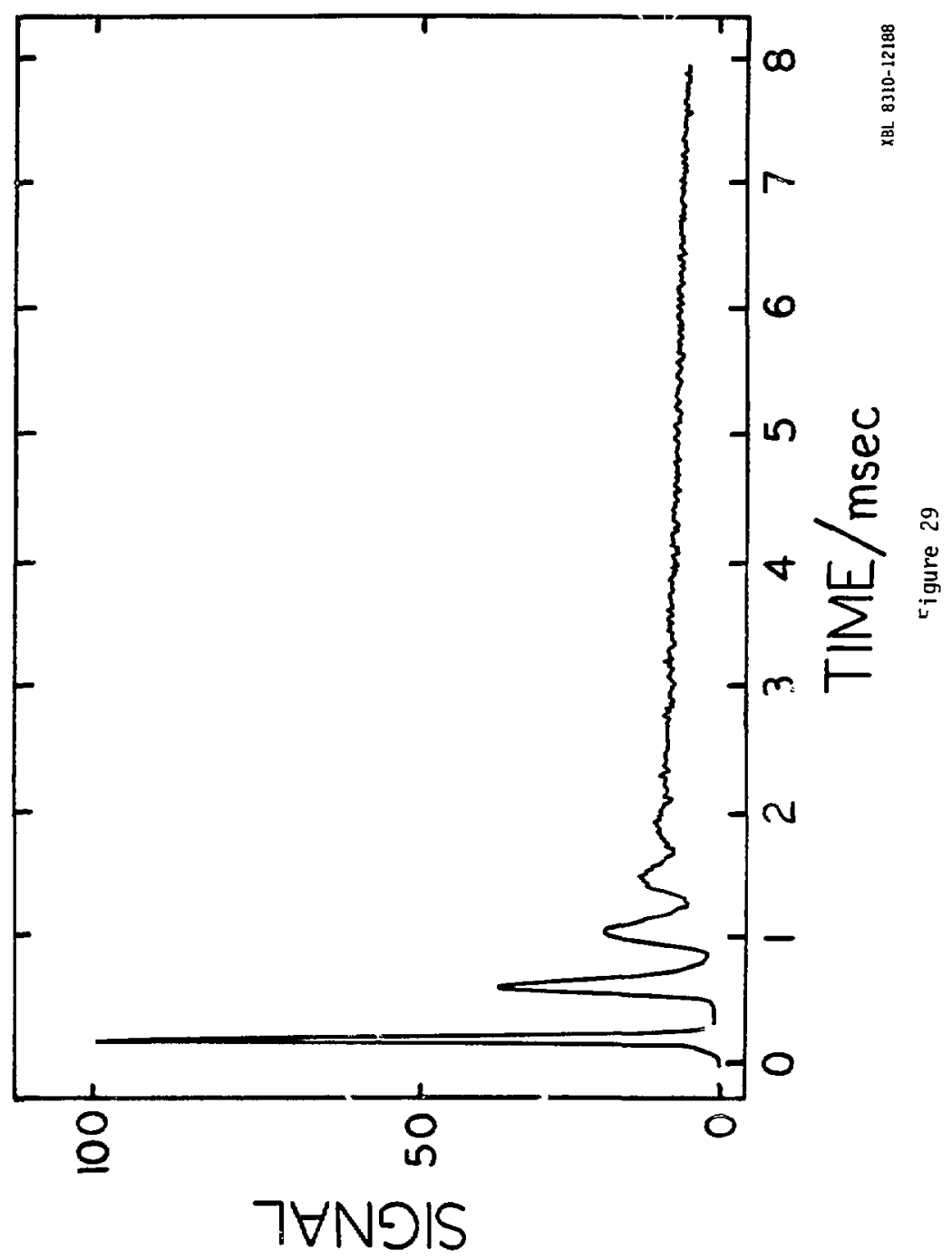




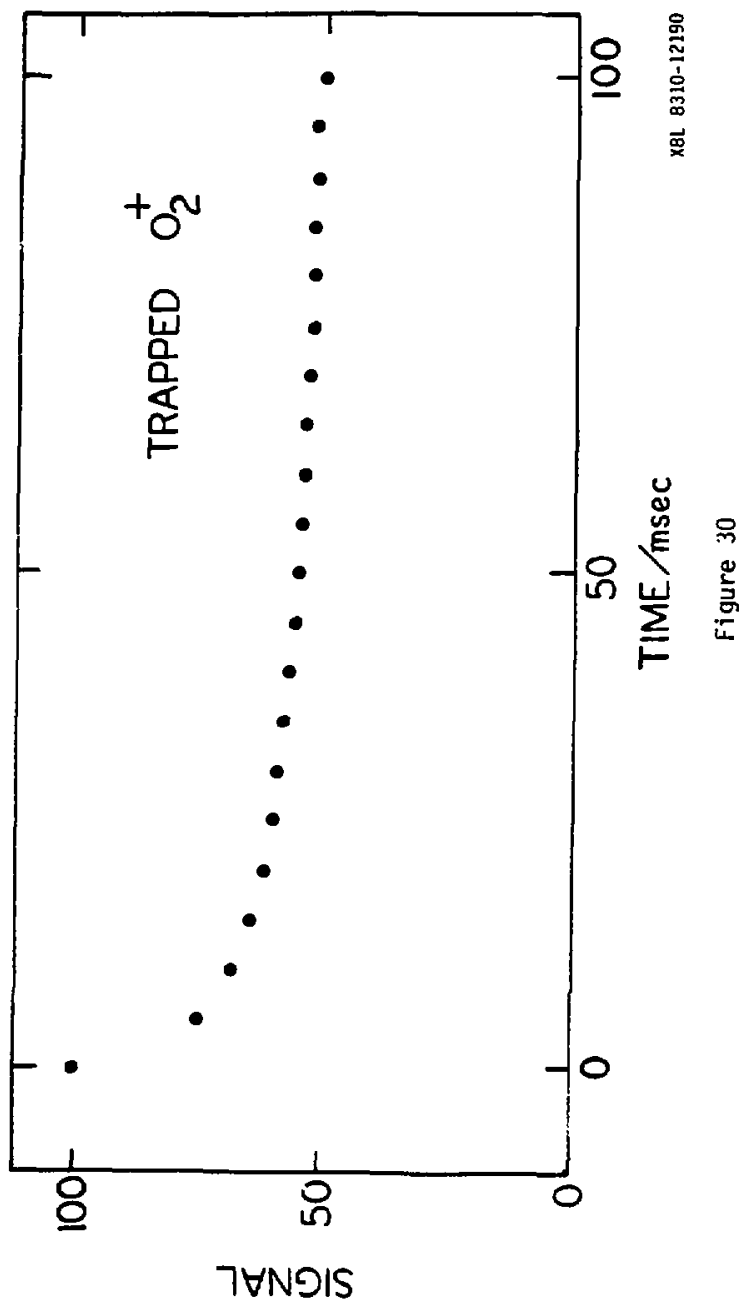




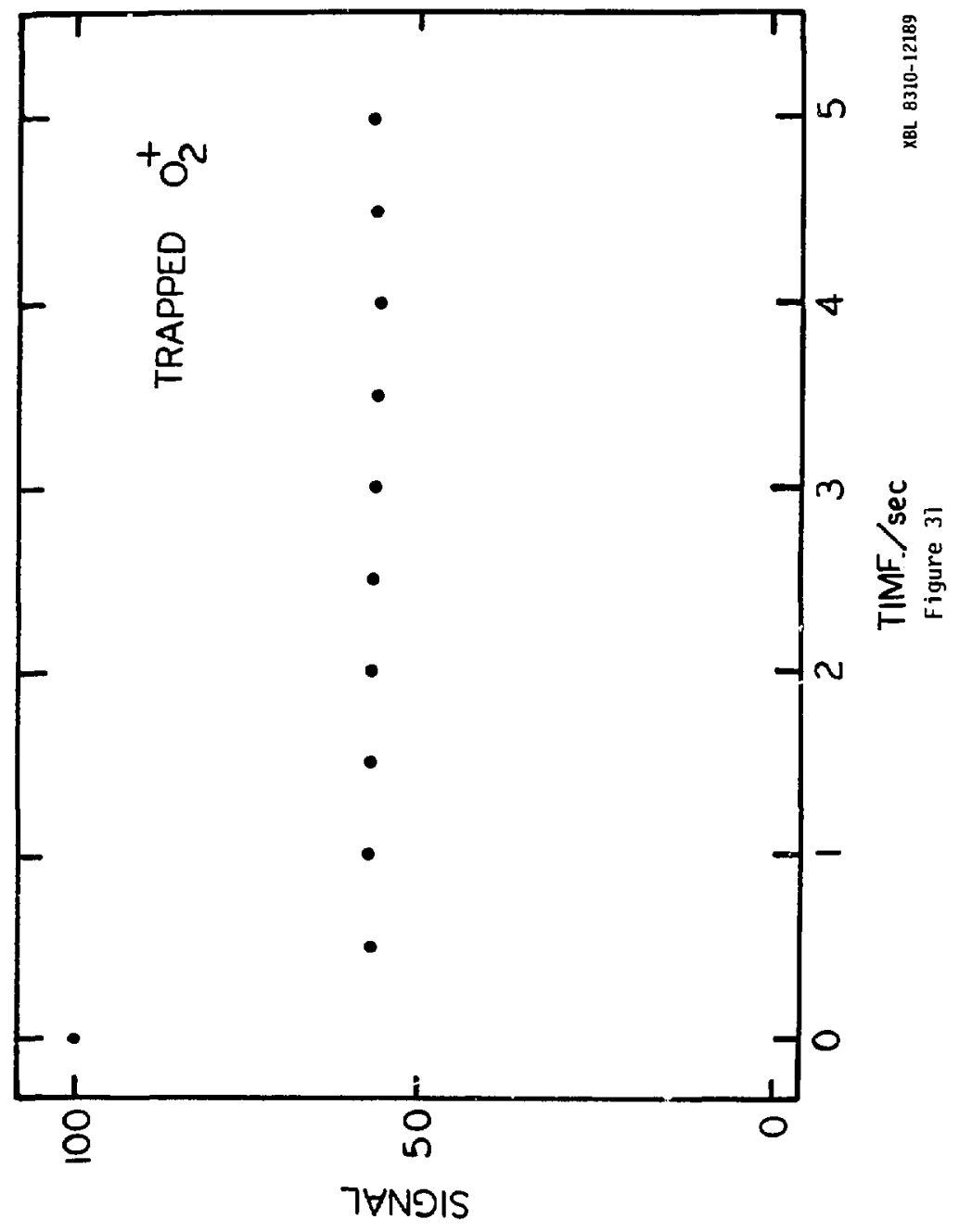




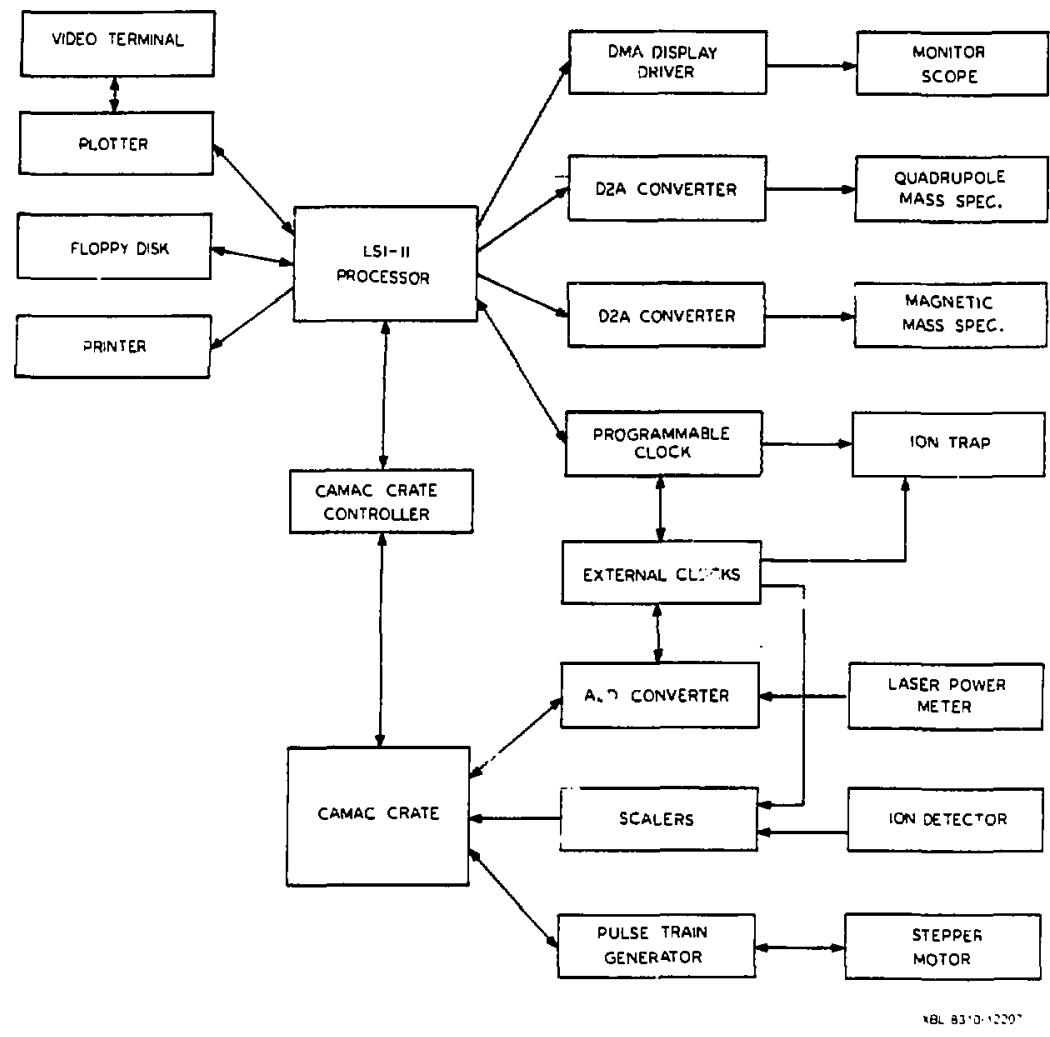

Figure 32 


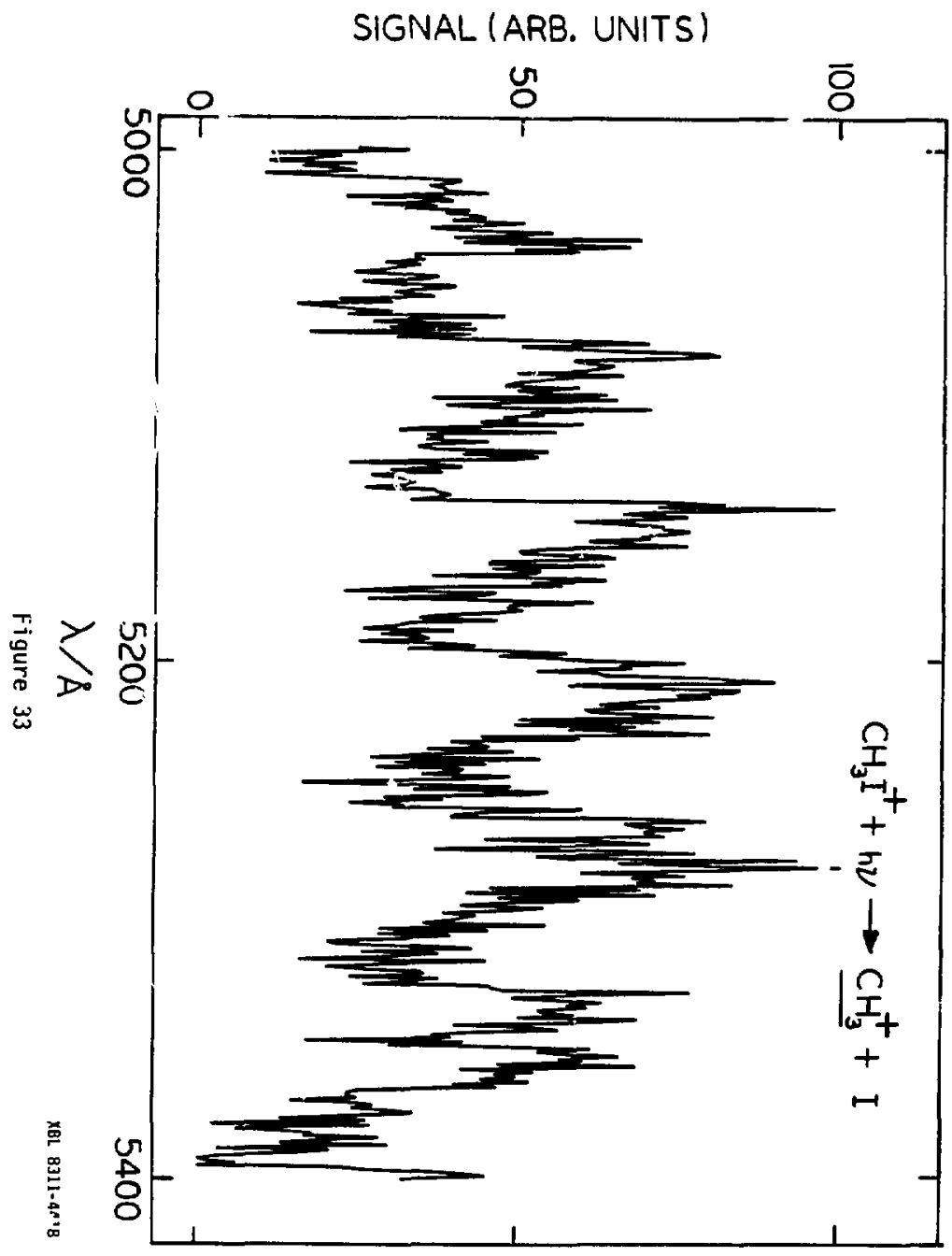




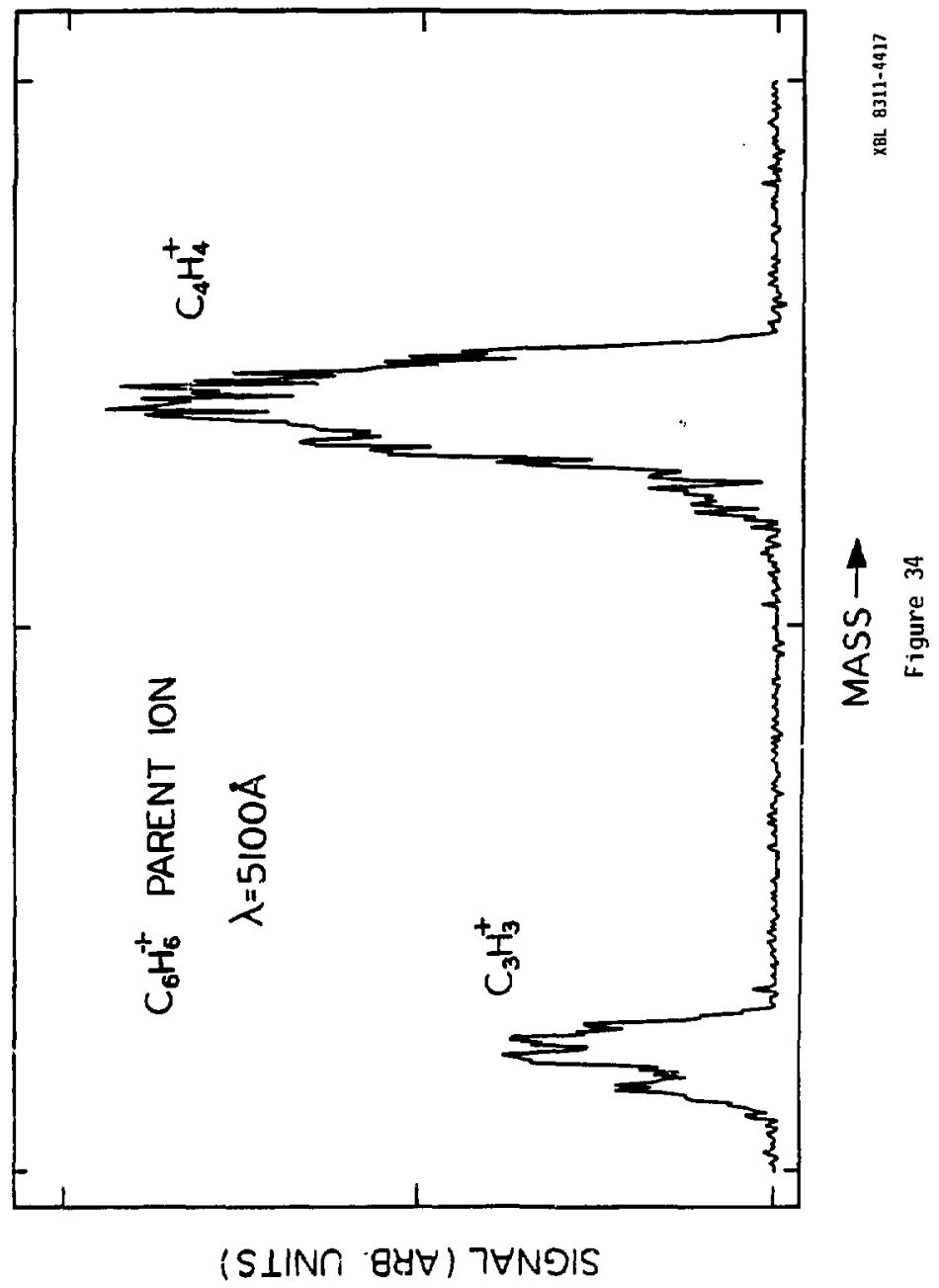




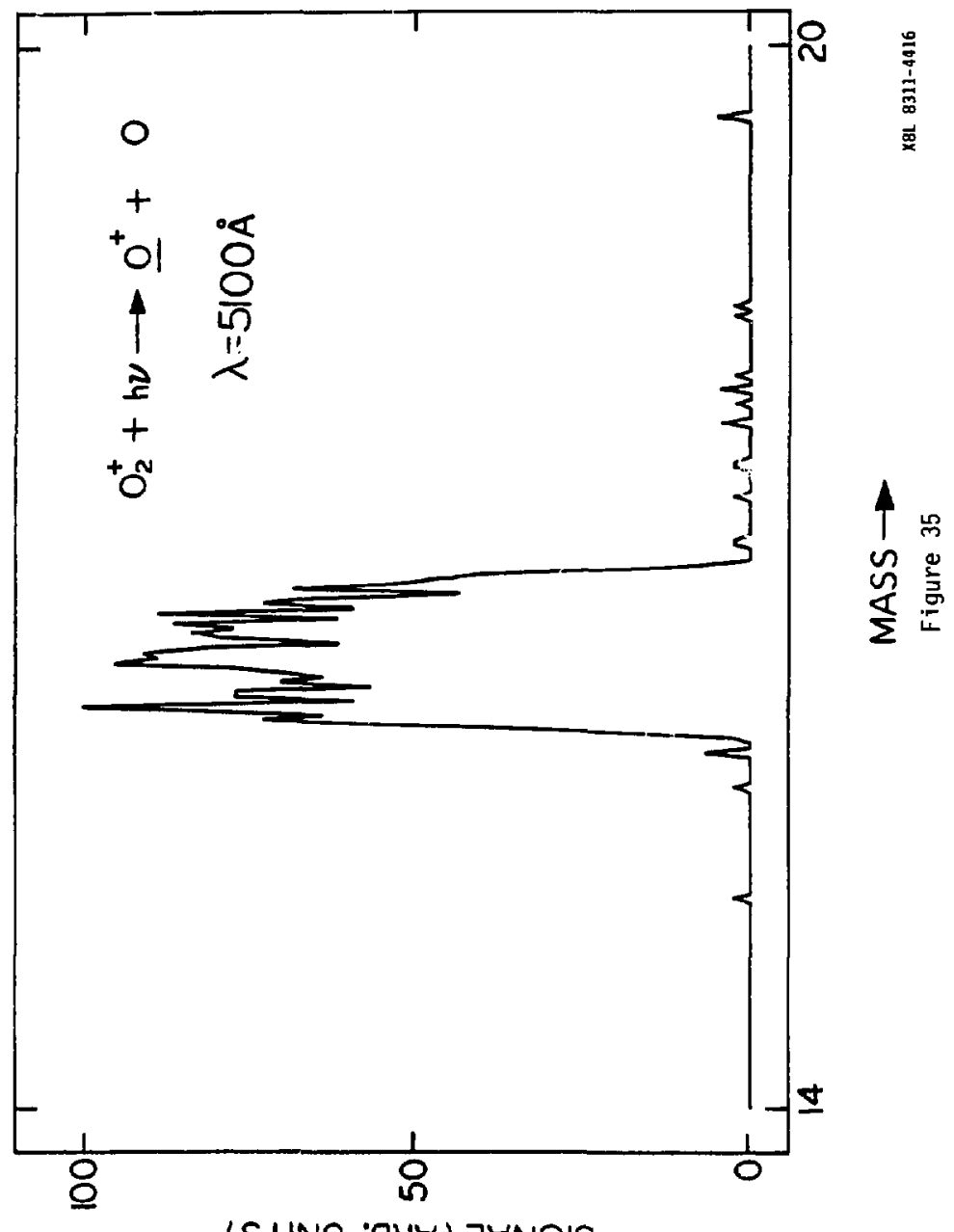

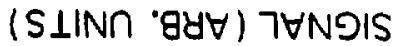


III. PHOTOFRAGMENTATION OF Ot:

\section{THE LIFETIME OF THE a $\boldsymbol{q}_{\boldsymbol{1}}$ M METASTABLE STATE}

\section{A. Introduction}

Molecular oxygen, an abundant and reactive species, is involved in many cremically important environments. Of interest is the fact that many of these environments are harsh enough to create the $\mathrm{O}_{2}^{+}$ion. In the gas phase one finds $\mathrm{O}_{2}^{+}$in flames (combustion), plasmas, electrical discharges, and by solar ionization, in the upper atmosphere. The ambition to better understand and predict the chemical evolution of these systems leads to the desire to know as much as possible about this important species.

Because $\mathrm{O}_{2}^{+}$has been the subject of much esperimental and theoretical work, it is one of the most understood molecules. Its spectroscopy, in particular the $b^{4} \Sigma_{g}^{-} \rightarrow a^{4} \pi_{u}$ First Negative band, has been studied for many years by emission iechniques. The high resolution emission work of this band by Nevin (1) in 1938 provided high quality information on the $b^{4} \Sigma_{g}^{-}$and $a^{4}{ }_{n}$ states.

Figure 1 shows the pertinent potential curves for this discussion.

More recently vestal et al. (2) using $6000 \AA$ radiation observed photodissociation of $\mathrm{O}_{2}^{+} \mathrm{a}^{4} \pi_{u}$ created by electron impact ionization of $\mathrm{O}_{2}$. This led to much work on the ion using laser photofragment spectroscopy by observing the predissociation of $\mathrm{O}_{2}^{+}$ $b^{4} \Sigma_{g}^{-}$state resulting from transitions shown in Fig. 1 as type $1 .{ }^{(3)}$ In this manner the $b^{4} \Sigma_{g}^{-} \leftarrow-4_{\pi_{u}}$ band was studied at very high resolution. In addition, the $f^{4} \pi_{g} \leftarrow-a^{4} \pi_{u}$ system was studied 
using photofragment spectroscopy-this resultei in the only reported case of $a^{4} \pi \leftarrow-{ }^{4} \pi$ system. $(2 g, 2 j)$

Numerous chemical studies have been done on $\mathrm{O}_{2}^{+}$. Here great advantage may be taken of the wealtir of information available on the potential energy surfaces for this ion. The reaction of $\mathrm{O}_{2}^{+}$to yield $\mathrm{O}_{3}^{+}$first gave evidence that $\mathrm{O}_{2}^{+}$was formed in a metastable state by electron impact ionization. (4) The metastable state responsible for the reaction and the photodissociation by visible light was identified as the $a^{4} \pi_{u}$ state: Much of the reactivity of the $\mathrm{O}_{2}^{+}$ion is due to the $a^{4} \pi_{u}$ metastable state. (5) Thus it is clear that the lifetime of this state is an important parameter in modelling studies. For example, A. Dalgarno et al. (6) state that the composition of the ionosphere in the E- and F-regions may depend significantiy on the $\mathrm{O}_{2}^{+} \mathrm{a}^{4} \pi_{u}$ state. In order to evaluate how strongly the $a^{4} \pi_{u}$ state will influence its chemical environment, ics lifetime must be known. However, in many studies, both chemical and spectroscopic, assumptions have had to be made concerning the lifetime of the $\mathrm{O}_{2}^{+} \mathrm{a}^{4} \pi_{u}$ metastable state, since a direct measurement was lacking. The lifetime has been generally assumed to be $\tau \geq 1 \mathrm{msec}^{(7)}$ since its radiative relaxation to the $x^{2}{ }_{g}$ state is sp in forbidden.

Our spectrometer is a low resolution insirument, being Doppler limiter. The study of the $b^{4} \Sigma_{g}^{-}+-a^{4}{ }_{u}$ predissociation spectrum was not of interest to us for the sake of the spectroscopy alone since it is already well known. However, because our 
spectrometer could generate the photofragment spectrum as a function of time, where the time could be varied from -1 millisecond to 100 's of milliseconds, we could readily measure the lifetime of the $a^{4} \pi u$ state-a measurement worth making. We recorded the photofragment spectrum of $0_{2}^{+}$, generated by electron impact ionization of $0_{2}$, at low resolution $\left(-1 \mathrm{~cm}^{-1}\right)$ as a function of time. This led us to discover that the decay of the $a^{4} \pi_{u}$ state is strongly dependent on its spin component identity.

\section{B. Experimental}

The $\mathrm{O}_{2}^{+}$was produced by electron impact ionization of $\mathrm{O}_{2}$ at $5 \times 10^{-5}$ torr. The electron energy was $-80 \mathrm{eV}$. This ionization produces, after a few microseconds, $\mathrm{O}_{2}^{+}$in essentially two electronic states: $-30 \%$ in the $a^{4} \pi_{u}$ metastable state and $-70 \%$ in the $x^{2} \pi$ ground state. $(4 c, 8)$ The ions thus produced were passed through a sector magnet mass filter which allowed only $\mathrm{O}_{2}^{+}$to be placed into the RF octapole interaction region. This region was maintained at about $7 \times 10^{-10}$ torr during the photofragmentation measurements.

The experiment was run in a pulsed mode. Ions were pulsad into the RF octapole trap. After a selected length of time the laser was fired, and then the product ions were sent through the final quadrupole mass filter to be counted by the ion detection system. The counts from this laser sequence were placed into a signal-plus-background $(S+B)$ buffer. This laser sequence was followed by an identical pulse 
sequence, except that the laser was not fired. The counts obtained from this no-laser sequence were placed into a "background" (B) buffer. The laser correlated signal was then taken to be $(S+B)-B$. Figure 2 shows the details of the pulse sequence used in this data collection cycle. The RF dumping pulse was used to pulse the RF supplied to the octapole rods off for a short period of time, thus ensuring that the jon trap was free of ions at the start of a new pulse sequence. The data were collected in two modes. In the first mode delay-x $\left(D_{x}\right)$, the amount of time the jons remained in the trap before the laser was fired, was held constant while the laser frequency was varied: thus signal versus laser frequency was measured for a given ion storage time. In the second mode, the laser frequency was held constant while delay-x was varied: photofragment yield as a function of time for a given laser frequency was thus measured. In each mode the $0^{+}$photofragment was detected. Figure 3 shows typical results for a wavelength dependence scan and Figure 4 shows the $0^{+}$ yield as a function of time for the indicated wavelengths.

The linewidth of the pulsed dye laser was about $0.4 \mathrm{~cm}^{-1}$ and its pulse width was $-8 \mathrm{nsec}$. The lifetime measurements were carried out using $\sim 0.003$ watts of time averaged laser power. The repetition rate was $4.2 \mathrm{~Hz}$ and the beam diameter $0.4 \mathrm{~cm}$. The laser beam was carefully aligned so that it passed through the spectrometer without striking any metal surfaces: no laser correlated signal was observed when no $\mathrm{O}_{2}^{+}$molecules were in the interaction region. Figure 5 shows the $0^{+}$photofragment signal as a function of laser pulse energy. The lifetime measurements were carried out using pulse energies of $\sim 0.7 \mathrm{mj}$. 
The best resolution abserved in the wavelength scans was $\sim 1$ $\mathrm{Cm}^{-1}$. The average energy of the trapped ions was $-0.65 \mathrm{eV}$ with a spread of about $0.3 \mathrm{eV}$. As discussed in the previous chapter, the initial axial energy of the ions is distributed to the other ccordinates producing wide kinetic energy distributions in each coordinate. For $\mathrm{O}_{2}^{+}$at $-0.65 \mathrm{eV}$ median energy, one might expect a Doppler width of $\sim 0.3 \mathrm{~cm}^{-1}$ at $5000 \AA$. Our laser had a line width of $-0.4 \mathrm{~cm}^{-1}$. Thus, the observed resolution of $-1 \mathrm{~cm}^{-1}$ is in keeping with expectation.

Before continuing, some elaboration is necessary concerning experimental difficulties encountered during the course of the measurements. The first problem, evident in Fig. 4, was the escape of parent ion $0_{2}^{+}$from the ion trap (see Chap. II). This problem was not very serious since one could easily account for the loss of parent ions when treating the data. Also, as mentioned before, the losses were minimal after about 50 msec of trapping time.

There was however, a more bothersome consequence of the escaping $\mathrm{O}_{2}^{+}$parent ions. Some of these ions were being accelerated into metal surfaces during their "escape", and the resulting ion-surface collision fragmented some of the $\mathrm{O}_{2}^{+}$creating $\mathrm{O}^{+}$. A portion of these collisionally produced $0^{+}$ions recoiled back into the ion trap region and were contained by the trap. This interaction was taking place at the ends of the ion guide with the ion mirrors. This was demonstrated by measuring the $0_{2}^{+}$loss and $\mathrm{O}^{+}$appearance as a function of time while a pulse of ions was bouncing back and forth in 
the ion guide. Figure 6 shows the abundance of $0_{2}^{+}$and $0^{+}$in the ion guide as a function of time. The times at which the traveling pulse of ions encounters a mirror are indicated by the arrows. (The vertical scale for each ion is different.) Note that the encounter causes a loss of $\mathrm{O}_{2}^{+}$and at the same time results in the increase of $\mathrm{O}^{+}$ions within the ion guide. This increase of $0^{+}$was unexpected and produced signal-to-noise ratios which were much worse than anticipated, especially for long trapping times. Figure 7 shows how this $0^{+}$background increased with time.

\section{Results and Discussion}

Figure 8 shows the results of scanning the laser wavelength from 4902 to $5025 \AA$ in $0.48 \mathrm{~A}$ steps with ion trapping times held at $0.1 \mathrm{msec}$ and $100 \mathrm{msec}$. This wavelength region covers the left hand peak in Fig. 3. Figure 9 shows spectral simulations of the same wavelength region with the time equal to $0.1 \mathrm{msec}$ and $100 \mathrm{msec}$. The spectra were calculated assuming that the $F_{2}^{\prime \prime}$ and the $F_{3}^{\prime \prime}$ sp in components of the $a^{4} \pi_{u}$ state decay with a time constant of $6 \mathrm{msec}$, while the $F_{1}^{\prime \prime}$ and $F_{4}^{\prime \prime}$ components have a $129 \mathrm{msec}$ time constant.

At this point I will briefly describe the two states involved in these photofragment spectra. The upper $b^{4} \Sigma_{g}^{-}$state, being a state, is a Hund's case (b) state. Each rotational ievel is split into four components. These four components are labeled as follows: 


$$
\begin{aligned}
& F_{1}^{\prime}, J^{\prime}=N^{\prime}+3 / 2 \\
& F_{2}^{\prime}, J^{\prime}=N^{\prime}+1 / 2 \\
& F_{3}^{\prime}, J^{\prime}=N^{\prime}-1 / 2 \\
& F_{4}^{\prime}, J^{\prime}=N^{\prime}-3 / 2
\end{aligned}
$$

where $J '$ is the total angular momentum quantum number and $N{ }^{\prime}$ is the quantum number for the nuclear angular momentum apart from spin.

The lower $a^{4} \pi_{u}$ state is split into four sublevels by the spin-orbit interaction: the four levels are designated as above (e.g., $F_{1}^{\prime \prime}, J^{\prime \prime}=N^{\prime \prime}+3 / 2$ ). The spin-orbit interaction constant for this state is negative, (9) thus one has an inverted energy ordering of the $F$ " components. Using the ${ }^{4} \pi_{\Omega}$ designation $(10)$ for pure Hund's case (a) coupling, where $\Omega=\Lambda+\Sigma$ and $\Lambda$ and $\Sigma$ are the projections of the orbital and spin angular momenta respectively, one associates $F_{1}^{\prime \prime}$ with ${ }^{4} \pi_{5 / 2}, F_{2}^{\prime \prime}$ with ${ }^{4} \pi_{3 / 2}, F_{3}^{\prime \prime}$

with ${ }^{4}{ }^{1 / 2}$, and $F_{4}$ with the ${ }^{4}{ }_{-1 / 2}$ component. The order written is increasing in energy.

The $0_{2}^{+} a^{4} \pi_{u}$ state is characterized as Hund's case(a) for low $J$ " values. But as the nuclear rotational velocity increases with increasing $J^{\prime \prime}$, the electron spin uncouples from the molecular axis until the state approaches a Hund's case (b) description at high J" values. For most $\mathrm{J}$ " values an intermediate description must be used to correctly characterize the levels. Figure 10 shows the quartet splitting in the $a^{4} \pi_{u}$ state for sets of $J "$ values. The first set has $\mathrm{J}^{\prime \prime}=3-1 / 2,4-1 / 2,5-1 / 2,6-1 / 2$, and $7-1 / 2$. The figure is drawn 
with the lowest level of the set equal to zero and the largest value equal to 100 . The second set of values plotted has each $\mathrm{J}$ "value of the first set increased by 10 , and so forth. Four such sets-of $J^{\prime \prime}$ values are plotted. Note that for the low $\mathrm{J}$ " value set, the grouping is according to $\Omega$ value (Hund's case (a) grouping), while the set with the highest $J^{\prime \prime}$ values is tending toward $k$ value grouping (Hund's case (b)), where $K$ is the resultant angular momentum quantum number fomied from $A^{\prime \prime}$ and $N^{\prime \prime}$. Note that this figure indicates that an intermediate Hund's case description is certainly necessary from $J^{\prime \prime}=16-1 / 2$ to $J^{\prime \prime}=26-1 / 2$.

The spin component dependence of the lifetime for the $a^{4} \pi_{u}$ state of $\mathrm{O}_{2}^{+}$is similar to that found in the Cameron system of $\mathrm{CO},{ }^{(11)}$ where the dependence arises from different spin-orbit mixing of the $A^{\prime} \pi$ and $a^{3} \pi$ states. The $A^{2} \pi_{u}$ state of $O_{2}^{+}$is just above the $a^{4} \pi_{u}$ state. If this $A^{2} \pi_{u}$ state mixes with the $a^{4} \pi_{u}$ metastable state via the spin-orbit interaction, then the $a^{4} \pi_{u} \rightarrow x^{2} \pi_{g}$ transition will have some allowed character. Kovacs $(12)$ has shown how the spin-orbit mixing of a ${ }^{4} \pi_{u}$ state and $a^{2} \pi_{u}$ state depends on the Hund's coupling case used to describe the states. The $A^{2} \pi_{u}$ state of $0_{2}^{+}$is found to be a Hund's case (b) stale. (13) As discussed above, the $a^{4} \pi_{u}$ state is characterized as Hund's case (a) for low $\mathrm{J}$ ", but transforms into a Hund's case (b) for high J" values.

Acroording to Kovacs, if the $a^{4} \pi_{u}$ state is Hund's case (a) and the $A^{2} \pi_{u}$ state is case $(b)$, then only the $\Omega "=3 / 2$ and $1 / 2 \mathrm{sp}$ in components of the $a^{4} \pi_{u}$ state, that is $F_{2}^{\prime \prime}$ and $F_{3}^{\prime \prime}$, will 
mix well with the $A^{2} \pi_{u}$ state. Thus for low J" yalues, the $F_{2}$ and $F_{3}^{\prime \prime}$ components have ${ }^{2}{ }_{u}$ character and are able to relax faster to the $x^{2} \pi_{g}$ state. For rotational levels with $\mathrm{J}$ " great enough, the $a^{4} \pi_{u}$ state is Hund's case (b). In this case all the $\Sigma^{\prime \prime}$ components of the $a^{4} \pi_{u}$ state couple with the $A^{2} \pi_{u}$ state, although the $\Sigma^{\prime \prime}=1 / 2$ and $-1 / 2$ couple more strongly. Therefore in the high J" limit all the spin components gain intensity through spin-orbit mixing with the $A^{2} \pi_{u}$ state. Kovacs' treatrnent suffices in giving a qualitative understanding of the origins of the spin component dependence of the lifetimes.

The $\Delta v=3$ band of the $b^{4} \Sigma_{g}^{-}-a^{4} \pi_{u}$ system is fortuitously placed s.) that the $F_{1}^{\prime \prime}$ and $F_{4}^{\prime \prime}$ components are fairly easily distinguished from the $F_{2}^{\prime \prime}$ and $F_{3}^{\prime \prime}$ components. This is seen in Fig. 3 where a hole is seen in the middle of the $\Delta v=3$ peak at $t=100 \mathrm{msec}$ because of the absence of the $F_{2}^{\prime \prime}$ and $F_{3}^{\prime \prime}$ spin states. By using the spectra of the $\Delta v=3$ band taken at delayed times, two wavelengths were chosen at which to perform the lifetime measurements: 4947.0A, which contains mostly $F_{1}^{\prime \prime}$ intensity and $4967.2 \AA$ which has most 1 y $F_{2}^{\prime \prime}$ and $F_{3}^{\prime \prime}$ intensity. The $0^{+}$photofragment signal, wrich is proportional to the amount of $a^{4} \pi_{u}$ accessed at the particular wavelength, versus time (corrected for parent ion loss) is shown in Fig. 11. The decay at each wavelength is characteristic of several decay times. The data is complicated by the fact that at each wavelength one produces $0^{+}$signal via direct photodissociation to the repulsive wall of the $f^{4}{ }^{4}$ state (type II transitions in Fig. 1). This signal also has a time dependence. 
To get approximate values for the lifetimes of the $F^{\prime \prime}=2$ and 3 and $F^{\prime \prime}=1$ and $4 \mathrm{spin}$ components, I used a very simple model. I assumed that there were only two decay rates: one fast $\left(F^{\prime \prime}=2\right.$ and 3$)$ and one slow ( $F^{\prime \prime}=1$ and 4$)$. Added to this is the wavelength independent (but time dependent) signal from the direct dissociation. To get rid of this unwanted direct dissociation signal, the difference of the two sets of data is taken. The direct dissociation signal, being wavelength independent, vanishes from the picture. A plot of this difference will rise quickly. due to the fast decay term and then fall gradua'ly lecause of the slow decay. Figure 12 is a plot of the difference of the data shown on Fig. 11. The solid line is the curve generated using

$$
p(t)=A_{1} e^{-t / \tau_{1}}-A_{2} e^{-t / \tau_{2}}
$$

with $\tau_{1}=13 i \mathrm{msec}$ and $\tau_{2}=7 \mathrm{msec} . A_{1}$ and $A_{2}$ are population factors.

With the data we have, and using this simple approach, the following lifetimes were obtained: $\tau_{1}=130 \neq 50 \mathrm{msec}$ at $4967.2 \AA$ (the $F_{2} "$ and $F_{3} "$ spin components) and $\tau_{2}=7 \pm 2$ msec at $4947.0 \AA$ (the $F_{1} "$ and $F_{4} " s p$ in components). Keep in mind that these are average values. As illustrated by James for the Cameron band of $\mathrm{CO}$, the lifetime within a given multiplet can vary by an order of magnitude from low $\mathrm{J}$ to high $\mathrm{J}$. 
98

D. Conclusion

The laser photofragment spectrum of the $0_{2}^{+} b^{4} \Sigma_{g}^{-} \longleftarrow a^{4} \pi_{u}$ system from 4902 to $5025 \AA$ measured as a function of time indicates that the ${ }^{4}{ }^{4} 5 / 2$ and ${ }^{4} \pi_{-1 / 2}$ spin components of the $a^{4} \pi_{u}$, metastable state radiatively decay to the $x^{2} \pi_{u}$ ground state with a time constant of $130 \pm 50 \mathrm{msec}$ at $4967.2 \AA$; and similarly the ${ }^{4} \pi / 2$ and ${ }^{4} \pi_{1 / 2}$ sp in components decay with a time constant of $7 \pm 2$ msec at $4947.0 \AA$. This observation is qualitatively in keeping with the interpretation that these lifetimes depend on the amount of spin-orbit mixing of tine $a^{4}{ } u$ state with the $A^{2} \pi_{u}$ state. 


\section{REFERENCES}

1. (a) T. E. Nevin, Philos. Trans. R. Soc. London Ser. A 237, 471 (1938).

(b) T. E. Nevin, Proc. R. Soc. London Ser. A 174, 371 (1940).

(c) T. E. Nevin and T. Murphy, Proc. R. Ir. Acad. Sect. A $\underline{46}, 169$ (1941).

2. M. Vestal, G. Mauclaire and J. H. Futrel1, 23. Annu. Conf. Mass Spectrom., Houston, Texas (1975).

3. (a) A. Tabche-Fouhaille, J. Durup, J. T. Moseley, J.-B. Ozenne, C. Pernot, and M. Tadjeddine, Chem. Phys. 17, 81 (1976). (b) J. T. Moseley, M. Tadjeddine, T. Durup, J.-B. Ozenne, C. Pernot, and A. Tabche-Fouhaille, Phys. Rev. Lett. 37, 891 (1976). (c) M. Tadjeddine, R. Abouaf, P. C. Cosby, B. A. Huber, and J. T. Moseley, J. Chem. Phys. 69, 710 (1978).

(d) J. T. Moseley, P. C. Cosby, J.-B. Ozenne, and J. Durup, J. Chem. Phys. 70, 1474 (1979).

(e) C. Pernot, J. Durup, and J.-B. Ozenne, J. A. Beswick, P. C. Cosby, and J. T. Moseley, J. Chem. Phys. 71, 2387 (1979).

(f) F. J. Grieman, J. T. Moseley, R. P. Saxon, and P. C. Cosby, Chem. Phys. 51, 169 (1980).

(g) H. Helm, P. C. Cosby, and D. L. Huetis, J. Chem. Phys. 7, 2629 (1980).

(h) P. C. Cosby, J.-B. Ozenne, and J. T. Moseley, J. Mol. Spect. 79, $203(1980)$. 
(i) J. C. Hanson, M. M. Graff, and J. T. Moseley, J. Chem. Hhys. 74, 2195 (1981).

(j) P. C. Cosby and H. Helm, J. Chem. Finjs. 76, 4720 (1982).

(k) J. C. Hansen and J. T. Moseley, J. Cher. Phys. 77, 1206 (1992).

(i) J. C. Hansen, J. T. Moseley, and P. C. Cosby, J. Mol. Spect. 98, 48 (1983).

(m) M. Carre, M. Druetta, M. L. Gaillard, H. H. Buknw, M. Horani, A. L. Rocke, and M. Velghe, Mcl. Phys. 40, 1453 (1980).

(n) A. Carrington, P. G. Roberts, and P. J. Sarre, Mol. Phys. 34, 291 (1977).

(0) A. Carrington, P. G. Roberts, and P. J. Sarre, Mo1. Phys. 35, 1523 (1978).

(pi D. C. MCGilvery, J. D. Morrison and D. L. Smitr, J. Chem. Phys. $\underline{58}, 4759(1978)$.

(q) D. C. McGilvery, J. D. Morrison, and D. L. Smith, J. Chem. Pliys. 70, 4761 (1979).

(r) R. Frey, R. Katoschke, K. Muller-Dethlefs, and E. W. Schlag, Z. Phys. A-Atoms and Nuclei $307, \hat{z} 5$ (1982).

4. (a) J. T. Herron and H. I. Schiff, Can. J. C'nem. 36, 1159 (1959).

(b) R. K. Curran, J. Chem. Phys. 38, 2974 (1963).

5. (a) K. M. Refaey and H, A. Chupka, J. Chem. Phys. 43, 2544 (1965).

(b) J. J. Leventhal and L. Friedman, J. Chem. Phys. 46, $\$ 97$ (1966).

(c) K. R. Ryan, J. Chem. Phys. 51, 4136 (1969). 
(d) J. M. Ajello, W. T Huntress, A. L. Lane, P. R. LeBreton, and A. D. Williamson, J. Chem. Phys. 60, 1211 (1974).

(e) J. M. Ajello, K. D. Pang, and K. M. Monahan, J. Chem. Phys. 61, 3152 (1974).

(f) J. M. Ajello and P. Rayemann, J. Chem. Phys. 62, 2917 (1975).

(g) P. M. Dehmer and W. A. Chupka, J. Chem. Phys. 62, 2228 (1975).

(h) J. M. Ajello, J. Chem. Phys. 63, 1863 (1975).

6. A. Dalgarno and M. B. McElroy, Flanet. Space Sci. 13, 947 (1965).

7. D. W. Vance, Phys. Rev. 169, 263 (1968).

8. B. R. Turner, J. A. Rutherford, and D. M. J. Compton, J. Chem. Phys. 48,1602 (1968).

9. D. L. Albritton, A. L. Schmeltekopf, W. J. Harrop, R. N. Zare, and J. C.zarny, J. Mol. Spec. 67, 157 (1977).

10. Molecular Spe:tra and Molecular Struccure: 1. Spectra of Diatomic Molecules, G. Herzberg, p. 214, Van Nostrand Reinhold, New York (1950).

11. T. C. James, J. Chem. Phys. 55, 4118 (1971).

12. (a) I. Kovacs, Can. J. Phys. $\underline{36}, 309$ (1958).

(b) I. Kovacs, Can. J. Phys. 36,329 (1958).

13. D. L. Albritton, W. J. Harrop, A. L. Schmeltekc., and R. N Zare, J. Mol. Sper. 46,89 (1973). 


\section{FIGURE CAPTIONS}

Fig. 1. Relevant potential energy curves of $0_{2}^{+}$.

Fig. 2. Data collection timing sequence.

Fig. 3. The photodissociation spectrum of $\mathrm{O}_{2}^{+}$taken at trapping times of $0.1 \mathrm{msec}$ and $100 \mathrm{msec}$. The data shown has had a constant subtracted from it to remove signal from the direct dissociation process.

Fig. 4. The $0^{+}$photofragment yieid as a function of time.

Fig. 5. Power dependence of $\mathrm{O}_{2}^{+}$photofragmentation at $5320 \AA$.

Fig. 6. The number of $\mathrm{O}_{2}^{+}$ions decrease while the number of $0^{+}$ ions increase when an ion bunch collides with the octapole trap mirror.

Fig. 7. The $\mathrm{O}^{+}$background in the ion trap as a function of time.

Fig. 8. The photodissocation spectrum of $0_{2}^{+}$(the $\Delta v=3$ peak) taken at trapping times of $0.1 \mathrm{msec}$ and $100 \mathrm{msec}$. Again the data has a constant subtracted from it.

Fig. 9. Computer simulation of the data in Fig. 8 calculated using a lifetime of $120 \mathrm{msec}$ for the ${ }^{4} \pi_{5 / 2}$ and ${ }^{4} \pi_{-1 / 2}$ sp in components and $6 \mathrm{msec}$ for the ${ }^{4} \pi_{3 / 2}$ and ${ }^{4} \pi_{1 / 2}$ components.

Fig. 10. Correlation diagram for the ${ }^{4} \pi_{u}$ state of $0_{2}^{+}$showing the transition from a Hund's case (a) to nearly a Hund's case (b) description.

Fig. 11. The $0^{+}$photofragment yield as a function of time at $4947.0 \AA$ and 4967.2A corracted for parent ion leakage from the trap. 
Fig. 12. This figure shows the difference of the data shown in Fig. 11 . The solid curve represents a fit to the data with a long decay constant $\left(\tau_{1}\right)$ of $130 \mathrm{msec}$ for the $F_{1}^{\prime \prime}$ and $F_{2}^{\prime \prime}$ spin components and a short decay constant $\left(\tau_{2}\right)$ of $7 \mathrm{msec}$ for the $F_{2}^{\prime \prime}$ and $F_{3}^{\prime \prime}$ sp in components. The upper and lower dotted curves use $\tau_{1}=180 \mathrm{msec}, \tau_{2}=5 \mathrm{msec}$ and $\tau_{1}=80 \mathrm{msec}, \tau_{2}=9 \mathrm{msec}$, respectively. 


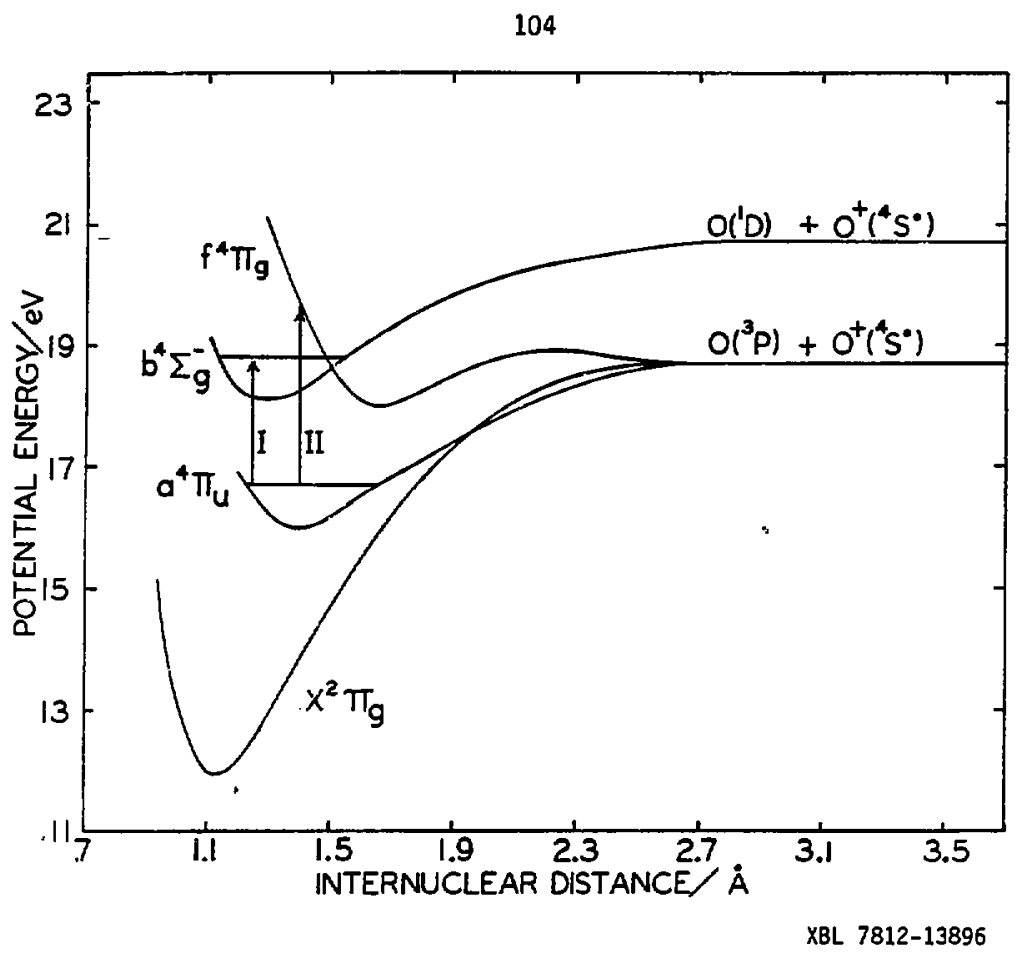

Figure 1 


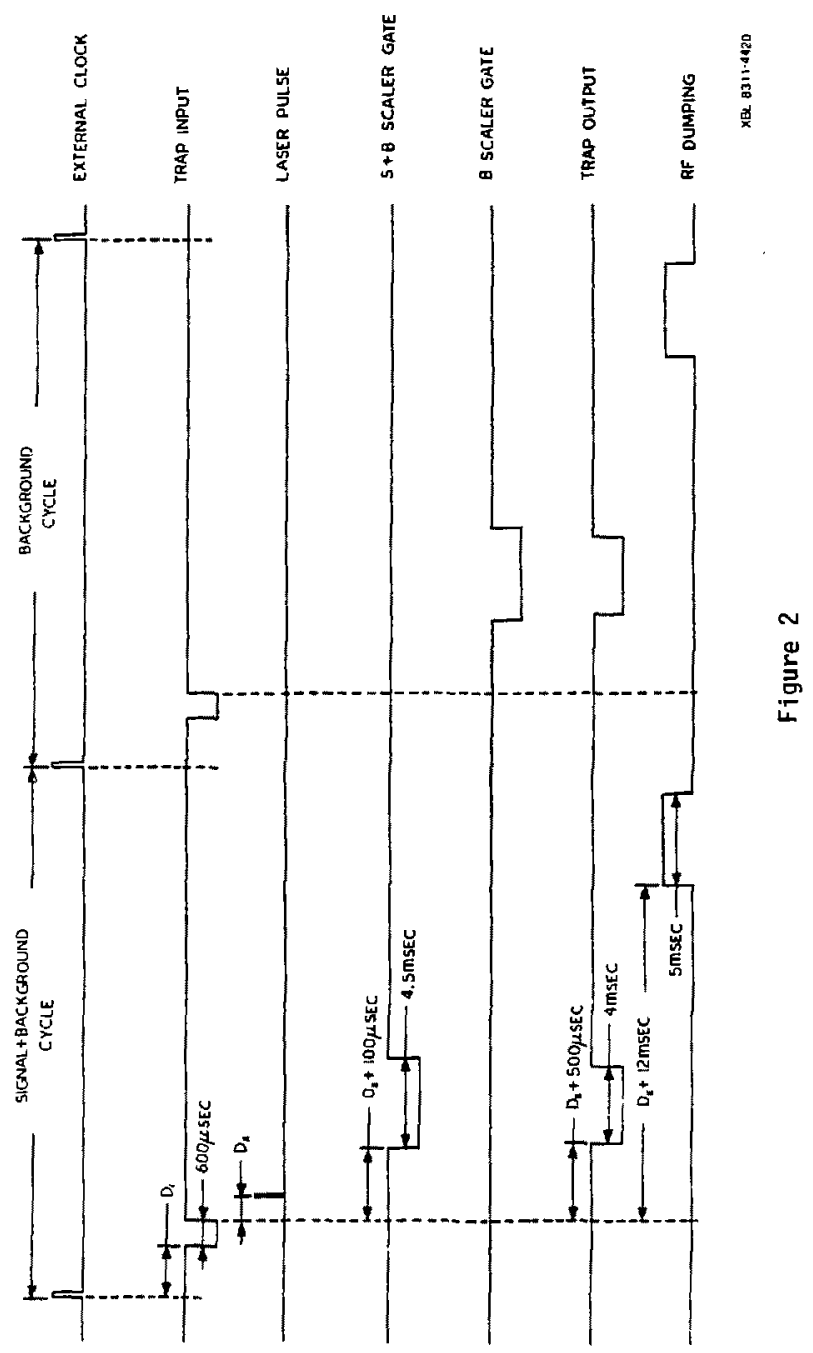




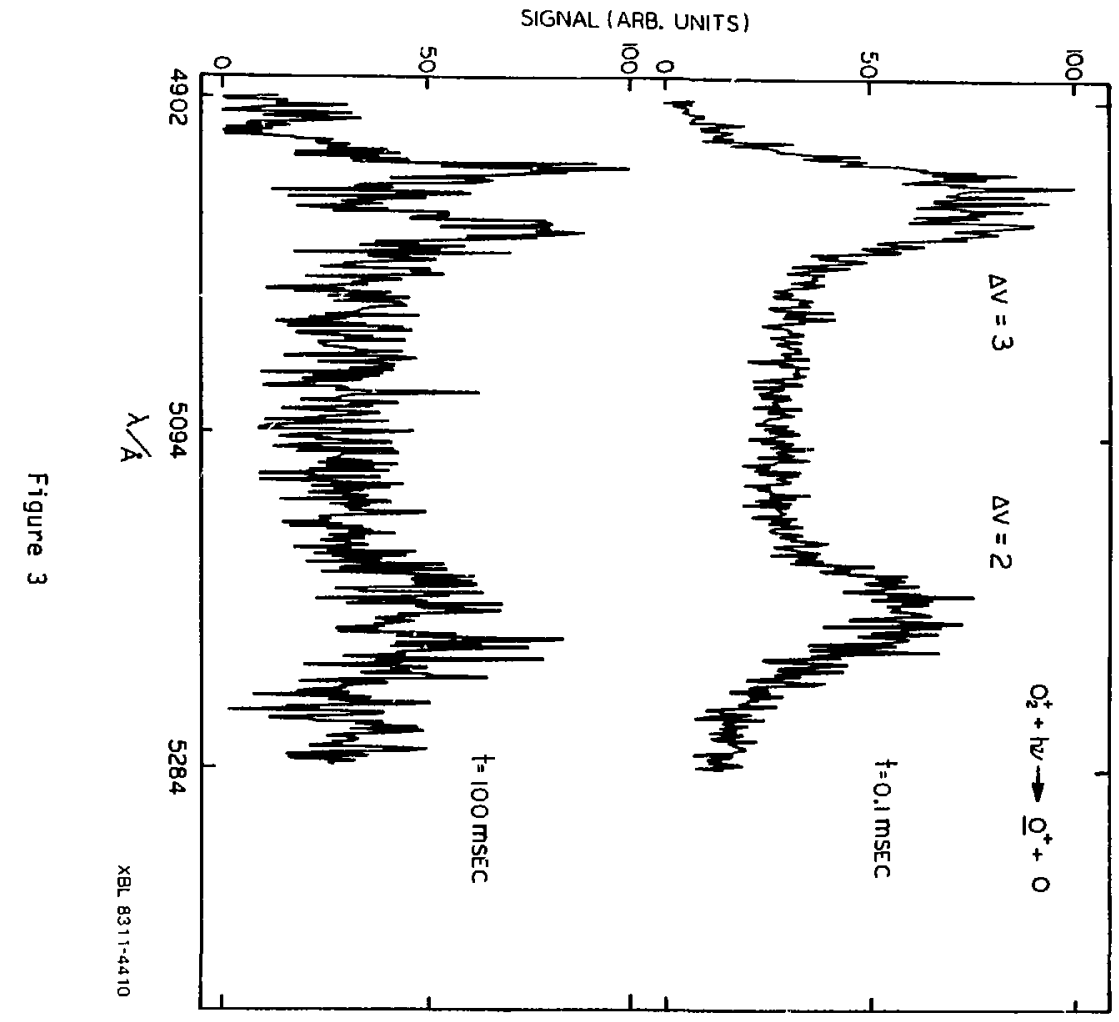

官 


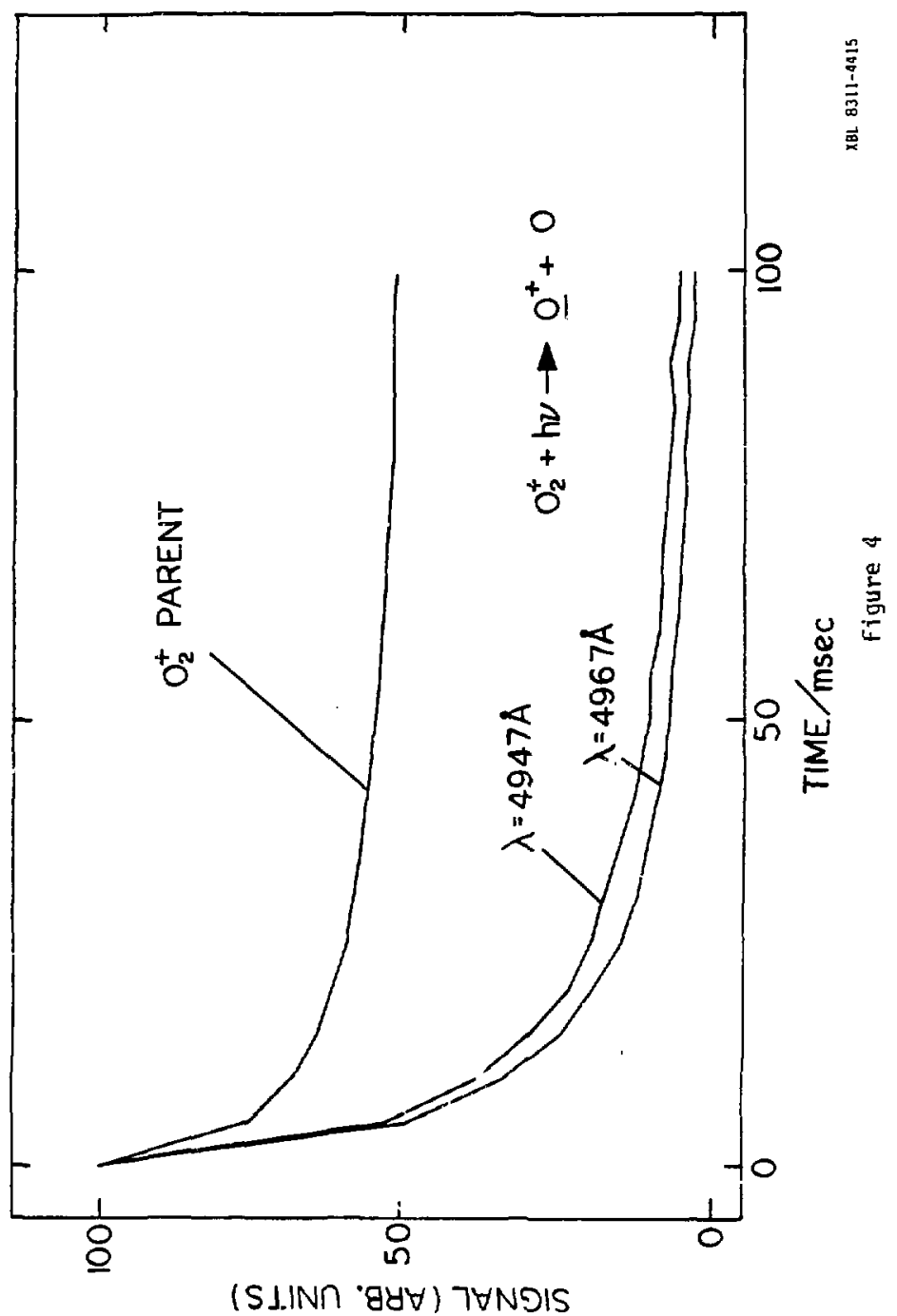




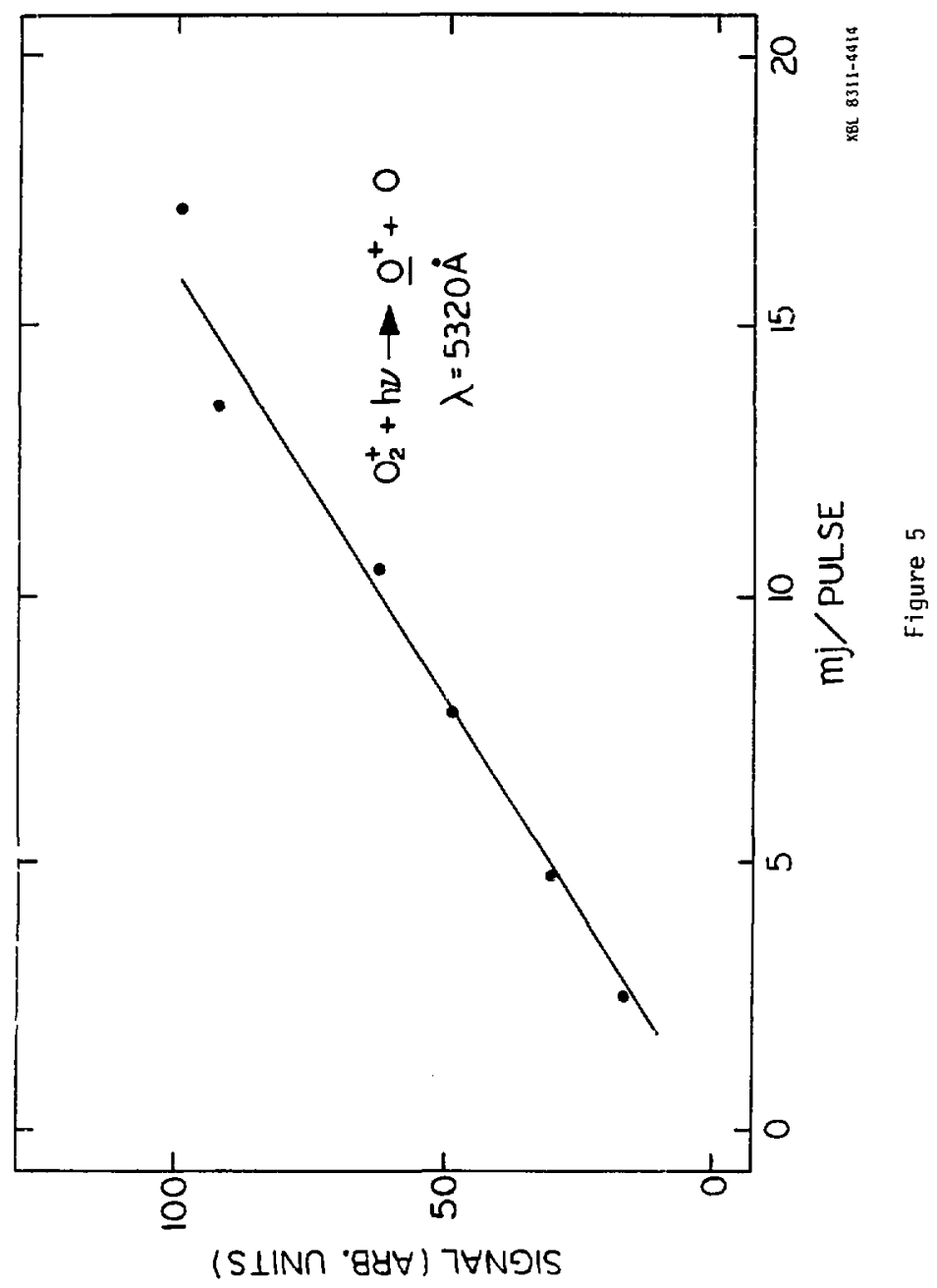




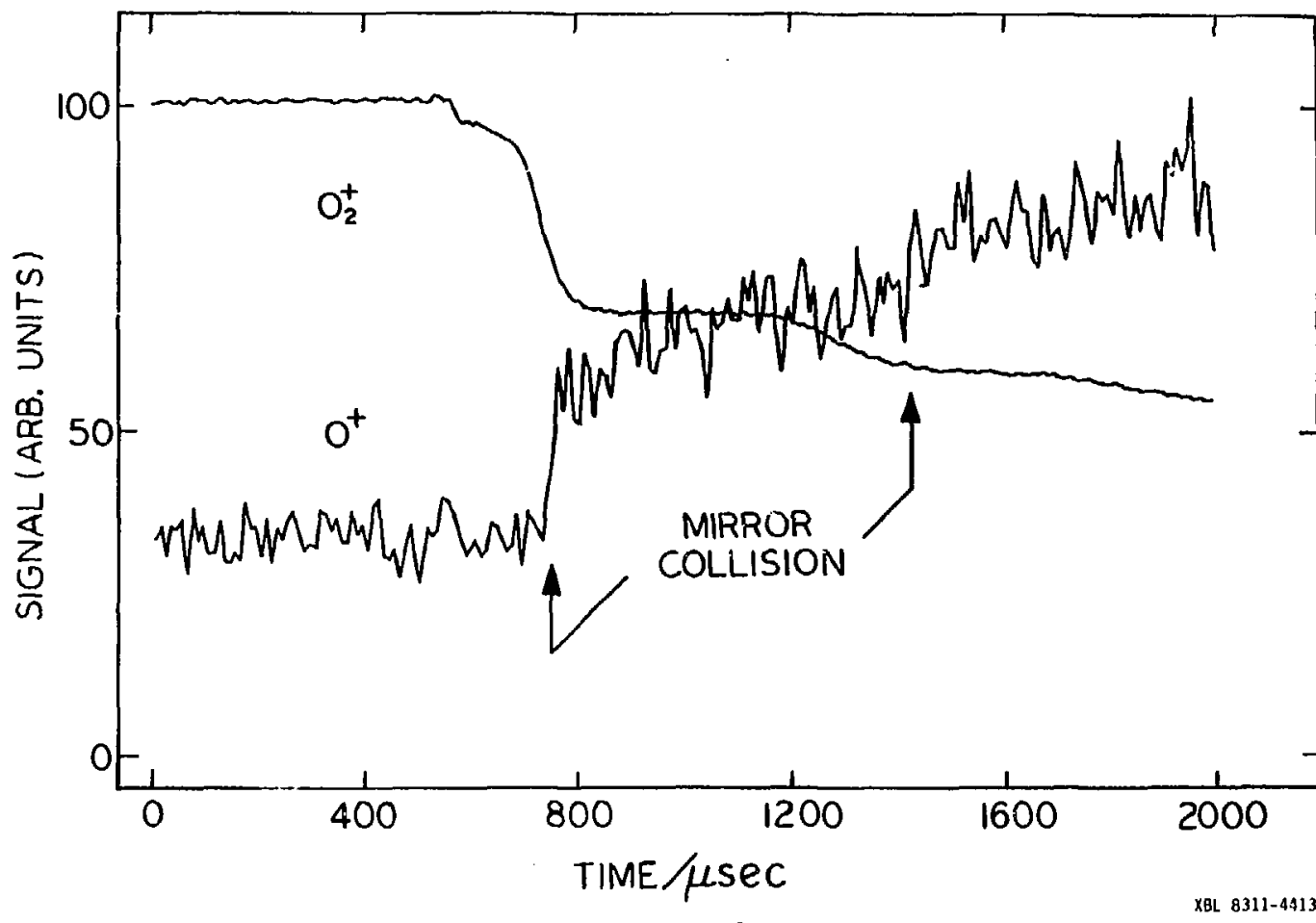

5

Figure 6 


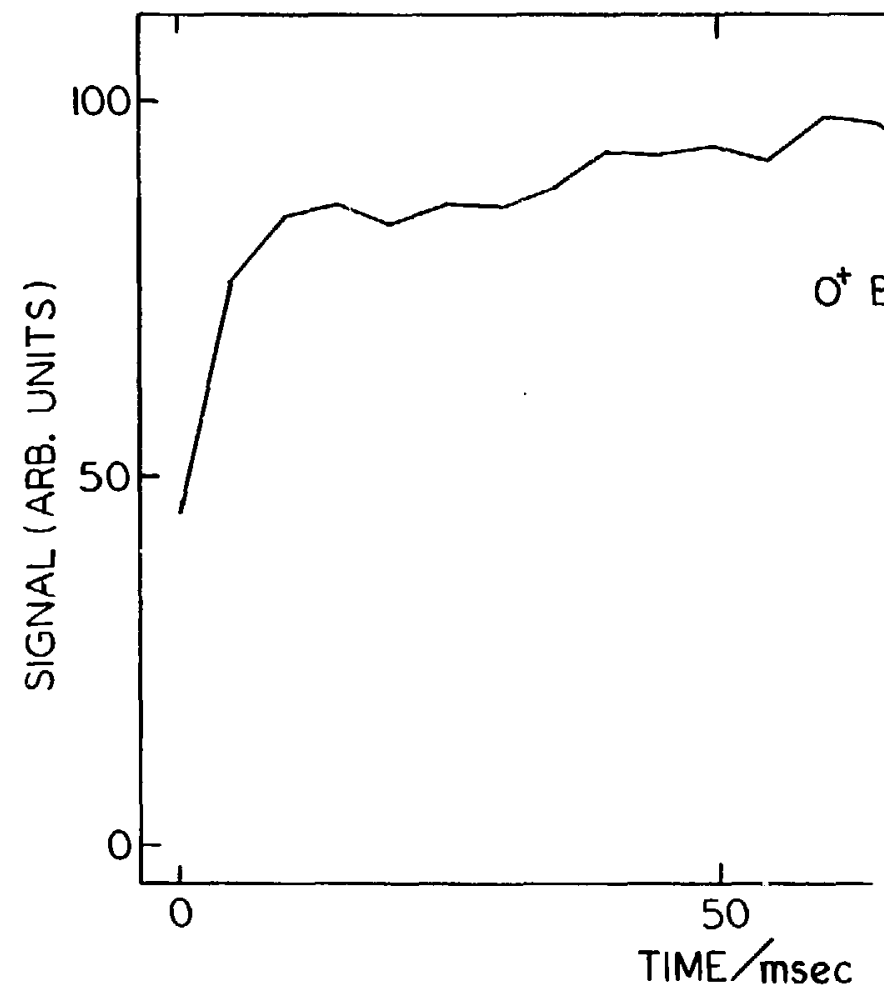

Figure 7

XBL 8311-4412 


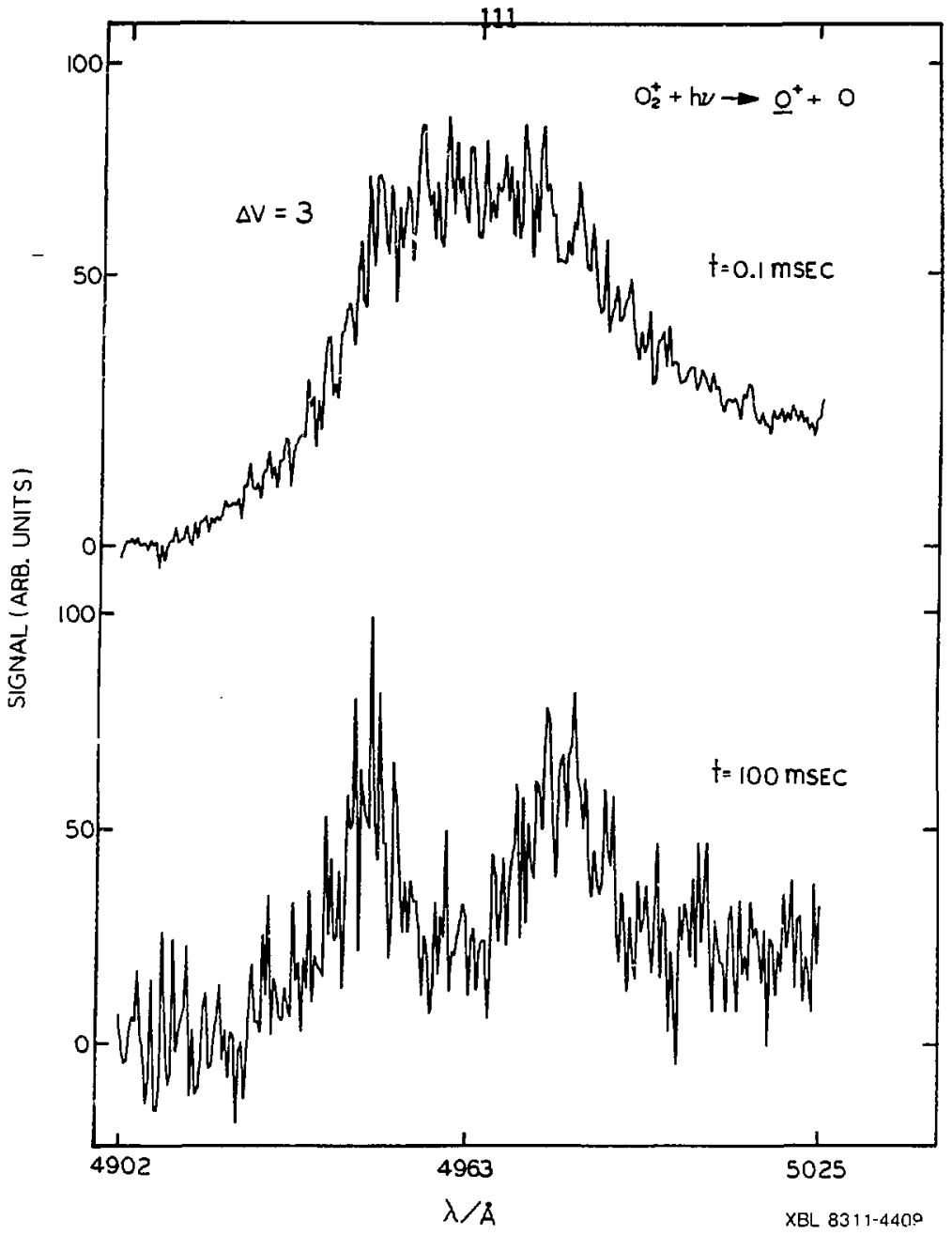

Figure 8 
112

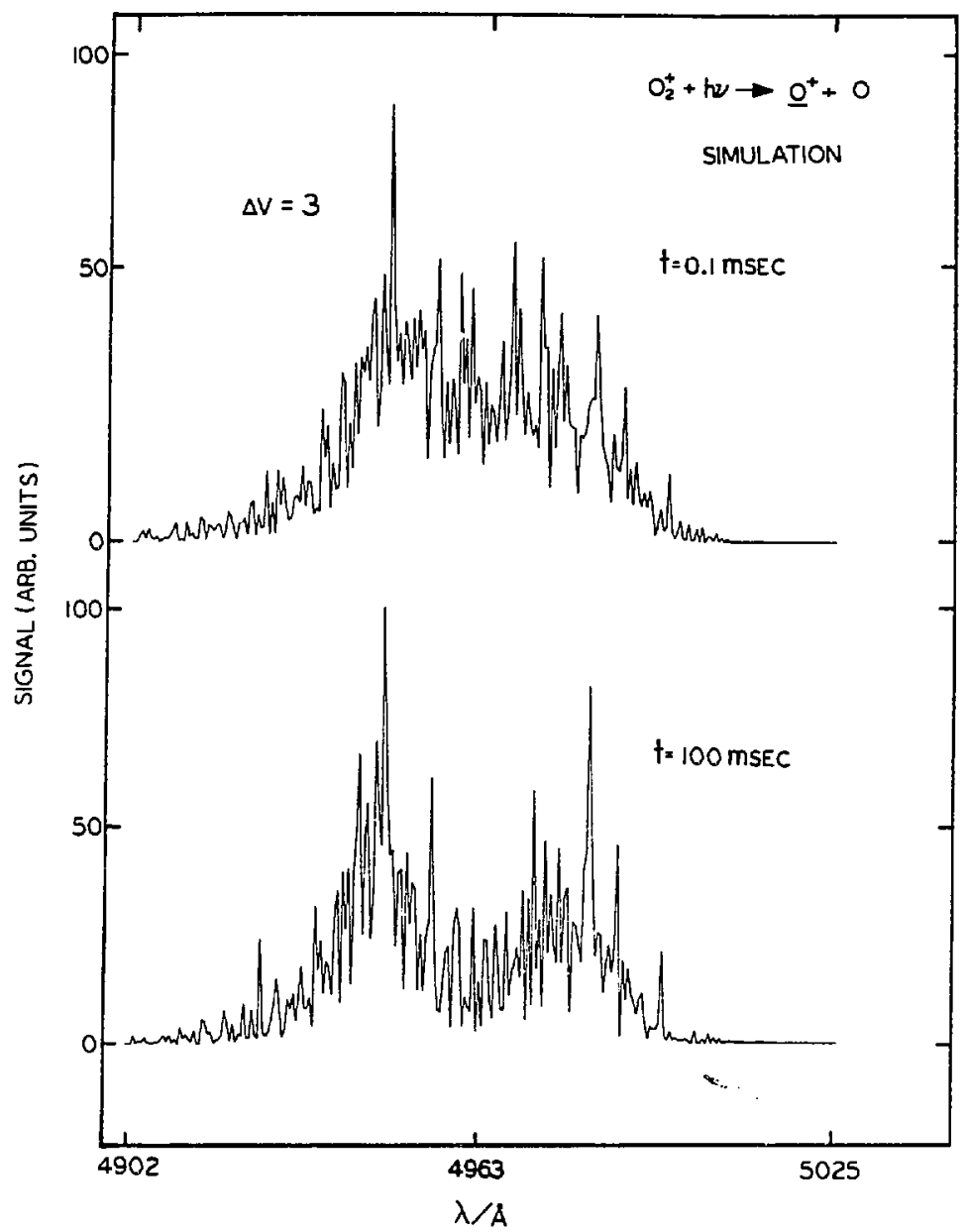

Figure 9

X日L 831 $\div-4470$ 


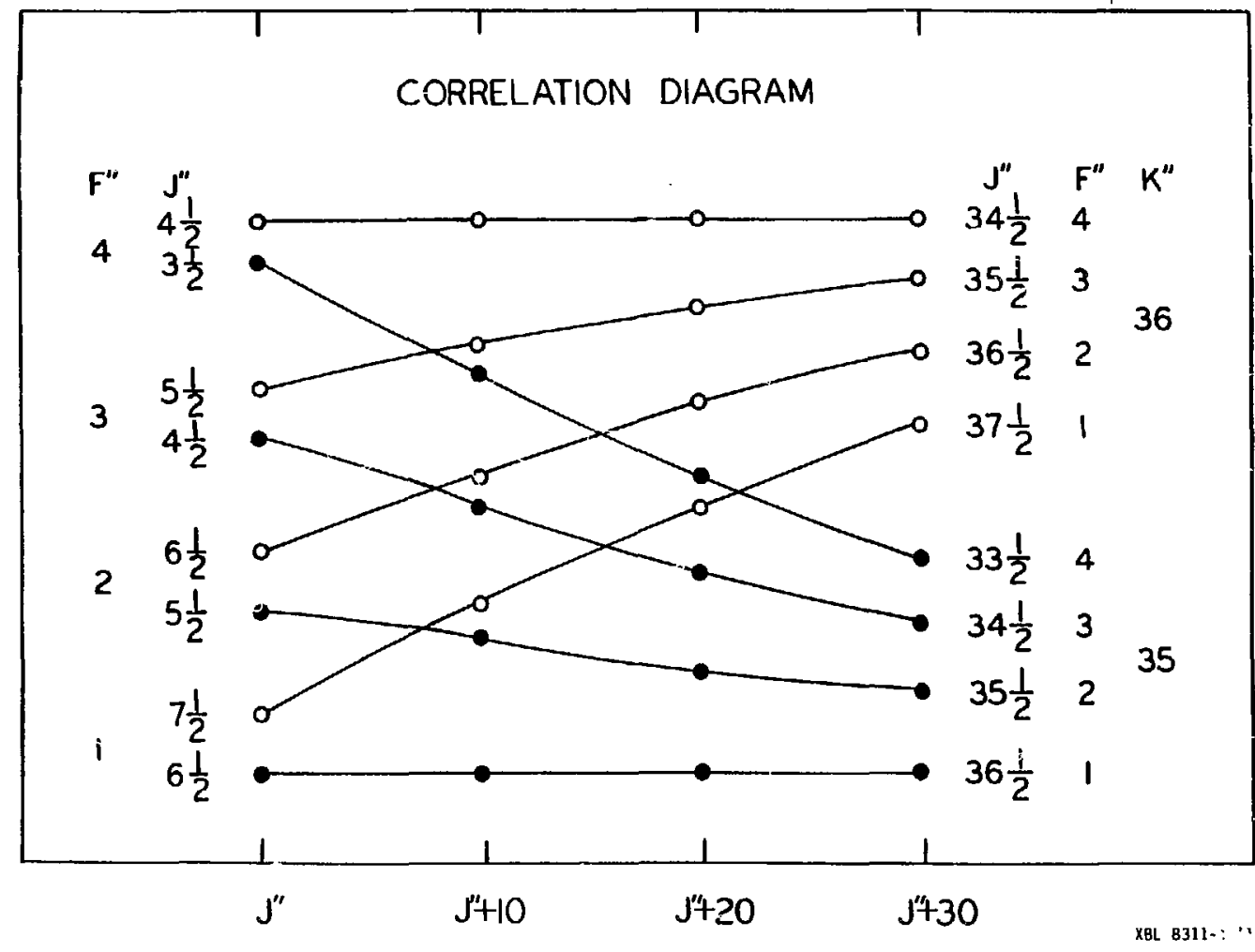

Figure 10 


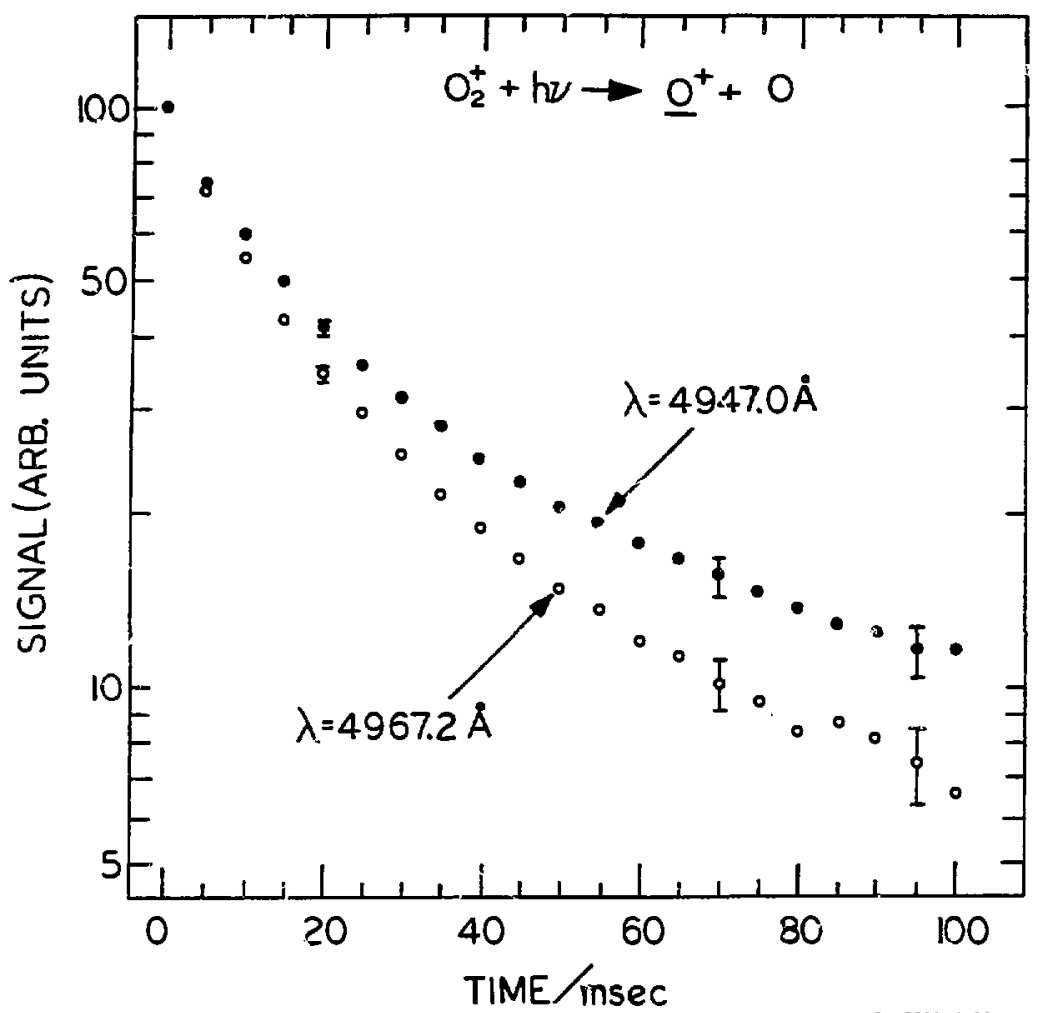

X8L 8311-4408

Figure 11 


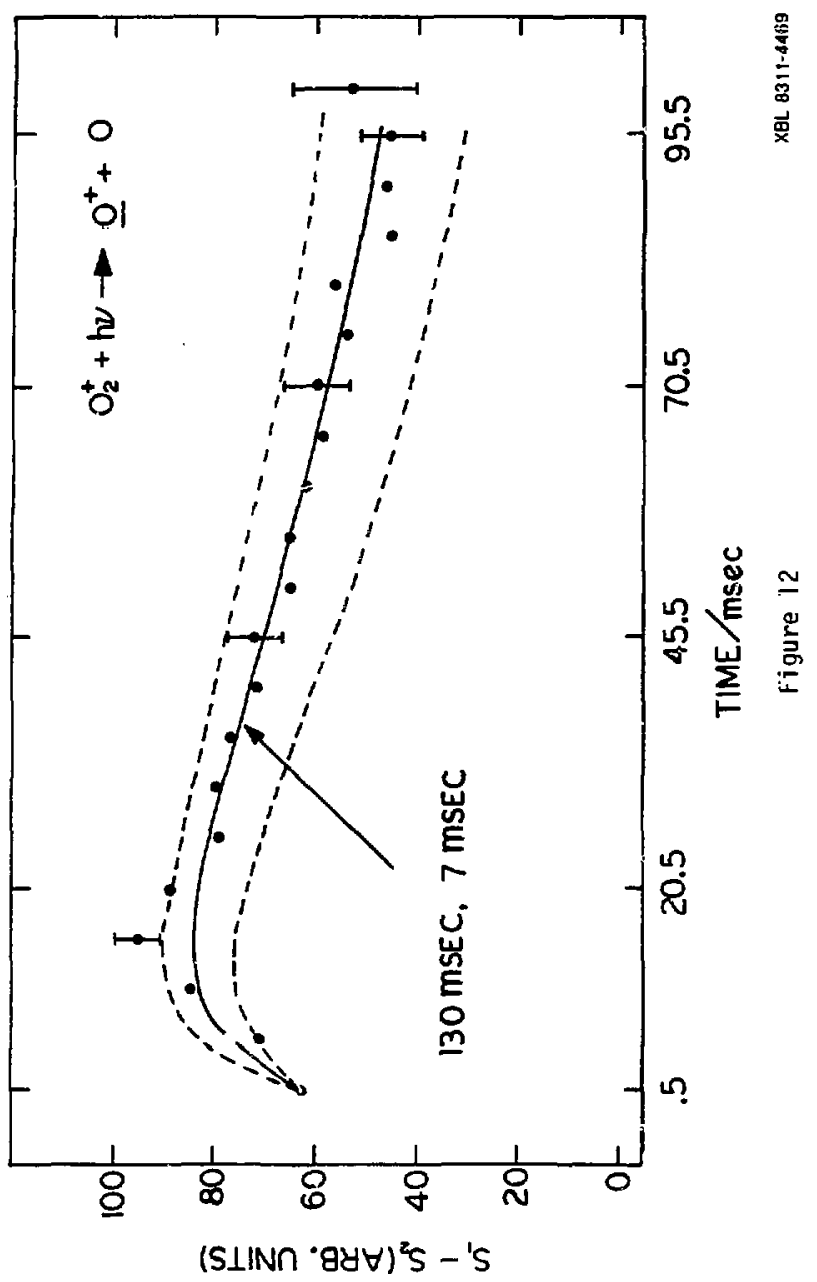




\section{APPENDIX: DATA ACQUISITION PROGRAM}

The progran to be listed here is a first version data acquisition/data management program written for the molecular ion spectrometer. It is to be considered in the developmental stage. The program contains oddities, inconsistencies, and some bugs (harmless bugs in the display routine and some timing constraints in the data collection cycles). But I think the program is basically sound and is presented here for reference.

ABBREVIATED MIPDS COMMAND LIST

$A B$

ACTIVE CHANNEL BRIGHTNESS

$A C$

ACCUMULATE DATA

AS

ABSOLUTE SCALING

$\mathrm{CL}$

CLEAR DATA BUFFER

CU

CLOCK UNITS

CS

CHANNEL SCALE

DC

DYE LASER CALIBRATION

DI

DI SPLAY

BA BACKGROUNO

DA DATA

EX EXPAND

PA PARAMETERS

PN POWER NORMALIZE 


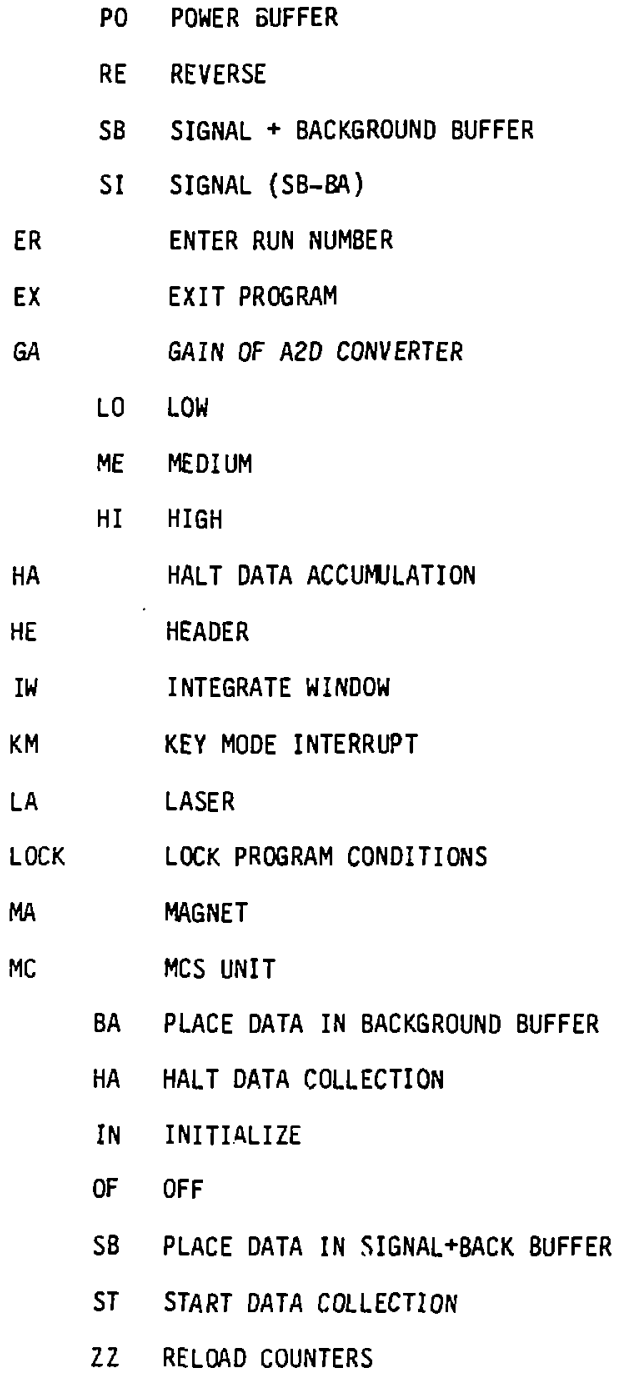

BA PLACE DATA IN BACKGROUND BUfFER

HA HALT DATA COLLECTION

IN INITIALIZE

OF OFF

SB PLACE DATA IN SIGNAL+BACK BUFFER

ST START DATA COLLECTION

22 RELQAD COUNTERS 


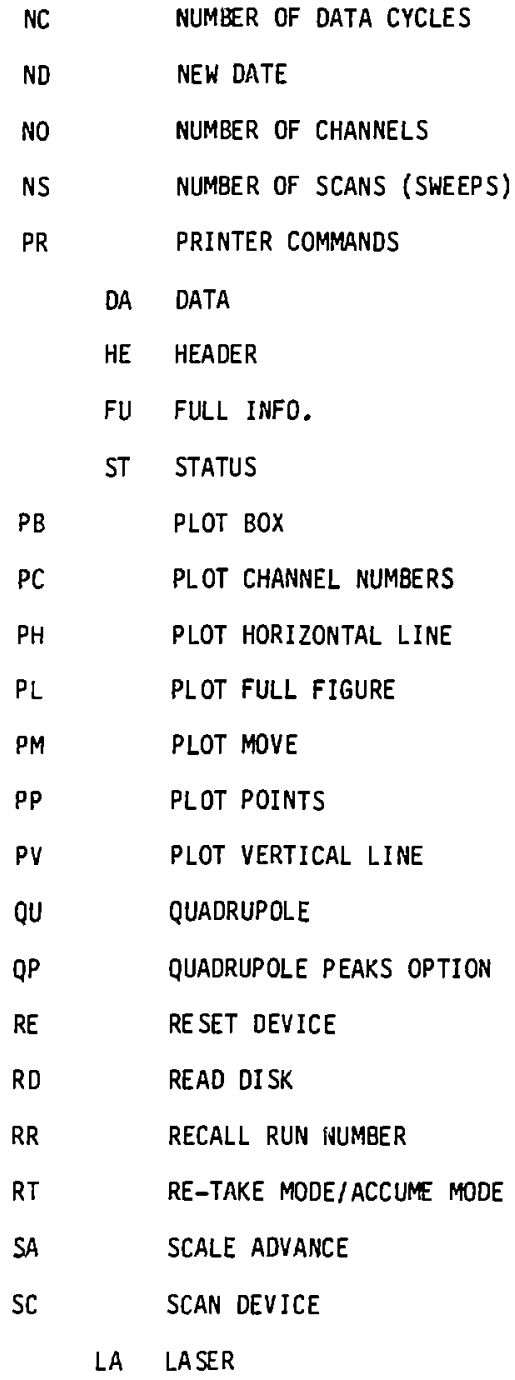




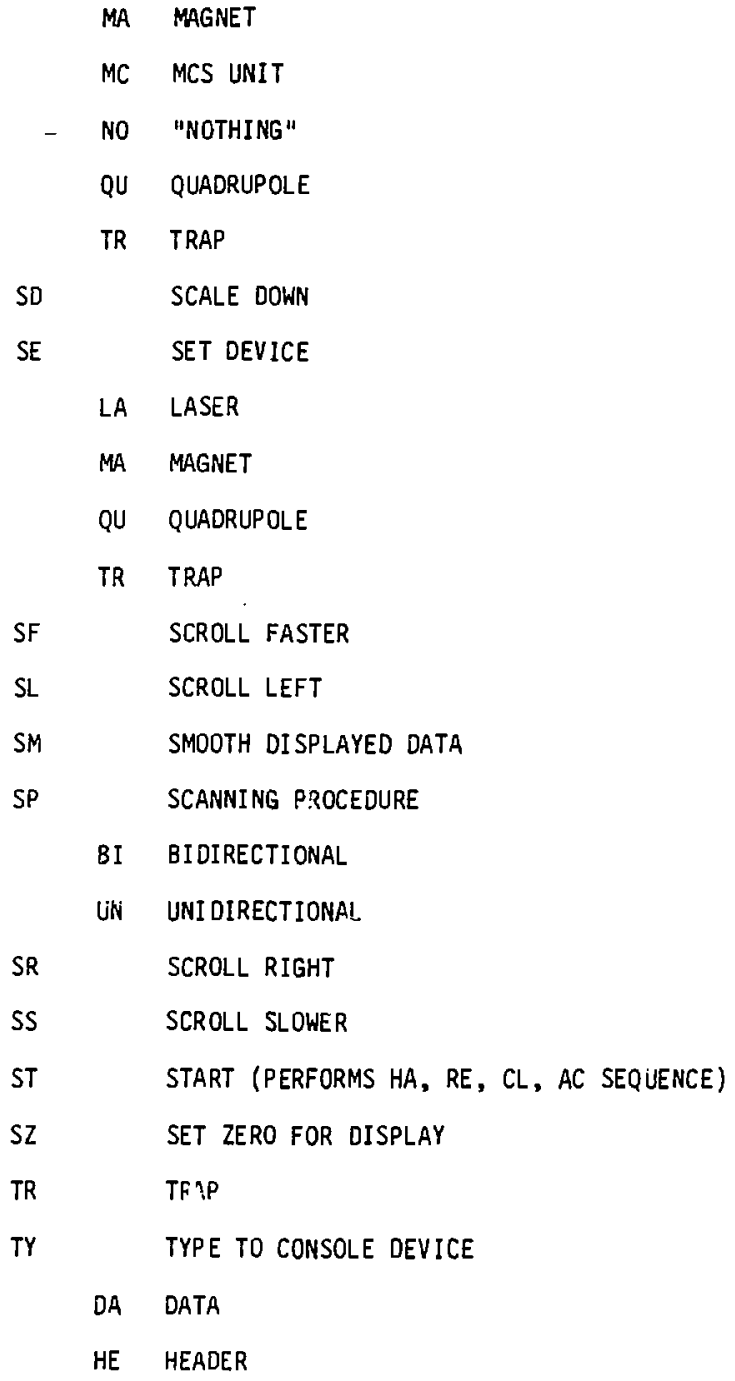




\begin{tabular}{|c|c|}
\hline ST & STATUS \\
\hline UP & UPDATE DISPLAY \\
\hline US & UPDATE SET (CHANNELS BETWEEN UPDATES) \\
\hline WA & WINDOW APERTURE \\
\hline WB & WINDOW BRIGHTNESS \\
\hline wo & WRITE TO DISK \\
\hline$W I$ & WINDOW INITIAL CHANNEL \\
\hline$W L$ & WINDOW LEFT \\
\hline WR & WINDOW RIGHT \\
\hline WB & WINDOW SCALE \\
\hline
\end{tabular}




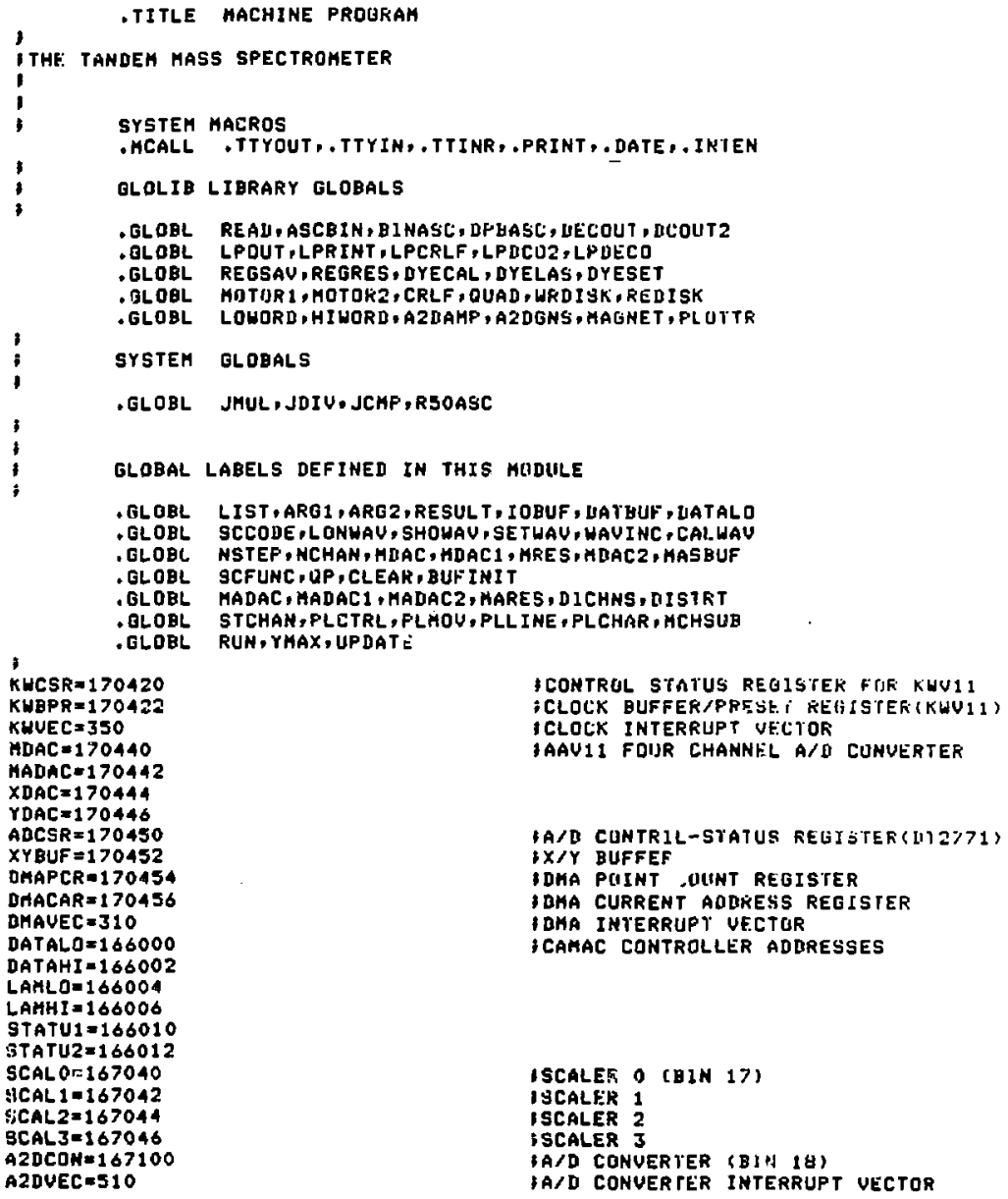




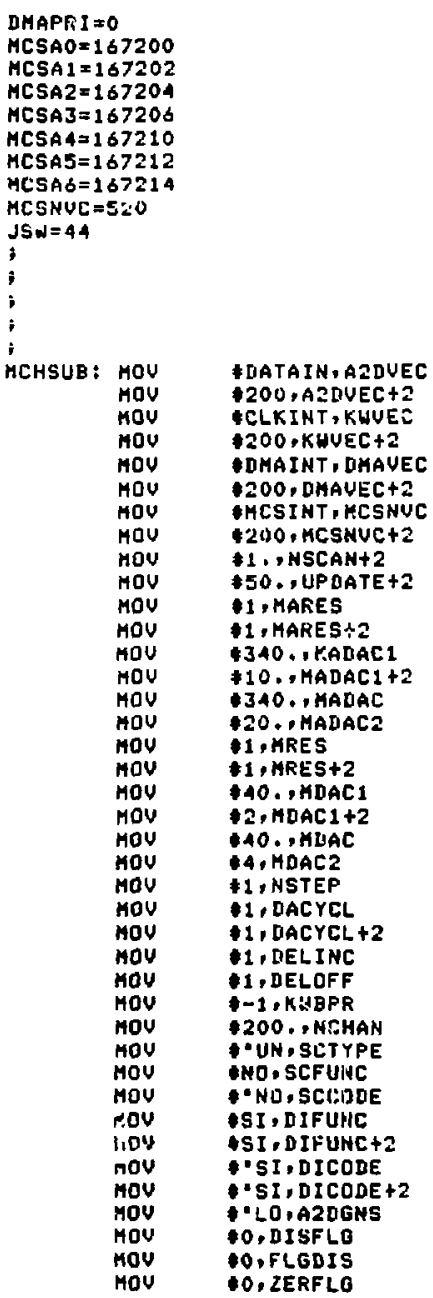

\author{
IHCS CRATE LOCATIUNS \\ JJOE STATUS HORI
}

iPOINT FLUTTEK VECTOK

iMCS VECTOR

IDEFaULT VALUE

IUPDATE PERIOD

IDEFALILT STEP SIZE FIIR MAGNET CUPY

DEFAULT LQH CURKENT FIR MAGNET IEUPY

SSET MAGNET LOW CURRENT

; DEFAULT HIGH CURRET UALUE

DEFaULT SIEP SYZE FIIR GUALI

ILIJPY

; DEFAULT LOW MASS FIIR gIIAE

\%LDPY

ISET GUAD loW HASS

I DEFAUL.T HI ISH HASS FIJR UUAD

I DEFAULT STEF SIZE FUR LASER

DNE DATA CYLI.E PER LHANNEL

isaue a cufy

- IHSEC DELAY INCREHENT

1 IMSEC DELAY UFFSET

ILOAD CLUCK BUFFER/RESET KEG. $\$ 200$ CHANKEL 5 BY DEFAULT IUNIDIRECTIUNAL SCANMING

- NOTHING FUNCTIUN BEING SLANNEI

" NOTHTNG. LUDE HORD

ISIGNAL BEING DJSFLAYED

ISAVE LODE

ILOA DISPLAY CUIE

- SAVE DICODE

IA2ע CONUERTER GAIN LOW(X1)

I AUTO-SLIALE

INORMAL--NOT PIJWER NIORM.

IZFRO SHIFT 


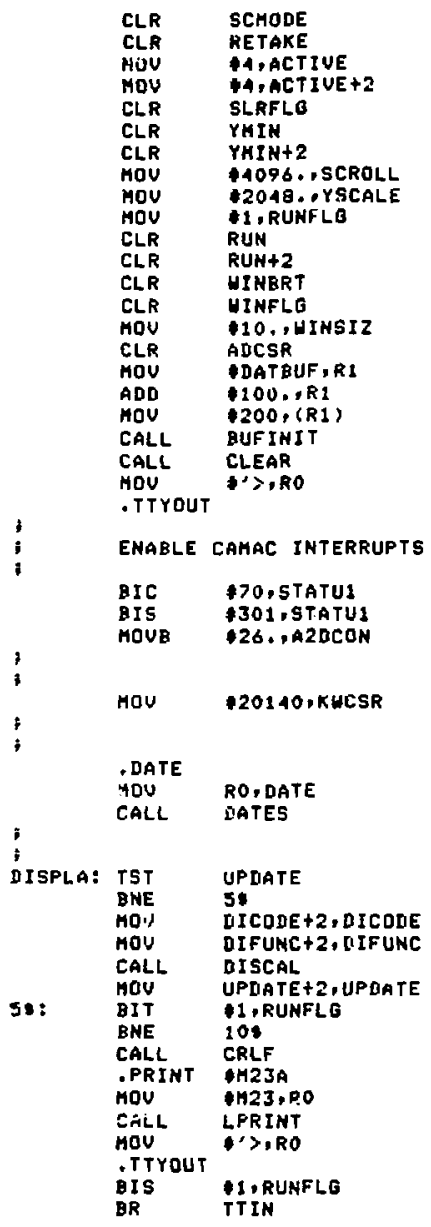

IEXT. INTERKUFT HODE

i ACCUMULATE HIJDE

IACT IUE CHANHEL BRIGHTHESS

IACTIVE CHANNFL BRIUHTNESS

†NO SCROLLIMG

I SCROLL SFEED

ISCALE FUR Y-AXIS

IRUN COMPLETEII FLAE

¿HO RUHS COMPLETE?

IDISPLAY WIHUOH NET BRIGHT

; CI.EAR HINDDH FLAG

IDEFALILT WINDOW STZE

I CLEAR AD CDNTKUL STATUS REg.

IDATA BUIFEER SIAKTING LOLATIUN TO RI

IPUINT TO FIRST HEAUER LUCATIOH

IFILL WITH TERMINATION SYHKOL

IGENERATE BUFFER PUINTERS

ICLEAR DATA BUFFER

IPROMPT CHARAC'TER

ICLEAR NIRE, HXE I I

\$SET IHE, REIN, OII

IENABLE AZD CINUERTER

ISET CLOCK COH'TROL STATUIS RËLIISTER

IGET STSTEM DATE

ISAUE

i DECODE

JUPDATE?

IBRANCH IF NOT EO YO EEPT

IGET RID OF "SH" IF THERE

IRESTOKE FUNCTIUN CUDE

IIF ZERO UPUATE DISFLAY hIIFFER

IREFRESH UPUATE

IRUN COHFLETEJ?

PTYPE CARKIAGE RE TURN-LINE FEED

I BEEP

ITYPE ' >" 


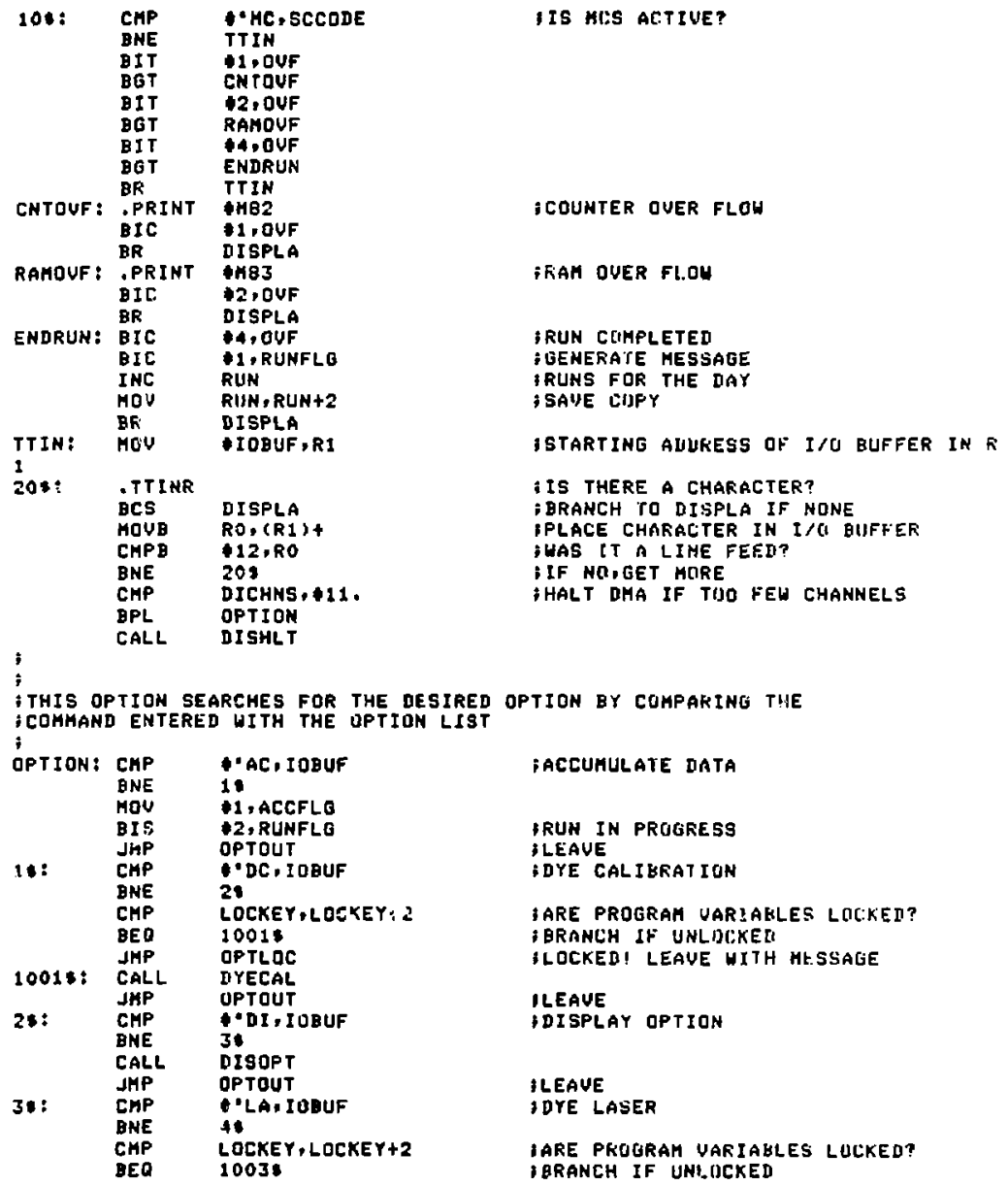




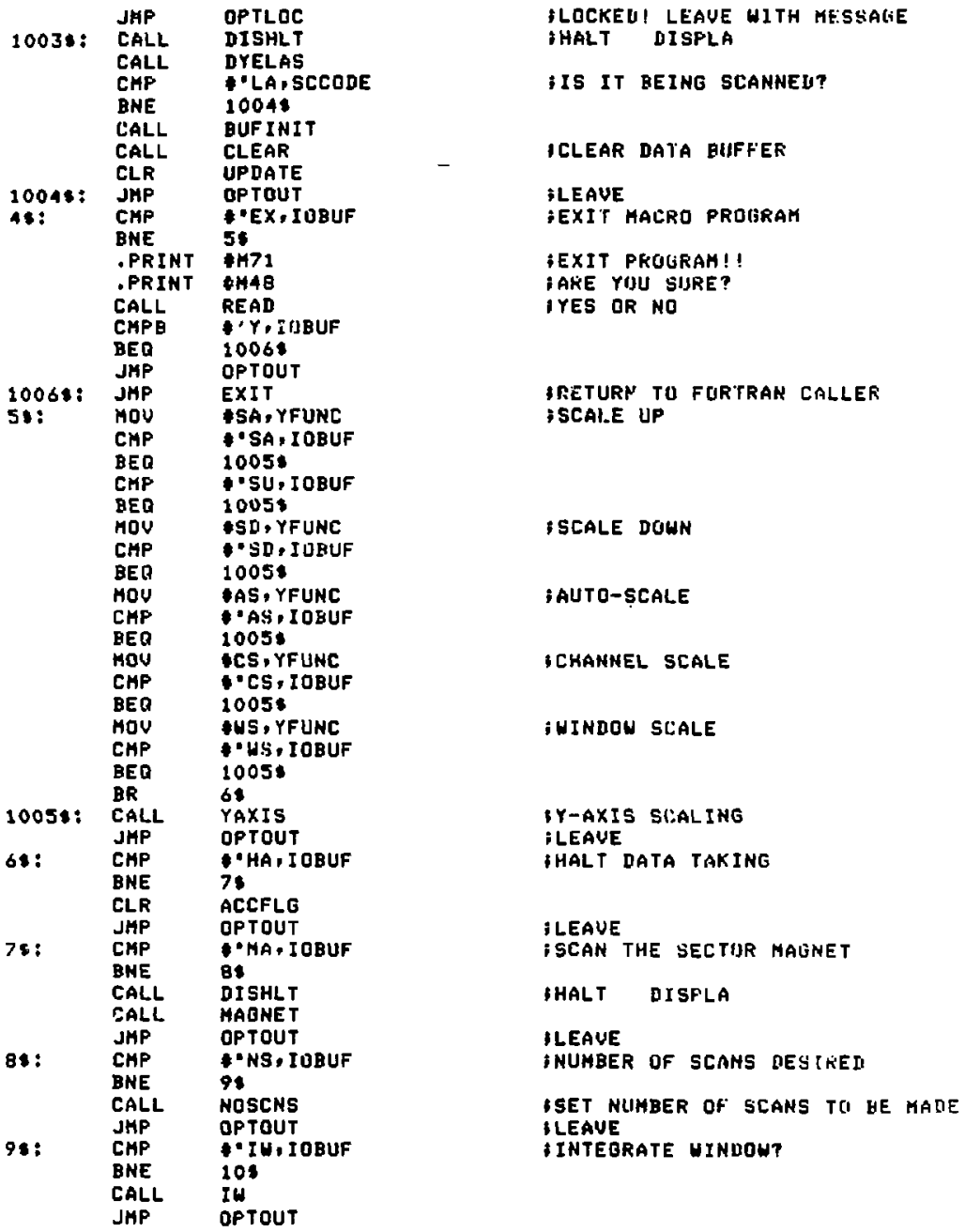




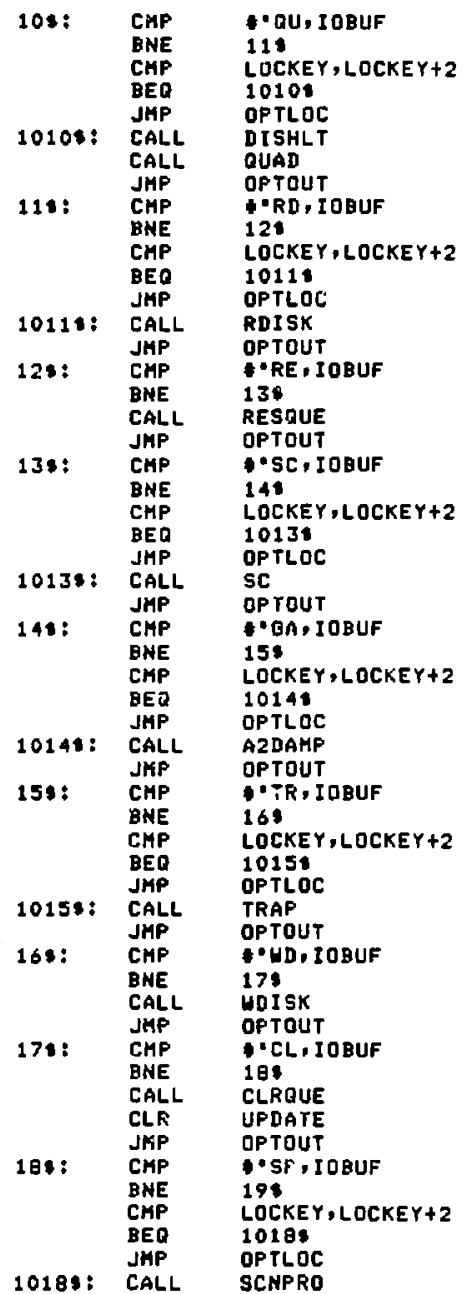

I QUADRUPOLE

iaRe PKOgFay UARIABLES lOCKED? I BRANLH IF IJNLOCKED

"LOCKED! LEAVE WITH MESSAGE

IHAL T DISPLA

iLEAVE

;READ THE DISK

I ARE PKLIGRAH UARJAKLES LUCKED?

I BRANCH IF UNLOCKED

iLOCKED! LEAUE WJTH MESSAGE

IREAD A DATA FILE

ileave

iRESET THE DEUICE GEIHG SCAMNEII

ileave

iscan DeUice

A ARE PKOGRAM UARIABLES LOCKEI? I BRANCH IF UNI.UCKED

ilocked! leave WJTH hesSage

ileave

ISET GAIN UF AZD CONUERTER?

IARE PROGRAH UARIABLES LOCKEU?

B BRANCH IF UHLIJCKEII

ilOCKEd! LEave with hessage

ILEAUE

ISC TRAP

IARE FRUGRaM UARI IABLES LOCKED?

IBRANCH TF UJMLOCKED

; LOCKED! LEave WITH MESSALE

ileave

IURITE TO DISK

ileave

i CLEAR... INIT

ILEAVE

ICHANLE METHUD UF SCANNING?

I ARE PROGRAM UARIABLES LUCKED?

I BRANLH IF UNLDCXEI

ilocked! LEAVE nITH hEsSage 


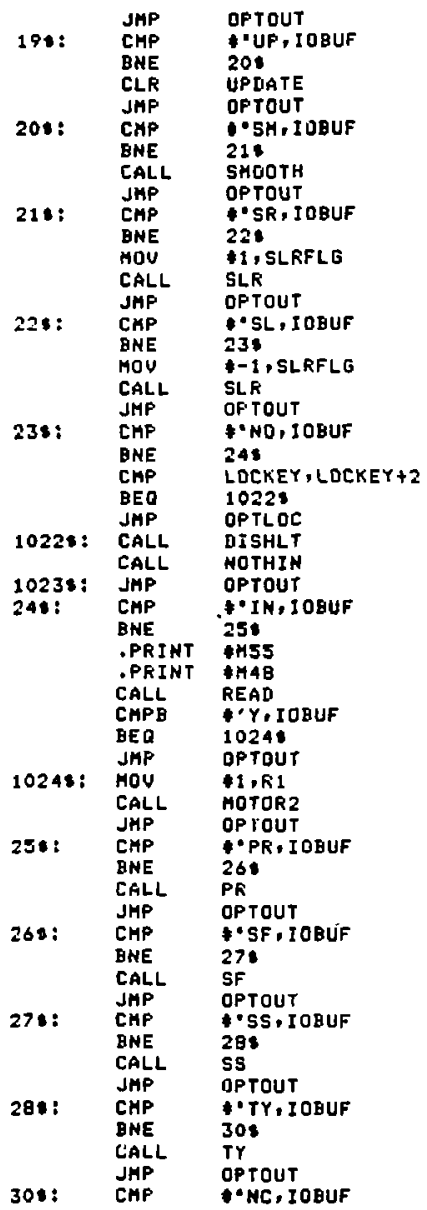

ILEAVE

I UP OATE?

ILEAUE

SSHOOTH IISPLAYET OATA?

IGET INPUT

iLEAVE

†SCROLL WINDOU RIGHT?

; SCROLL WINDOH LEFT?

CHANGE STAANHIHO CONDITION?

IARE PRUGRAM VARIABLES LOCKEI?

I GRANCH IF UNLOCKËI

†LOCKEI! LEAUE WJTH MESSACE

IHALT TIISPLA

1LEAUE

istaRt PULSE SEQUENCE?

;PULSE SEQUENTE INIT.

i ARE YUU SIJRE?

IYES DR NO

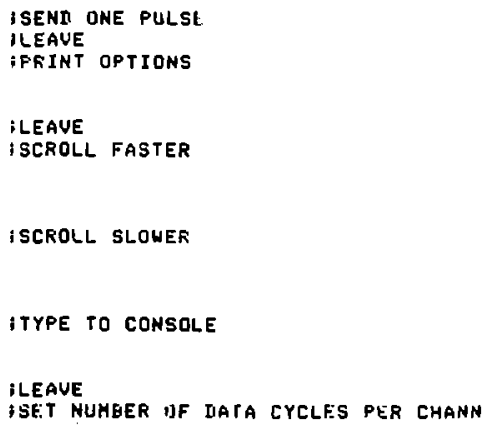


ELT

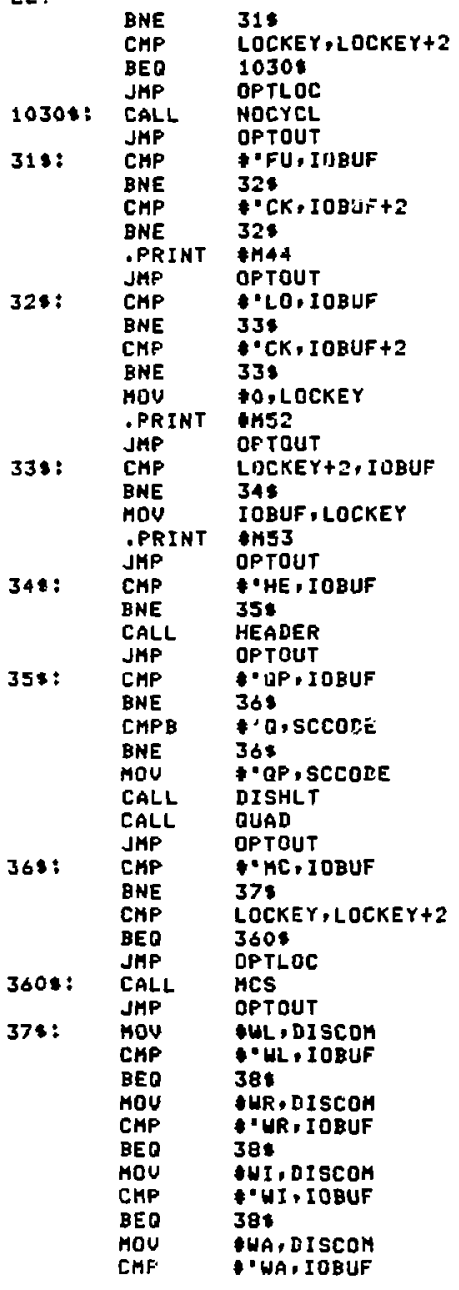

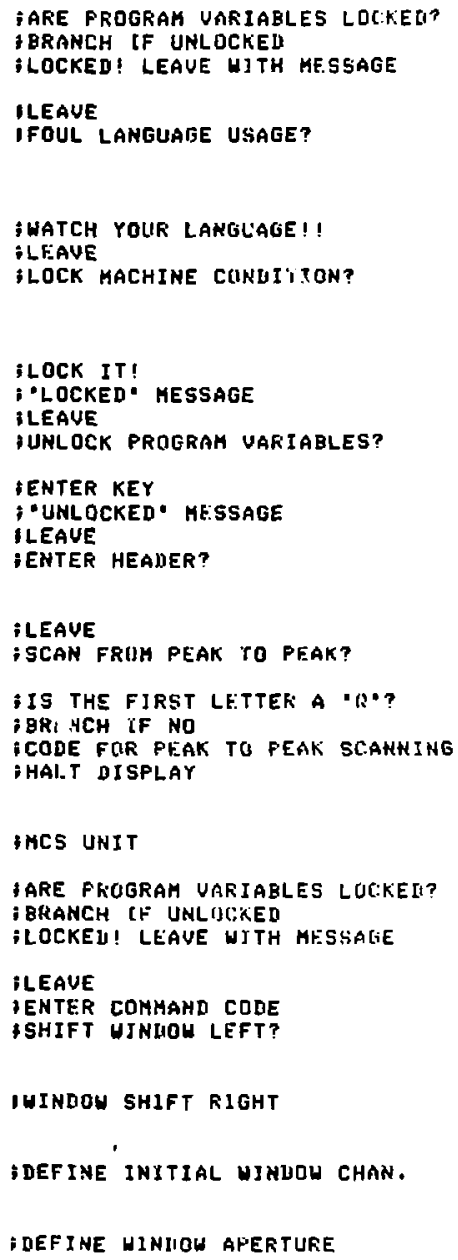




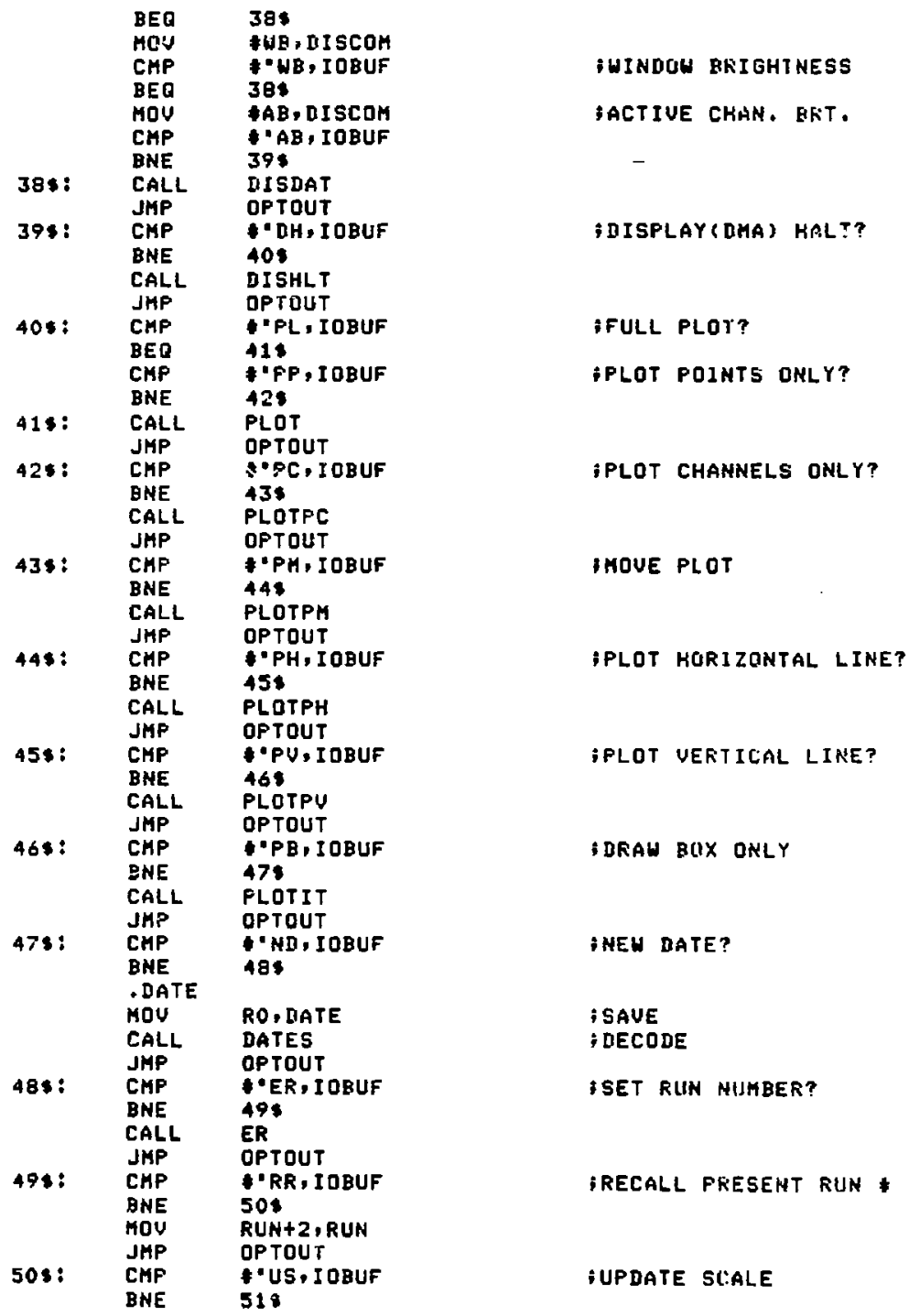




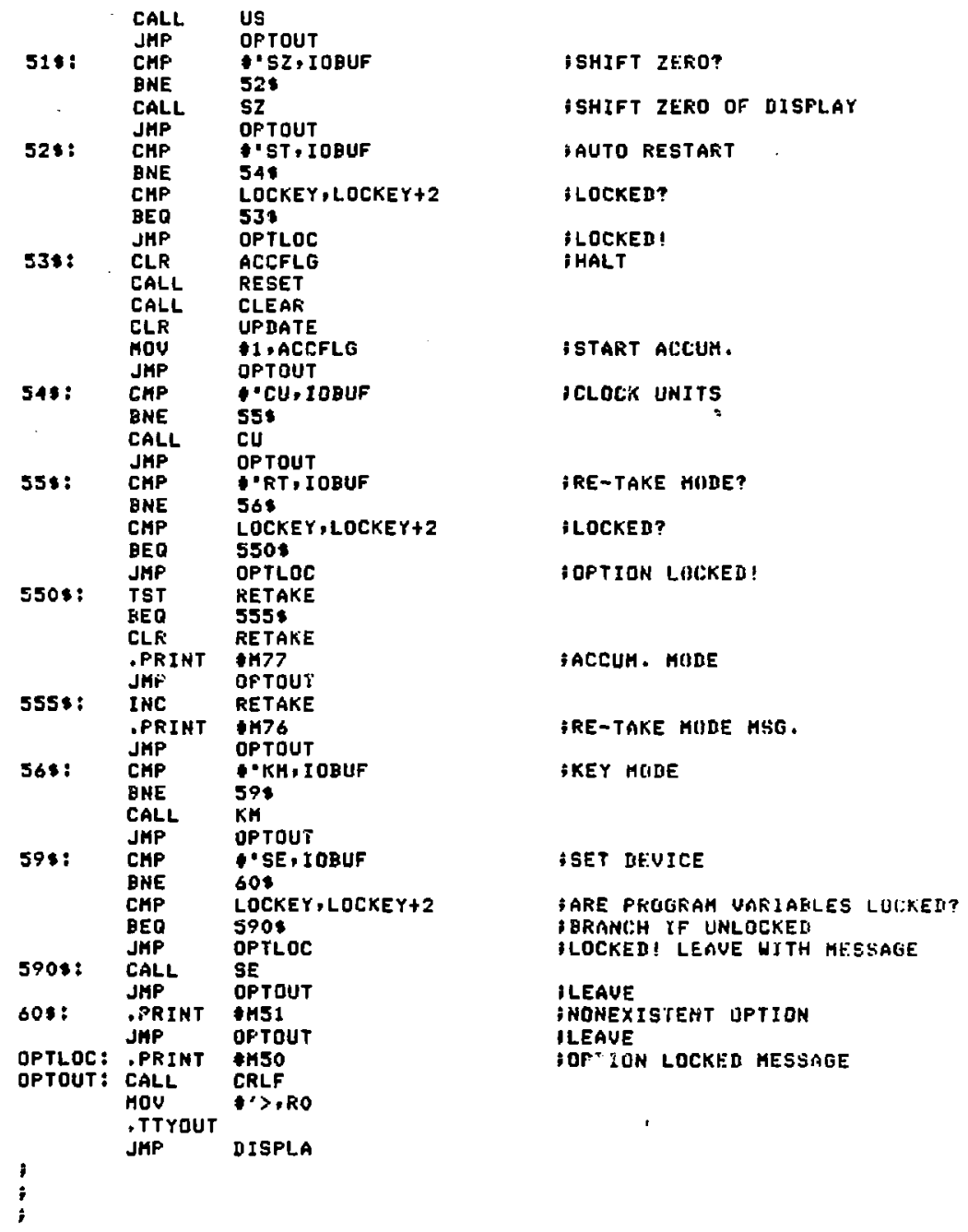




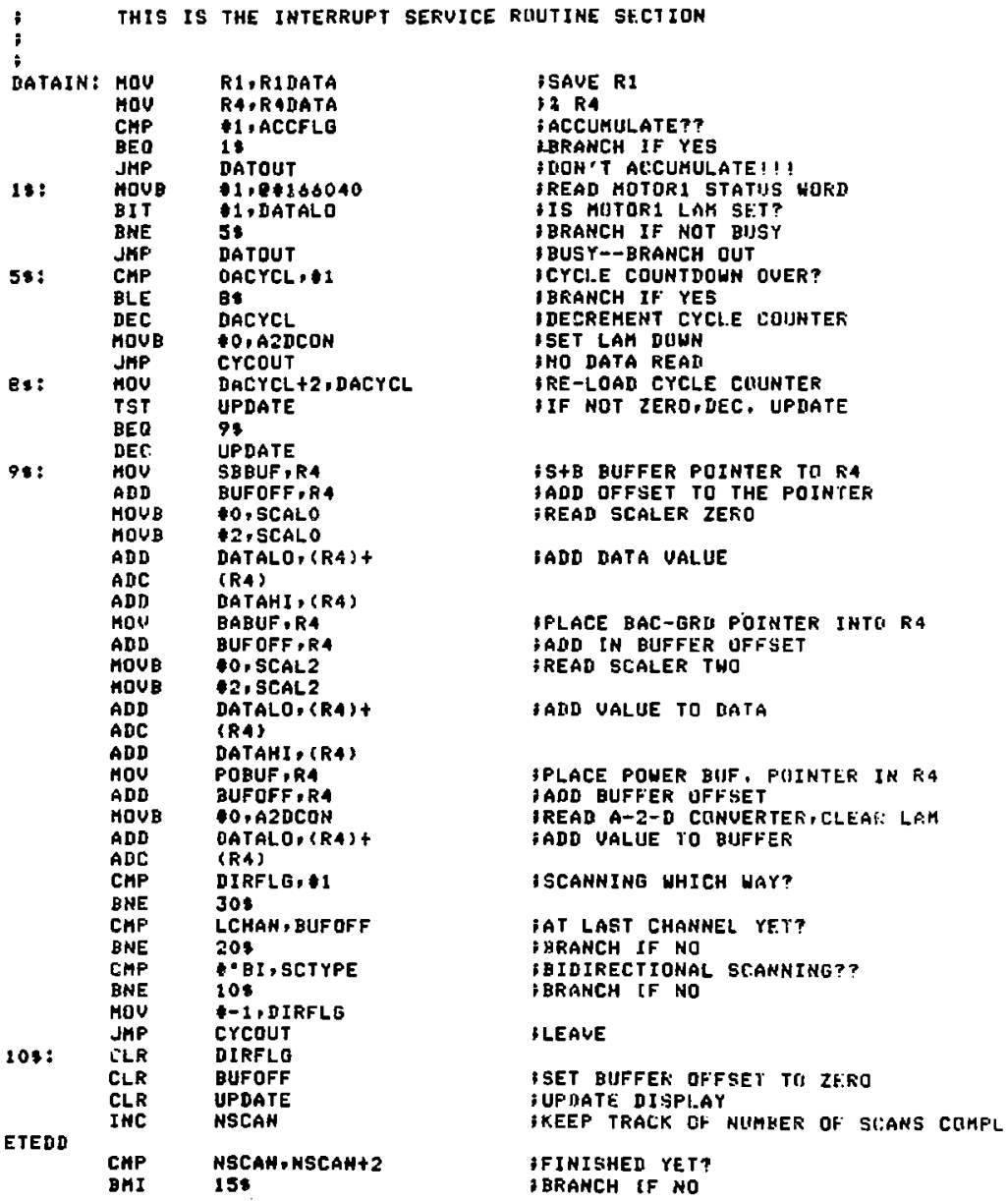




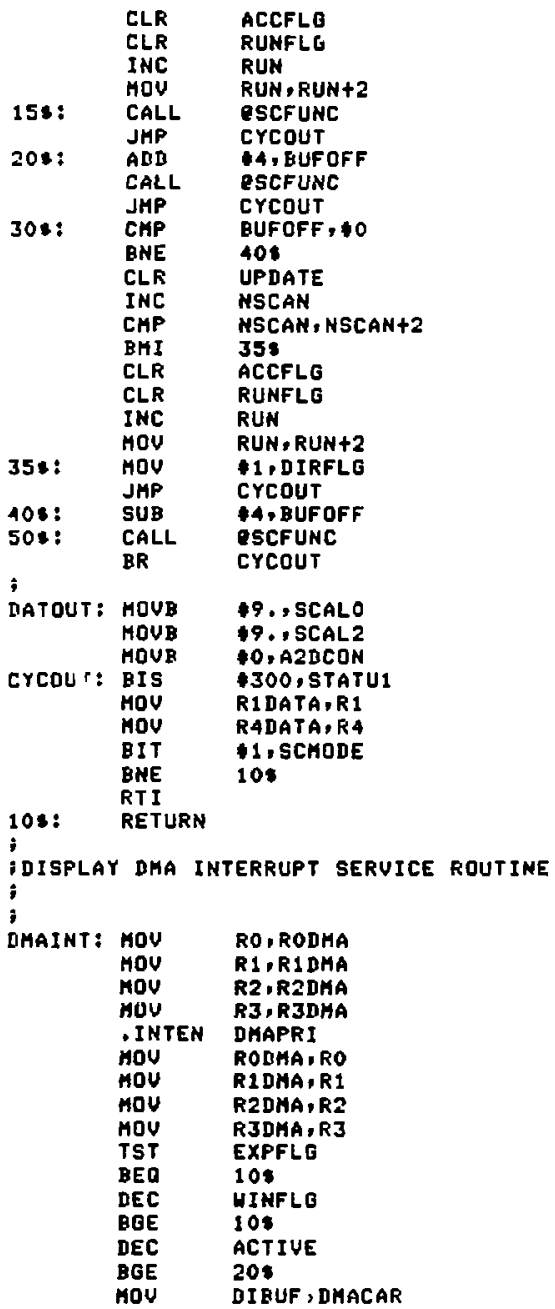

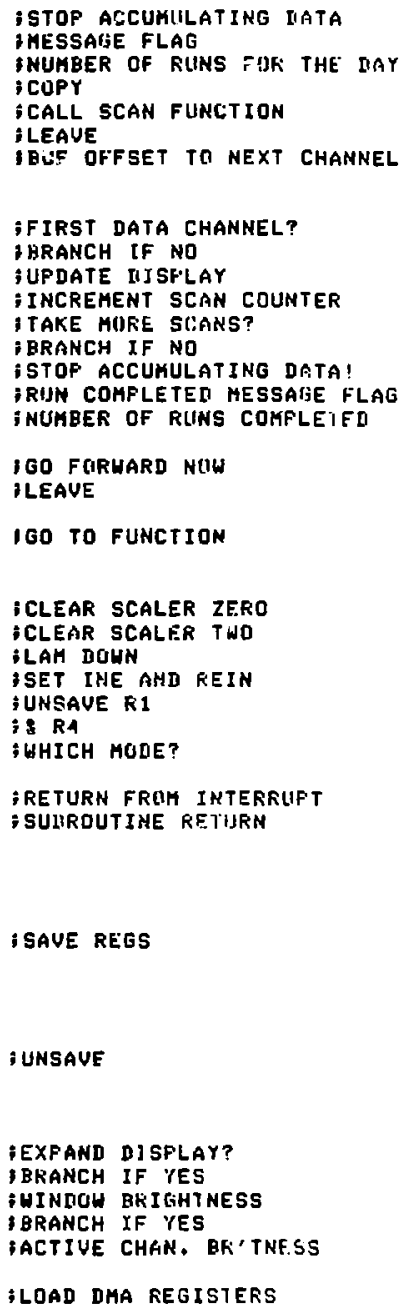




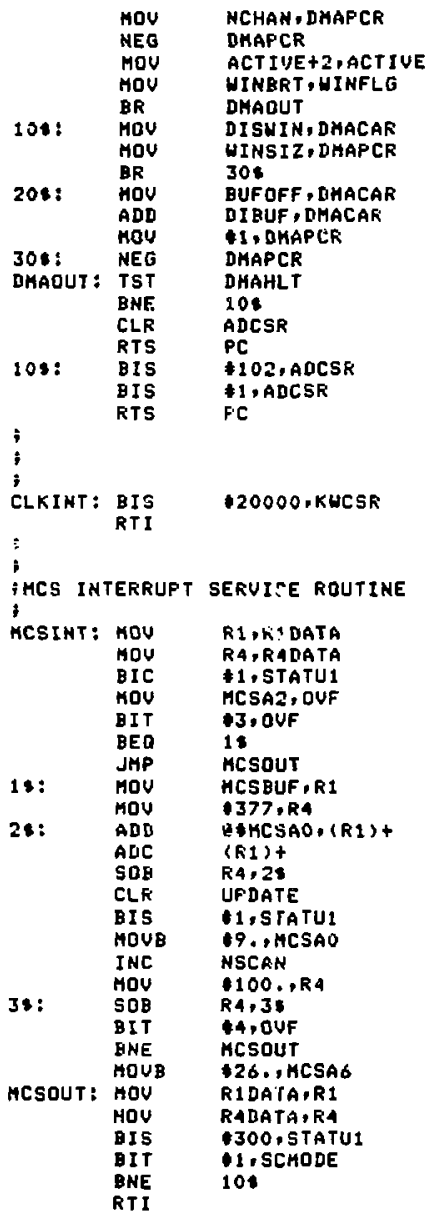

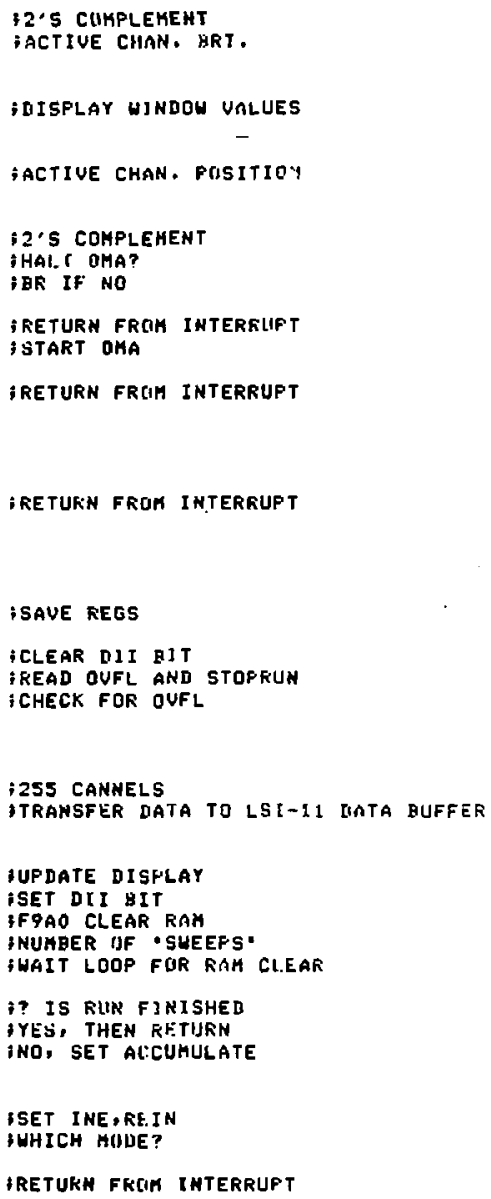




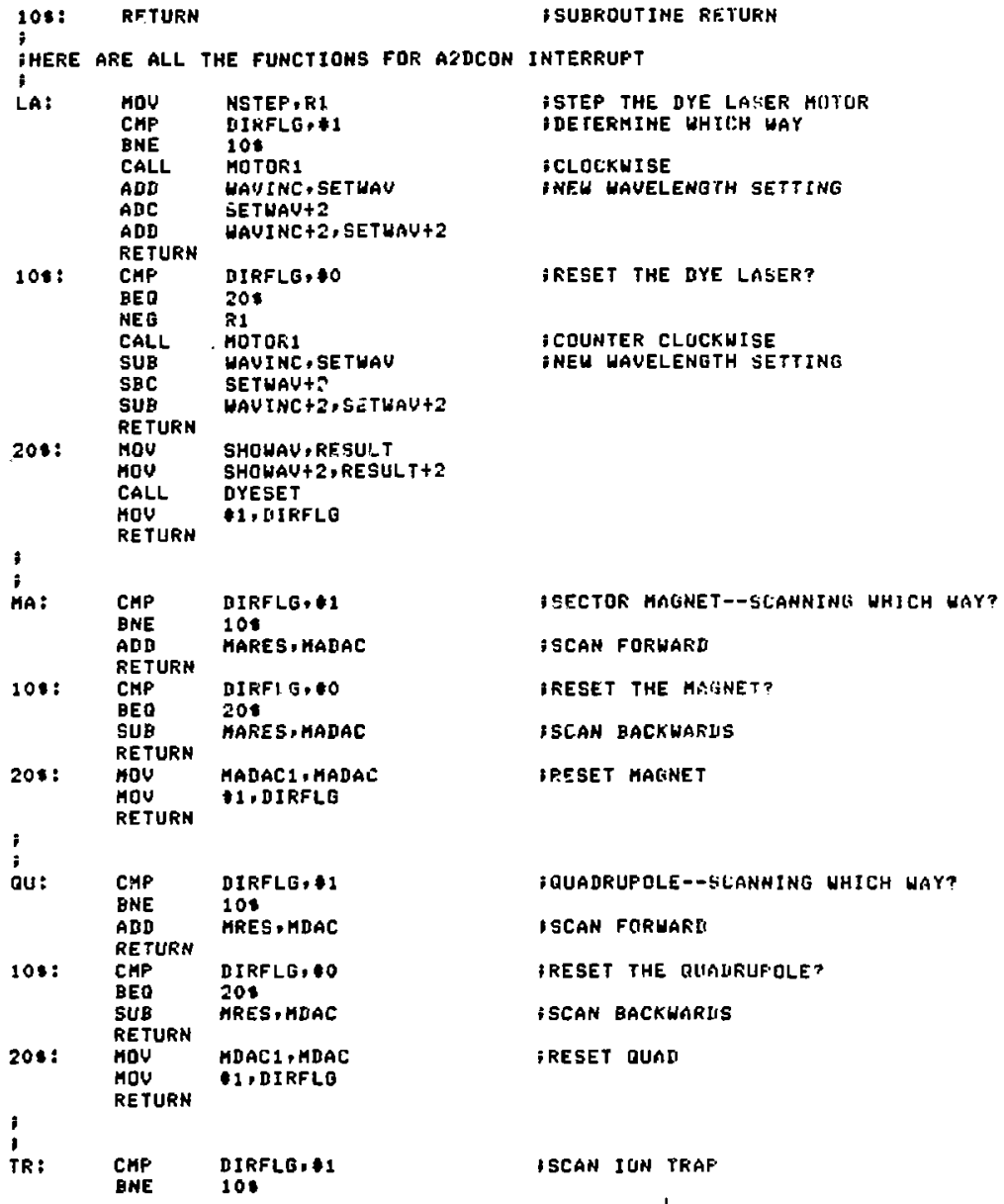




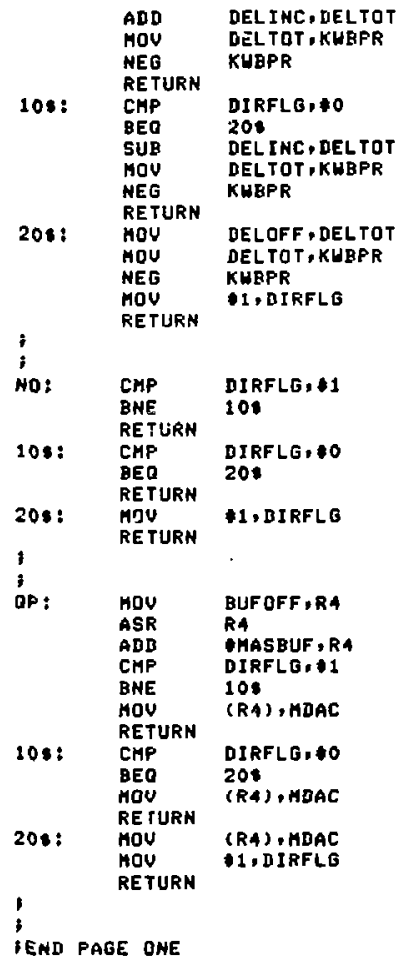

BRESET THE. ILIN TRAP?

i BACKHARDS

TRESET

ISET FOR FURHARD SCANNING

IND OFERATIDN!!

ISEAN FORWARD

fRESET THE SLARH PUINTERS?

\$SET SEAN DIRECTICIN FL.ALIFORWAFII

I BUFFER OFFSET TO RA

OOIUIDE BY TWD

IR4 HAS HASS PUINTER

I OUADRUPOLE--SLANHING WHILH WAY?

ISET QUaDRUPOLE TU hass PEAK

IRESET THE QUALRUPGLE?

iset quadrupale to mass ffak

IRESET OUAD 


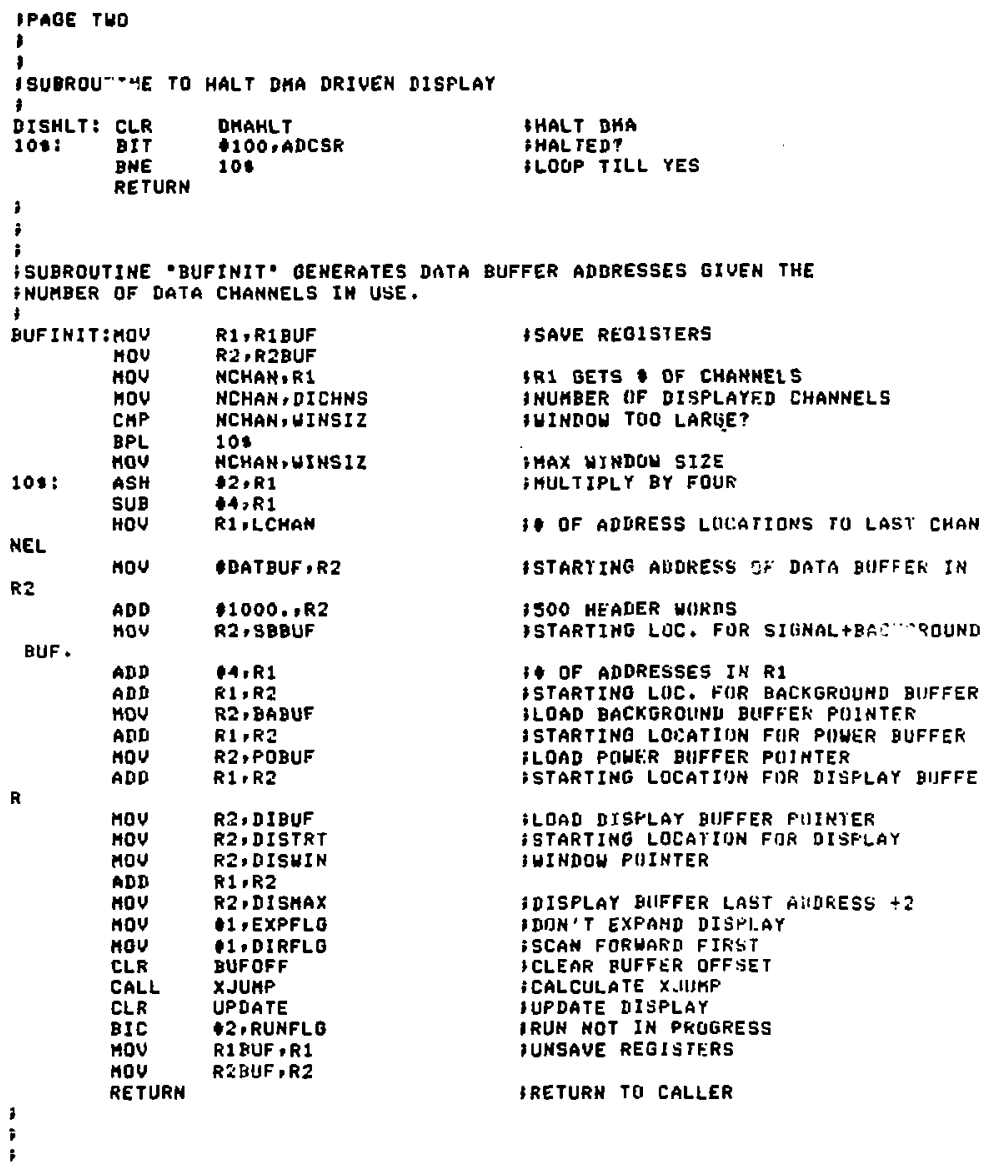




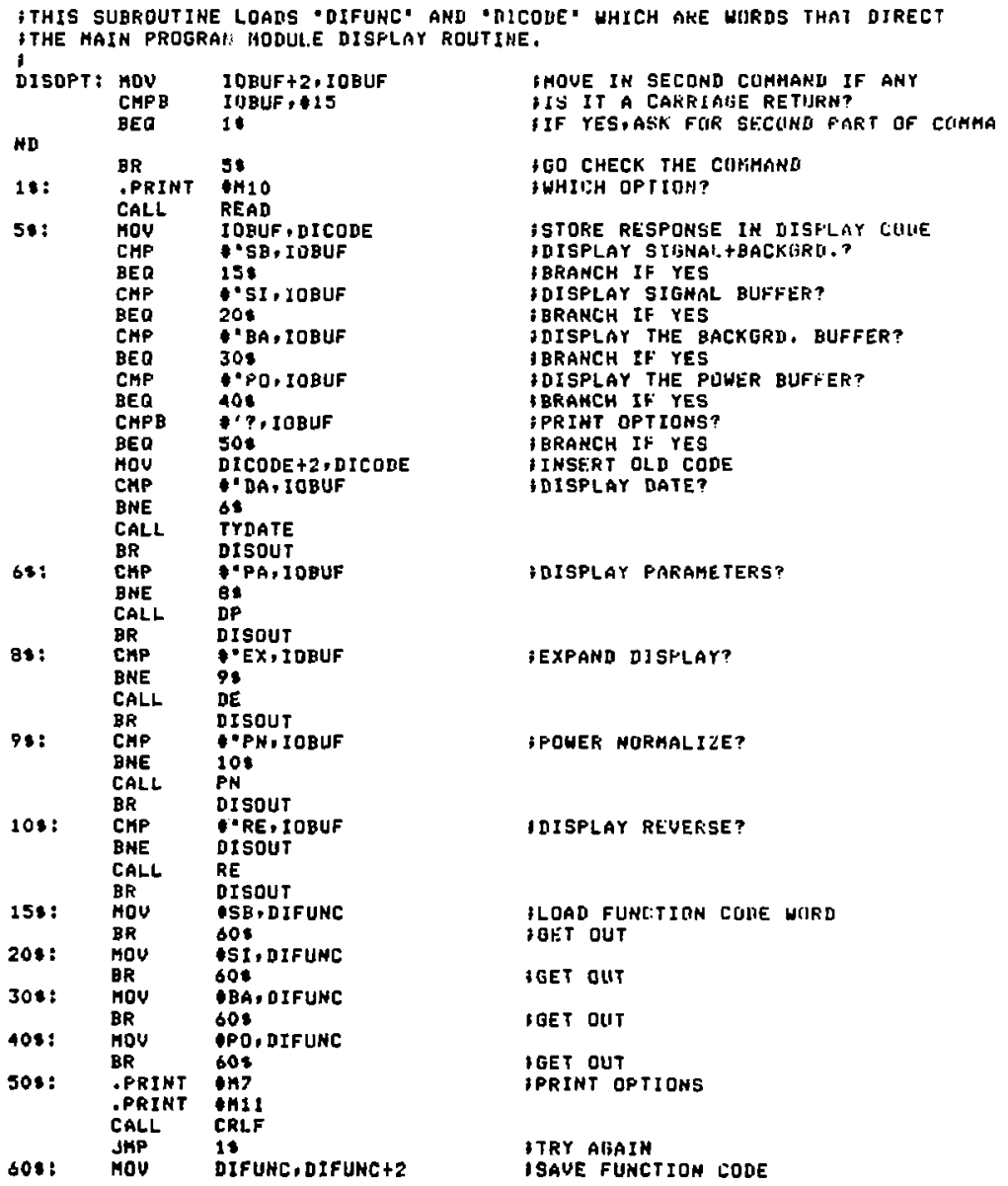




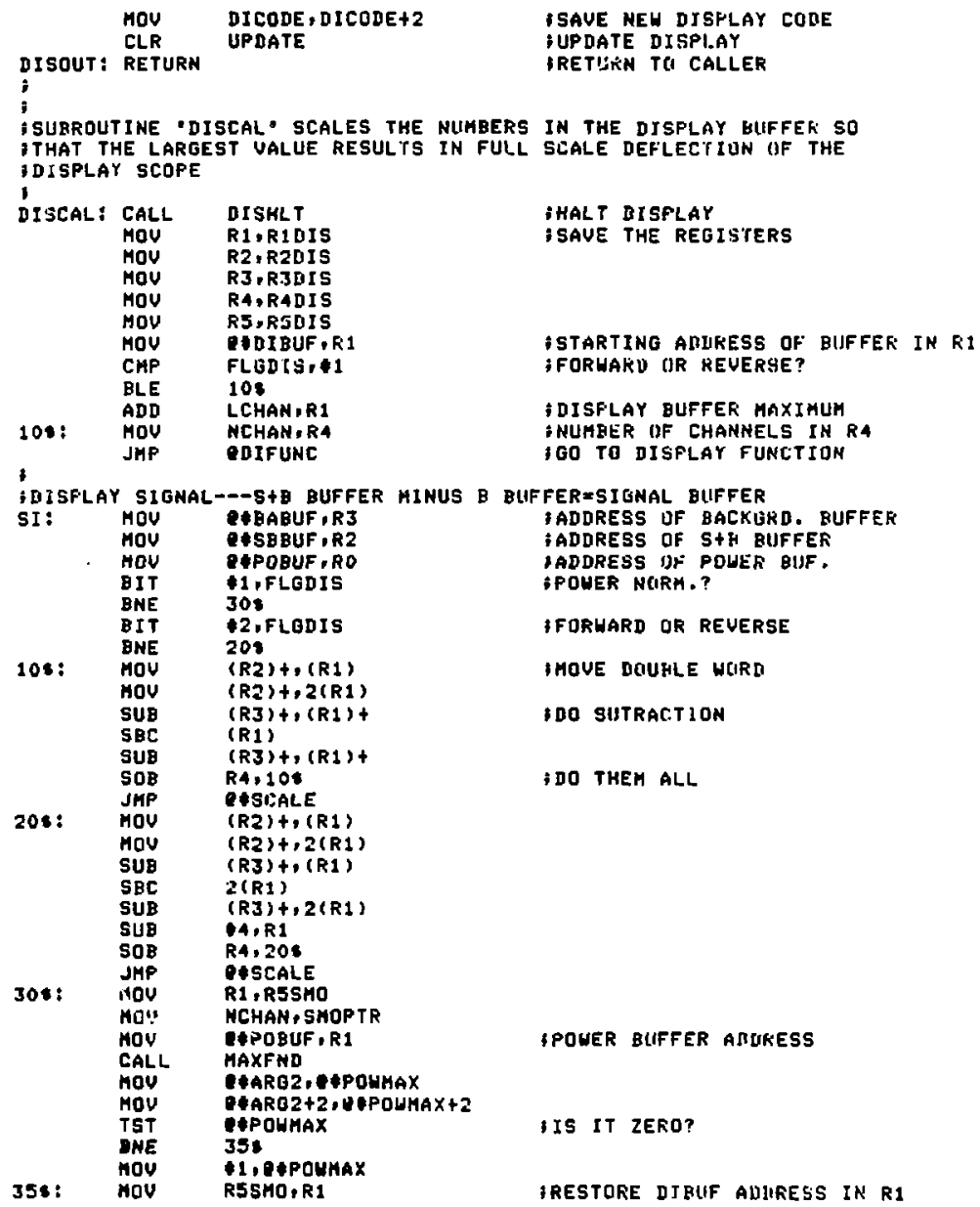




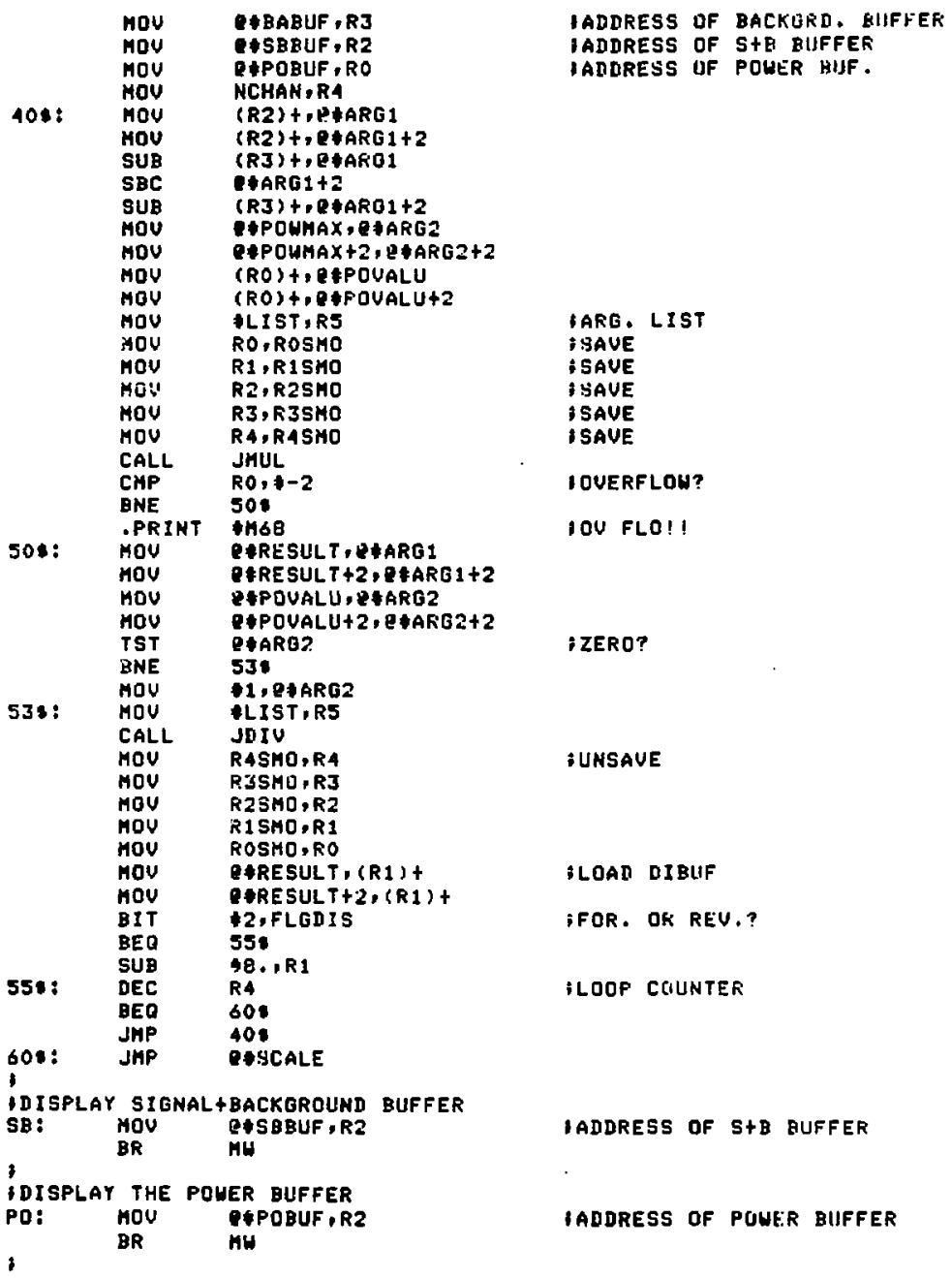




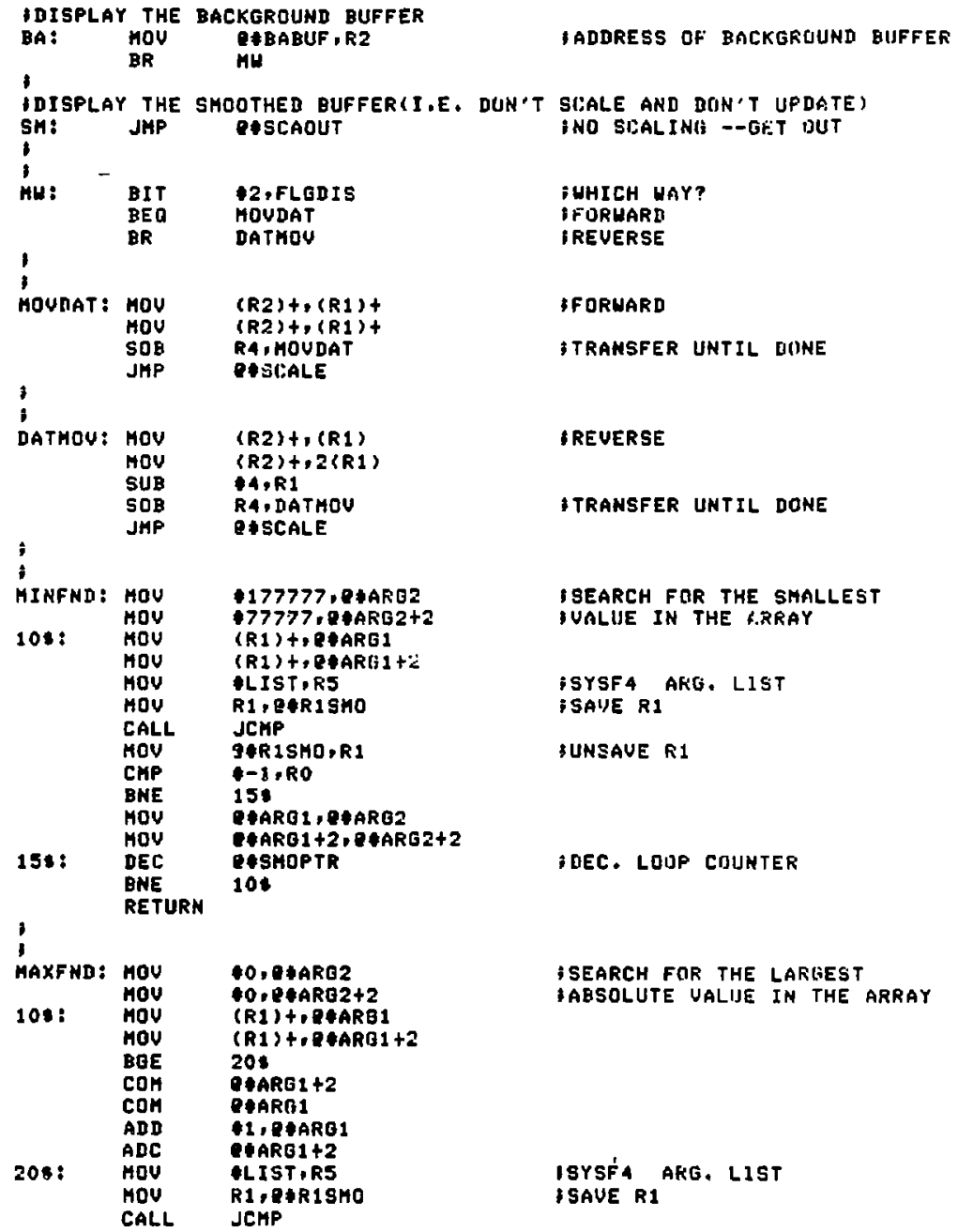

\section{IFORMARD}

itRANSFER UNTIL UONE

\section{IREUERSE}

ITRANSFER UNTIL DONE

I SEARCH FOR THE SHALLEST

UALUE IN THE G.RRAY

†SYSF 4 ARG. LIST

ISAUE RI

IUNSAUE RI

DEC. LUUP CDUNTER

; SEARCH FOR THE LARLEST

IABSOLUTE UALIJE IN THE aRRay

ISYSFA ARG, LIST

isave R1 


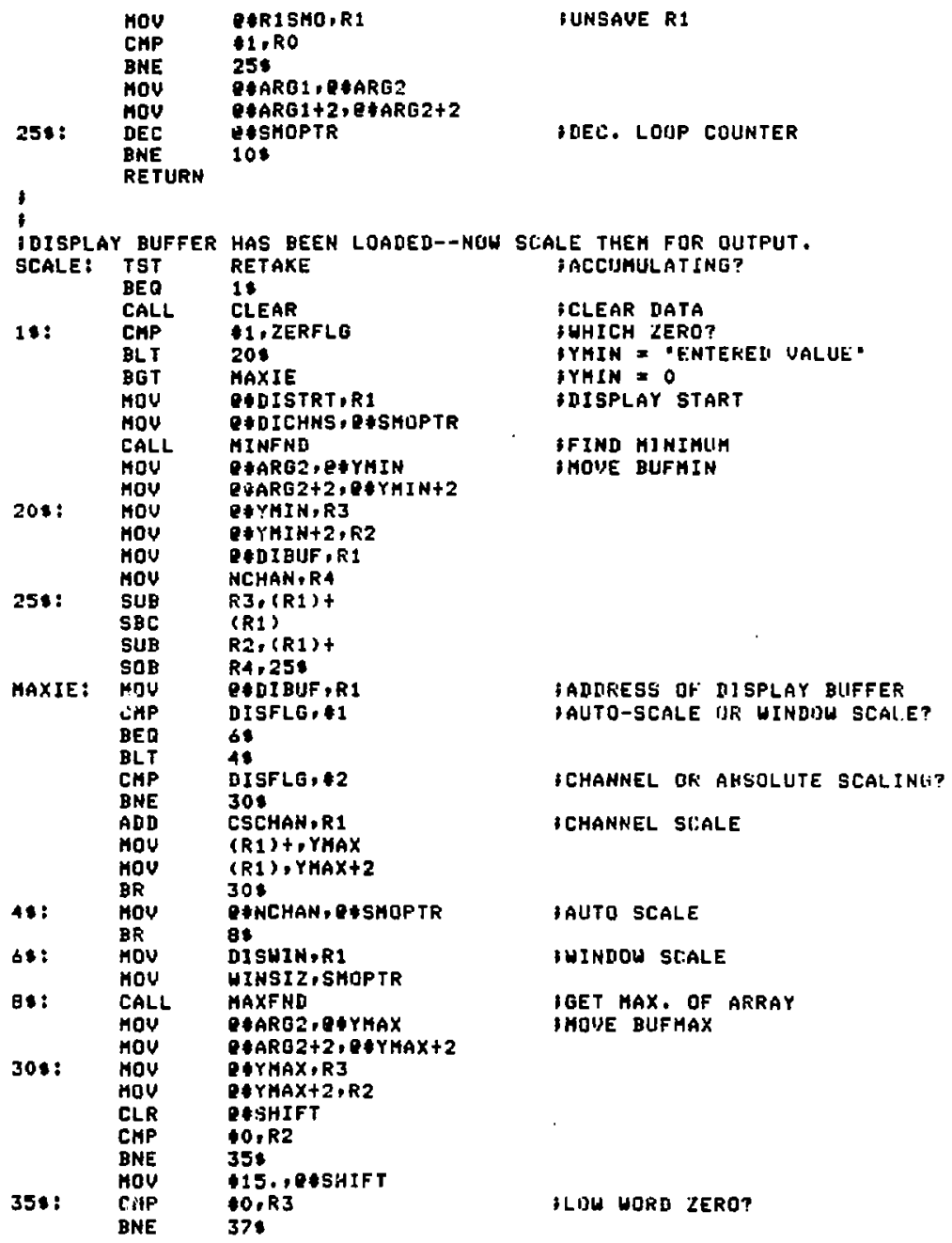




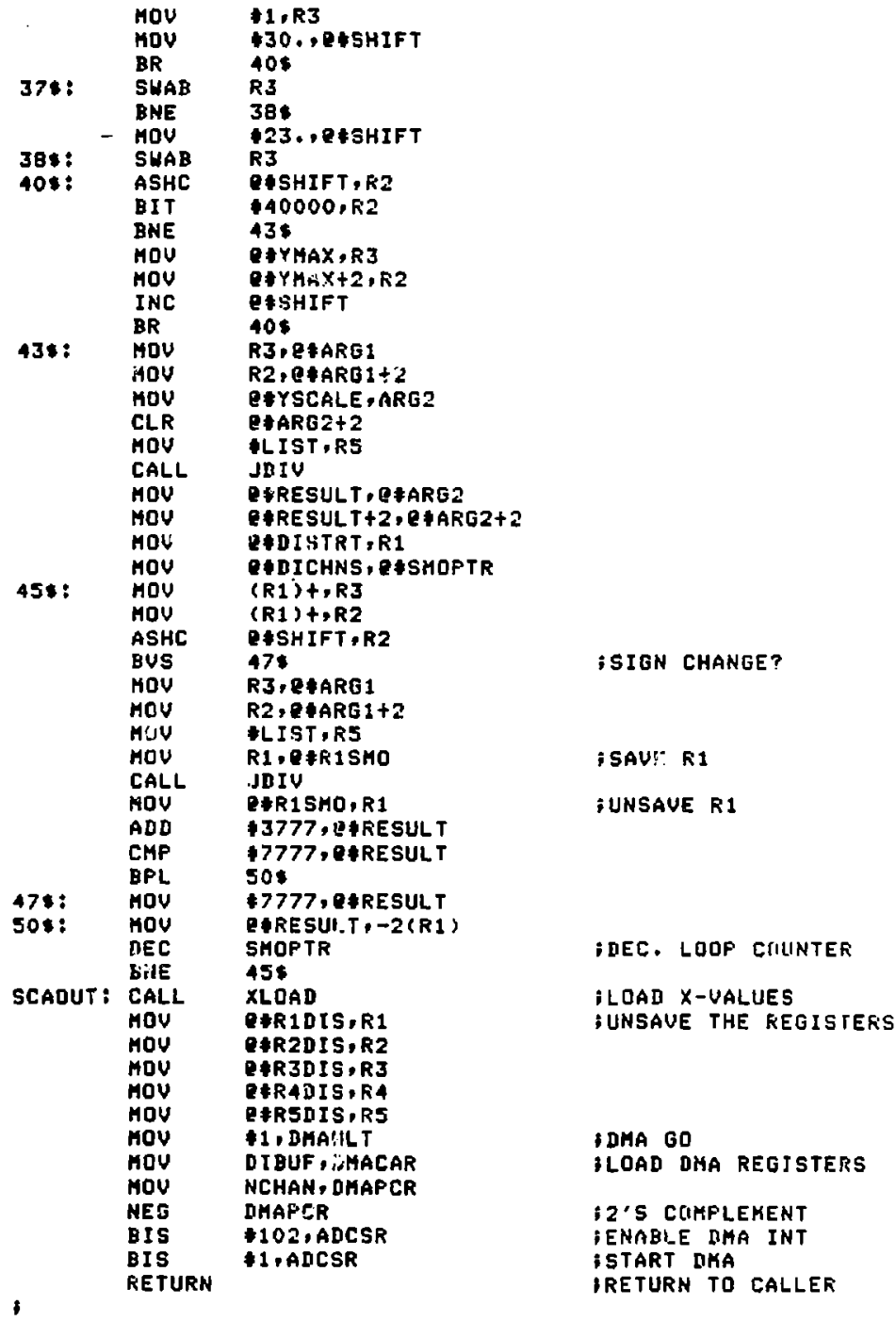




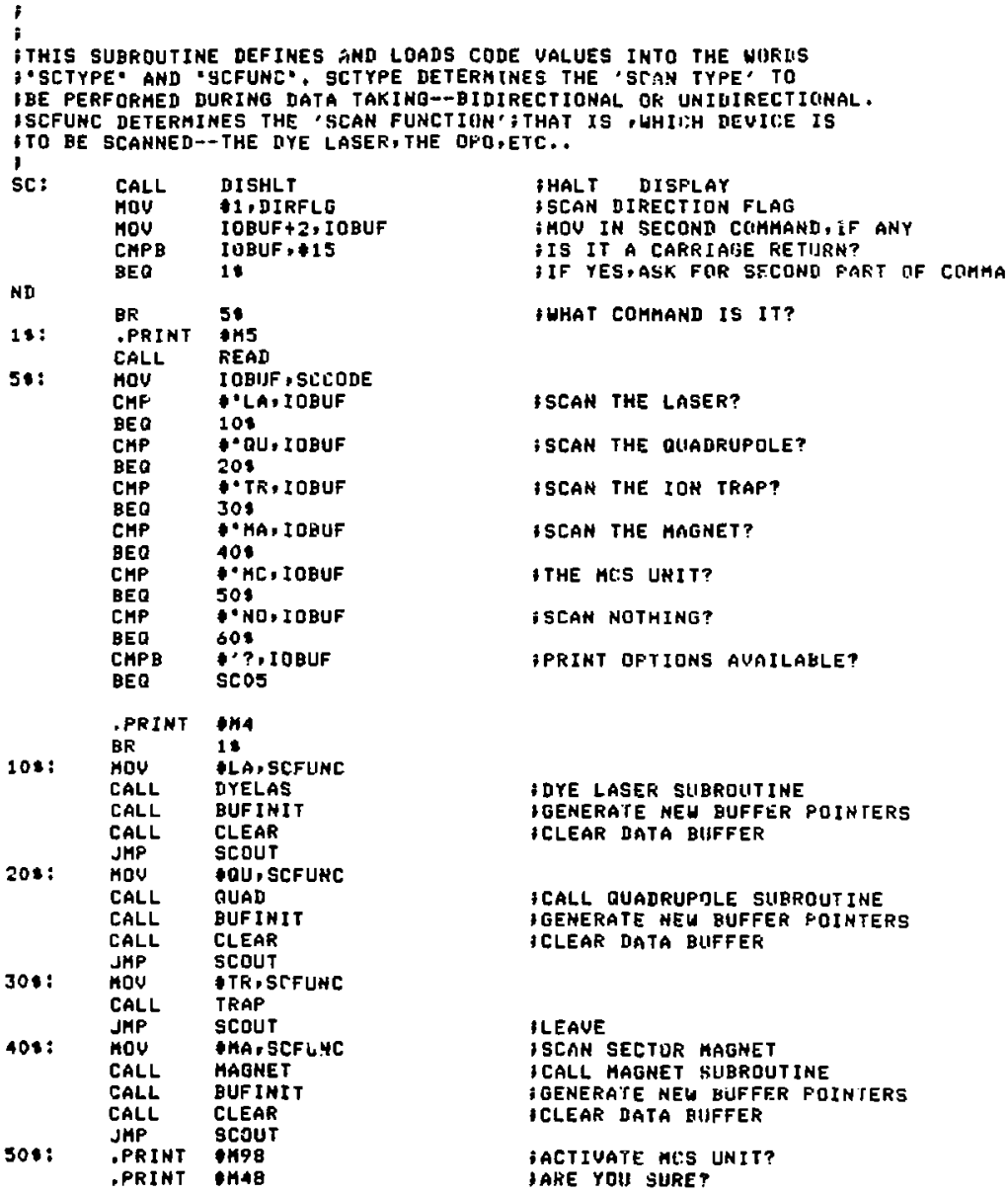




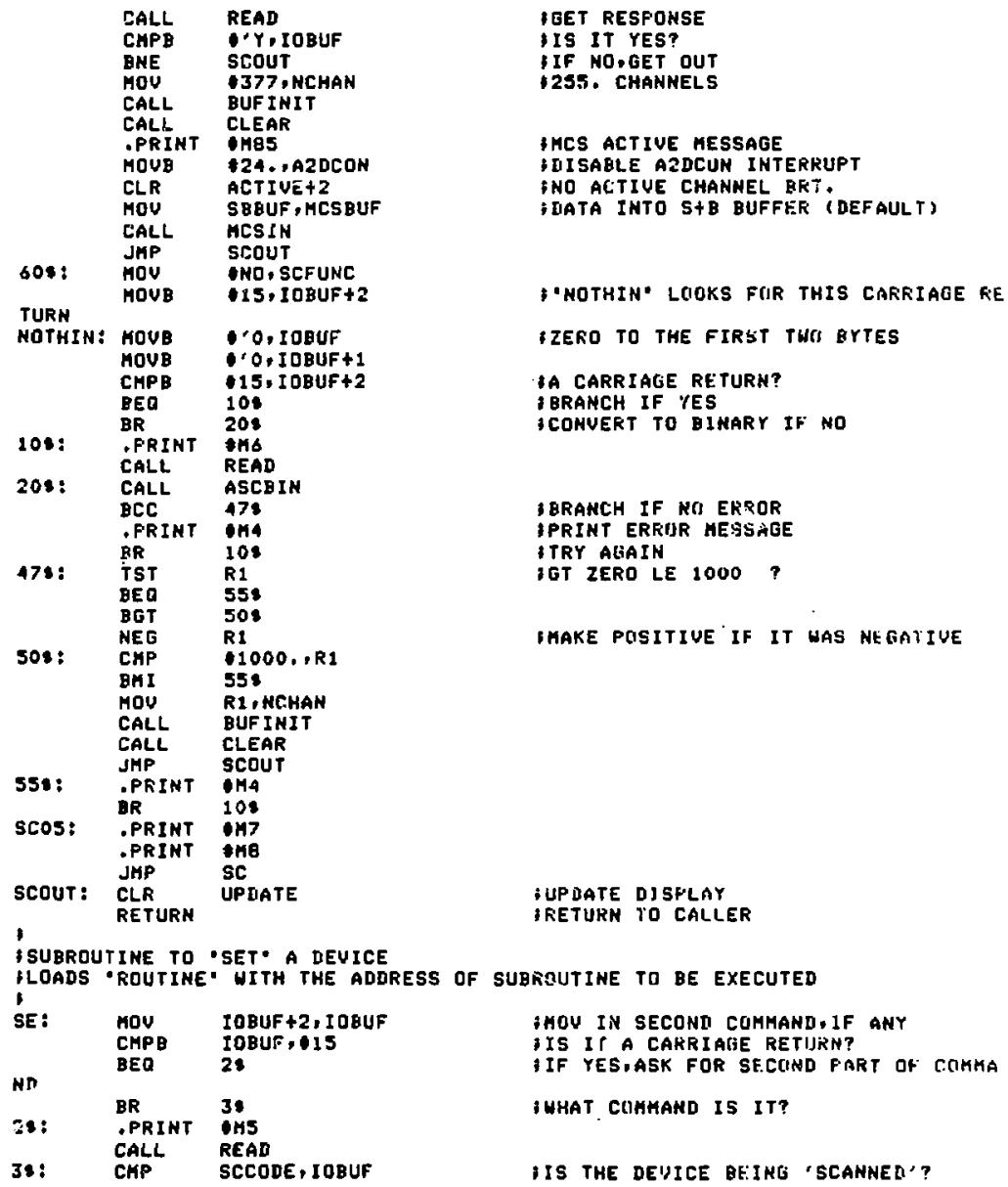




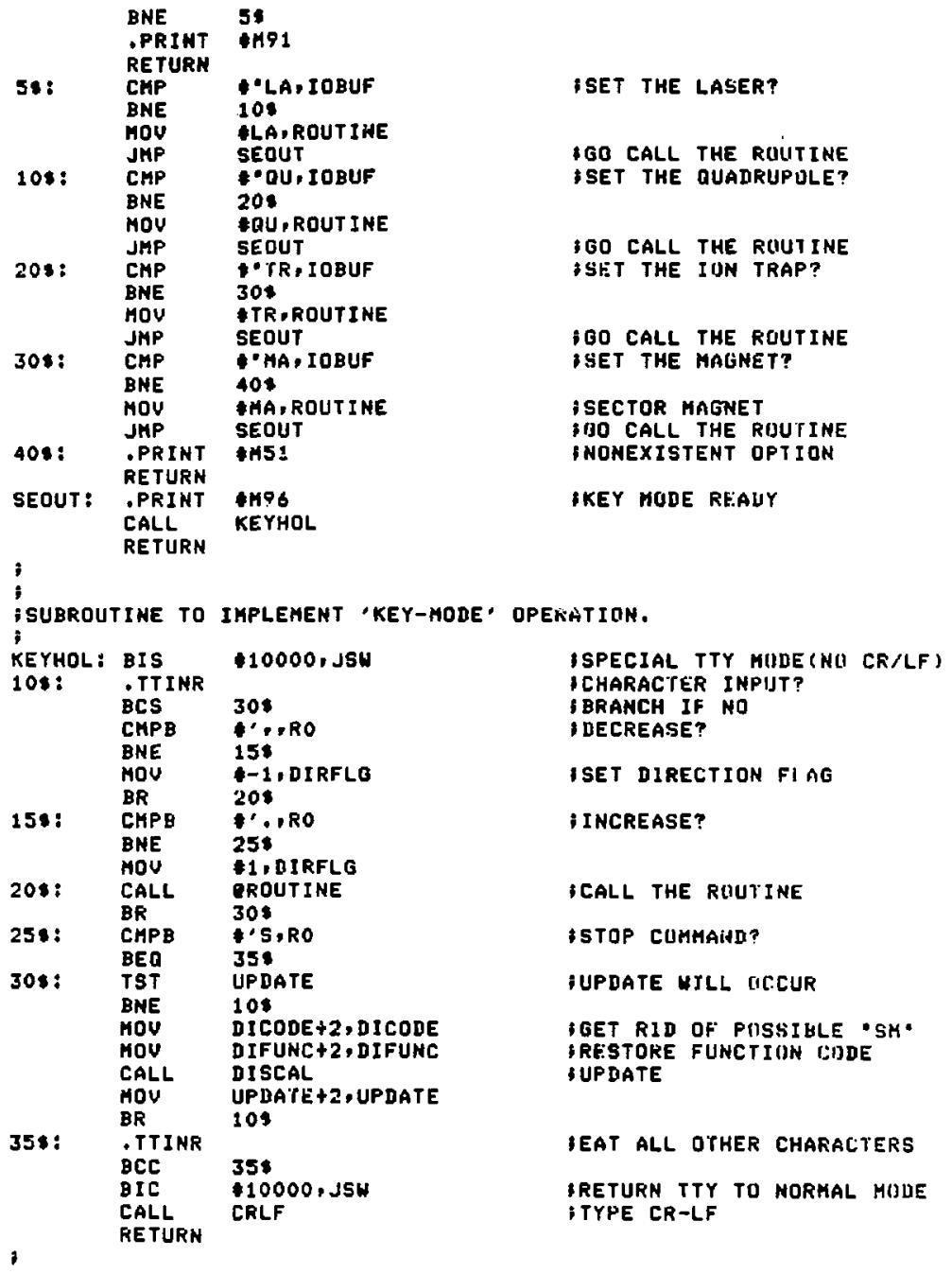




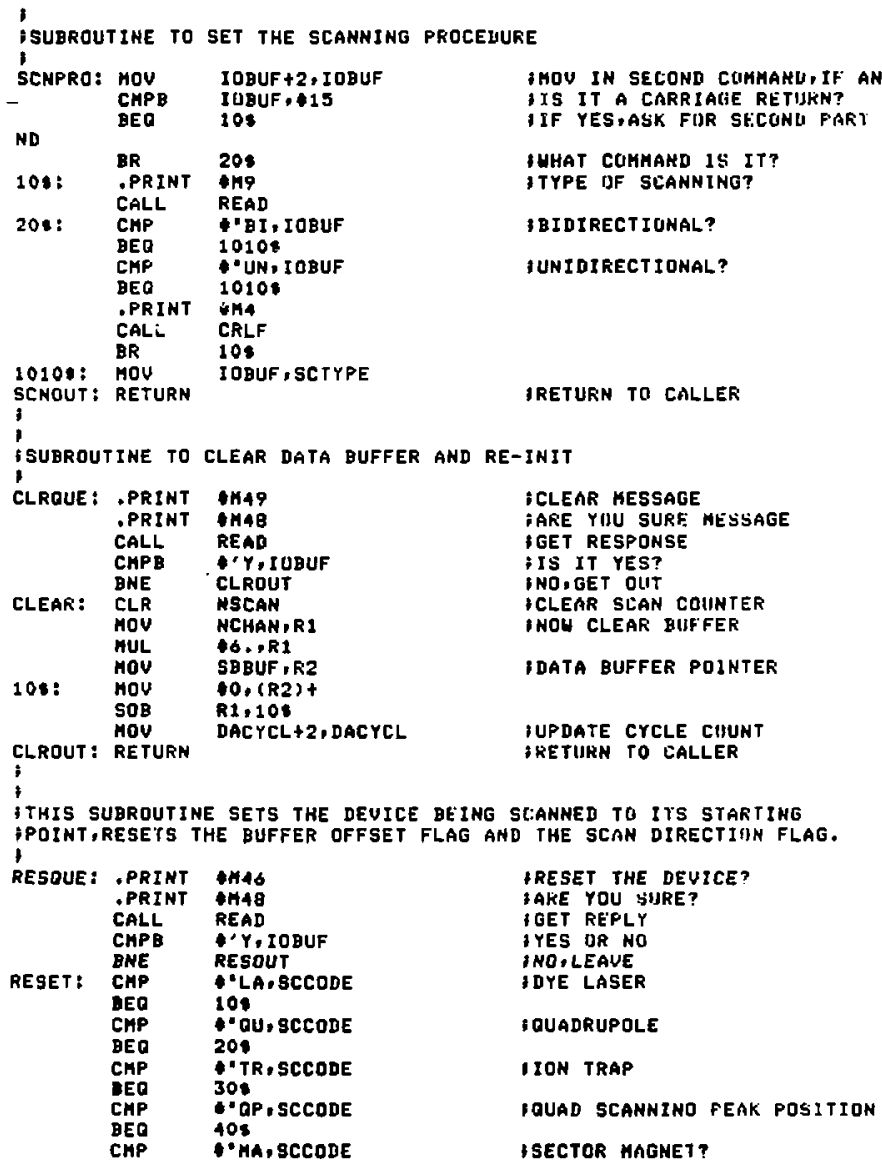




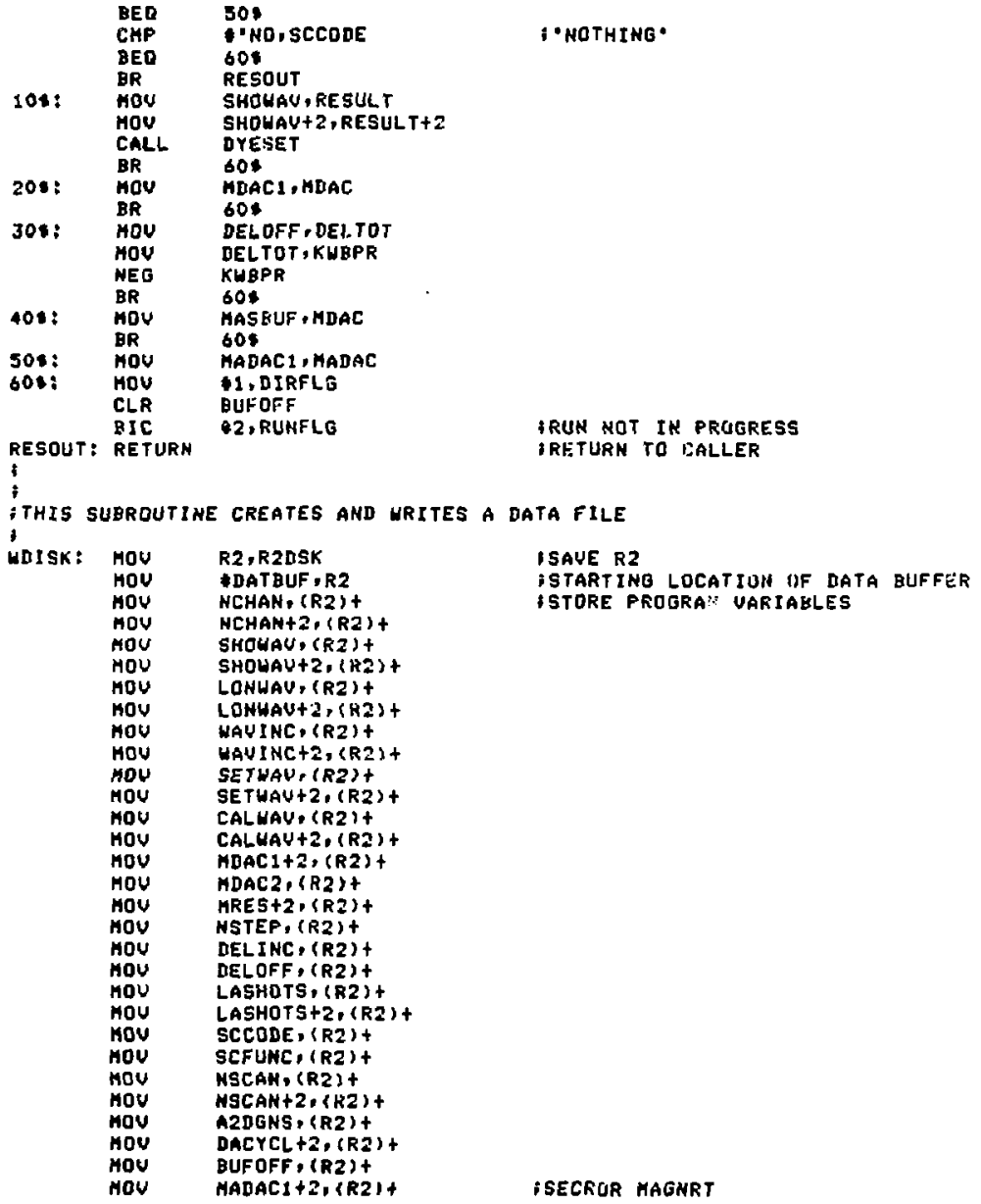




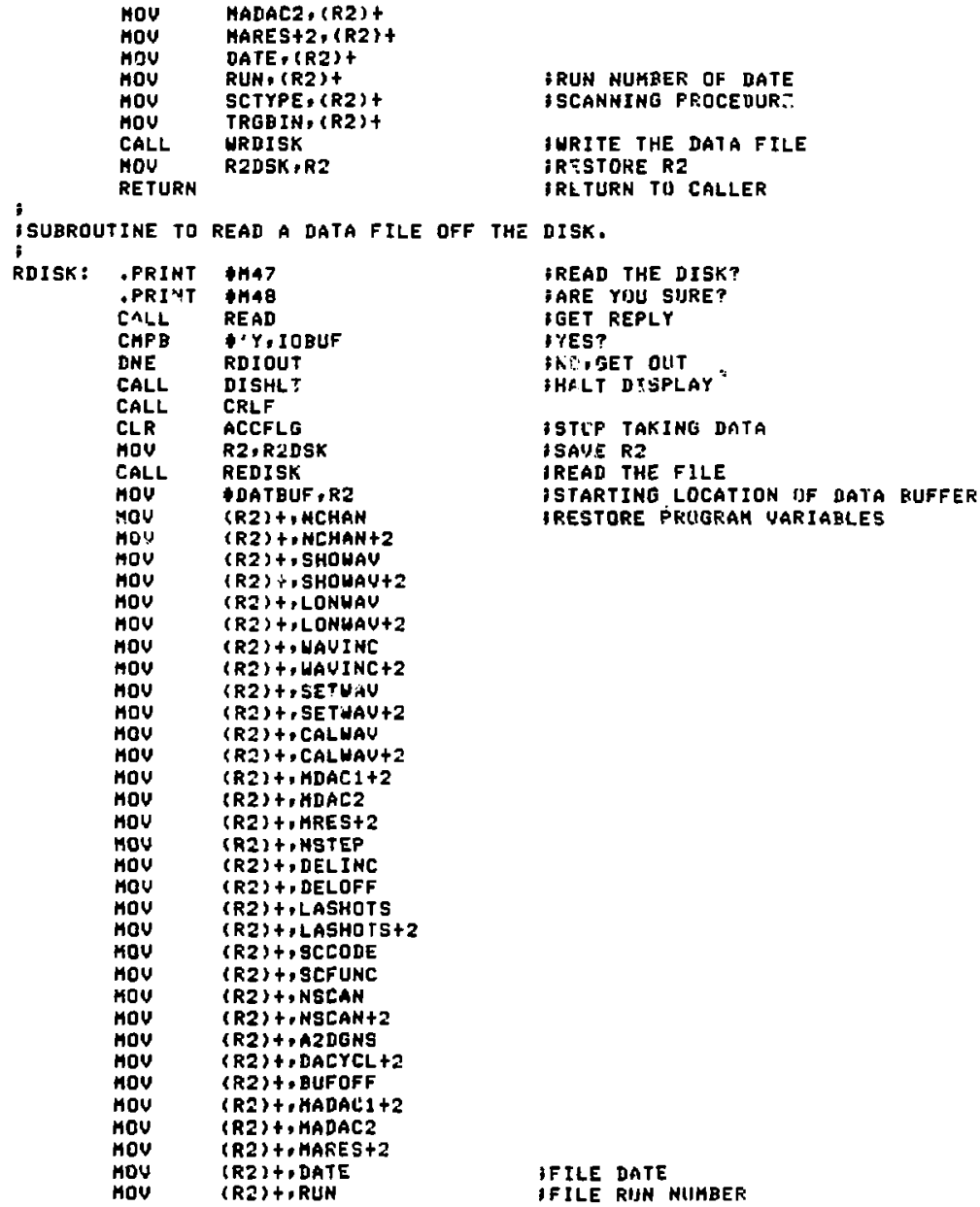




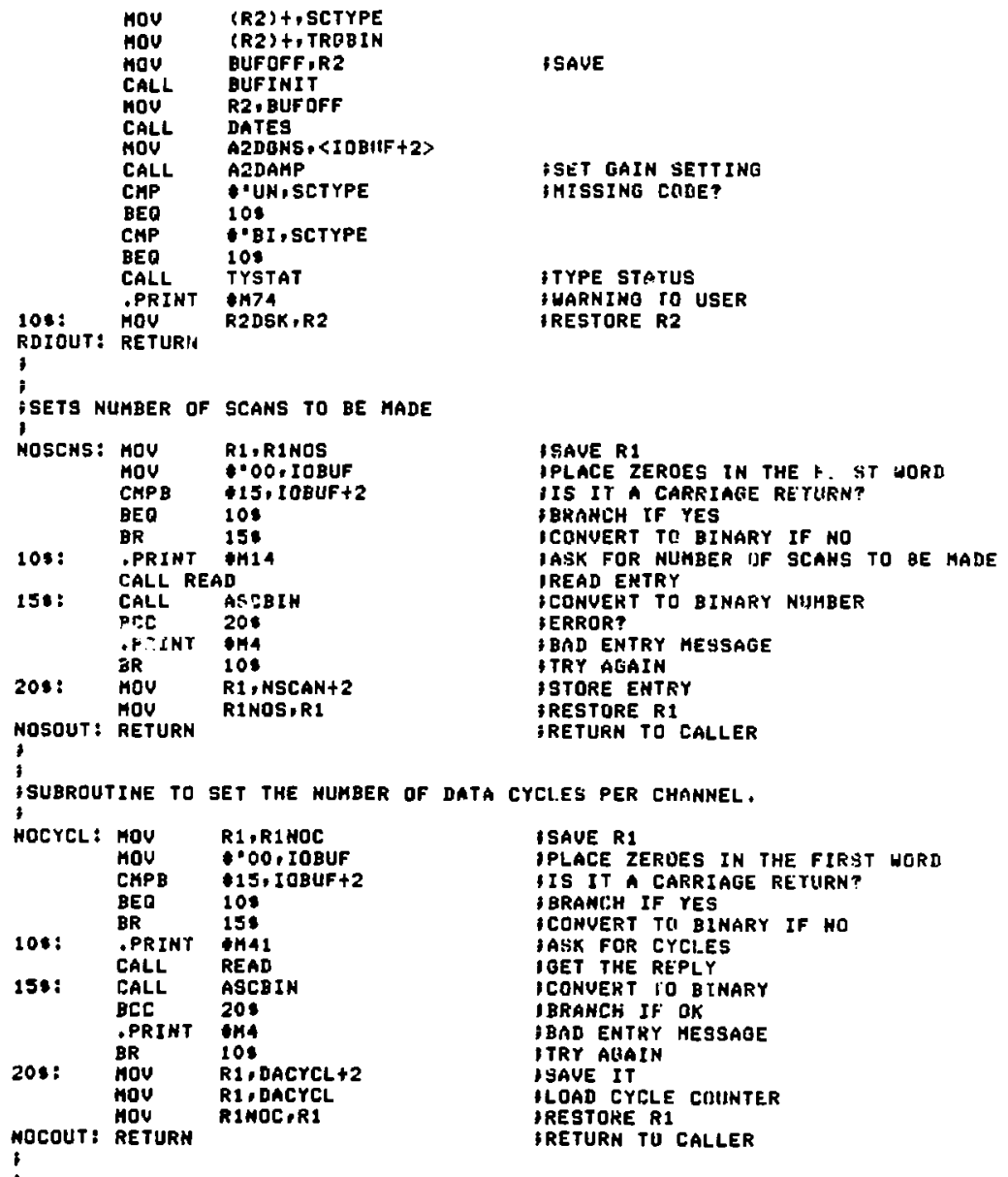




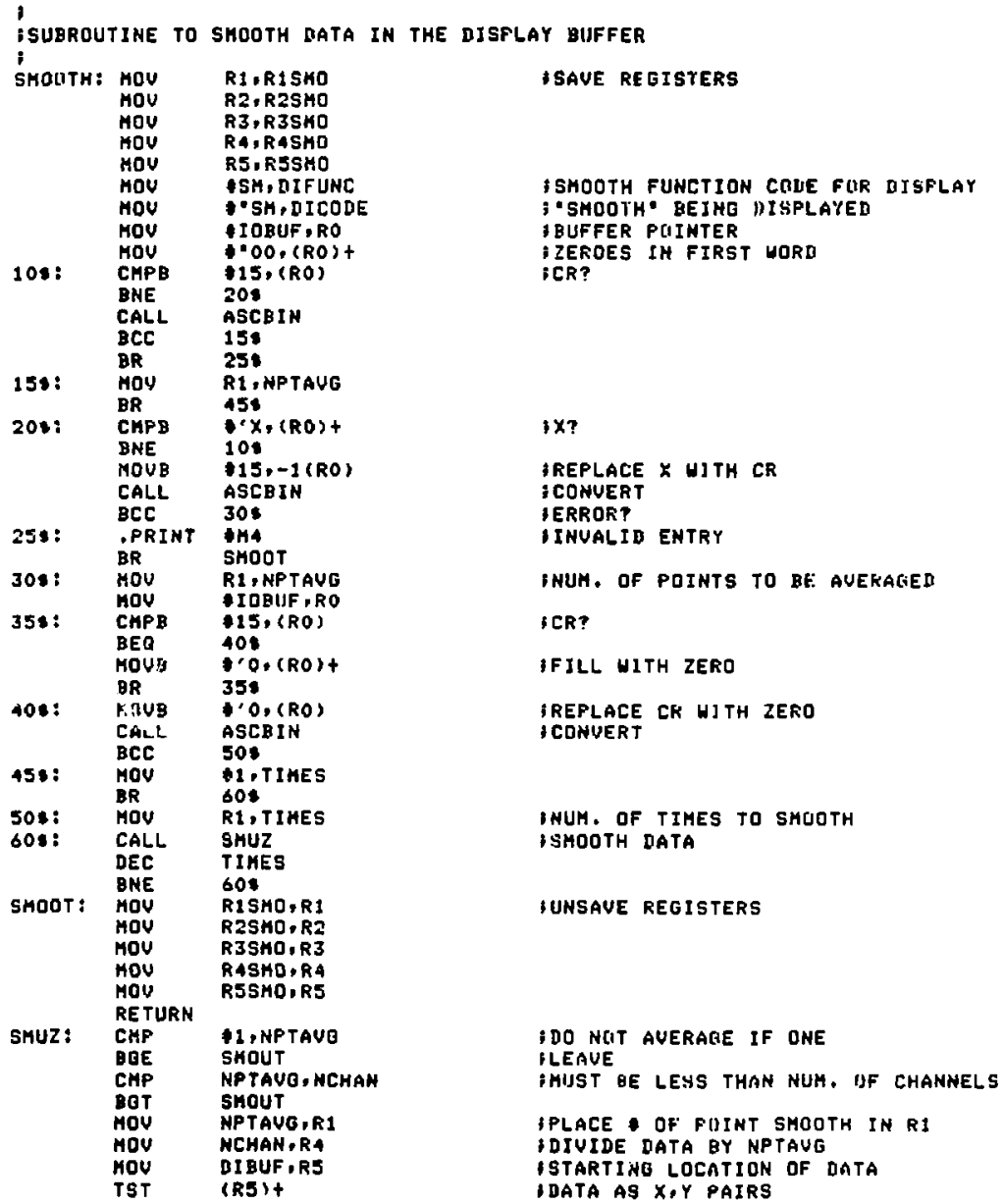




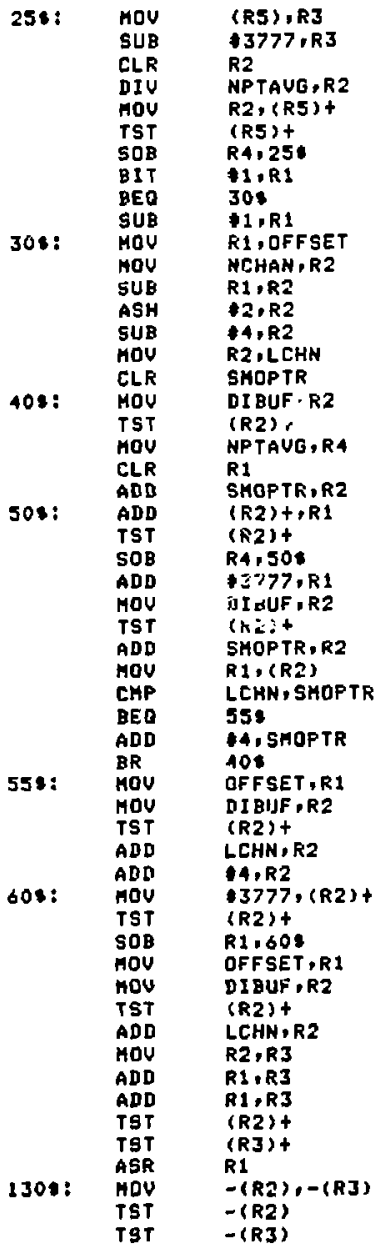

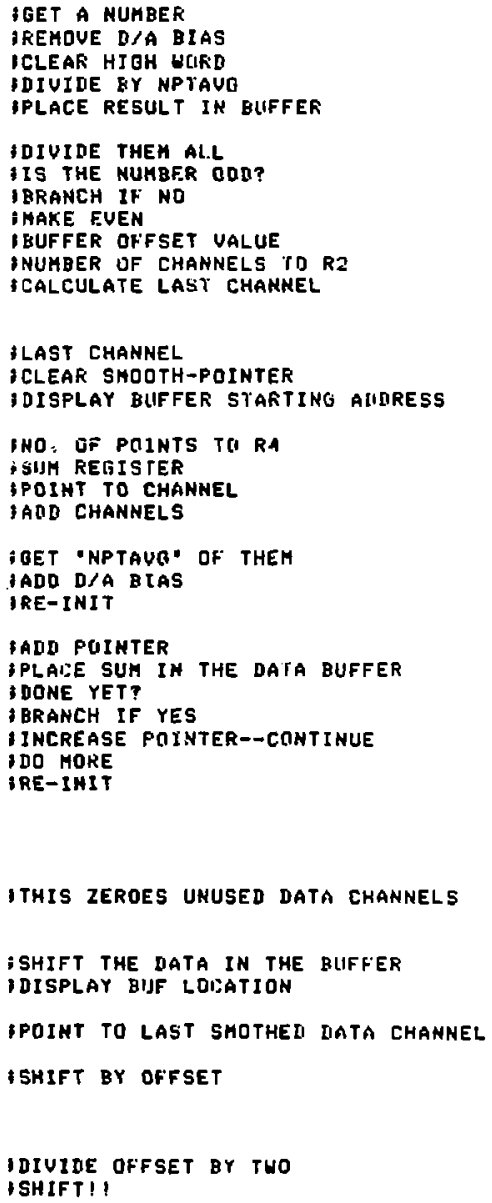

ITHIS ZEROES UNUSED DATA CHANNELS

;SHIFT THE DATA IN THE BLIFFER IDISPLAY BIJF LDISATION

IPOINT TO LAST SHOTHED IATA CHANNEL ISHIFT BY OFFSET

IDIUIDE OFFSET BY TWO ISHIFT!' 


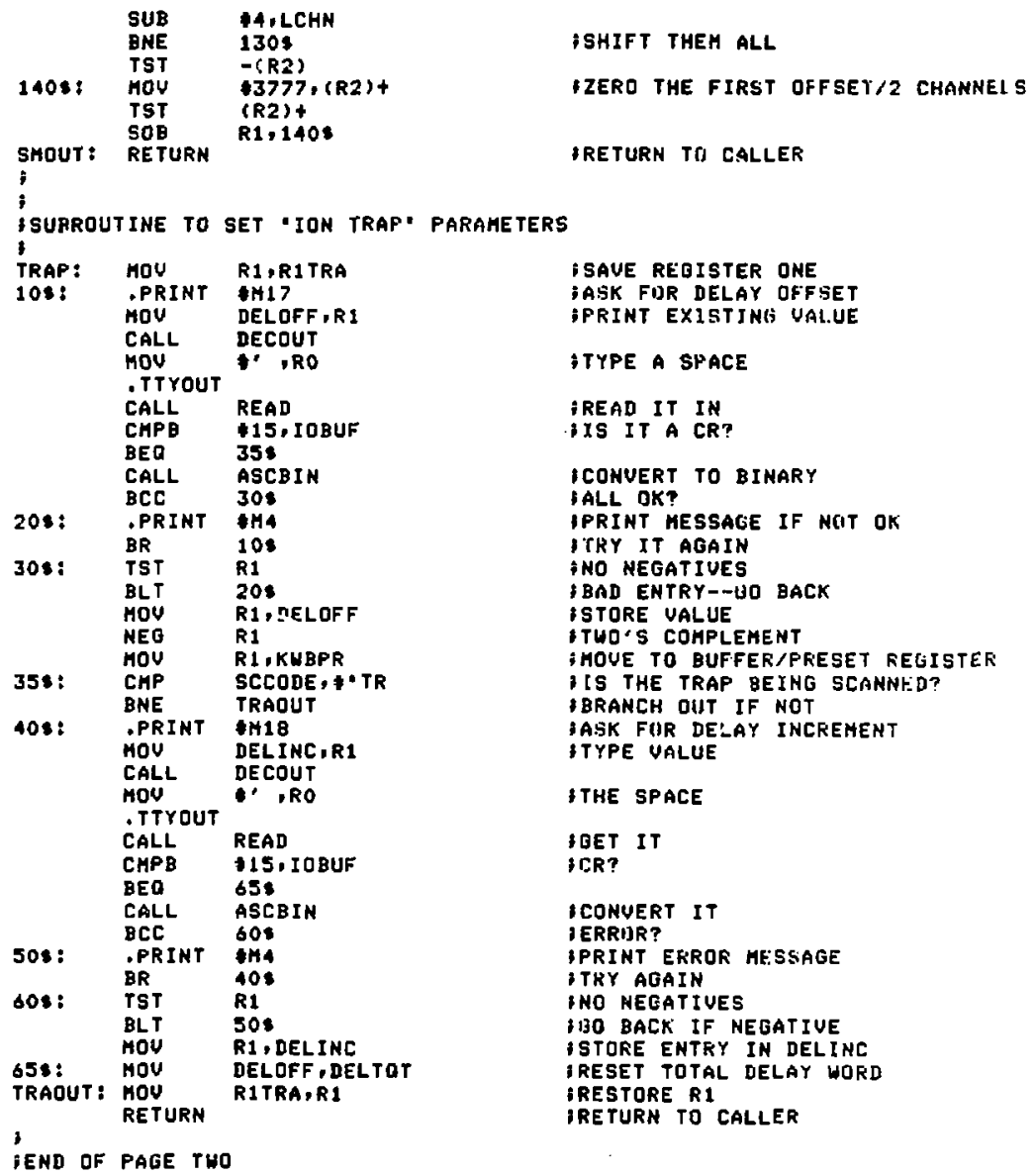




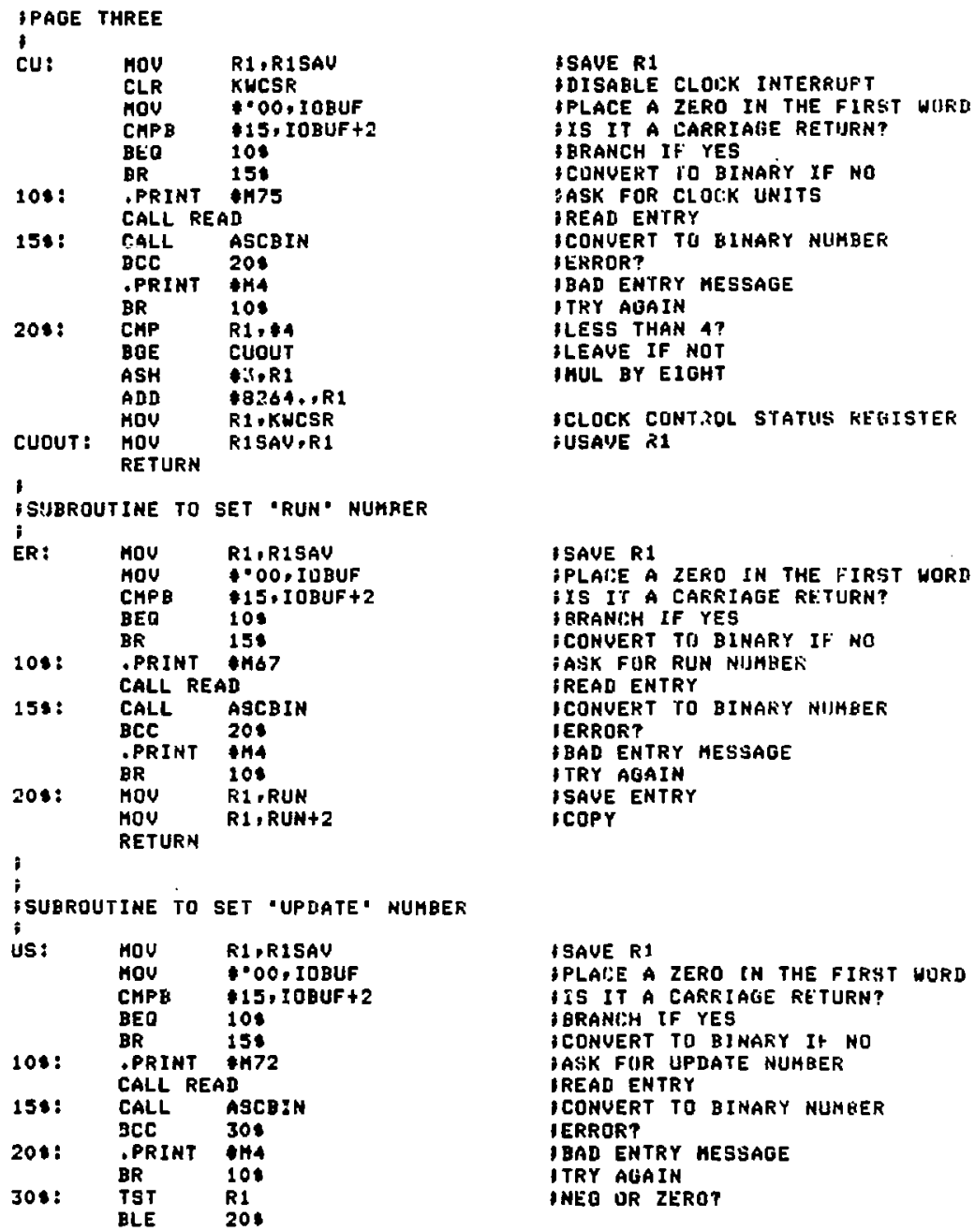

ISAUE R1

DISABLE CLOIK INTERRUFT

IPLACE A zERo IN THE FIRST WIIFD

ixs IT a carrialie RETURN?

IBRANCH IF YES

ICUNUERT IO BINARY YF NO

IASK FOR CLOC:K UNITS

IREAD ENTRY

ICONUERT TO GINARY NUMBER

ERROR?

IBAD ENTRY MESSAGE

ITRY AUAIN

ILESS THAN 4?

3LEAUE IF NOT

IMUL BY EIGHT

ICLOCK CONTROL STATUS REGISTER iUSAVE 21

ISAVE R1

IPLAI:E A ZERD IN THE FIRST WORD ixs ir A CAREIAGE RETURN? i GRANI:H IF YES

I CONUERT TIS BLNARY IF NO

IASK FUR RUN NIJHBES

IREAD ENTRY

ICONUERT TO BINARY NIJHBER

IERRORT

t Bad ENTRY MESSAge

ITRY AGAIN

ISAUE ENTRY

ICOPY

ISAVE R1

IPLALE A ZERO IN THE FIRST WURD

IIS IT A CAREIAGE RE'TURN?

I GRANIEH IF YES

ICONUERT TO BINARY It NO

IASK FIIR UPDATE NUHBER

IREAD ENTRY

ICONUERT TO BINARY NUMBER

IERROR?

ibad ENTRY MESSage

ITRY AGA IN

INEG UR ZERO? 


\begin{tabular}{|c|c|c|c|}
\hline & $\begin{array}{l}\text { HOU } \\
\text { HOU } \\
\text { RETURN }\end{array}$ & $\begin{array}{l}\text { R1, UPDATE } \\
\text { R1, UPDATE+2 }\end{array}$ & $\begin{array}{l}\text { ISAUE ENTRY } \\
\text { ICOPY }\end{array}$ \\
\hline \multicolumn{4}{|c|}{ 年 } \\
\hline PRINT & OUT (LP) & ROUTINE & \\
\hline PR: & $\begin{array}{l}\text { HOV } \\
\text { CHPB } \\
\text { BNE } \\
\text {-PRINT } \\
\text { CALL }\end{array}$ & $\begin{array}{l}\text { IOBUF }+2, \text { IOSUF } \\
\text { IOBUF, } \neq 15 \\
10 \\
\text { THIO } \\
\text { REAL }\end{array}$ & $\begin{array}{l}\text { IOPTION TO FIRST UURD } \\
\text { ICR? } \\
\text { OOPTION? }\end{array}$ \\
\hline $10 \$:$ & $\begin{array}{l}\text { CHP } \\
\text { BNE } \\
\text { CALL } \\
\text { BR }\end{array}$ & $\begin{array}{l}\text { "HE, IOBUF } \\
\text { COS } \\
\text { PRHEDR } \\
\text { SOS }\end{array}$ & IFRINT HEADE: \\
\hline $20 \div:$ & $\begin{array}{l}\text { CKF } \\
\text { BNE } \\
\text { CALL } \\
\text { BR }\end{array}$ & $\begin{array}{l}\text { *FU, IOBUF } \\
30 \text { s } \\
\text { PRFULL } \\
\text { 50: }\end{array}$ & IPRINT FULL INFO? \\
\hline $30 \leqslant:$ & $\begin{array}{l}\text { CMP } \\
\text { BNE } \\
\text { CALL } \\
\text { BR }\end{array}$ & $\begin{array}{l}\text { I'DA, I OBUF } \\
\text { 40S } \\
\text { PRDATA } \\
\text { SOS }\end{array}$ & SPRINT DATA \\
\hline 40s: & $\begin{array}{l}\text { CHP } \\
\text { BNE } \\
\text { CALL }\end{array}$ & $\begin{array}{l}\text { :ST, IOBUF } \\
\text { SOS } \\
\text { FRSTAT }\end{array}$ & IPRINT STATUS? \\
\hline $508:$ & RETURN & & \\
\hline TY: & $\begin{array}{l}\text { HOV } \\
\text { CHPB } \\
\text { BNE } \\
\text { PRINT }\end{array}$ & $\begin{array}{l}\text { IOBUF }+2, \text { IOBUF } \\
\text { IOBUF, } 15 \\
108\end{array}$ & $\begin{array}{l}\text {;OPTION TO FIRST WURD } \\
\text {;CR? }\end{array}$ \\
\hline & $\begin{array}{l}\text { PRRINT } \\
\text { CALL }\end{array}$ & $\begin{array}{l}\text { IMIO } \\
\text { READ }\end{array}$ & IDPT ION? \\
\hline 10s: & $\begin{array}{l}\text { CHP } \\
\text { BNE } \\
\text { CALL } \\
\text { BR }\end{array}$ & $\begin{array}{l}\text { PHE, IOBUF } \\
208 \\
\text { TYHEDR } \\
408\end{array}$ & IPRINT HEADER? \\
\hline $208:$ & $\begin{array}{l}\text { CMP } \\
\text { BNE } \\
\text { CALL } \\
\text { BR }\end{array}$ & $\begin{array}{l}\text { 'ST, IOBUF } \\
\text { 3OS } \\
\text { TYSTAT } \\
\text { 4OS }\end{array}$ & †PRINT FULL INFO? \\
\hline $30 s:$ & $\begin{array}{l}\text { CMP } \\
\text { BNE } \\
\text { CALL }\end{array}$ & $\begin{array}{l}\text { —'DA, IOBUF } \\
\text { 4OE } \\
\text { TYDATA }\end{array}$ & IPRINT DATA \\
\hline 105: & RETURN & & \\
\hline ISURROUT & TINE TO E & ENTER THE HEADER TO DATA & BUFFER. \\
\hline HEADER : & MOU & $\begin{array}{l}\text { R1 R R HEA } \\
\text { R2, R2HEA }\end{array}$ & I SAVE REGISTERS RI,R2 \\
\hline 5s: & $\begin{array}{l}\text { PARINT } \\
\text { CALL } \\
\text { CHPB }\end{array}$ & $\begin{array}{l}\text { MSA } \\
\text { REAB } \\
\vdash Y, \text { IOBUF }\end{array}$ & $\begin{array}{l}\text { INEW HEADER? } \\
\text { ITES OR NO } \\
\text { ILOOK FOR Y }\end{array}$ \\
\hline
\end{tabular}




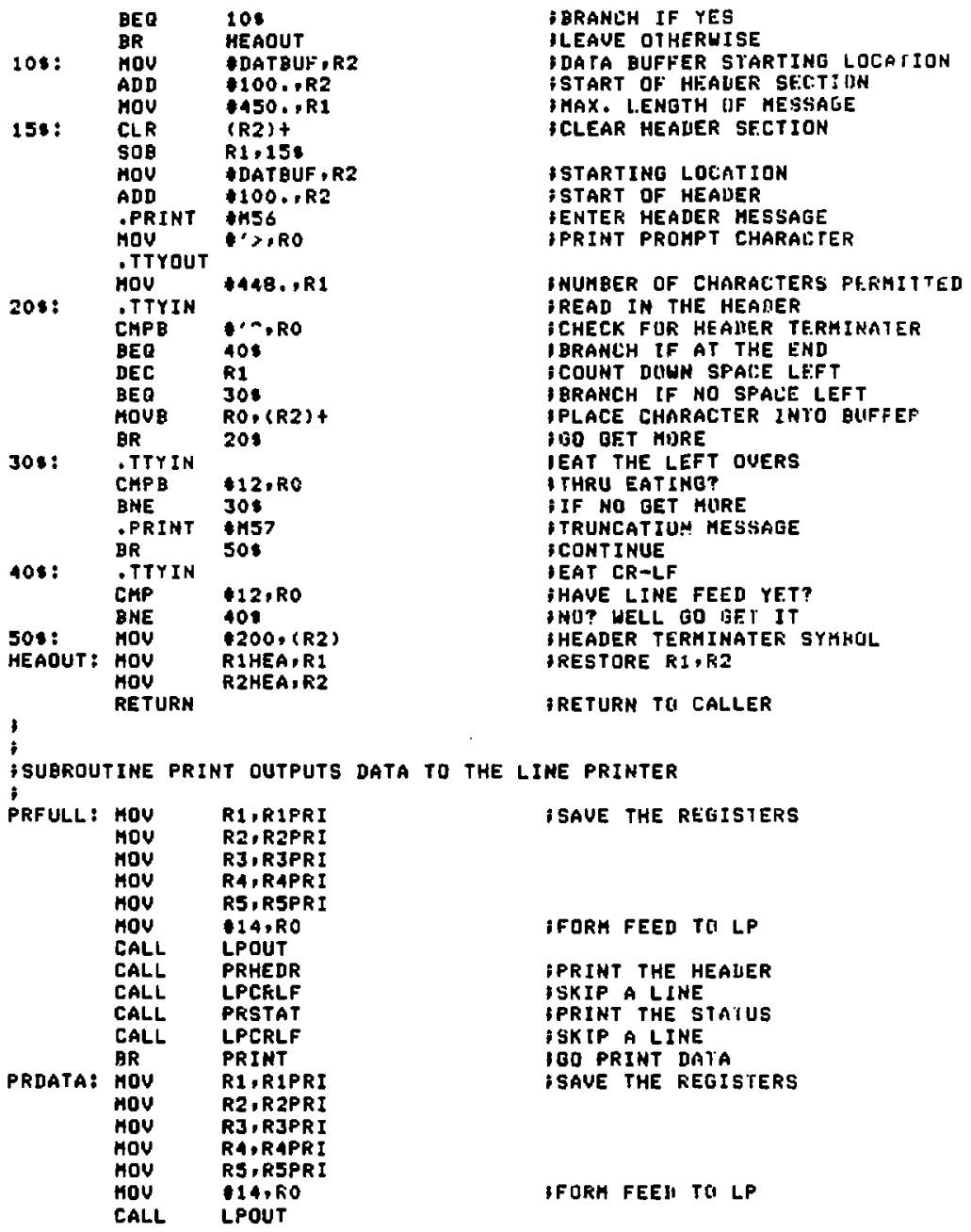




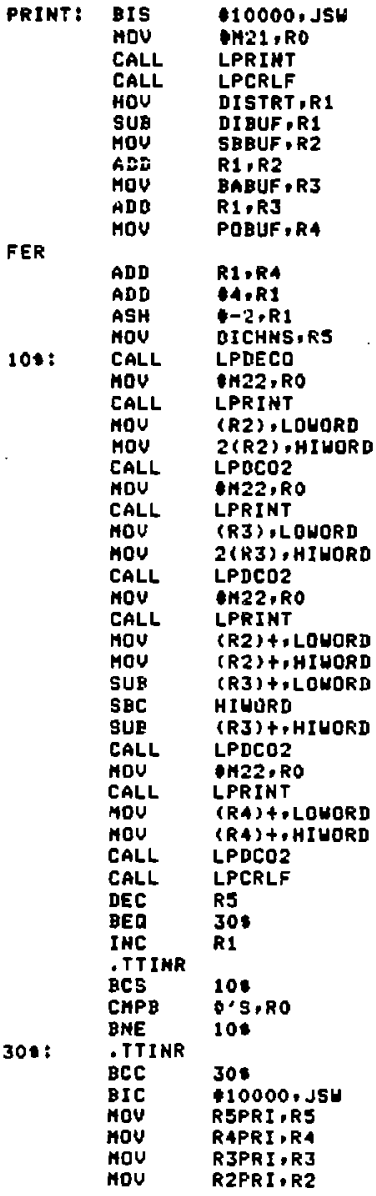

ISPECIAL TTY MUDE

IADDRESS OF ASCII STRING

IOUTPUT TO LINE. FRIATER

iCARRIAGE RETURN-LINE FEED

ICHANNEL CQUNTER

ISTARTIHG ADURESS OF $5+8$ BUFFER

BSTARTIHG AUDRESS OF BACKGRD. BUFFER

ISTARTIHG AUURESS OF LASER FUUER HIIF

ISTHRTING CHANNEL NUHGEK

4 HUMBER OF DATA EHANNELS

IPRINT THE CHANNEL NUHBER(IN R1)

IASCII STRJHG

IPRINT THE SPALES

ILOAD SIG.+HACK. FIIR OIJTPUT

IPRIN1 THE NUHBER

IPRINT THE SPACES

iLQAD BACKGROUND

IPEINT IT

IPRINT THE SPACES

icallllate the siginal

ISUBTRACT BACKGRDUND FRUA SIG. rBACK.

IPRINT THE SIGNAL

IPRINT THE SPAEES

ILDAD LASER-POWER FUR DUTPUT

IPRINT IT!

PCARP.JALE RETURN-LINE FEEU

ICOUNT THE LOUFS

IBRANCH DUT IF DONE

I IHCREMENT CHANNEL MIIMEER

CHELK FUR ' TOP. CUMHAND

BNOHE--GO AHEAD

"S" $\mathrm{S}$ THE STIJP CO "AND

CONTINUE IF NOT ' $\mathrm{S}$.

IEAT DTHER CHaRaCtERS

INORAAL TTY MODE.

+RESTORE THE REOISTERS 


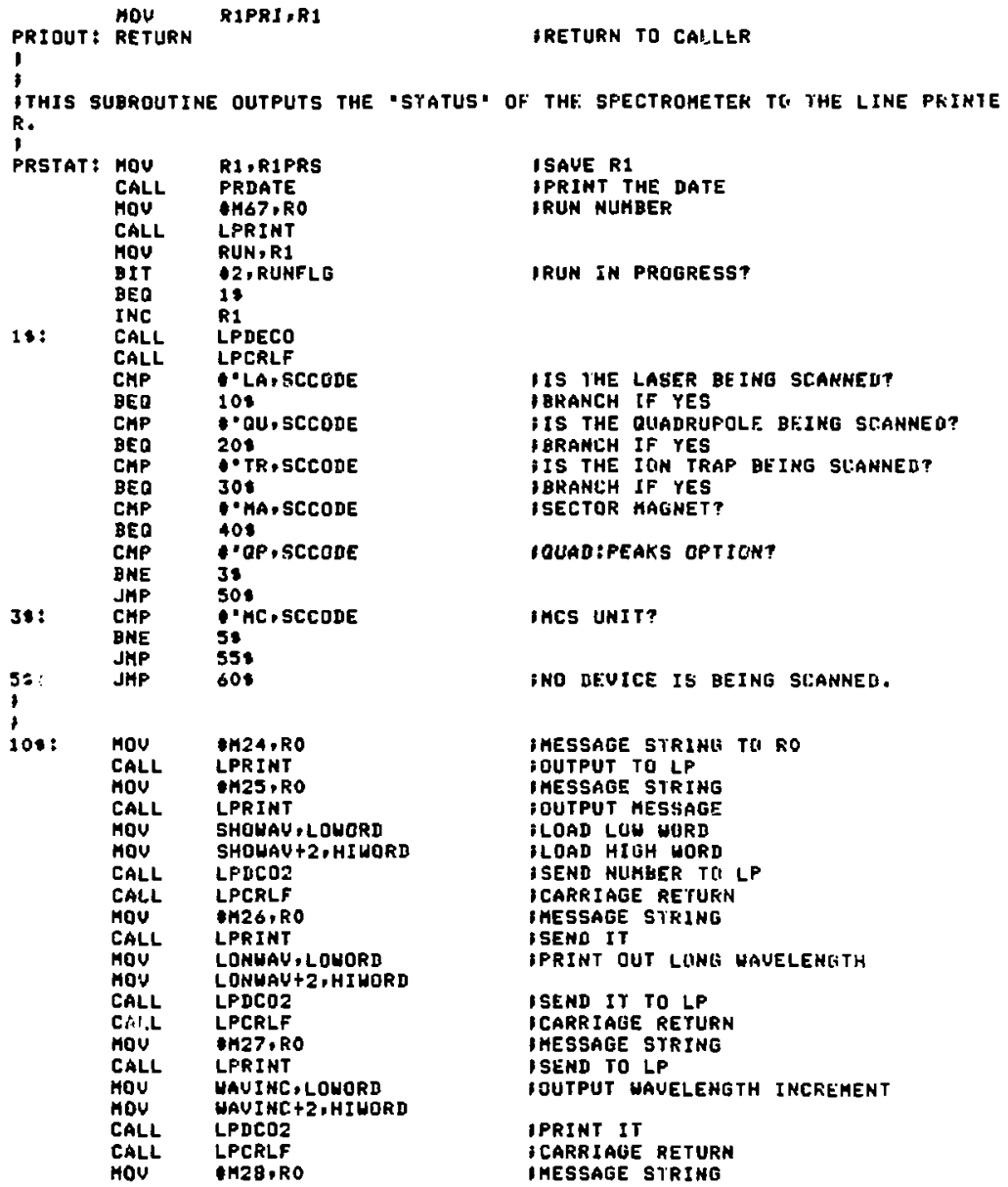




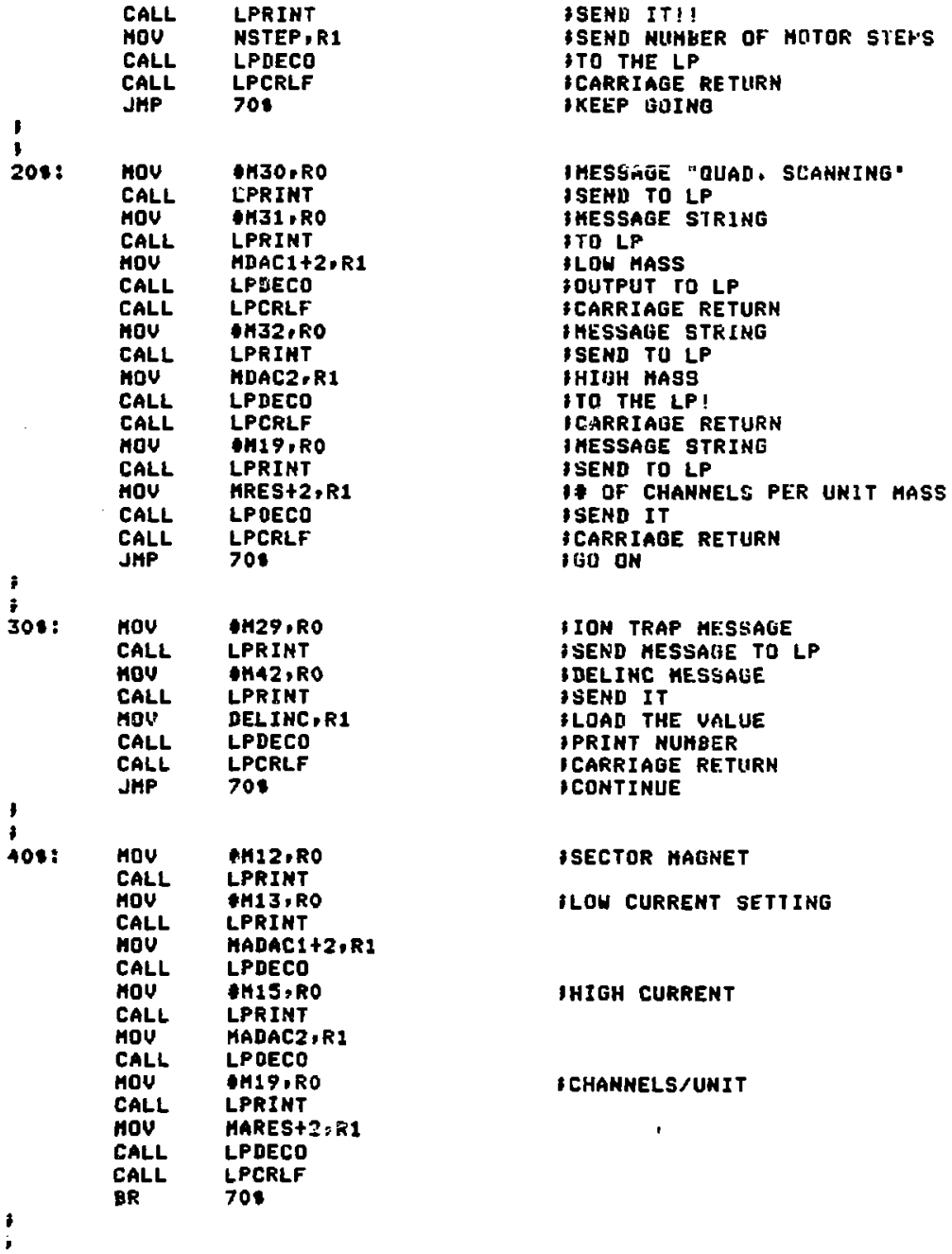




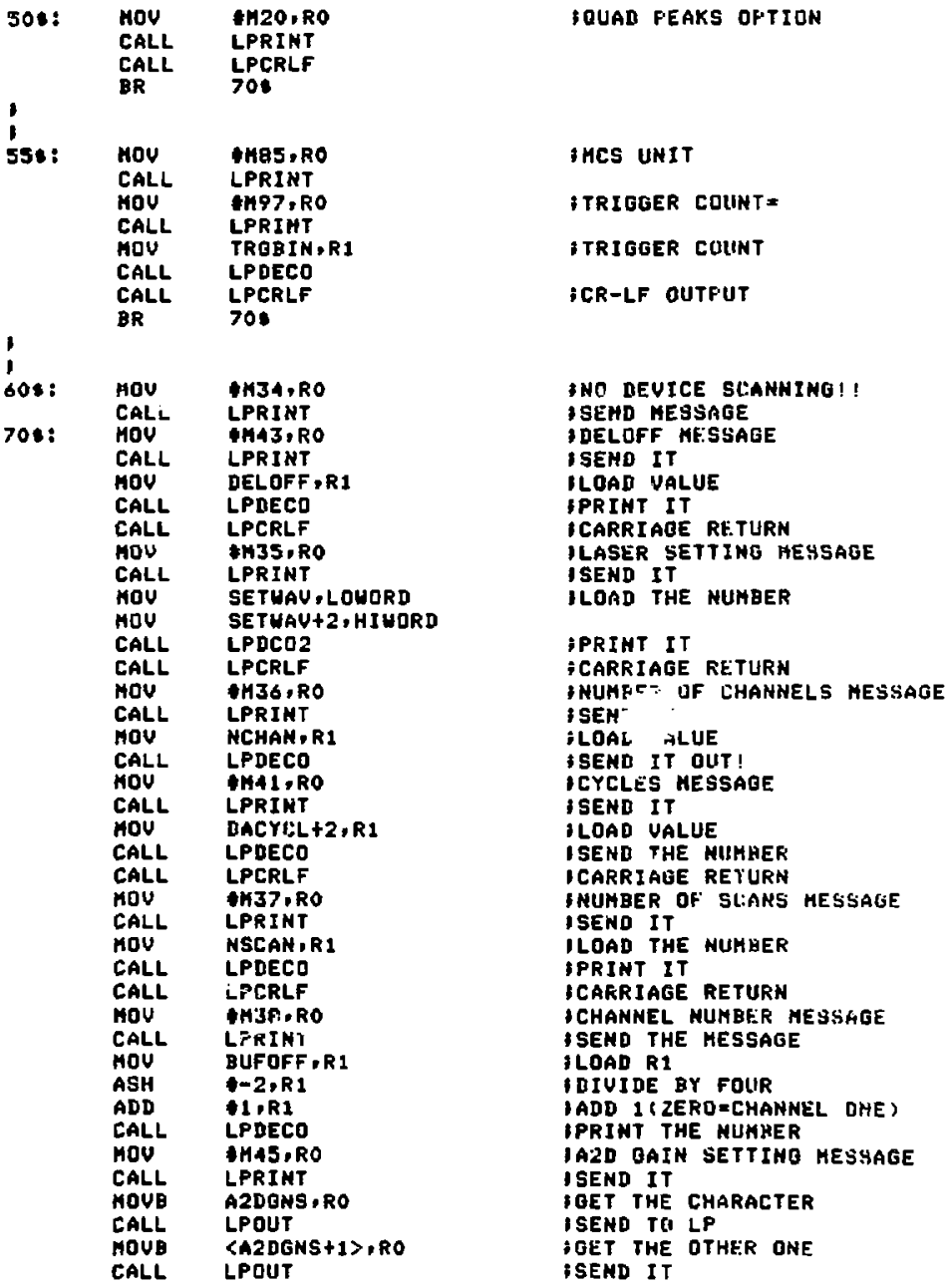




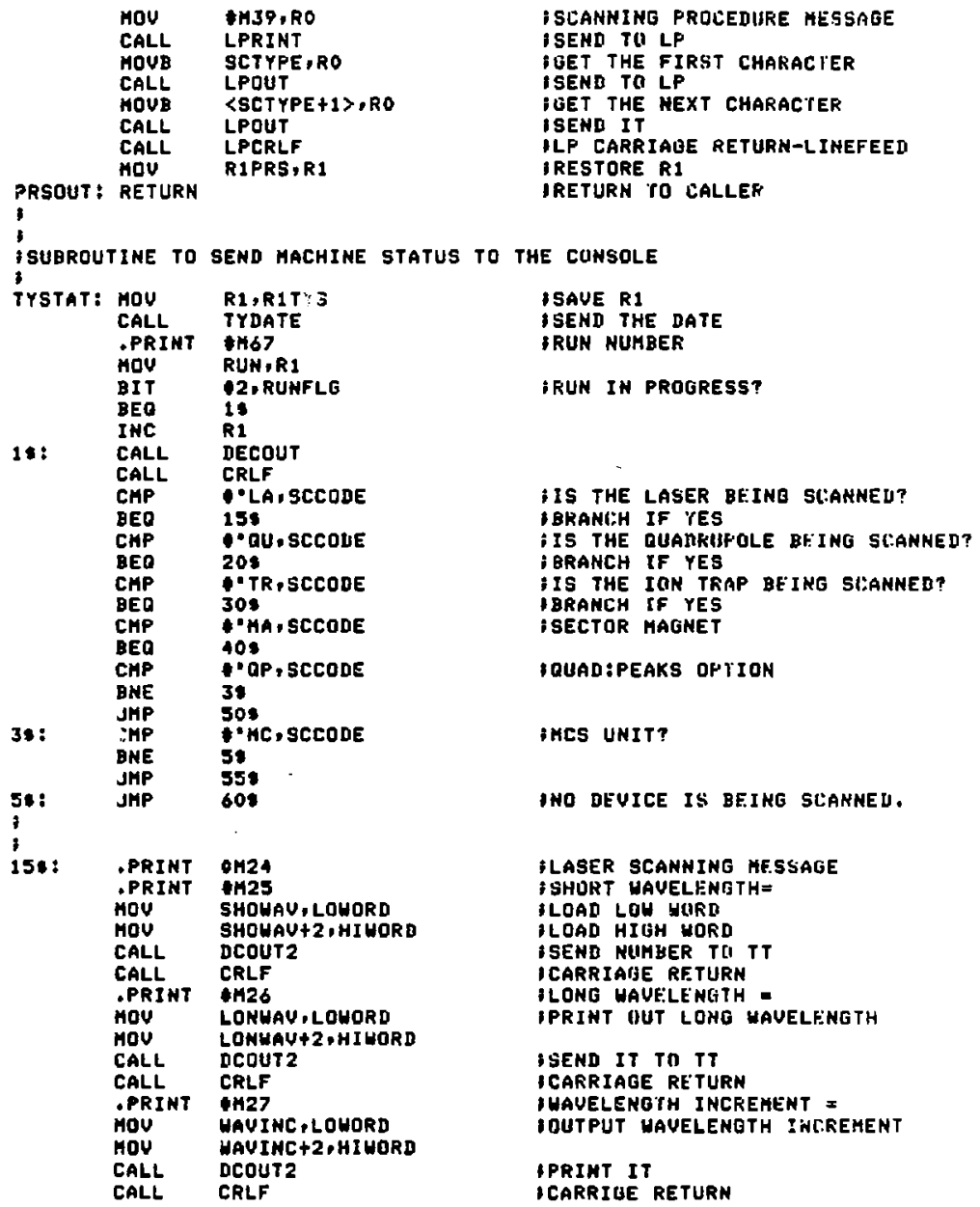




\begin{tabular}{|c|c|c|c|}
\hline & $\begin{array}{l}\text { •PRINT } \\
\text { MOU } \\
\text { CALL } \\
\text { CALL } \\
\text { JHP }\end{array}$ & $\begin{array}{l}\text { OH2G } \\
\text { NSTEP, RI } \\
\text { DECOUT } \\
\text { CRLF } \\
\text { PO: }\end{array}$ & $\begin{array}{l}\text { INUHBER OF MUTUR STEPS = } \\
\text { ISEND NUMRER IJF MOTUR STEPS } \\
\text { ITO THE TT } \\
\text { ICARRIALE RETURN } \\
\text { IKEEP OUING }\end{array}$ \\
\hline \multicolumn{4}{|r|}{ 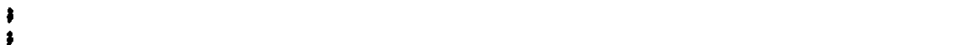 } \\
\hline 20s: & $\begin{array}{l}\text { PRINT } \\
\text { PRINT } \\
\text { HOU } \\
\text { CALL } \\
\text { CALL } \\
\text { PRINT } \\
\text { HOU } \\
\text { CALL } \\
\text { CALL } \\
\text { PPRINT } \\
\text { MOU } \\
\text { CALL } \\
\text { CALL } \\
\text { JMP }\end{array}$ & 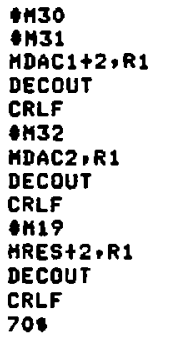 & 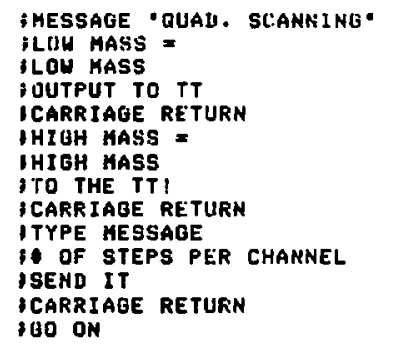 \\
\hline \multicolumn{4}{|r|}{ - } \\
\hline $30 s:$ & $\begin{array}{l}\text { PRINT } \\
\text { PRINT } \\
\text { MOU } \\
\text { CALL } \\
\text { CALL } \\
\text { JHP }\end{array}$ & $\begin{array}{l}\text { PH29 } \\
\text { OHA2 } \\
\text { DELINC, RI } \\
\text { DECOUT } \\
\text { CRLF } \\
\text { 7O\$ }\end{array}$ & $\begin{array}{l}\text { IION TKAP KESSAGE } \\
\text { IDELINC MESSAGE } \\
\text { ILOAD THE VALUE } \\
\text { iPRINT NUMGER } \\
\text { ICARR IAGE RETURN } \\
\text { ICONTINUE }\end{array}$ \\
\hline \multicolumn{4}{|r|}{ (5). } \\
\hline \multicolumn{4}{|r|}{ ISECTOR HAGNET } \\
\hline 40\$: & $\begin{array}{l}\text {-PRINT } \\
\text { PRINT } \\
\text { HOU } \\
\text { CALL }\end{array}$ & $\begin{array}{l}\text { M12 } \\
\text { OH13 } \\
\text { MADAC1 + 2, R1 } \\
\text { OECOUT }\end{array}$ & $\begin{array}{l}\text { ISECTOR MAGKET } \\
\text { ILUH CURRENT }\end{array}$ \\
\hline & $\begin{array}{l}\text { PPRINT } \\
\text { MOU } \\
\text { CALL }\end{array}$ & $\begin{array}{l}\text { M15 } \\
\text { MADAC2,R1 } \\
\text { DECOUT }\end{array}$ & IHIOH CURRENT \\
\hline & $\begin{array}{l}\text { MPRINT } \\
\text { MOU } \\
\text { CALL } \\
\text { CALL } \\
\text { BR }\end{array}$ & $\begin{array}{l}\text { PH19 } \\
\text { MARE } 5+2, R 1 \\
\text { DECOUT } \\
\text { CRLF } \\
\text { 708 }\end{array}$ & CHANNELS/UNIT \\
\hline \multicolumn{4}{|c|}{80} \\
\hline 50:: & $\begin{array}{l}\text { PPRINT } \\
\text { CALL } \\
\text { BR }\end{array}$ & $\begin{array}{l}\operatorname{maO} \\
\text { CRLF } \\
708\end{array}$ & IOUAD:PEAKS OFTIOH \\
\hline \multicolumn{4}{|c|}{ Nor } \\
\hline 55: : & $\begin{array}{l}\text { PPRINT } \\
\text { PPRINT } \\
\text { MOU } \\
\text { CALL } \\
\text { CALL }\end{array}$ & $\begin{array}{l}\text { HES } \\
\text { HM97 } \\
\text { TRBBIN,RI } \\
\text { DECOUT } \\
\text { CRLF }\end{array}$ & $\begin{array}{l}\text { HCS UNIT } \\
\text { ITRIGUER COUNT= } \\
\text { ITRIGGER COUNT } \\
\text { I DECIMAL OUTPUT }\end{array}$ \\
\hline
\end{tabular}




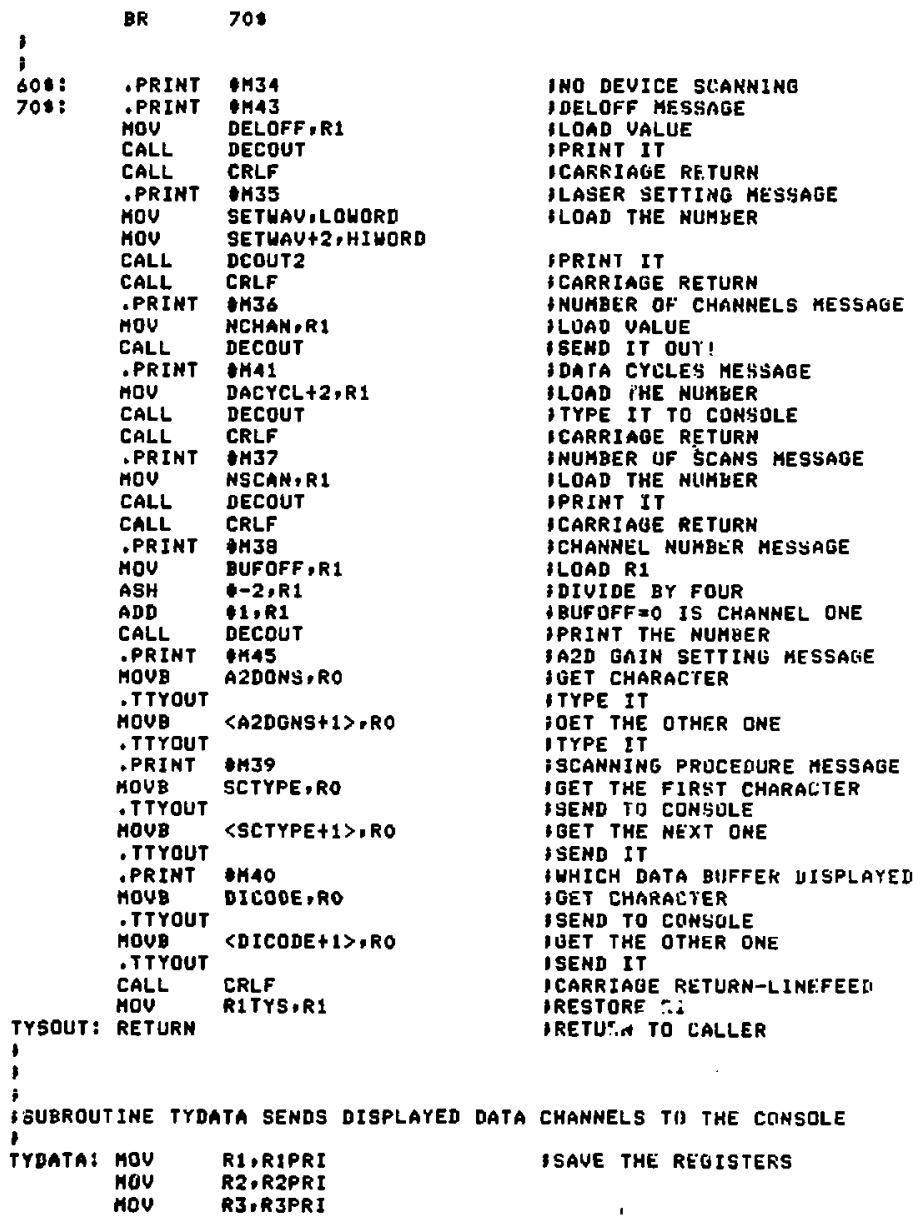




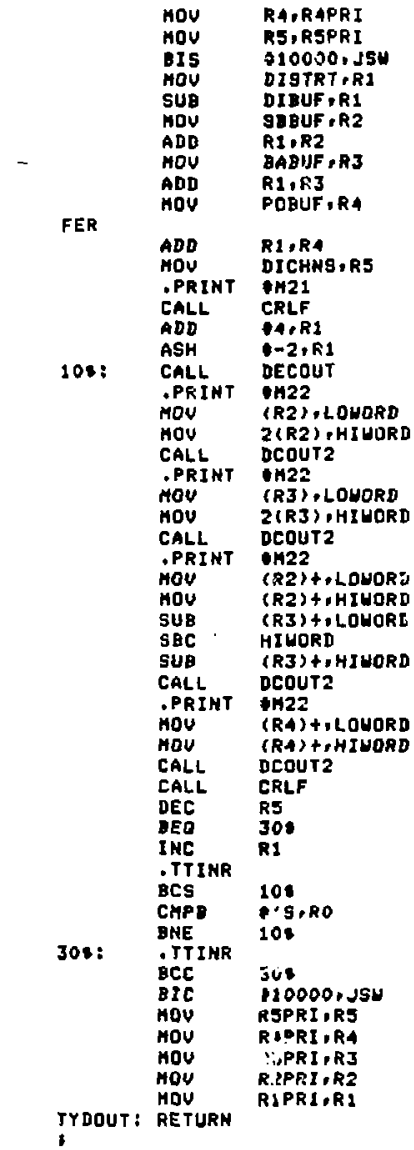

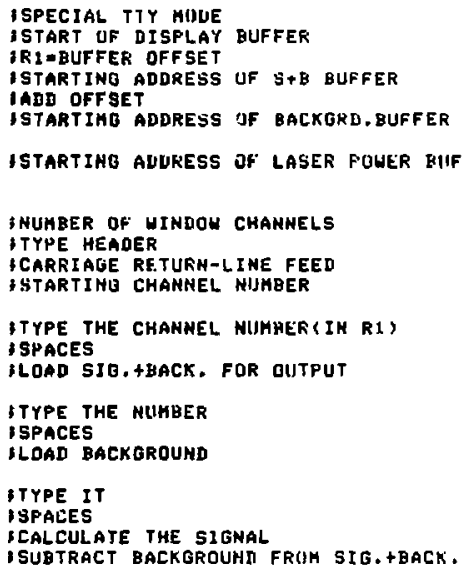

IRETURN TO CALLER 


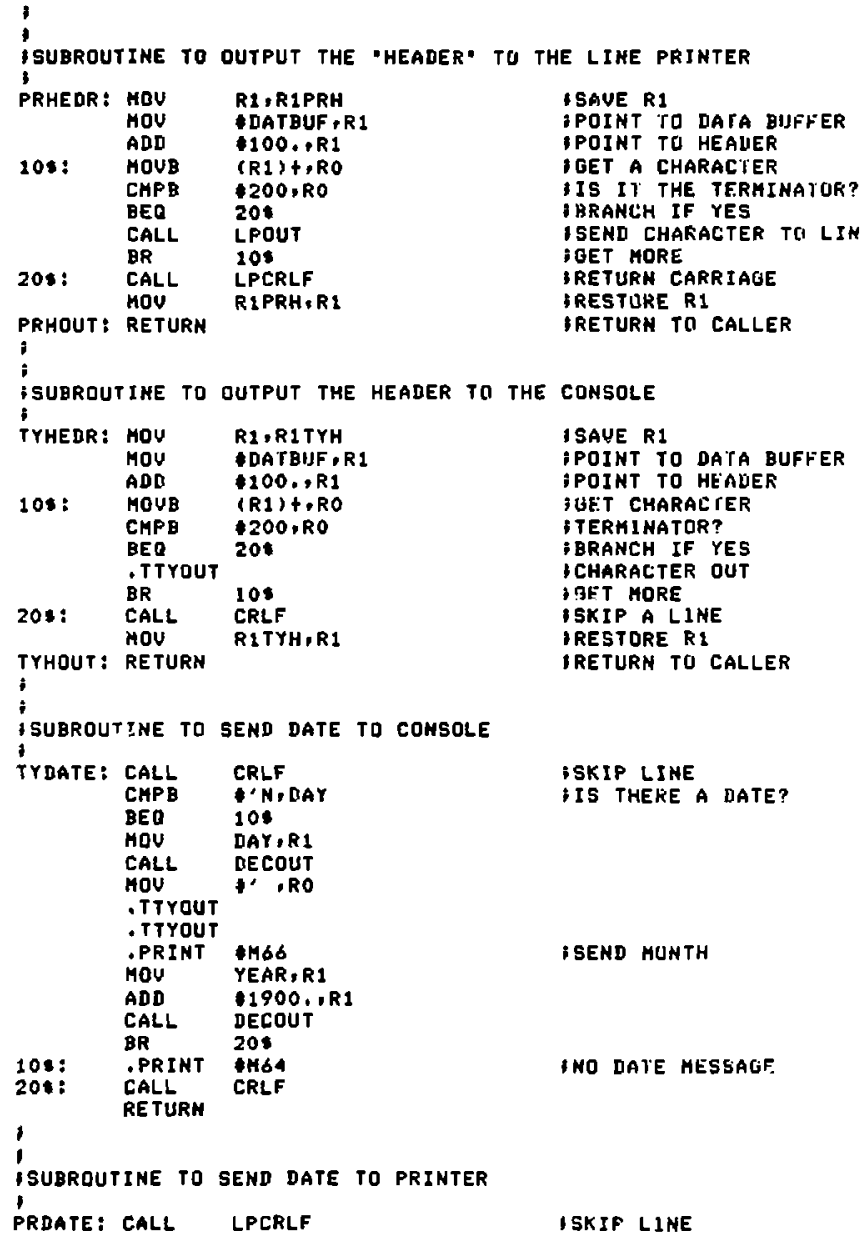




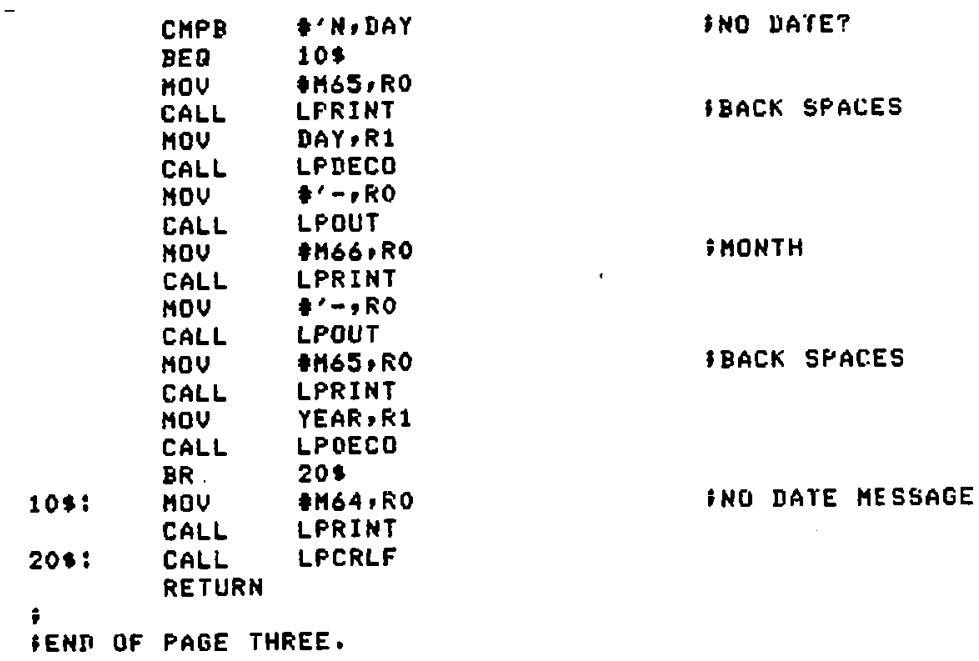




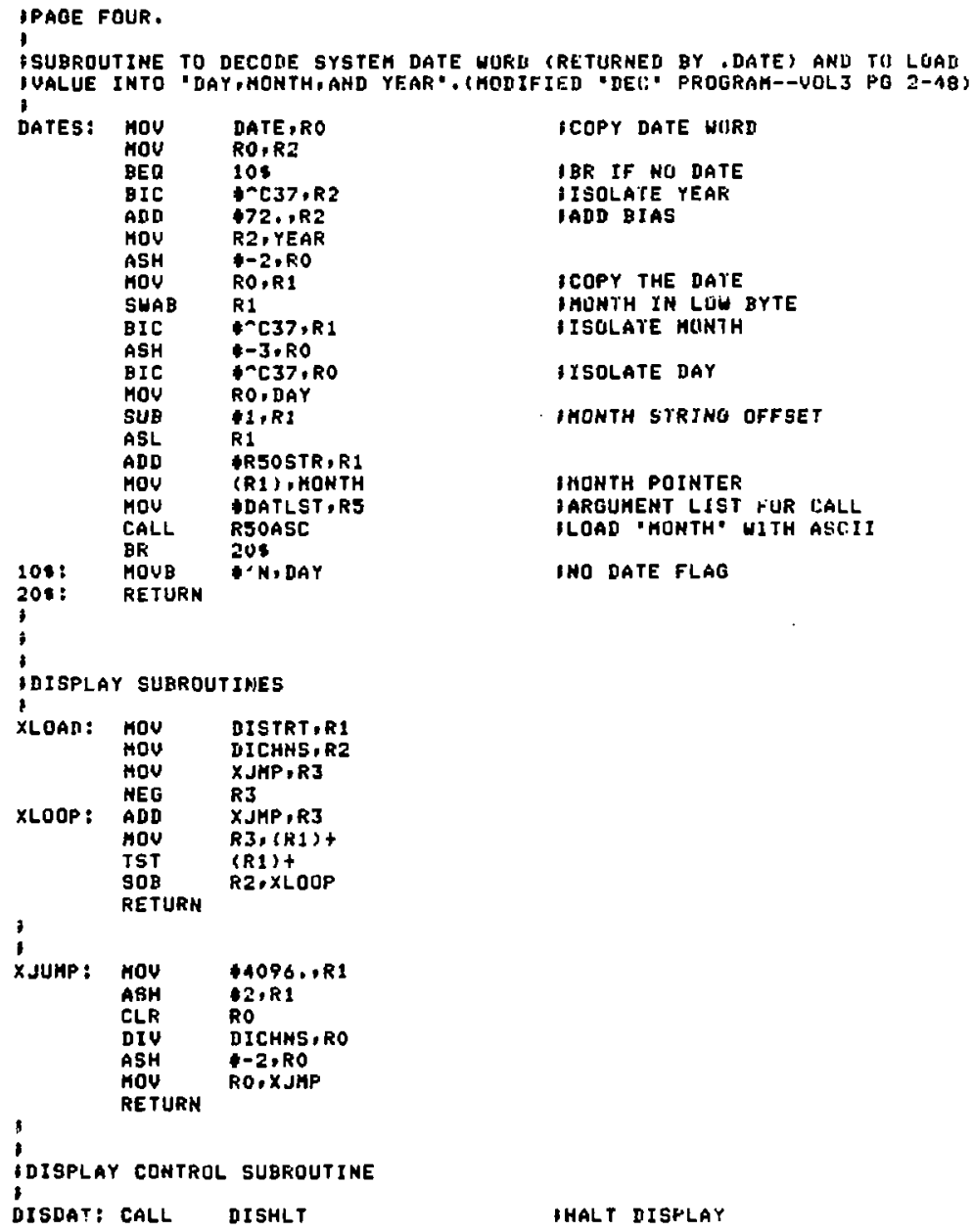

DISDAT: CALL DISHLT IHALT DISFLAY 


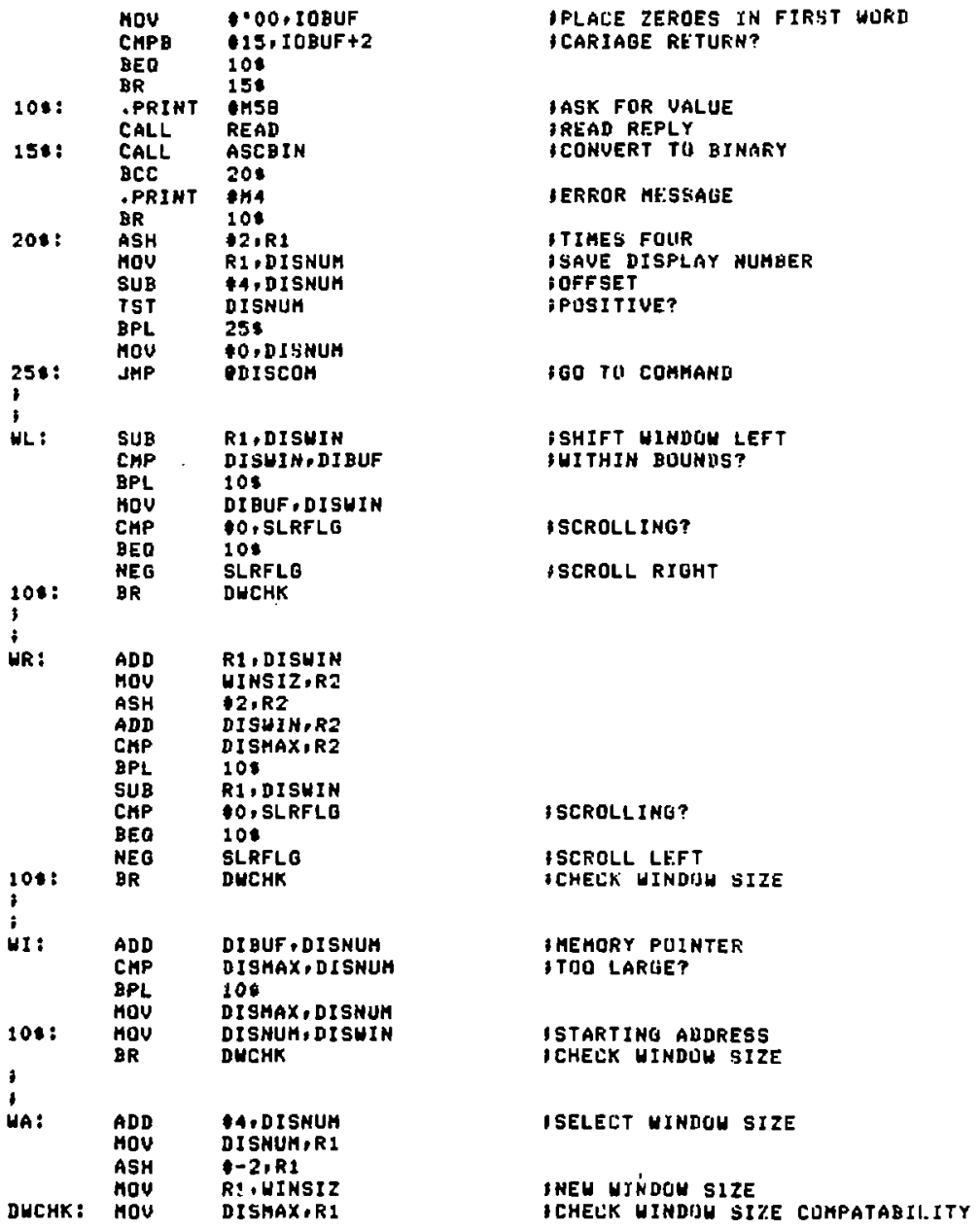




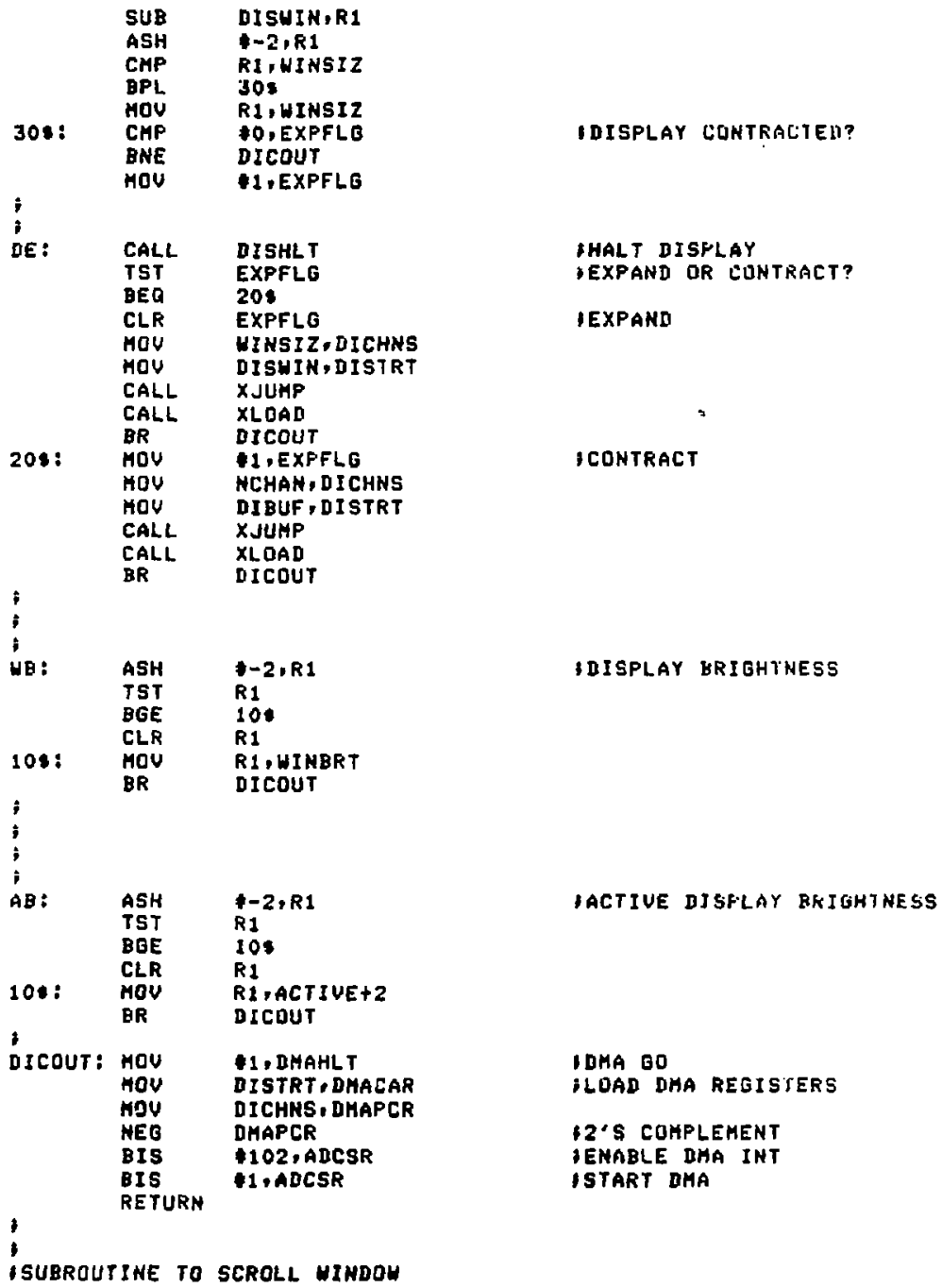




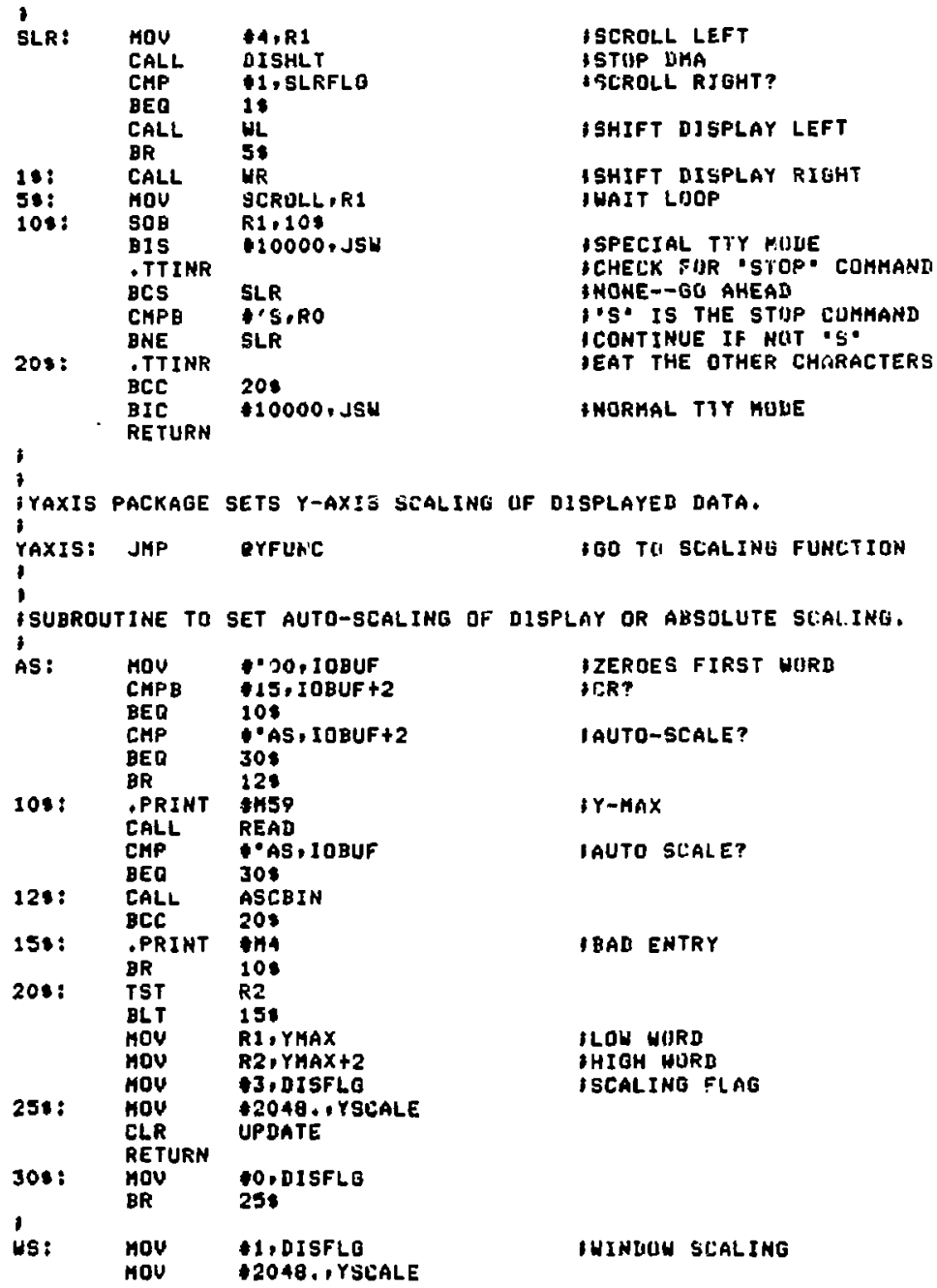




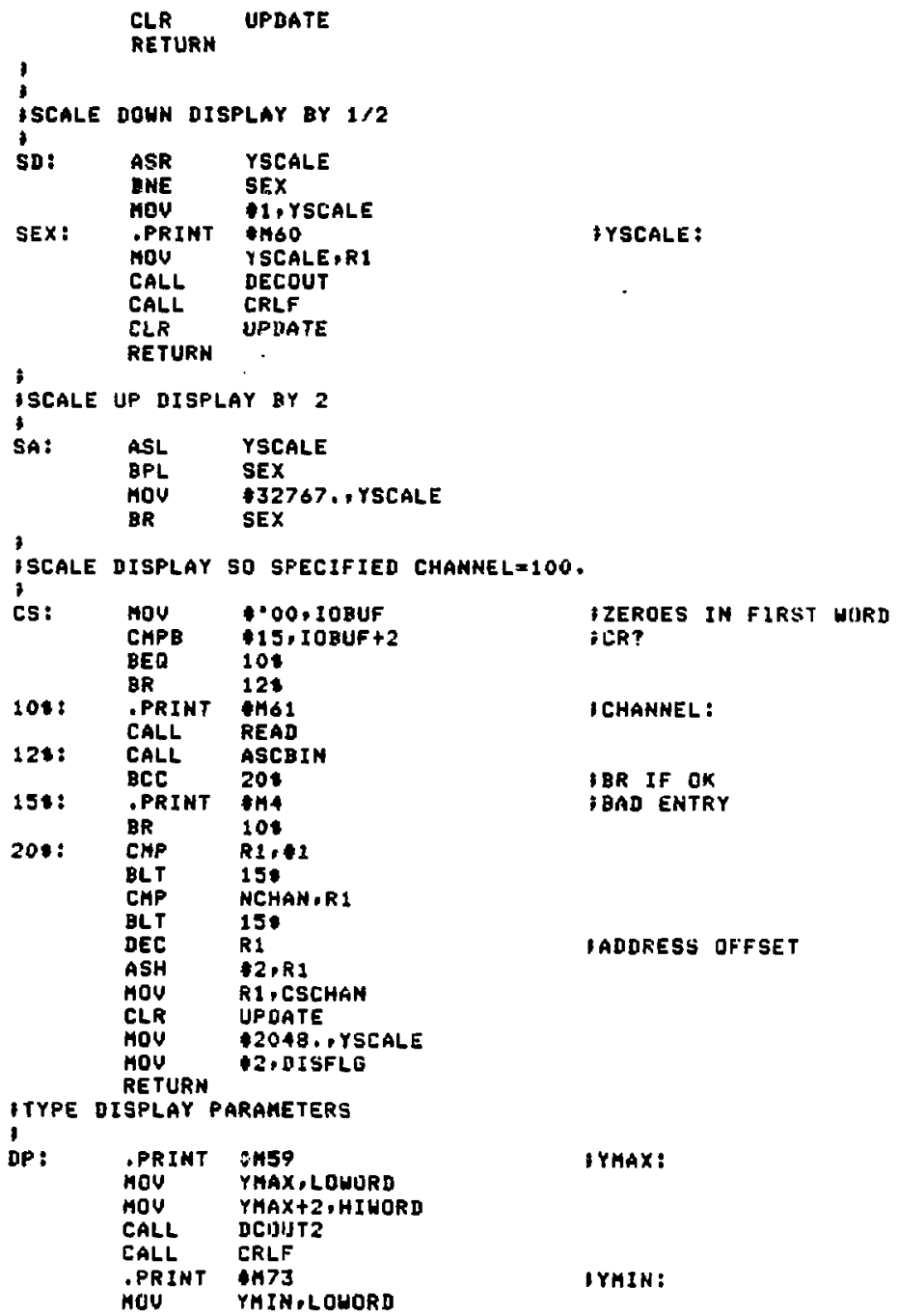




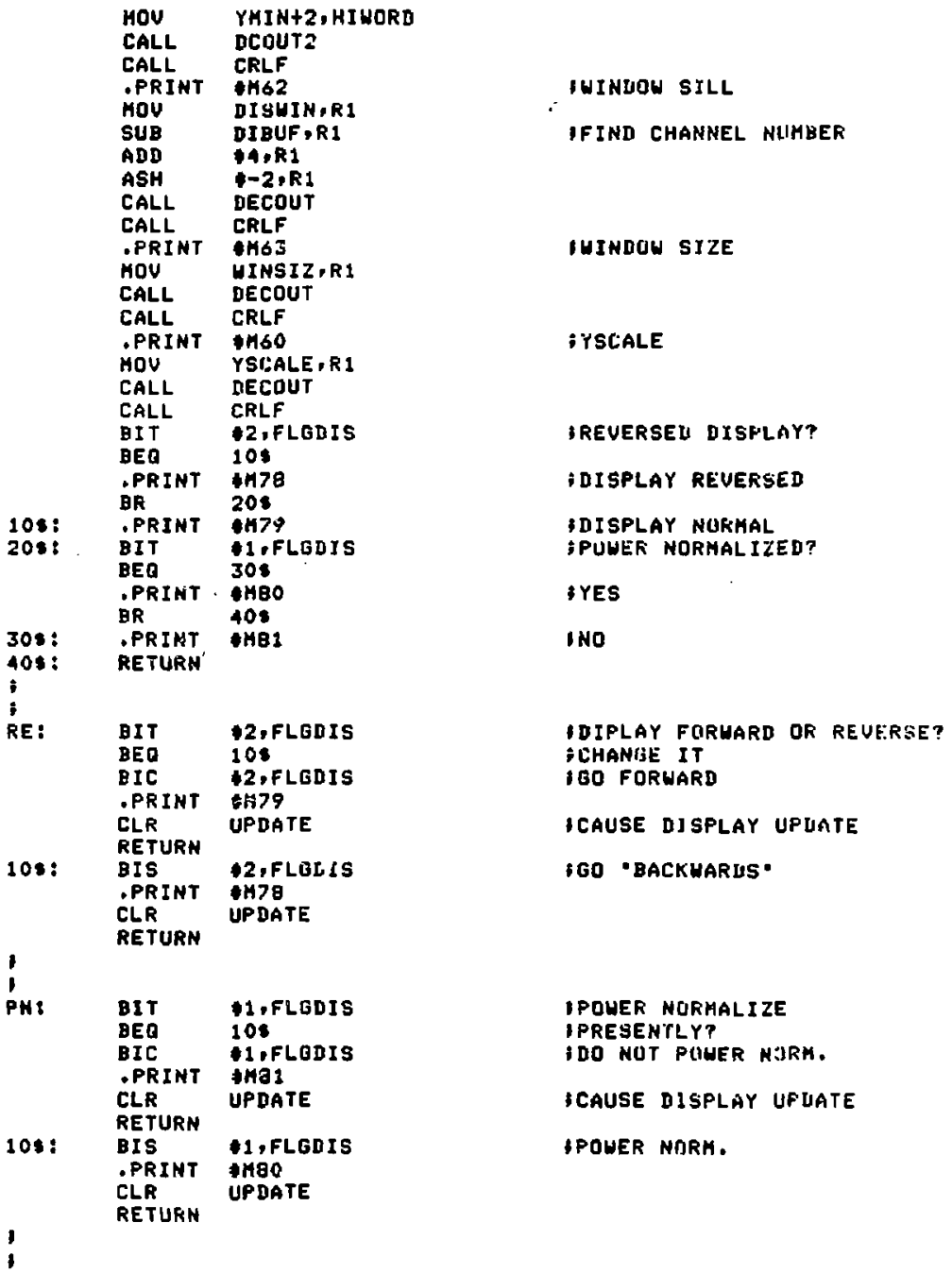




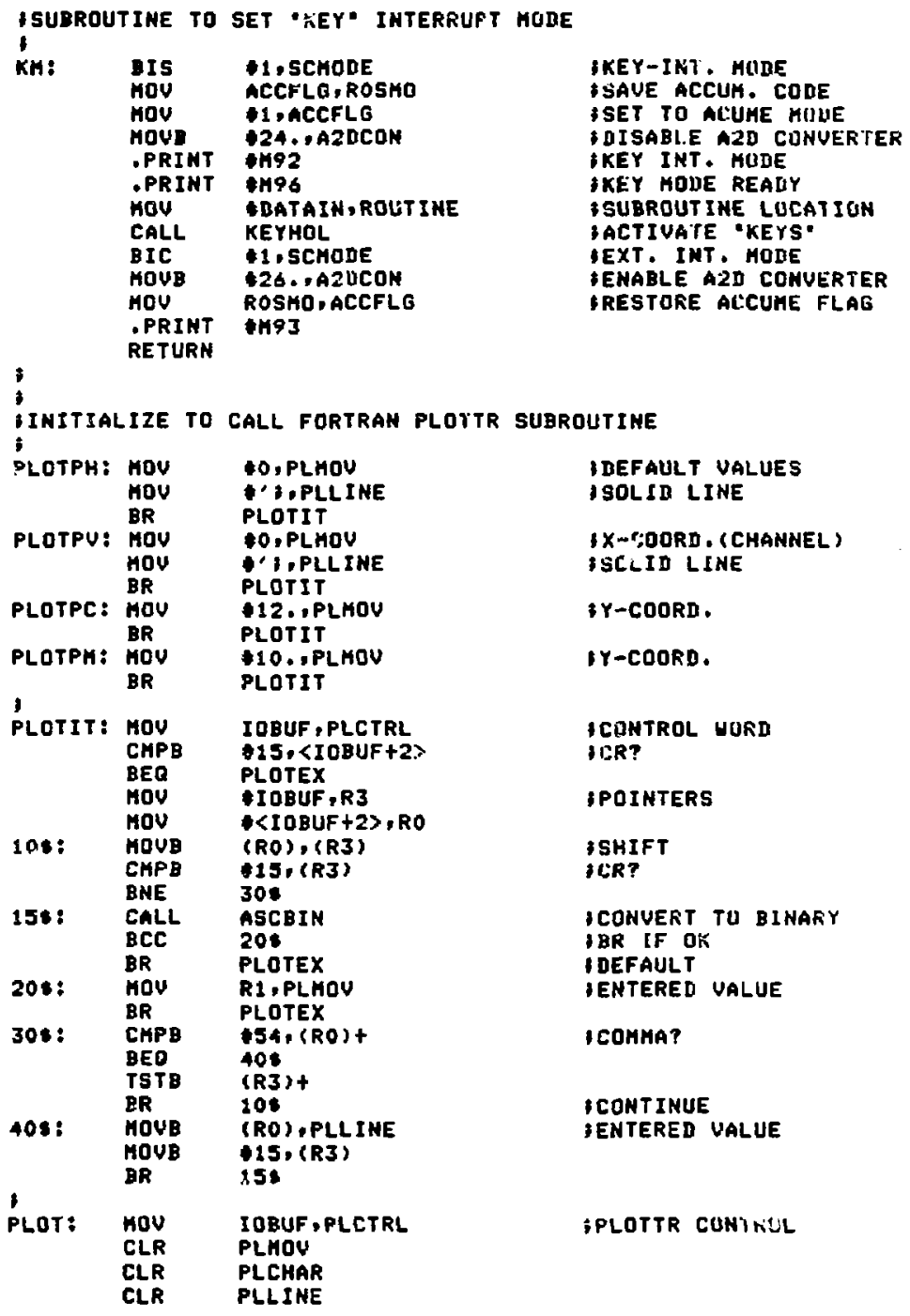




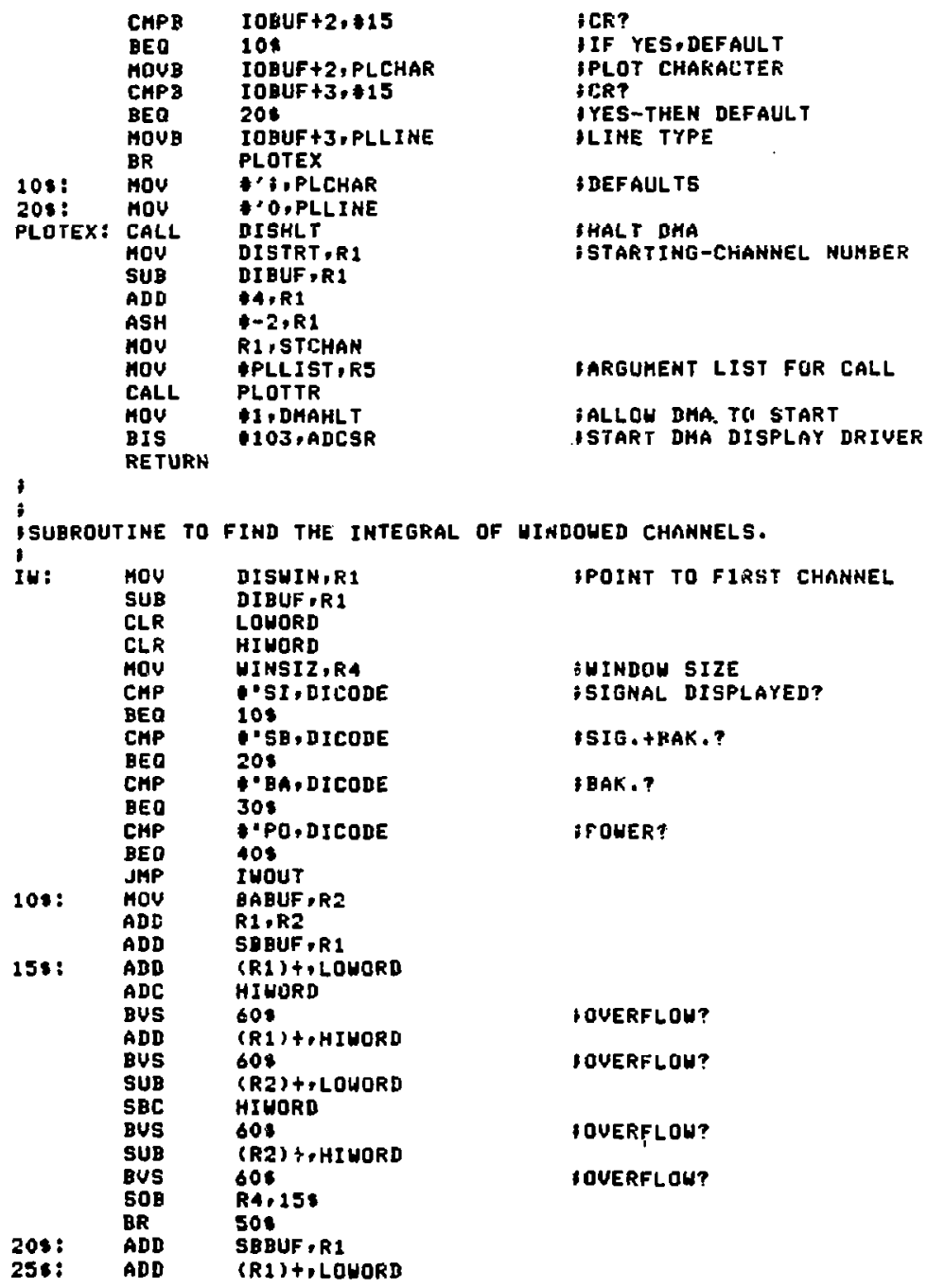




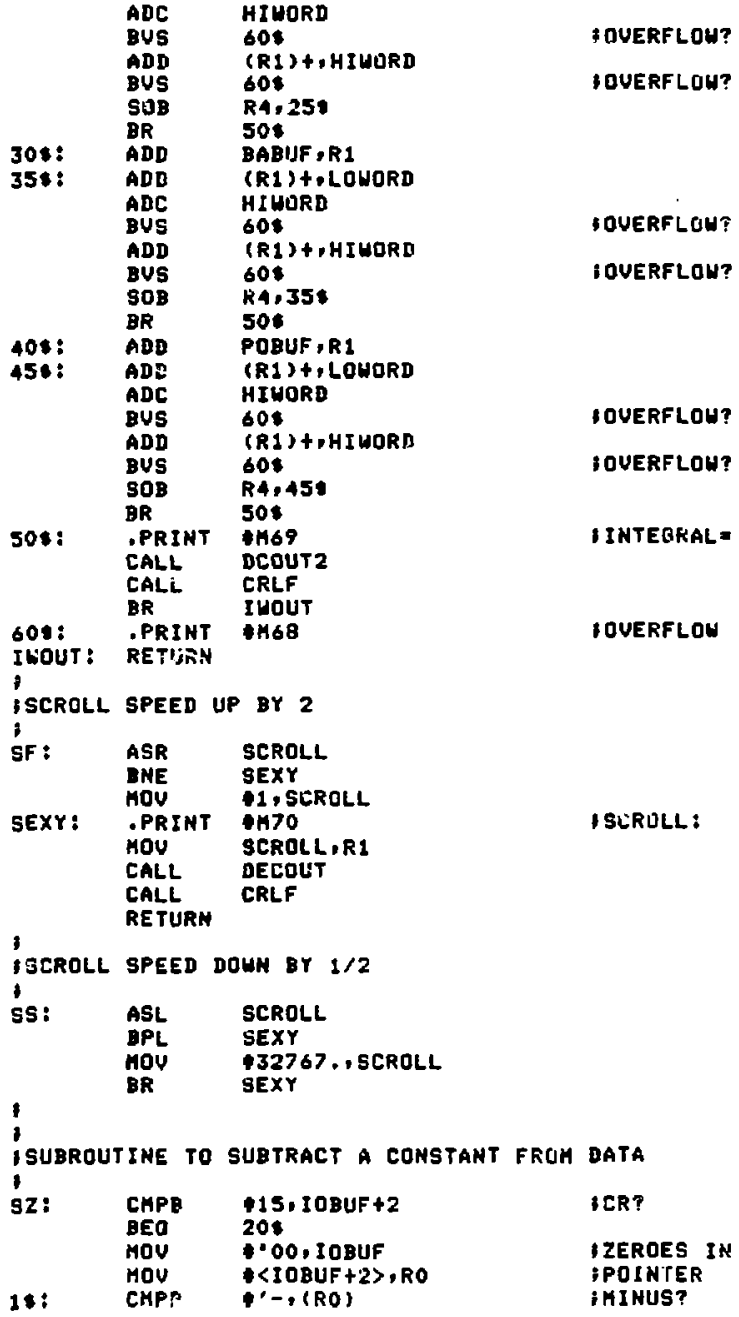




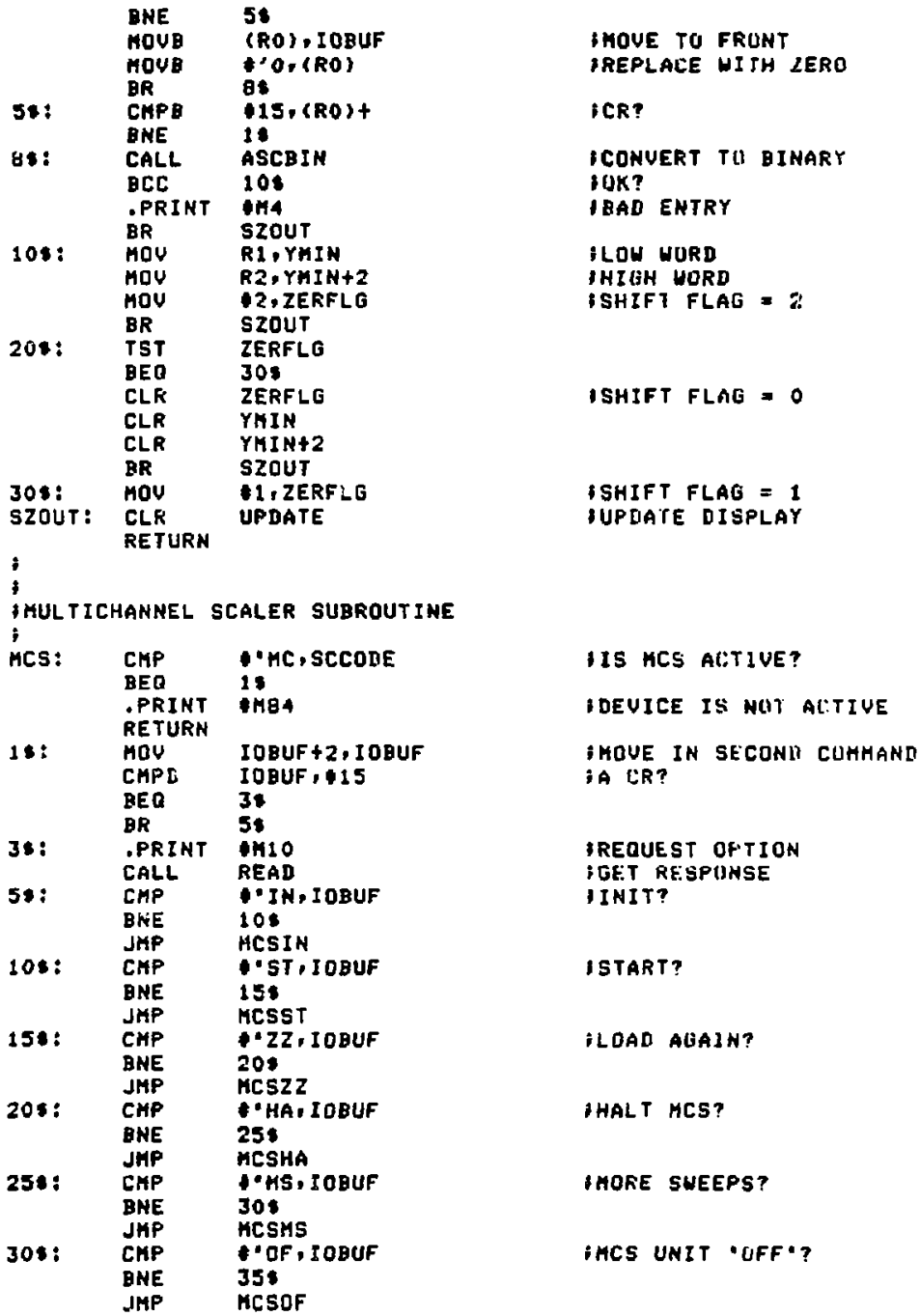




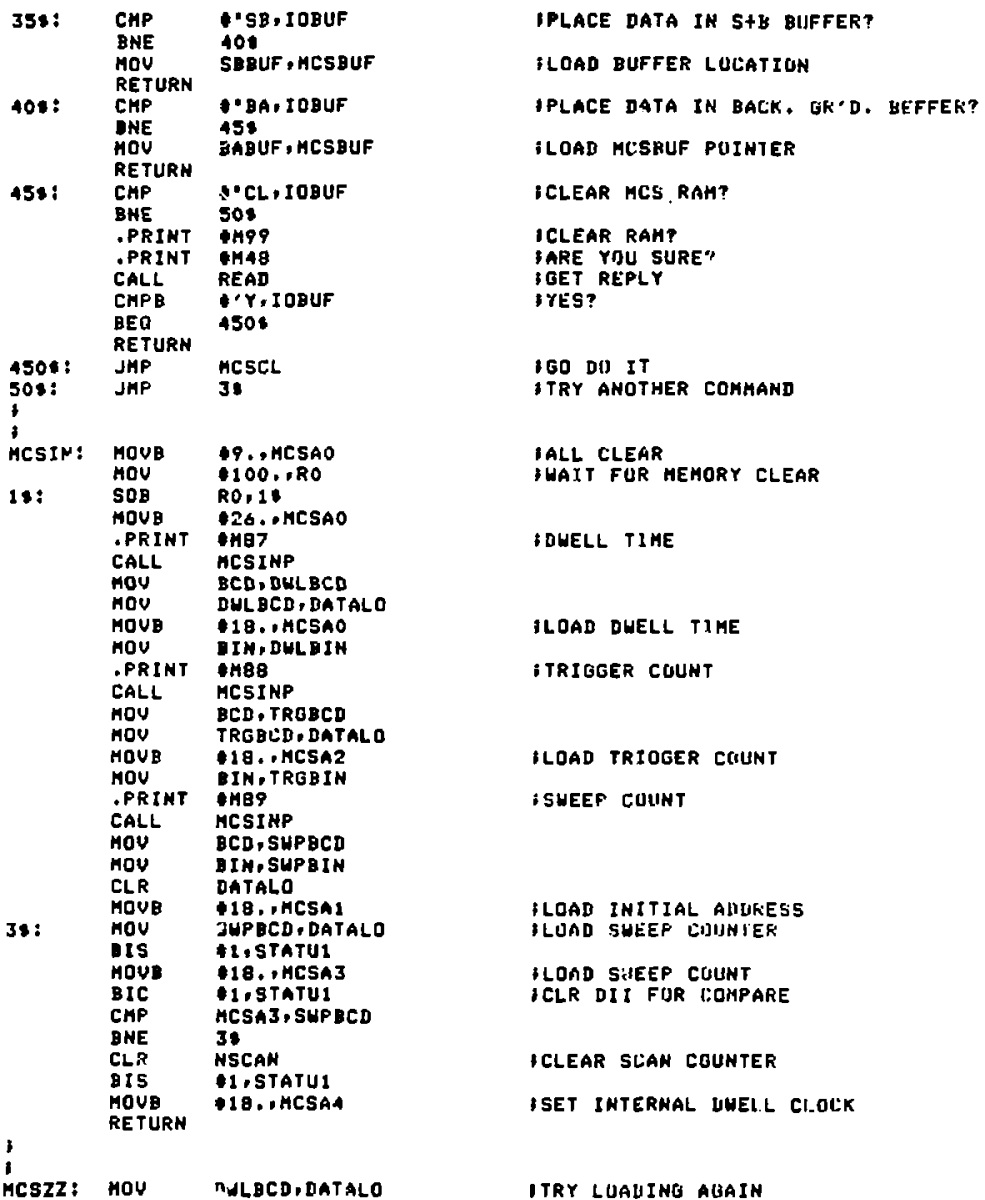




\subsection{7}

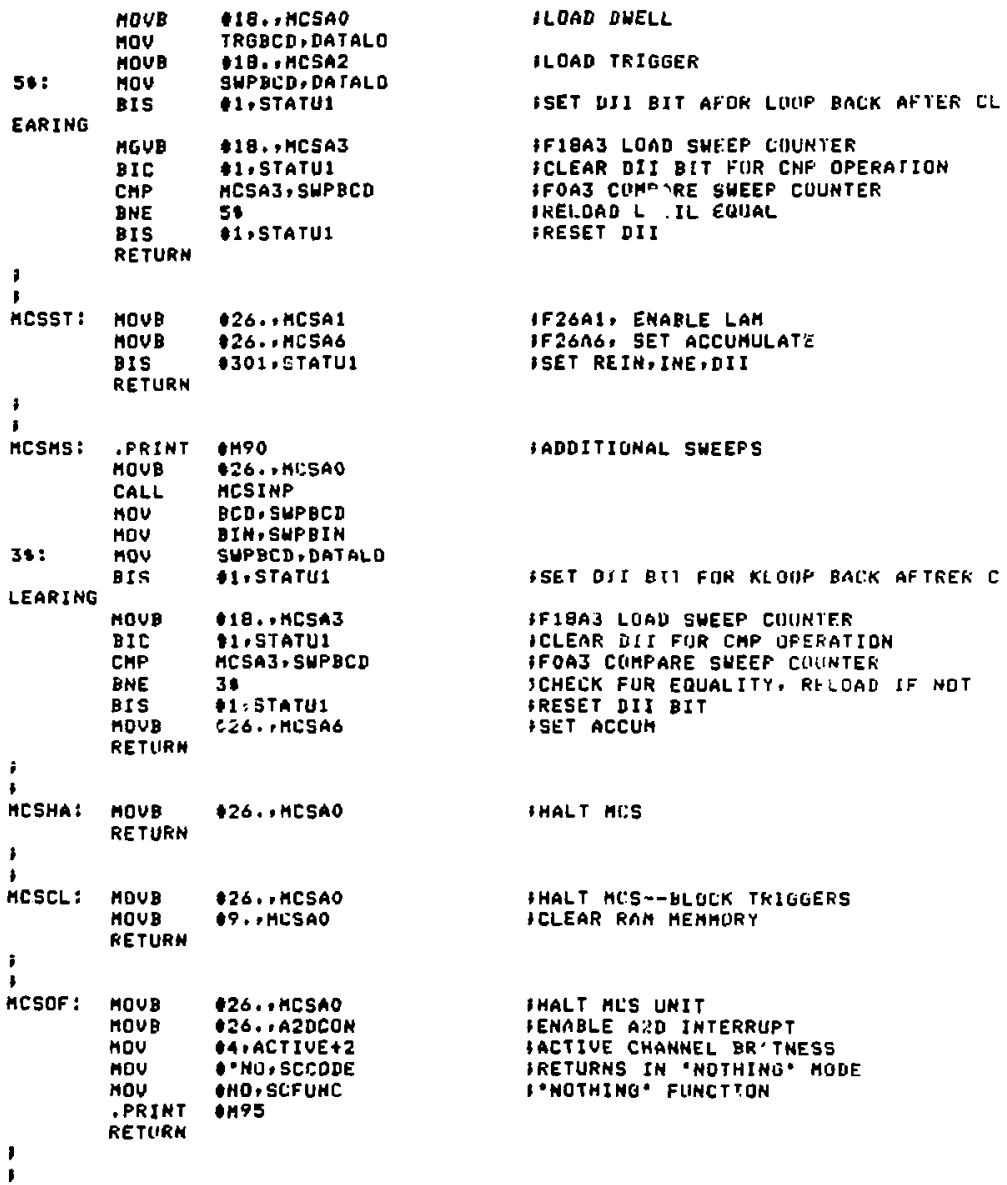




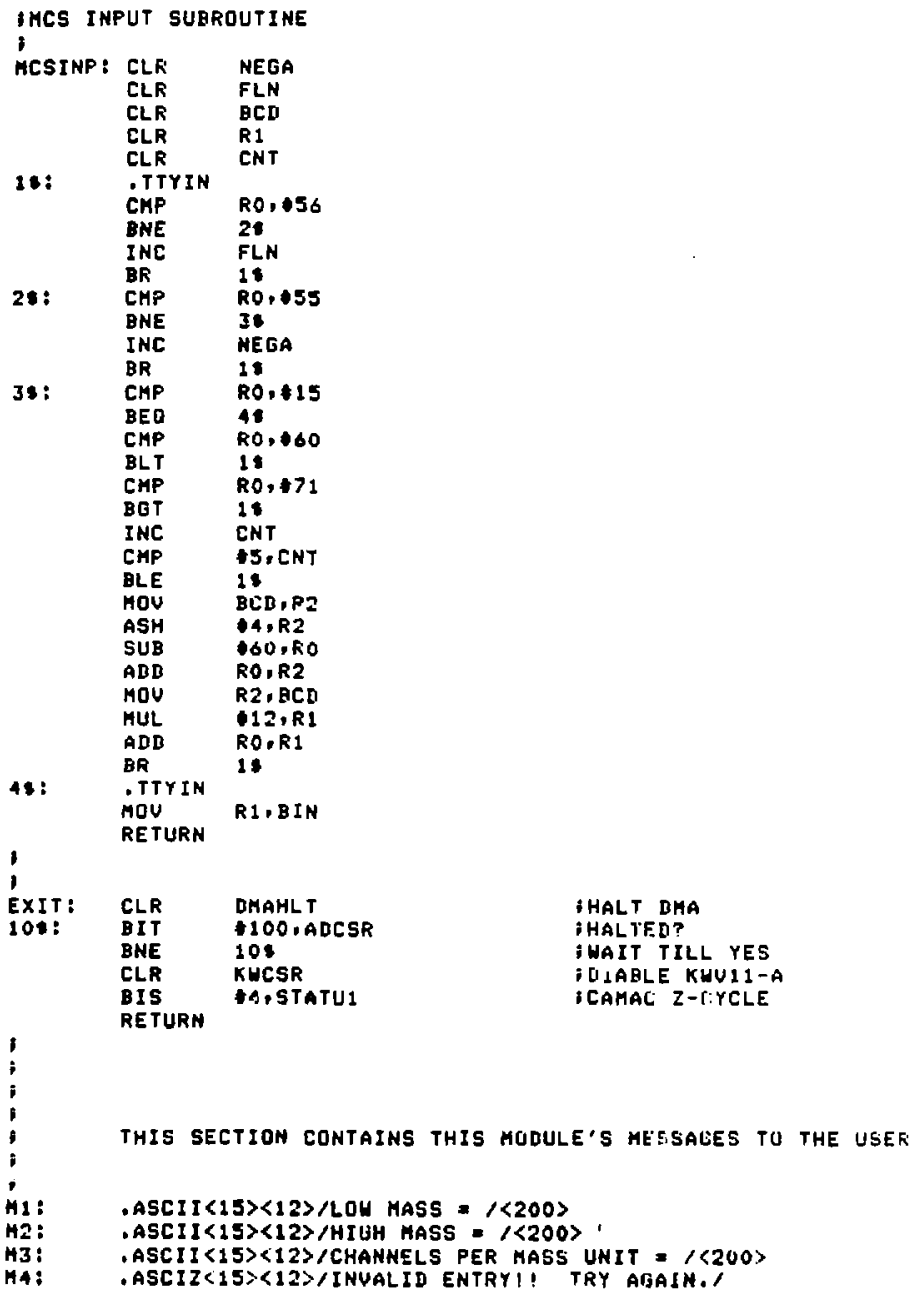




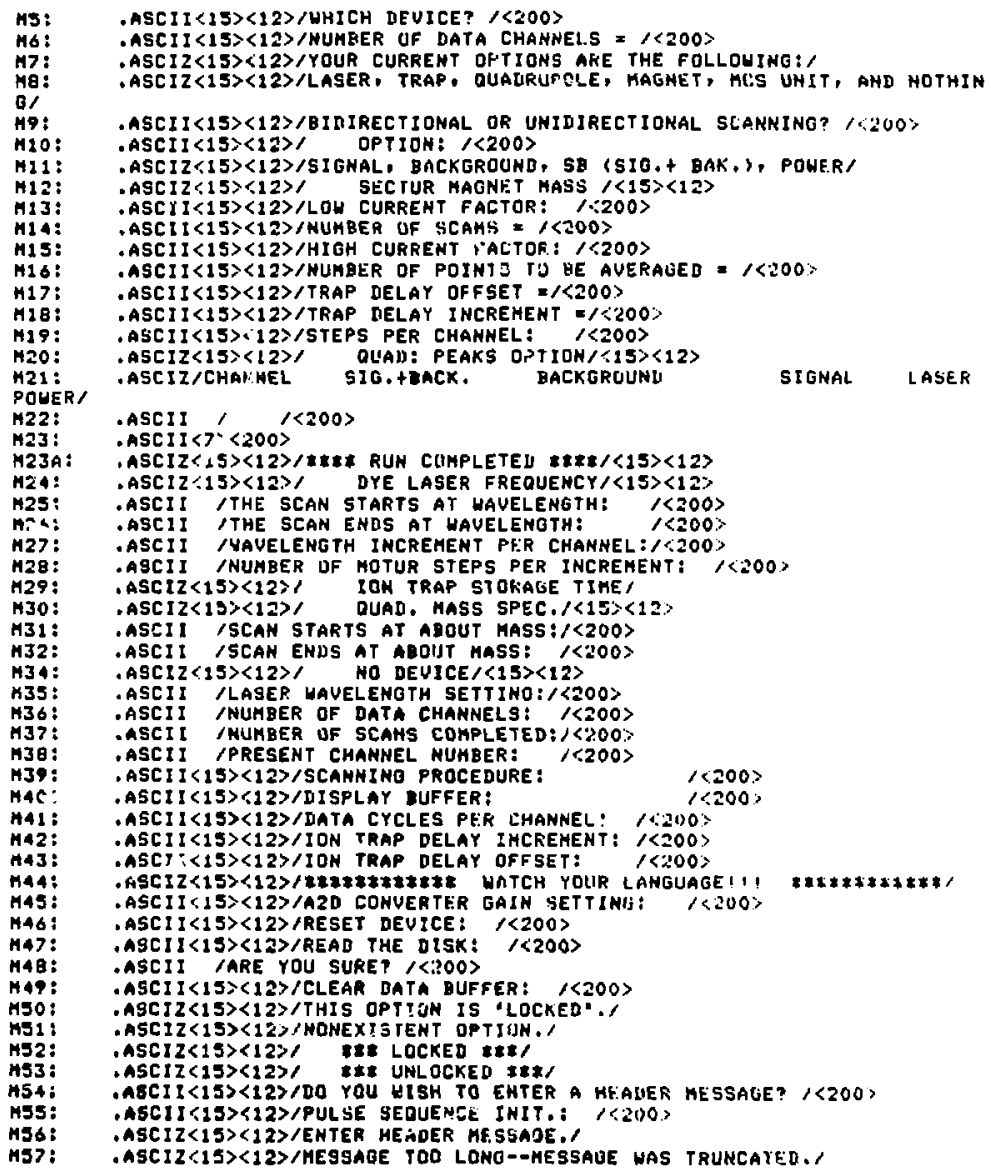




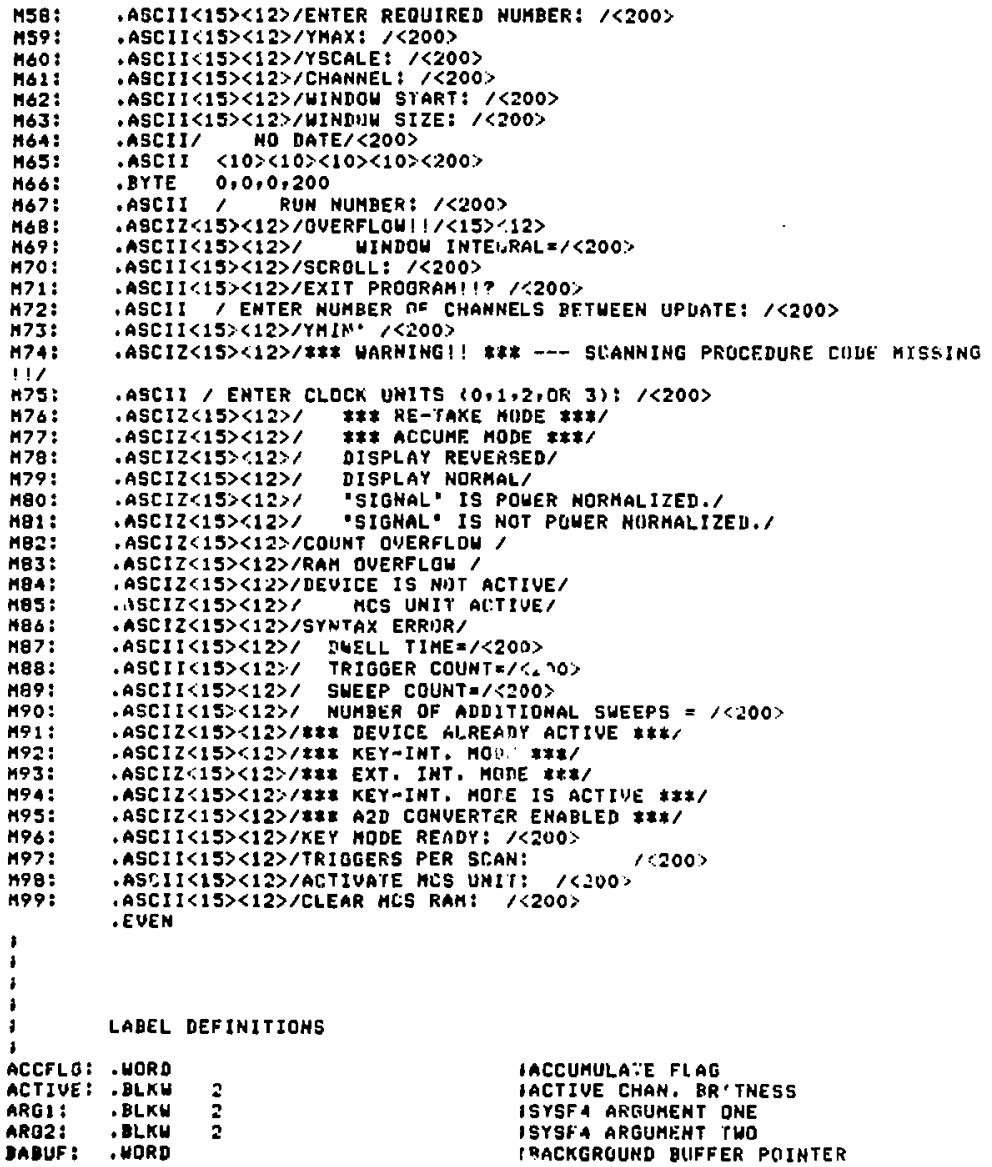




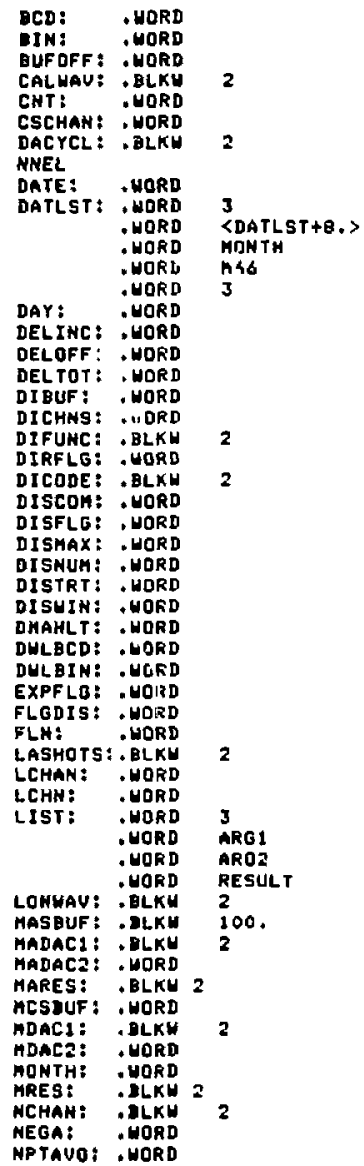

I HCS UHIT

IMCS UNIT

I DATA BUFFER UFFSET

3 CAL I ERATI ON WAVELENGTH

MHES UNIT

ISCALING CHANNEL

IUORDS FUR NUMBER OF OATA CYCLËS/CHA

IPRGgRAK DATE UIRD

ILIST FOR "RSOASI:" SYSFA CALL

IDAY OF THE M(INTH(DATE)

IION STORAGE TIME OFFSET

- TOTAL IUN STORALie TIME

IDISPLAY BUFFER PUINTER

IDISPlay function nuRd

ISCAH DIRECTIUN FLAG

IDISPLAY CUUE UIRO

IDISPLaY comiand WORD

IDISPLaY yaXIS SCALE FI.AG

DISPLAY BUFFER MAX

IDISPLAY COHHAHL NUIMEER

IDISPLAY START-FDR XLUAD

IDISPLAY UINUOW STARTING ADURESS

I DHA "NALT" MURD

I MCS UNIT

DDISPLAY EXPAHD FLAG

ISECOHD DJSPLAY FLAG.

IHCS UNIT

INUME-X IF LASER SHOTS

1 dF addresses to lasi chanNel

DLAST AUERABED DATA CHANHEL

IARAUMENT LIST FUR SYSFA I:ALLS

ILONG MAVELENGTH

HUFFER FUR MASS PEAKS

ILOU VALUE FUR SECTOR MALIKET

IHIJH VALUE FOR SECTIIR MAUNET

ISECTOR MAONET RESOLUTIUA UURI

IHLS UAIT MATA BUFFER POTNTER

HLOU MASS FOR QUADRUPOLE

IHITH MAGS FUUR QUADRUPOLE I HONTHCDATE)

IOUAD. RESOLUTIUN HDRD

I HUHEER OF OATA CHAKNELS

IMCS UNIT

INUABER OF POINTS AUERAGED 


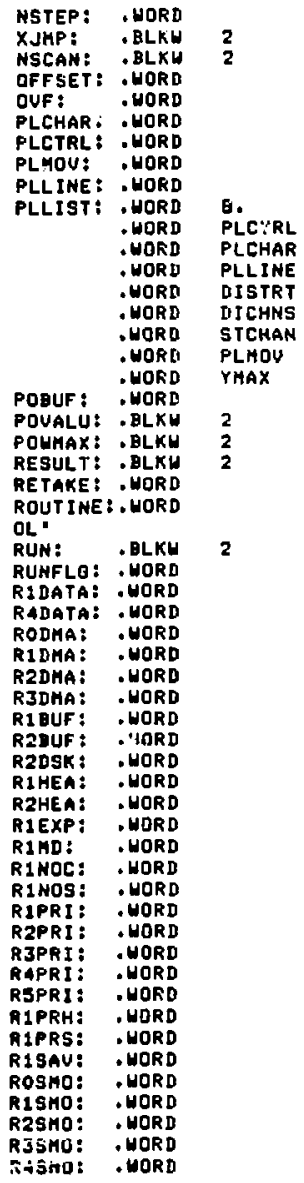

IMUHBER IJF MOTIR STEPS

IX-AXIS INCREHENT VALUE

INUMAER DF DATA MI:ANS

IOFFSET IN SUBROUTINE SHOOTH

I HE:S UNIT

iPLOT CHARACTER

IPLOTTER CONTRILL WORD

IPLOT HOVERENT

IPLOT LIHE TYFE

iaro. List far plotTer call

\author{
I POWER SLIFFER POIHTER \\ i poller chanNel value \\ IPOUER BUFFER MAX. \\ ISYSF A RESULT WURIIS \\ IRETAKE MUDE FLAG \\ ICONTAING SIJB-RIN LDCATIIIN FIJR 'KEYH \\ IRUN NUKKER WIIRD \\ BRUN COMPLETED FLAG \\ ISAVE WORDS FOR 'DATAIN" \\ BSAUE HORUS FOR "IMMAIKT"
}

iREGISTER SAUE SIIBROITINE BUFJHIT

1REG. SAVE FOR DISK IHPLIT, OIITPUIT

IREOS. SAUE SIJRIJUTIHE "HEADER"

IREGISTER SAVE SIJBROUTINE "EXPAND" IREGISTER SAVE 'MD' SU8RIIITINE iREG. SAUE SIIBROLIT IME - NOCYCL.

IREO. SAVE SUBRUUTINE "NISIEN"

IREG, SRUE SUBROUTIHE 'PRINT.

IAND SUQRIUTIHE 'TYOATA'

IREG. SAVE FOR SUYROUTIME PKTITL IREG. SAUE FISR SUBROUTIME PRSTAT IREG. SAVE GKiNERAL USE IREg. SAVE SUBROUTIAE "SMUIITH" 


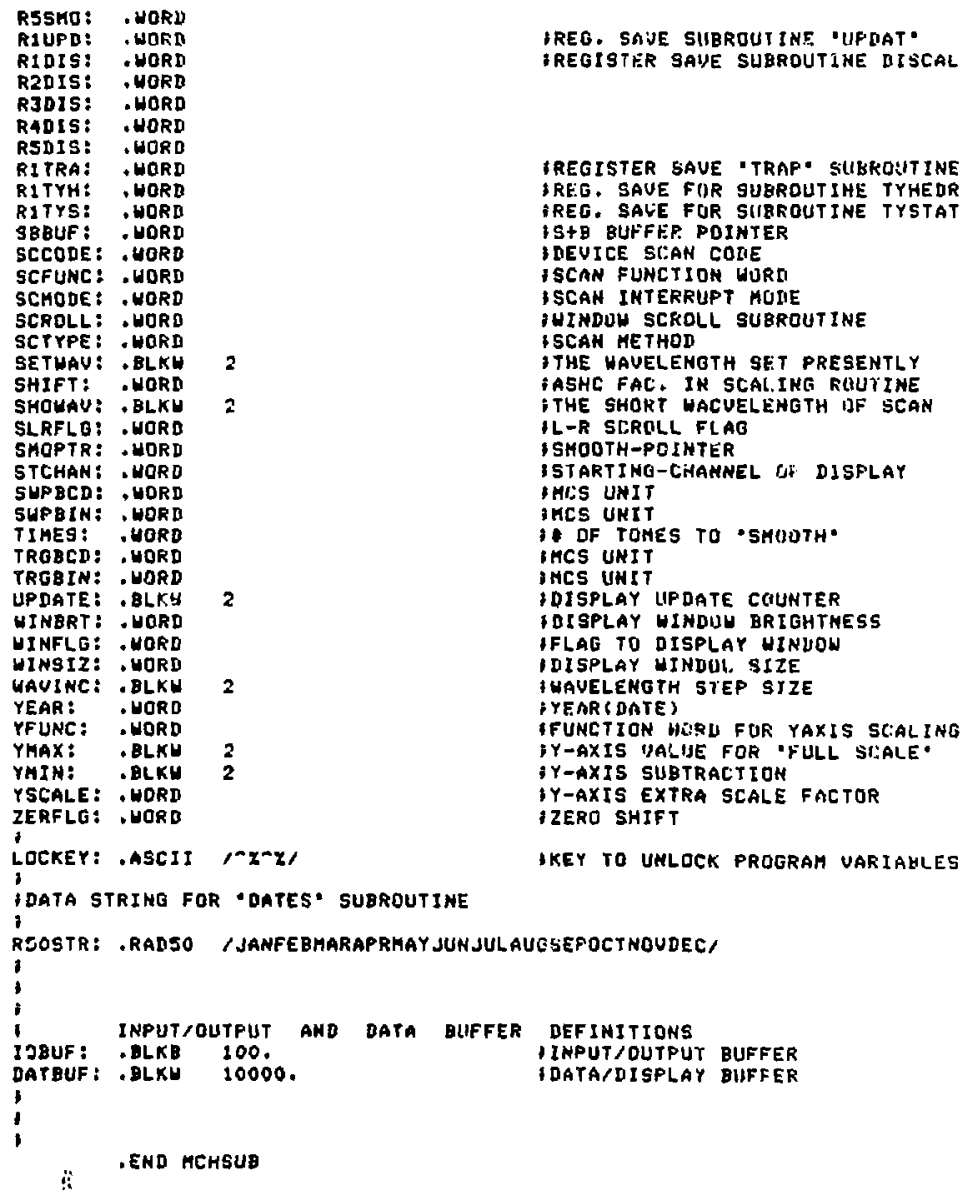


TIILE ALUAMP

ISUBROUTINE TO SET THE GAIN UF THE 3SBi-ZIA ANALOG-TO-DIGITAL LOUERTEK'S

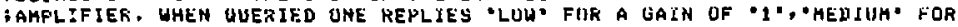

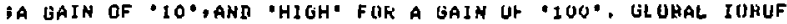

IHUST DE DEFINED BY THE CALLING PKUGRAH, IHIS RDUTIIJE IS USED BY A

; CALL azRAMF" INSTRUCTION.

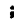

i

SYSTEH MACED

- MLALL .PRINT

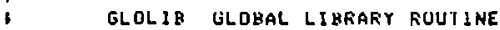

- GLOBL KEAD

- glogal defined in main frugkah

- Glohl ifjeuf

; GLQBal DEFINEI BY THIS MUDULE

.GLUBL ATIIAMF, AZIIUNS$$
\text { ; }
$$$$
\text { A.TLLON }=167100
$$$$
\text { AIIIAMP: MOUB }
$$

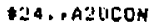$$
\text { MOU }
$$$$
\text { CHPR }
$$

IOBUF + 2, I GSUF

IOBUF, $\$ 15$

ES

REd $10 \%$

109

BR 158

-PRIHT OHI

15: HOU IOHUF, ALLENS

CHF 'LO+IOEUF

BEQ 20

CMP "HE, IUHUF

BED 30S

CHF HFI, IOEUF

BEO AOS

- FRINT

-FRINI ANZ

$\begin{array}{lll} & B R & 10 \$ \\ \text { 208: } & \text { MOUB } & 125.4\langle A 2 B C U H+2\rangle\end{array}$

8R jot

308: MOUS T2S. AALLONA4: BF 504

408: HOUE HES. S SADUCON+6;

SOL: MOU 20000 . DELAY

GOS: DEC DFLAY

HNE SOL

MOUG OOALOCON

MOUH $26.1 A 2 D C O N$
IA2D CONWERTER (BYN 1H)

- DISABLE THE LAM KEQUEST

IGE S SECUNII COMMAND IF ANY

IIS IT A LARRIAIJE RETILKN?

IASK ? UR SECUNL PART OF COMHAND: IF Y

igU LIELUDE. COMMANL

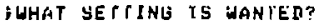

\$REAU THE RE.FI.Y

SSALE THE DESERTE LAIN SETIINE

IA LIAIN UF" '1"?

; TES.SET LAOIN TUL 1 .

ia lialN UF "la*?

IIF YES,SET GAIN TU 10.

IA GAIN UF 100 ?

; IF YESPSET GAIN IU 100.

IINUALIII RESFUNSE-OIFLL USER

IGD BACK--TKY ALAIN

ISELELT LIAIN IDF 1 .

ILO WAIT

isElect GaIN UF 10.

IGO HAIT

ISELECT LAYN DF 100.

ILUAB UELLAY WUKLU

- gelar lojup

IWAIT FUR CONUERTILIN IIS FINJSH

IDEAH. THE LAM

IENABLE THE LAM REGLIEST

IHE TUKN TU CAI.LER 


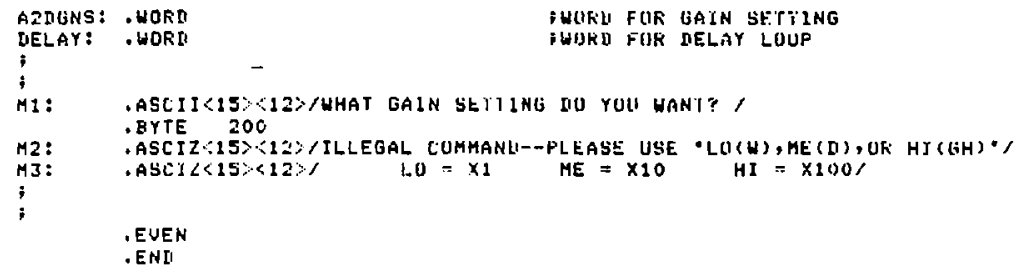




\section{-TITLE ASCBIN}

ISUBROUTINE TO CONUERT ASLII CHARALTERS JH I/L BUFFEK(TIBHA) TO IA SINART NUMDER IN RI (LOW HORD) AND Ra (HItH WDHDS. I IORUF IS NOT CHANGED. - oLOEL IOBUF, ASCBIN.JHUL - GLQBL KEgSAviREgRES

, ASCBIN: MO

CLR

HOU

MOU

MOU

CHPB

BHE

CLR HOU

BR

108: CHPB

BNE HOUA

20s:

MOV

HOV

HOU

HOV

30s: HOV

MOV

HOU

CHPB

BED

CHPB

BGT

CHPB

BEE

408: SEC

508:

RR

SUB

CALl

call

CALL

CAP

BEO

ADD

$A D C$

BR

$608:$

CMP

BNE

COH

COH

$A D D$

$A D C$

130: $\mathrm{MOU}$

HOU

CLC

ASCOUT: HOU

RETURN
RSIRSASC

R2

QLIST,RS

- IUBUF , R1

1 , NEGFLG

- - (R1)

108

NEGFLG

- O. (R1)

205

$+t(R 1)$

208

4'O, (RI)

\%0, RESUL T

40, PE SUL T + 2

110.,ARG2

CO. ARO2+2

RE SUL † , ARG1

RESUL T + 2 + ARE 1 + 2

(R1),$+ R 2$

$\$ 15, \mathrm{R} 2$

608

$+60 . \mathrm{R2}$

408

$\$ 71, R 2$

508

ASCDUT

$\rightarrow 60, R 2$

REGSAU

JHUL

RELRES

$+-2, \mathrm{kS}$

408

RZ, RESULT

RESULT + 2

305

ПO, MEIJFLG

1308

RESULT

RESULT+2

1. RESULT

RESULT+2

RESULT , $R 3$

RESUL T +2, R2

RSASC , RS

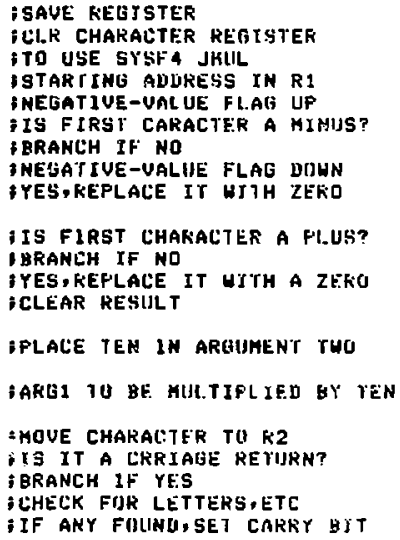

I ANSWER IN RI

+AHU Rz

ICLEAR CARRY: NU ERKURS

+ UNGAUE REGTSTER

IRETURN TO (:ALLER 


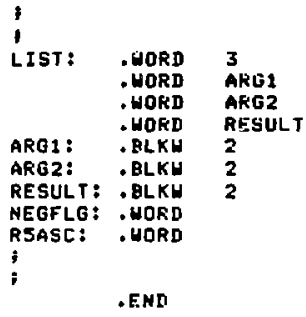


-TITLE BINASC SUBRUUTitime

SSUBRUUTINE "BIMASC" IS A RUUTINE TU LUNUEKT A SIGNED BIHARY MUMBER IIN RI TO AN ASCII BYTE STKIHG WITH STAKTING LULATION "TUBUF" THE IASEI I CODED SIRING CONSIST JF SIX CHARACTERS. A MINUS STGN FUR ; NEGATIUES WITH LEAIING 2EROES SUPPRESSEU:THE HINIS SIGN IS PLACED

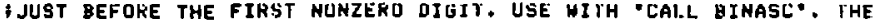

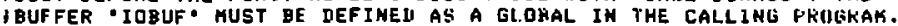
. Globl iobuF, EIMASC

BINASC: $\mathrm{HOU}$ RI,RIBIN HOU R2.R2BIA

MOU R3,R3BIN

MOV RA,R4BIN

MOV TOEUF, RA

TST R1

BPL 108

NEG RI

MOUB $\because-,(R 4)+$

BR 15\%

108: MOVB,$(R 4)+$

BIN1,R2

HOV $\quad 5, k 3$

20\$: CLR RO

DIV (R2) + $R O$

ADD $\$ O, R Q$

HOUB RO, (R4)t

SOB R3.20

ISAVË KEGISTERS

IBUFFER STAETIHE LUCAIIUN

iIS IT NEUATIUE?

iNO

iYES. TAKE ABS. VALUE

IPLACE MINUS SIGN IN BUFFER

TEU TU CONUEK TIUN SETYYION

IPLACE A SPACE IN BUFFEK

IPOINTER TO OIUISIJR TAGLE

IFIUE LIUISURS

i LLEAR HIGH HURD

IFIS DIUIDE

TADD ASCII BIAS

IPLACE RESULT IN BUHFER

I DO I T FIUE TIHES

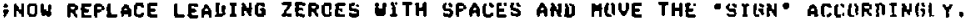
HOU IUBUF,RA TBUFFER STARIING ADURESS

MOUB IOBUF,RI

CLR R3 TCLEAR LUTP CUUNTER

305: INCB R4 IGEY NEXT HYTE LUCAT 1OH

INCE RJ IINCREHENT LUUP COUNTER

CMPB ISIRS IS IT THE FIFTH IIML?

BEQ AOS IIF YES,ËXIT

CAPB $O$ O, (RA)

BNE $40 \%$

MOUB R1, (RA)

MOUB,$-1(R 4)$

BR $30 \%$

401: MOU FABIN,RA

HOV RSGIN,R3

HOU RESIN,R2

HQV RIBIN,RI

RETURN ;RETURN TU CALLING PRUGKAH

BIN1: . HORD $10000 .+1000.1100 .110 .11$

R1BIN: UORD

R2BIN: WURD

R3BIN: .WORE

RABIN: - HORD

- END

IIS THE CHARALIER A ZERU?

PNU,EXIT RIJUTINE

i yesikEPLALE It HITH SILN

IREPLALE FIRST SIISN WITH SPACE

iLUUK FUR MURE 2L.RUES

DUNSAYE RELISTEKS 
- TITLE BLDHIN

TBCDBIN SURRUUTINE CONUFRTS BCD NUIAEE

IIN RI TO A HINARY NUMBER IN RI

-GLOHL BCDAIN

BCDBIN: $M O U$ R2,R2KCD

MOU R3.RSBCD

MOV RA,R4HCI

MOU RS,RSBCD

MOU R1,RS

;CQFY INTO RS

HOU †ASHIFI,R2 IINTT.

MOU IAMUL, $R 3$

CLR BIN

MOV $4, \mathrm{RA}$

ECD1: MOU RS,R1

IFOUR DF THEK

ASH (R2)+,R1

ilje' THE NUMBER

BIC $\$ 177760, R 1$

IMASK THE BITS

MUL $(R 3)+, R 1$

FHULTIPLY BY PUHER OF TEN

ADI R1 BIN

SOB RA,BCDI IFOUR TIMES

MOU BIN,RI

- PLACE BINAKY IN RI

MOU R2BCD,R2

MOV RJELL, R3

MOV R4BCI,R4

MOU REECD,RS

RTS PC TRETUKN

ASHIFT: , WORD $-12,,-8,,-4,0$

AMUL: ,WOKD $1000,1100,110,1$

BIN: WURD

RABCI: , WORE

FIBCD: . WOKD

R4FL:D: WORD

FISBCD: . WORD

- END 
-TIFLE DECOUT SUBROUTINE

IIECOUT SUBRUUTINE OUTPUTS THE BINAKY NUMBER CUNTAINED IN RI - IN DECIMAL FORIAT TO THE CUNSOLE DEUTCE. SIX CHARACIERS ARE ;OUTFUT: A MINUS SIGN IF THE NUMBER IS NEGATIUE AND WITH ANY ¿LEADING ZEROES REFLACEB BY SFALES. THE MYNUS SIGN APFEARS INEXT TO THE FIRST NOWZEKO DIGIT. - MCALl iTTYUUT . GLOBL DECOUT, FSNAGL, IOEUF

DECOUT: MOU RI,RILIEC MOU R2, H2LEC CALL EINASC MOV \$G,R1 MOU $\quad I O H U F, R 2$

10: MOUE (R2) t,RO -TTYOUT SOE R1,10\% MOV R2DEC,R2 MOU RIVEC,R2 RETURN isave REgISTERS irENUERT KI TO ASEII STKING ISIX CHAKALIERS UUTPUT i RUFFER STARTING AlHIIRESS IUUTPUT CHARACIEKS ONE BY ONE કUNSAUE REgISTERS

iRETURN TUI CALLINT; PRULGKAM

RIDEC: . WORD

RILEC: . WORD

$$
\text { - EN I }
$$


-TITLE UCOUTZ SUBROUTINE

IICOUT2 SUBKOUTINE IIUTPUTS THE GINARY NUMBFR LONIALNFD IN HORDS

ILONDRD AND HIWORI IN DECIMAL FURMAT TO THE CUNSOLE UFUICE. TEN CHARACIEKS PARE JUTFUT A MINUS SIIN IF THE NUHBER IS NEGATIVE AND WTTH ANY

iLEADING ZEROES REPLALEI HY SFACES. THE MINUS SIGN APFEARS

INEXT TO THE FIRST NONLEKO BIGIT. - HCALL - TTYOUT -gLDBL DCUUT2 RAPASE, IUgUF

DCOUT2: MUV K1,RILEC

MOU R2,RZUEC

CALL IUPBASC

MOU $11 \ldots R 1$

MOU IOHUF,RZ

10s: MUUE (K2) +,RO

- TTYOUT

SOB R1.10s

MOU K2DEC, R2

HOV RILEC, RL

isAUE RELISTERS

RETURN

R1 LEC: . WOKL

R2DEC: , WOFD

- ENII

iCQNUERT "WIJRDS" TU ASLII STKIHG

IELEUEN SHAKAC TERS UUTPUT

i BUFFEF STAKTINL ALURESS

;UUTFUY CHARACIERS UHE BY ONE

iUNSAVE RELISTERS

FRETURN TO LALLING FRQGHAH 


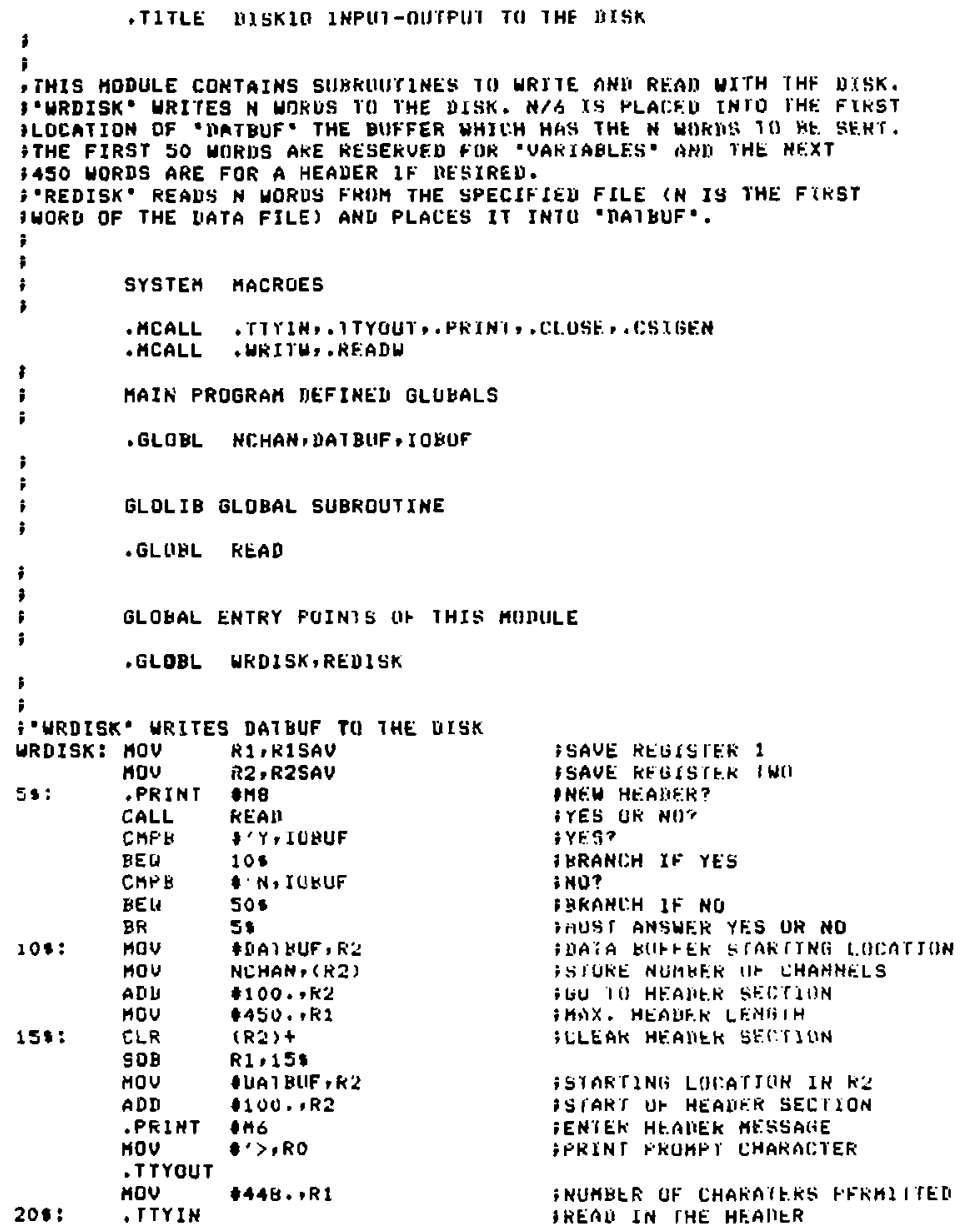




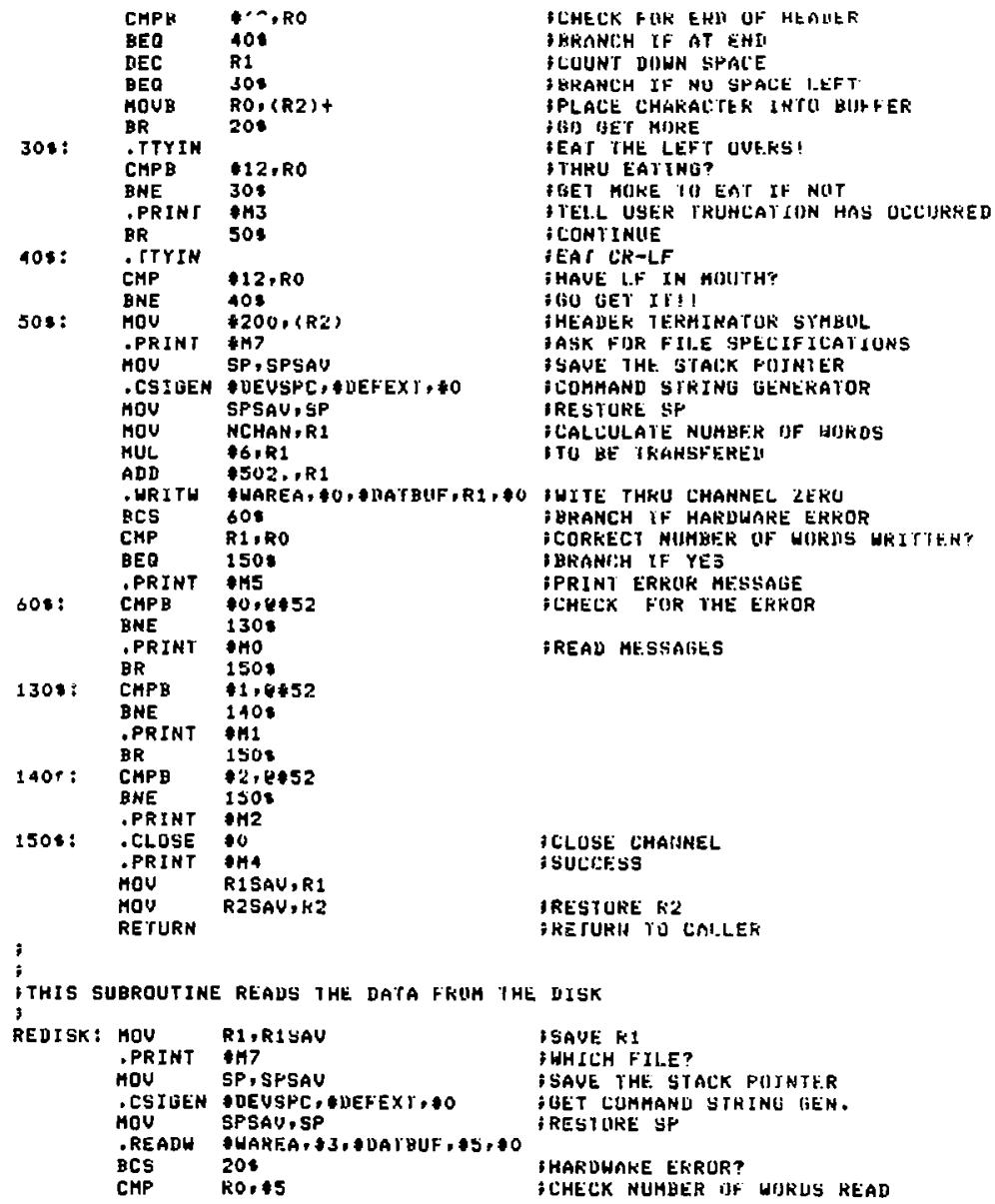




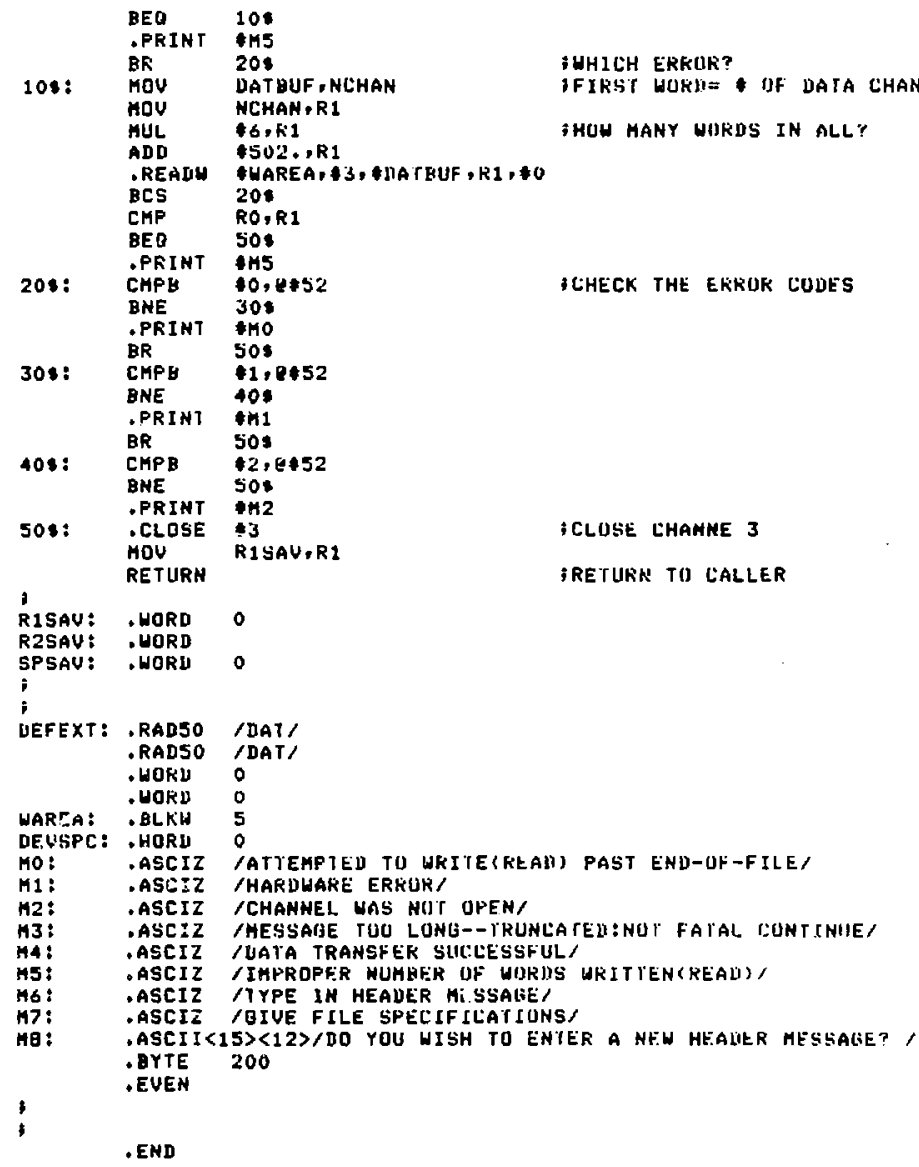


- TITLE DFHASL SURRUUTINE

; DQUHLE PRECISION IHTEGER ASCII DFLIMAL CUTPUT PRUGRAM-WILL FI.ALE 1 KTO A ; SPECIFIED RYTE STRINO 10 ASEII NUMERALS AND A SIGN IF HEUATIVE. LEADING IZEROES ARE SUPRESSED ANU THE SIGN IS PLALEU IMHEUTATELY HEF URE THE ;FIRST HON-ZERO DIGIT UF THE HUMBER. ITO ENTER:

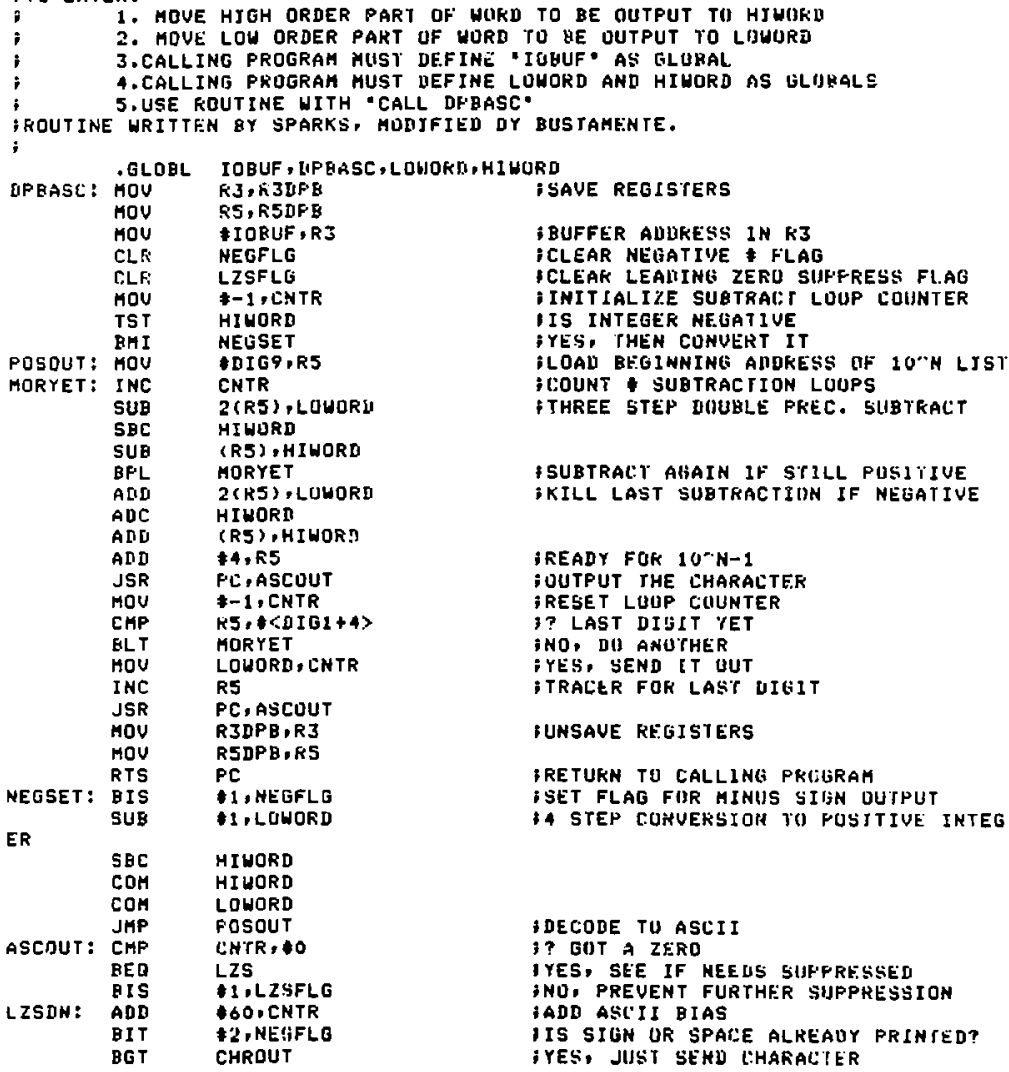




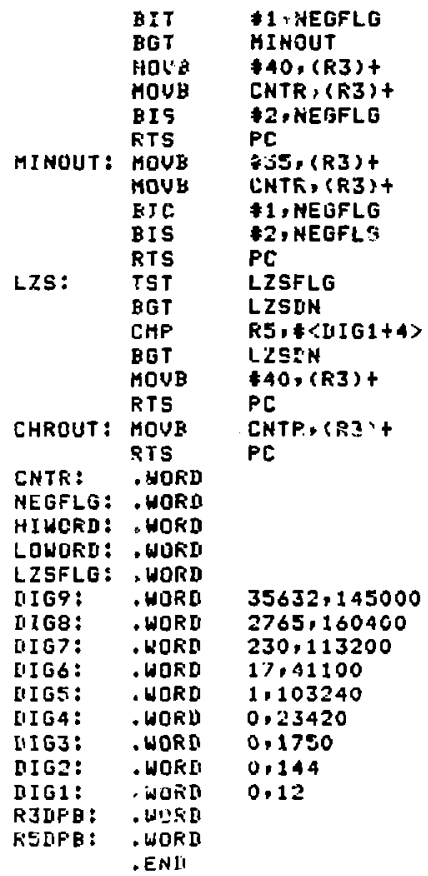

INO, DO WE NEEII A MINUS SIGN? iYES, DUO IT

INO. SENI A SPACE

THEN SEHU CHAKACTER

IMU MURE SPALES

FBACK TO CALLER

DSENT KINUS SIGN

ISEND CHARACTER

- MINUS SIGN DONE

iNO SPACES WANTED

ILEADING ZERUES UVER WITH?

IYES, OON'T SUPPRESS

ILAST DIGIT YET?

IYES, THEN PRINT EVEN IF LERE

INO, SENL A SPACE

;5EMD CHARALTEP? 
-TIILE CKLF

SCRI.F SUHROUTINE INITIALIZES CONSULE DHUJCE C:AKHJAGE - MCALl , TTYOUT

CFLF:: HOU $\$ 15$, RO - TTYUUT

HOV $\$ 12, R O$

- TTYUUT

RTS

PE

- EllD s PRINT LR

iPRINT LF

TRETURN 


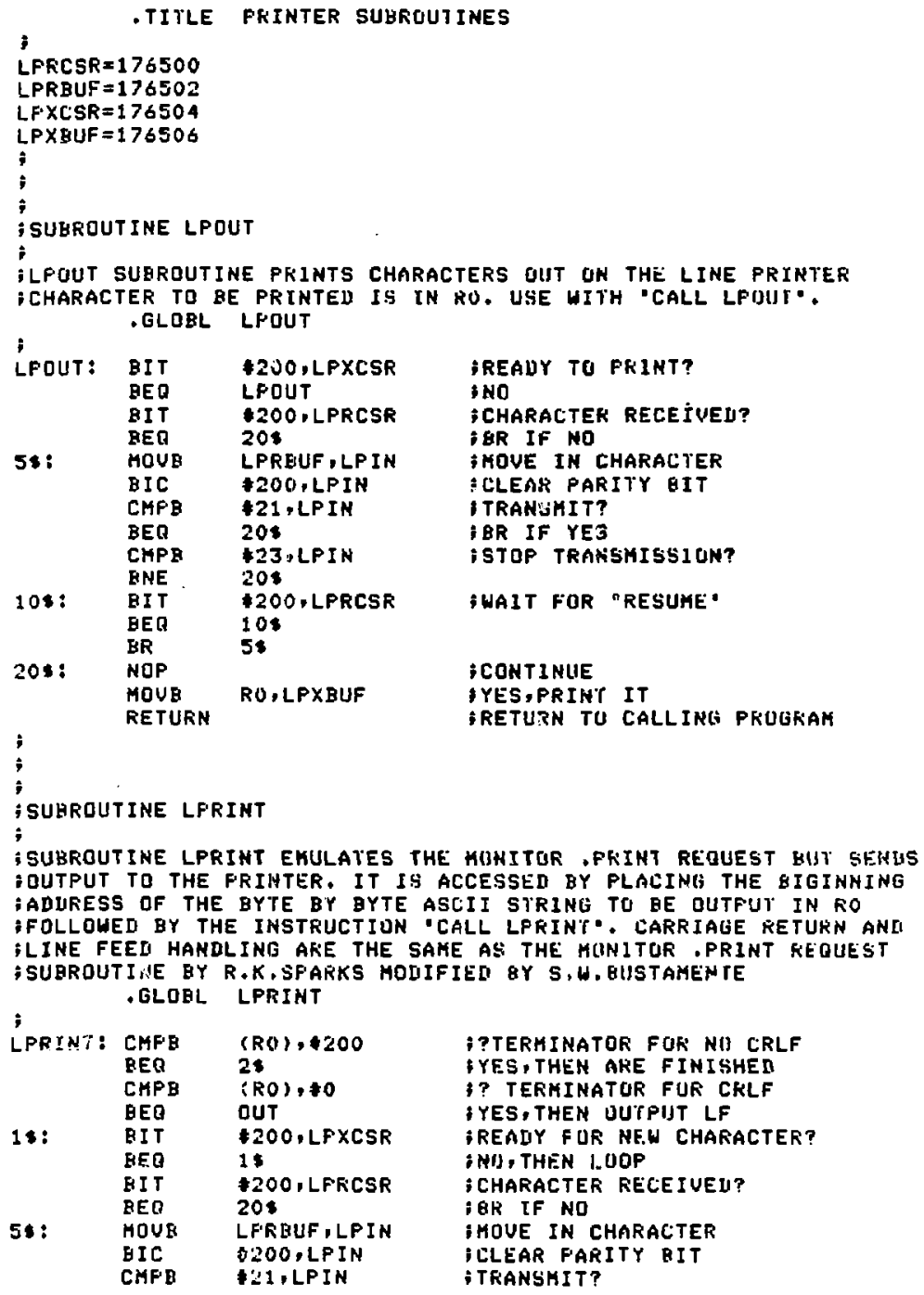




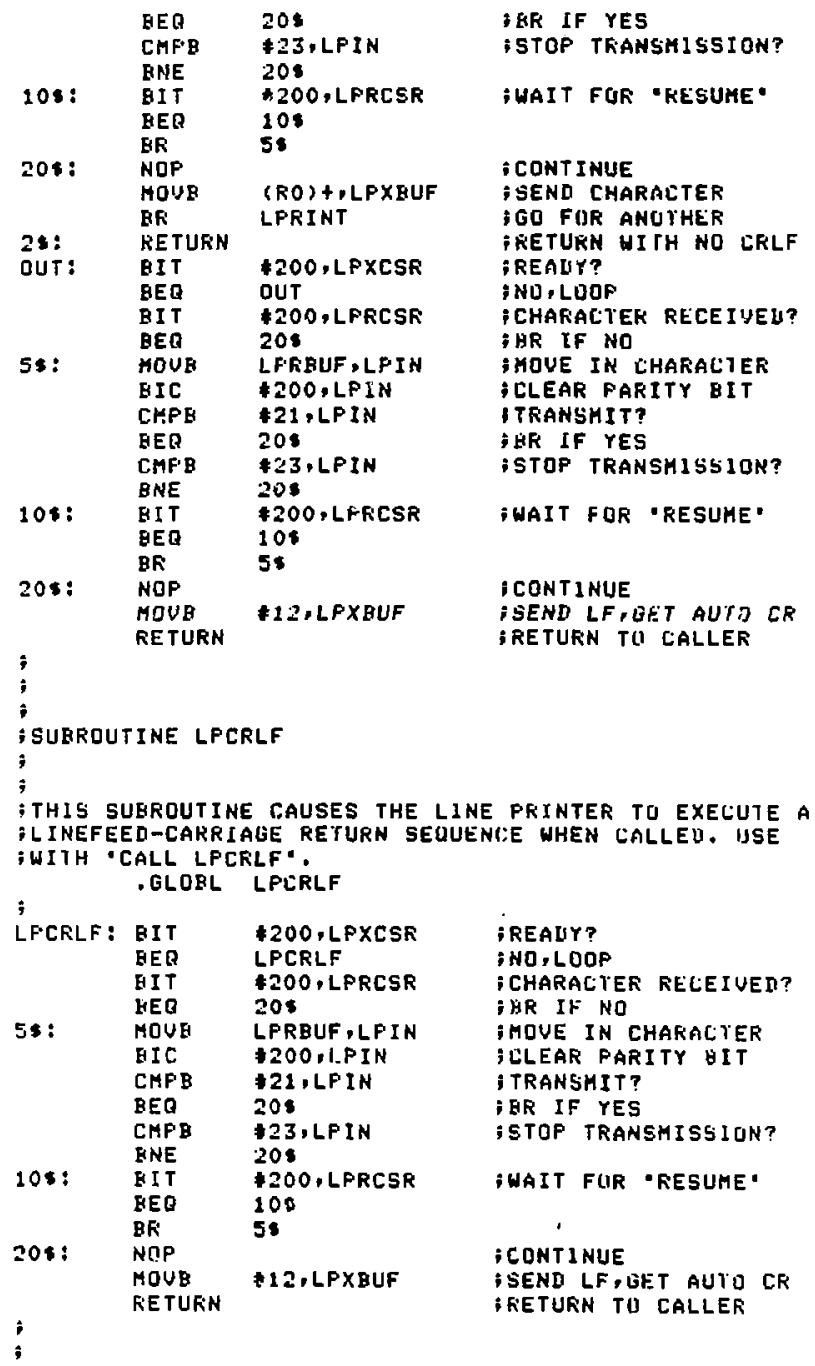




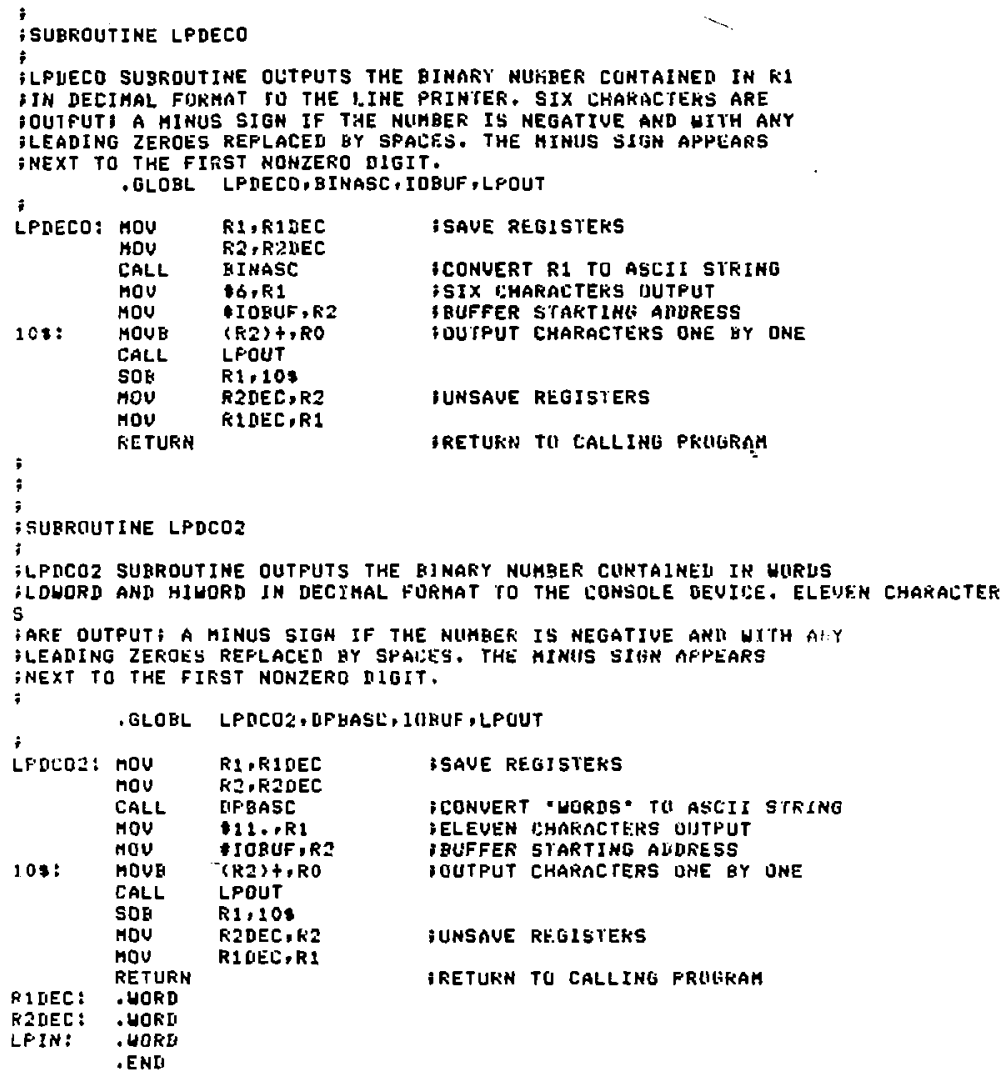

ISAUE REGISTEKS

ICONUERT " HORDS" TU ASCII STRING

iELEVEN CHARACTERS UIJTPUT

I BUFFER STARTIHG ALDRESS

IOUTPUT CHARACTERS DHE BY UNE

iUNSAUE RE.GLSTEKS

IRETUKN TO CALLING FRULIRAH 
- TITLE LASER CONTROL GLOHAL RUUUTINES

;THIS -LASER MUDULE COMTAINS GL.OBAL SUBRJUITINES HHICH AKE. LISE ;OFERATE THE QUAHTA RAY DYE LASER AND THE UPU.

SYSTEH MACROS

.MCALL ,FRINT,.TIYIN

SYSF 4 LIBRAFY GLOBALS

.GLOHL JUIU,JCAF, JHUL

GLOLIB LIBRARY GLOHALS

, GLURL REAU,ASCBIH, MOTUR1, REESAN, RE GRES

MAIN FROGRAH DEFINED GLUGAL LAKELS

- GLOEL SLCOLE, NSTEF, HCHAN, IOHUF

-GLOEL LIST,ARG1,AKG2,RESIJLT

. GLORL SHOWAU, LONGAU, SETWAU, CALUGU, UNUINE

- glohl datalo

GLOEAL ENTRY FOINTS OF THIS SLIBKOUTINE

- GLUHL DYESET, DYECAL, RE.HAVE, MYELAS

- orelas subroutine allows one to set the are laseg tor a given mavilemgih ;OR TO SET FARAHETEKS IJF THE LALLING PROGRAH HHILH RESULT IN THE LASFR GEING ;SCANNED FROH WAVELENGTH ONE TO WAVELENGIH TWO WYTH THE DESIRE "GRID SIZE.

UYELAS: MOU RS,RSIL

MOU RIPRIOL

CMP SCCODE, $*$ LA

BEQ 5 :

,PRINT HHI

CALL. RELAVE

CALL DYESET

HOU SEDL,R5

RETURN

5s:

,PRINT \#H15

isAUE RS

ISAVE R1

;IS THE LASER BEING SCANHEL"?

iREAU IN WAUELENGTH

iSET THE GKATING

iREgISTER UNSAUE

IHETURN TO LALLER

iAUTO SET?? 


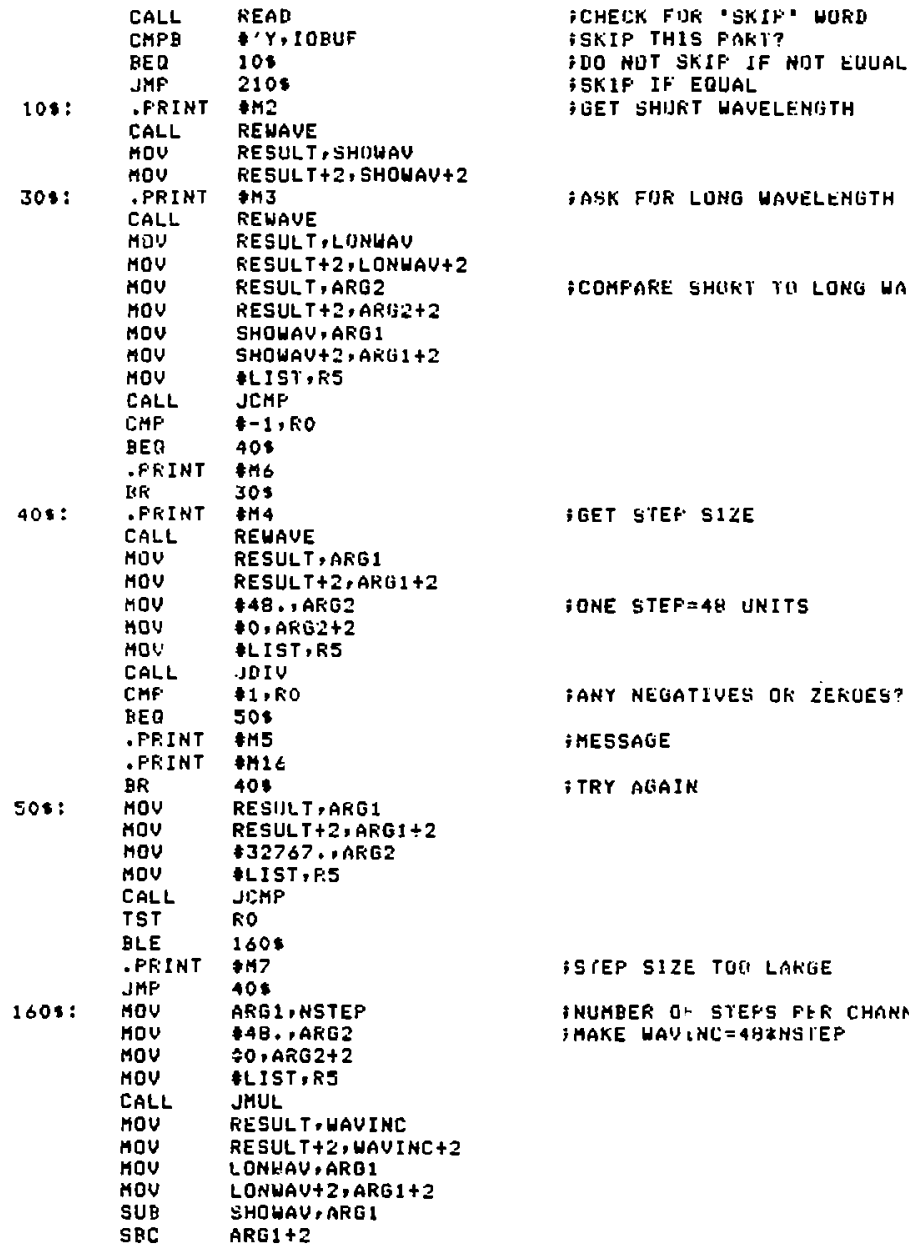




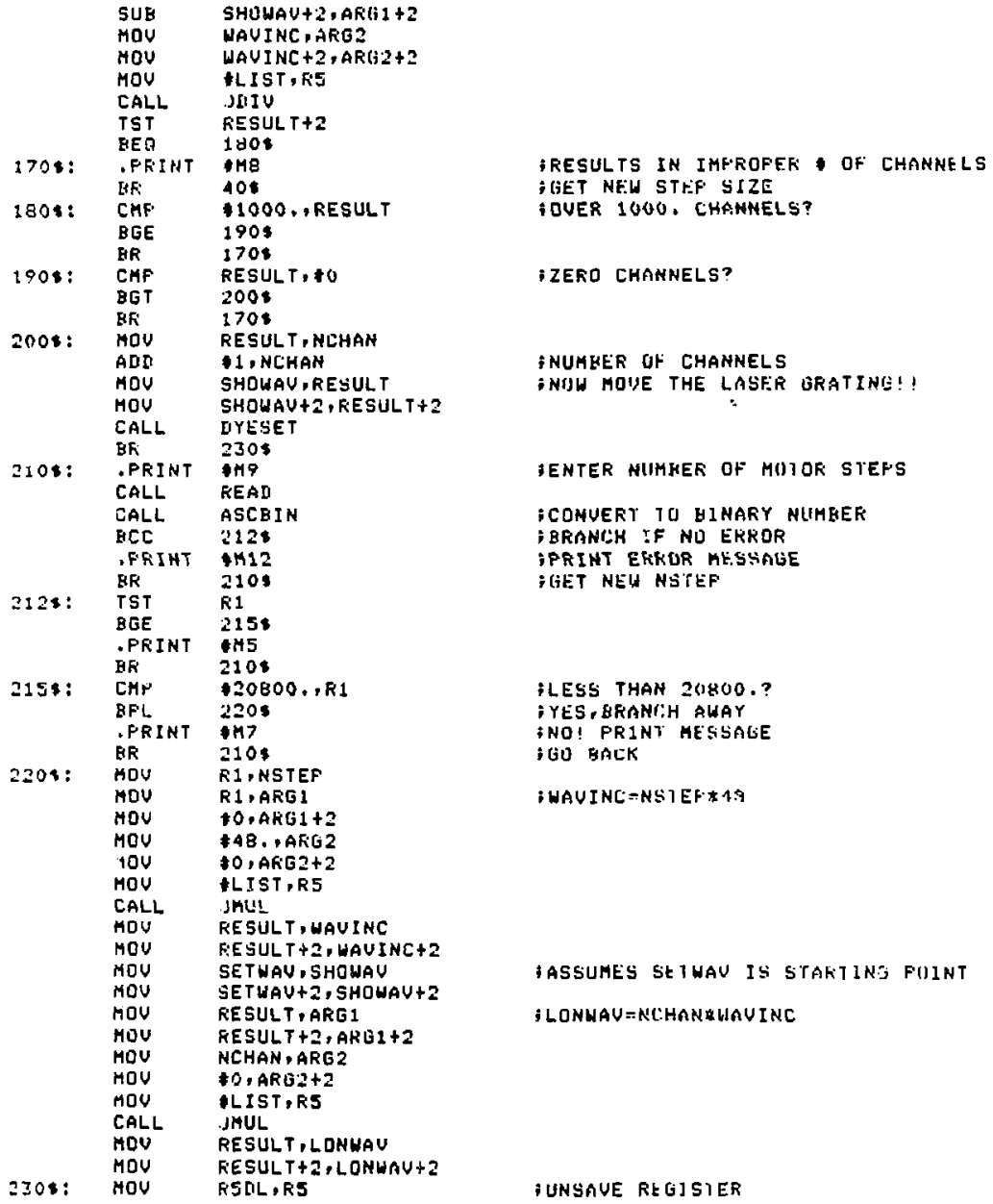

;RESULTS IN IMFROFER - OF CHANNELS ;GET NEW STRF SIZE

i UNSAUE RE[j]SIER 


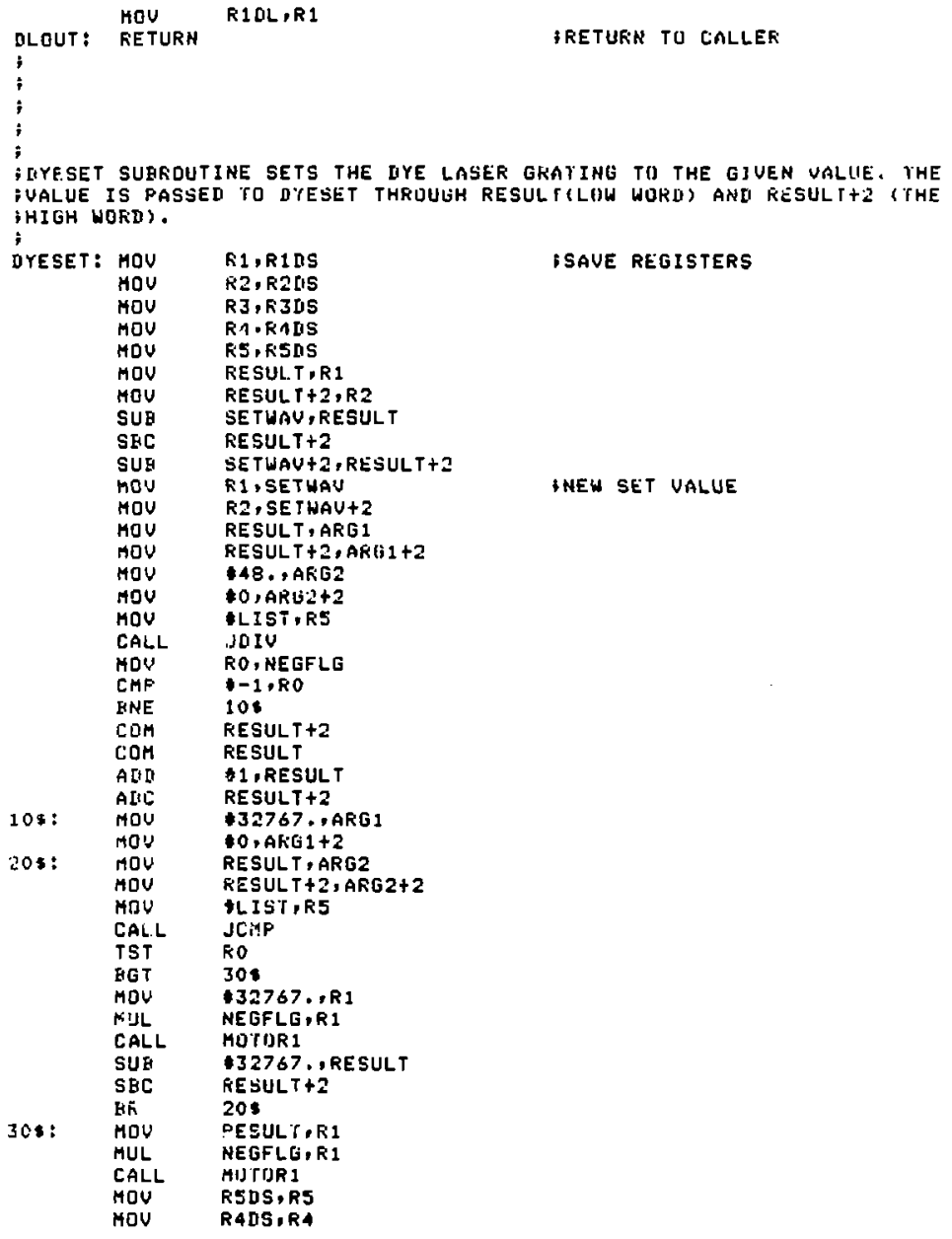




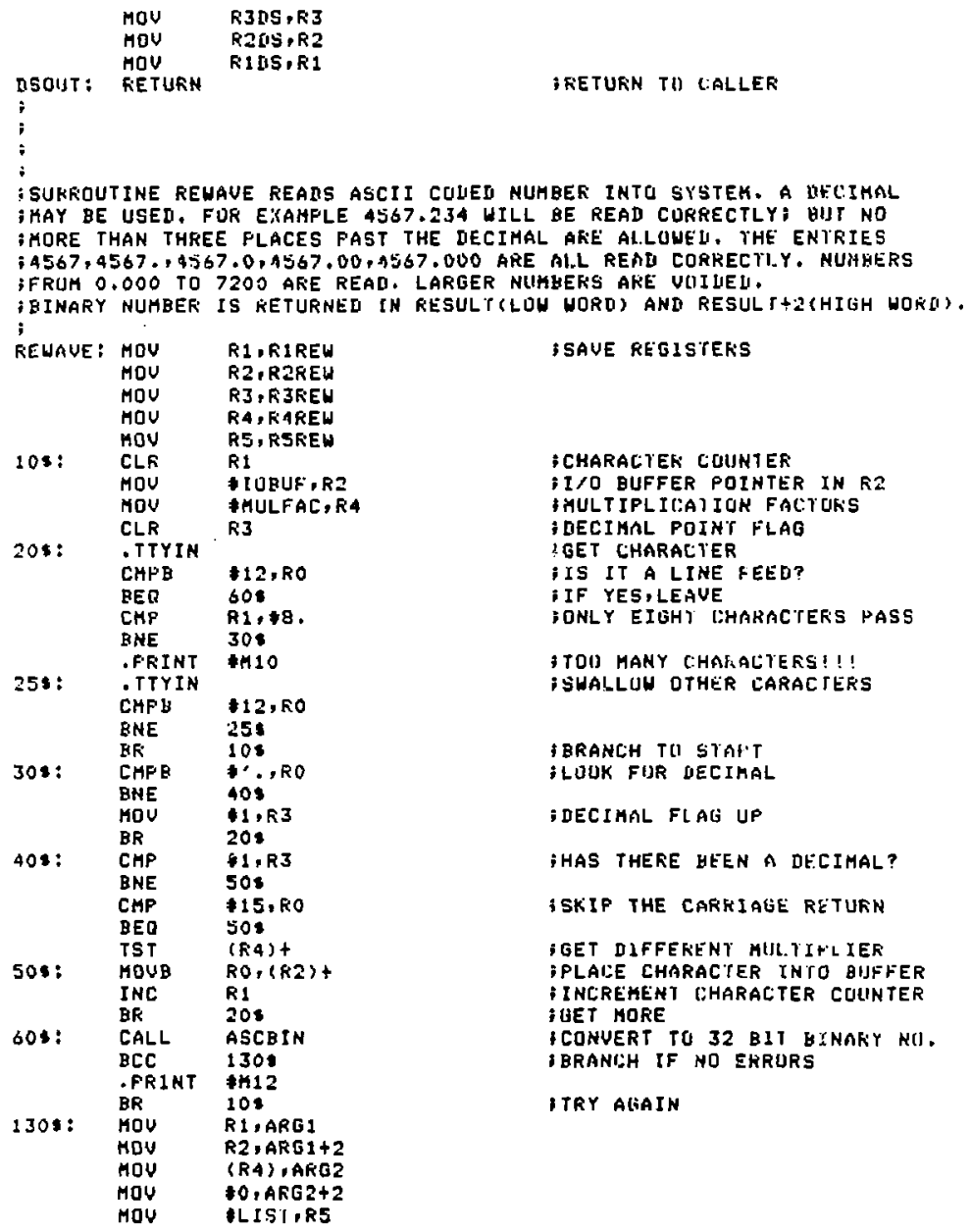




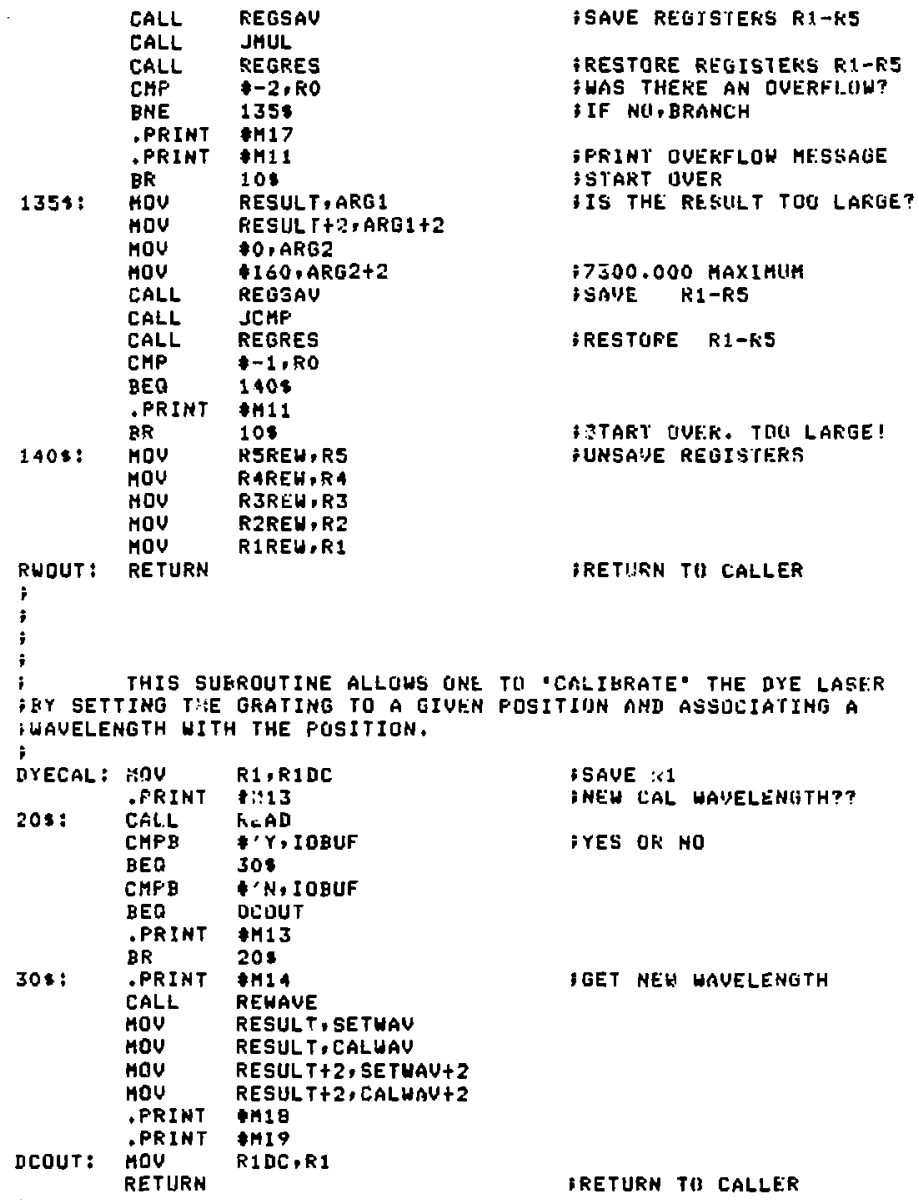

; THIS SUEROUTINE ALlQHS ONE TU 'CALIBRATE' THE DYE LASFR BEY SETTING T:AE GEATING TO A GIUEN POSITIJN AMD ASSUEIATIHG A IWAUELENGTH WITH THE PUSITION.

$$
\text { ; }
$$

$$
\text { ; }
$$

$$
\text { i }
$$




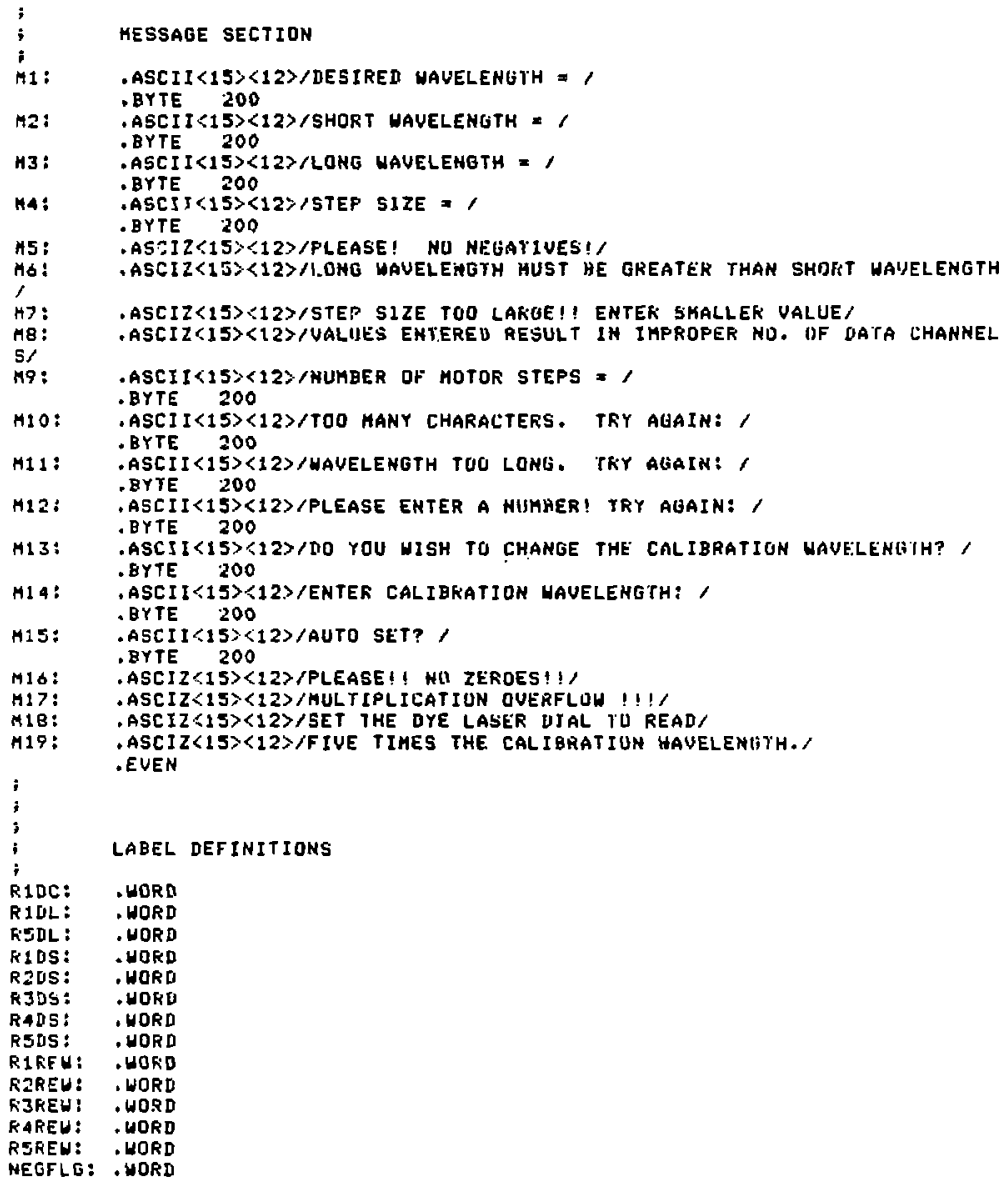




\section{8}

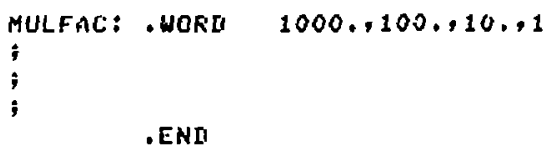




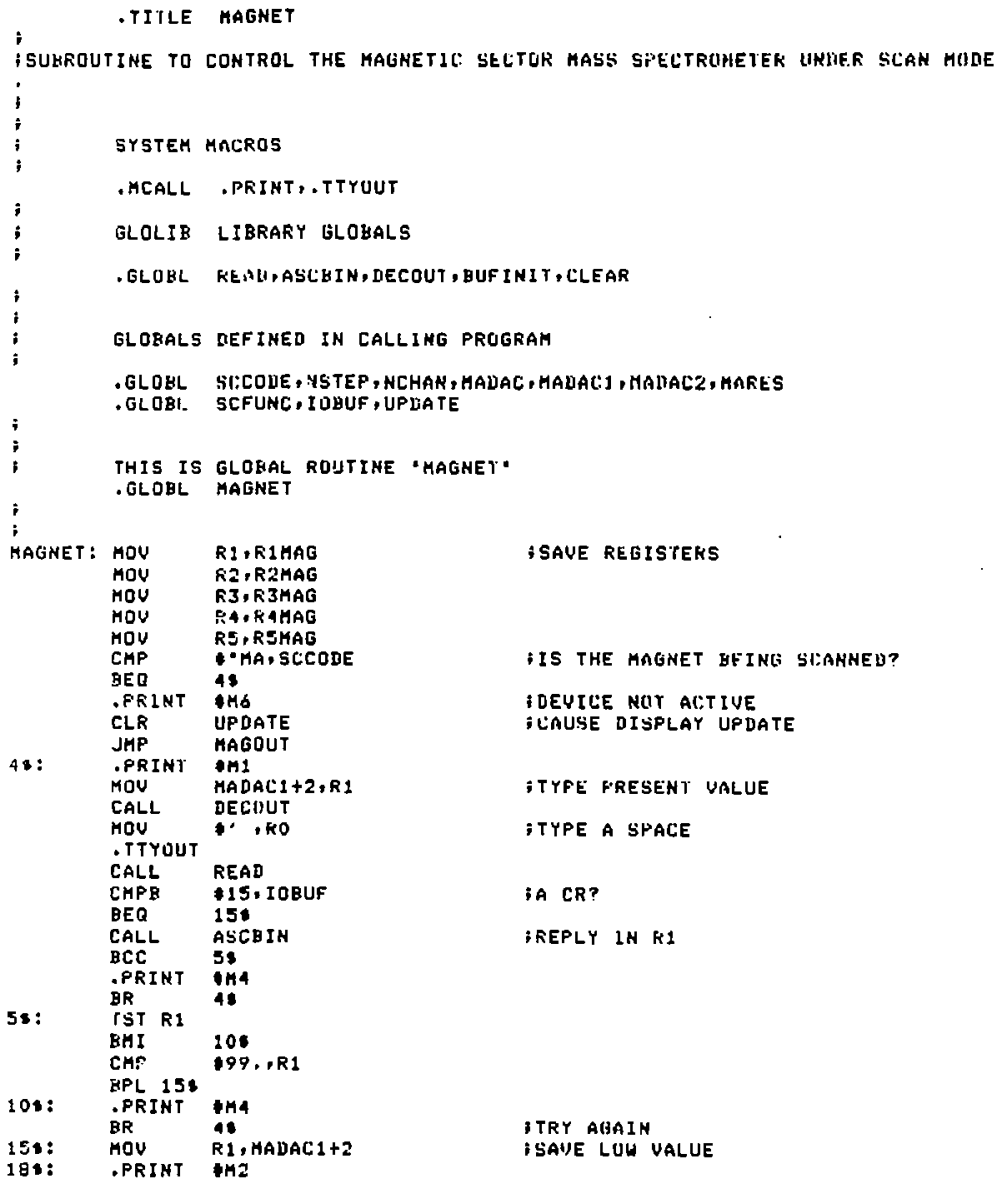




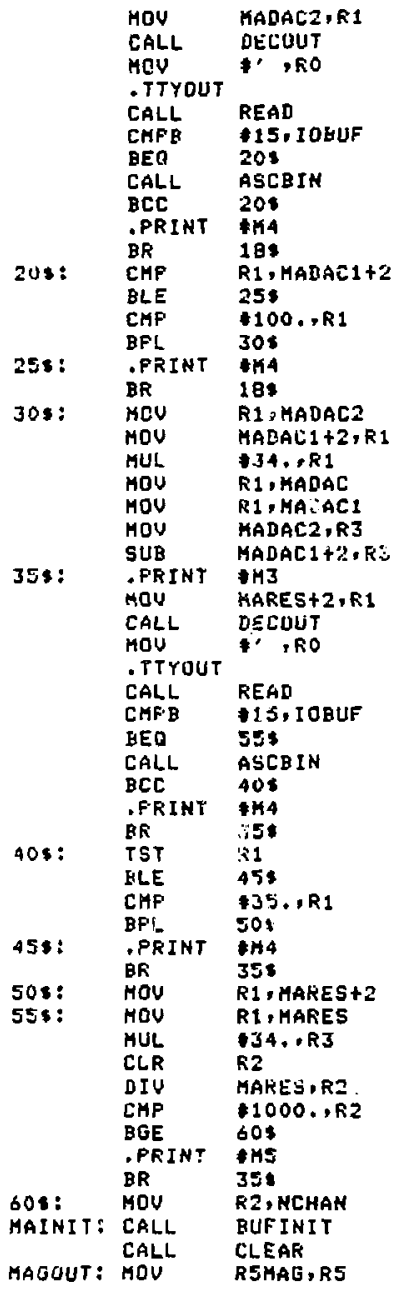

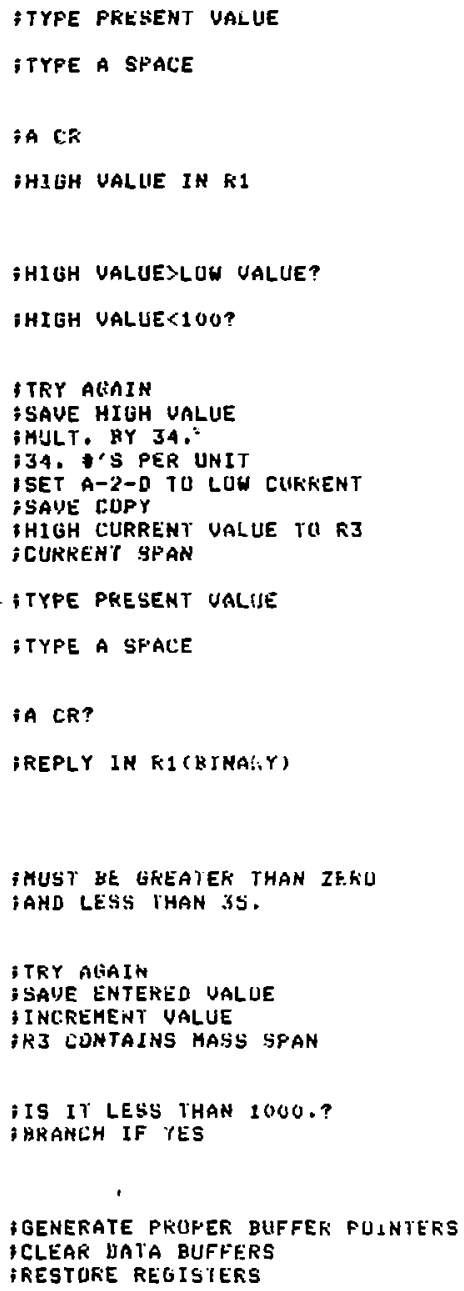




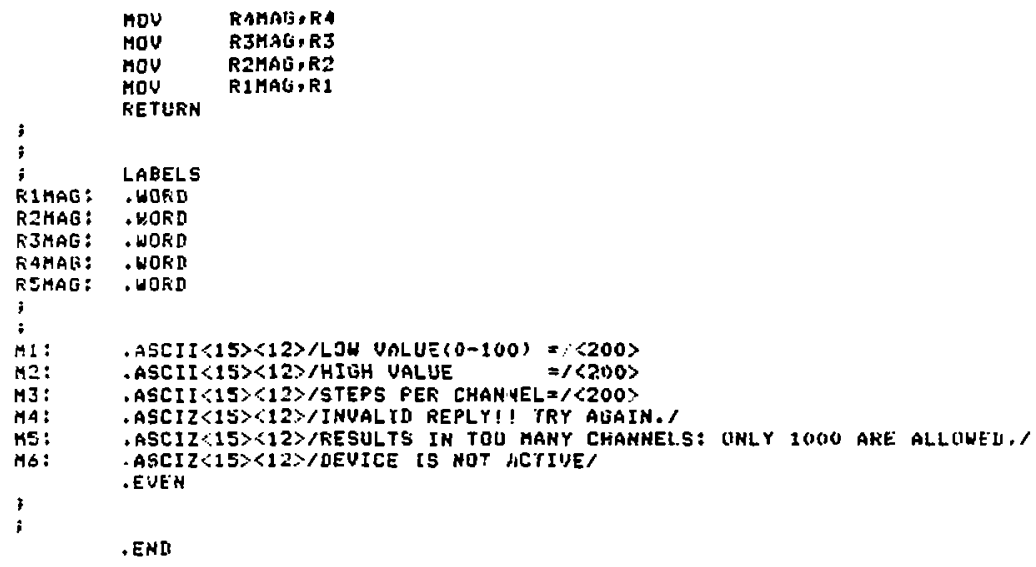


-TIILE MUTOR 1

-MOTOR SUHROUTINE SENDS 'R1. FULSES TO STEFFING MOTOR. ; POSITIUE NUMBER FUR CLUCKHISE RUIATIUN AMO A NELATIUE ; NUMBEF FOR COUNTERCLOCKWISE RUTATION. USE WITH A ;CALL MOTOR1"STATEMENT.

- MCALL PFRINT - gloel mujuki

DATALO $=166000$

MOTUR 1: MOUE

BI T

BEQ

11,04166040

* i, Datalo

MOTOR 1

BIT $\$ 2, D A I A L O$

BEQ 108

,PRINT $\$ M 1$

10\$: BIT \$4, IATALO

BER $20 \%$

.FFINT \$H2

205: TST R1

HGE 30 S

NEG R1

BIS $\$ 100000,51$

30\$: BEQ $40 \%$

MOY RI, U\$166040

40\$: RETURN

M1: .ASCIZ 215$\rangle\langle 12\rangle /$ WARNING!! - EUEN

H2: $\quad$ ASCIZ $\{15\rangle\langle 12\rangle /$ WARNING!! - EVEN

,END
TREAU MUTUR SIATUS WOKL

i IS LAF SET?

INU, WAIT

i IS CCHL SET?

iNO

YYES-PRINT HARNING

IIS LHL. SET?

iNO

; YES-PRINT HARNING

IIS RI NEGATIUE?

iNO

YYES-HAKE PUSITIUE

SSIGN BIT $=1$

- Do nut load a zero

ilual counter

CCU LIMIT OF HOSUR 1 REACHEN!'

CW LIAYT UF MUTOR 1 REACHEM!' 


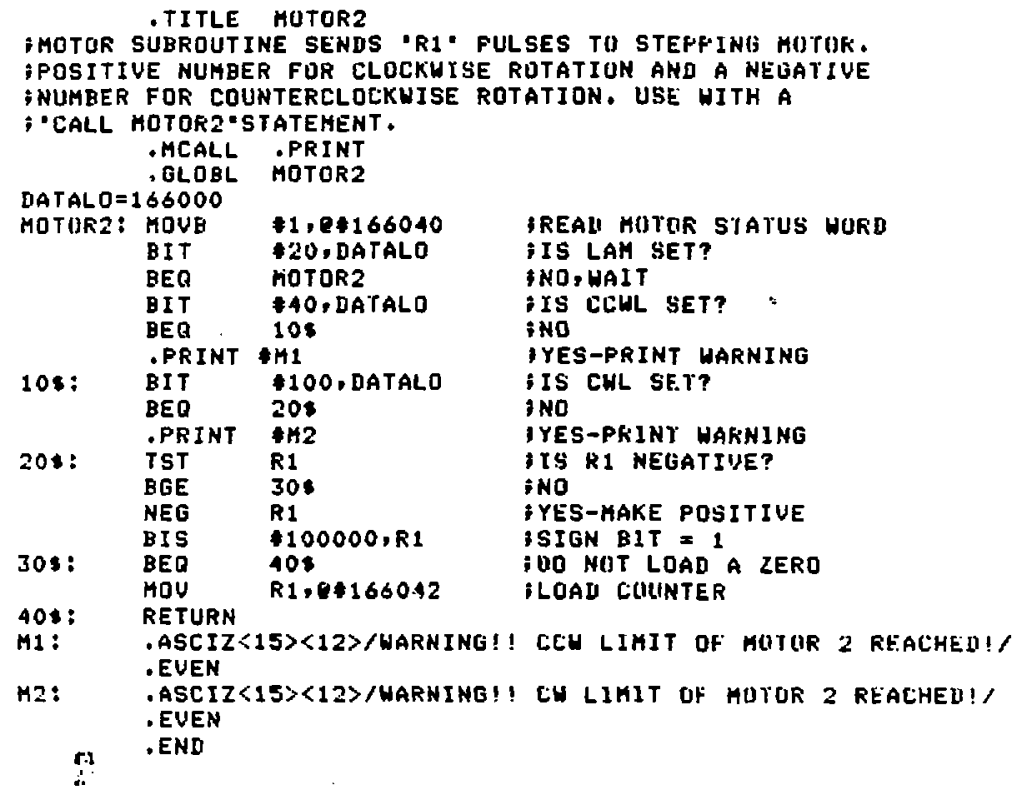




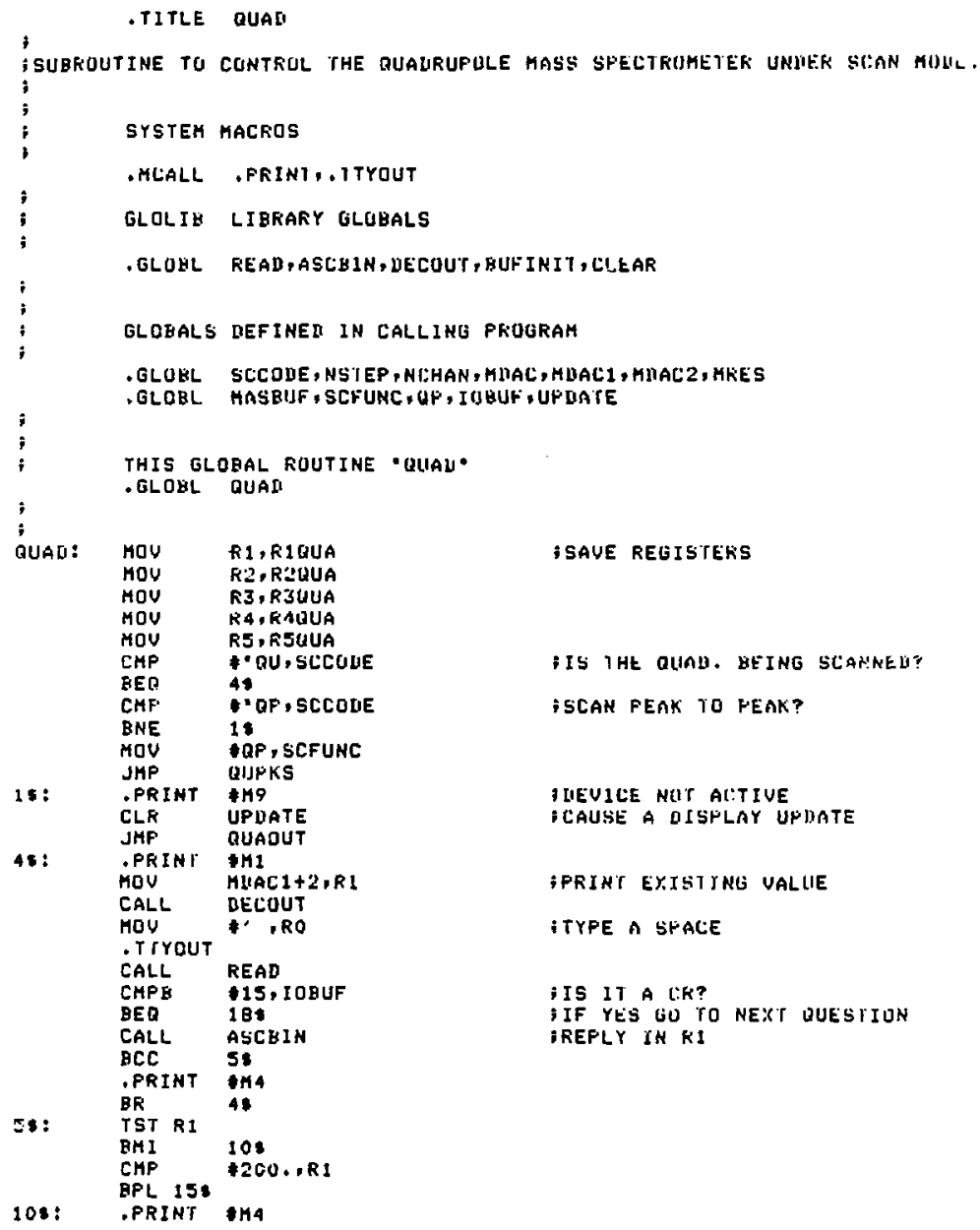




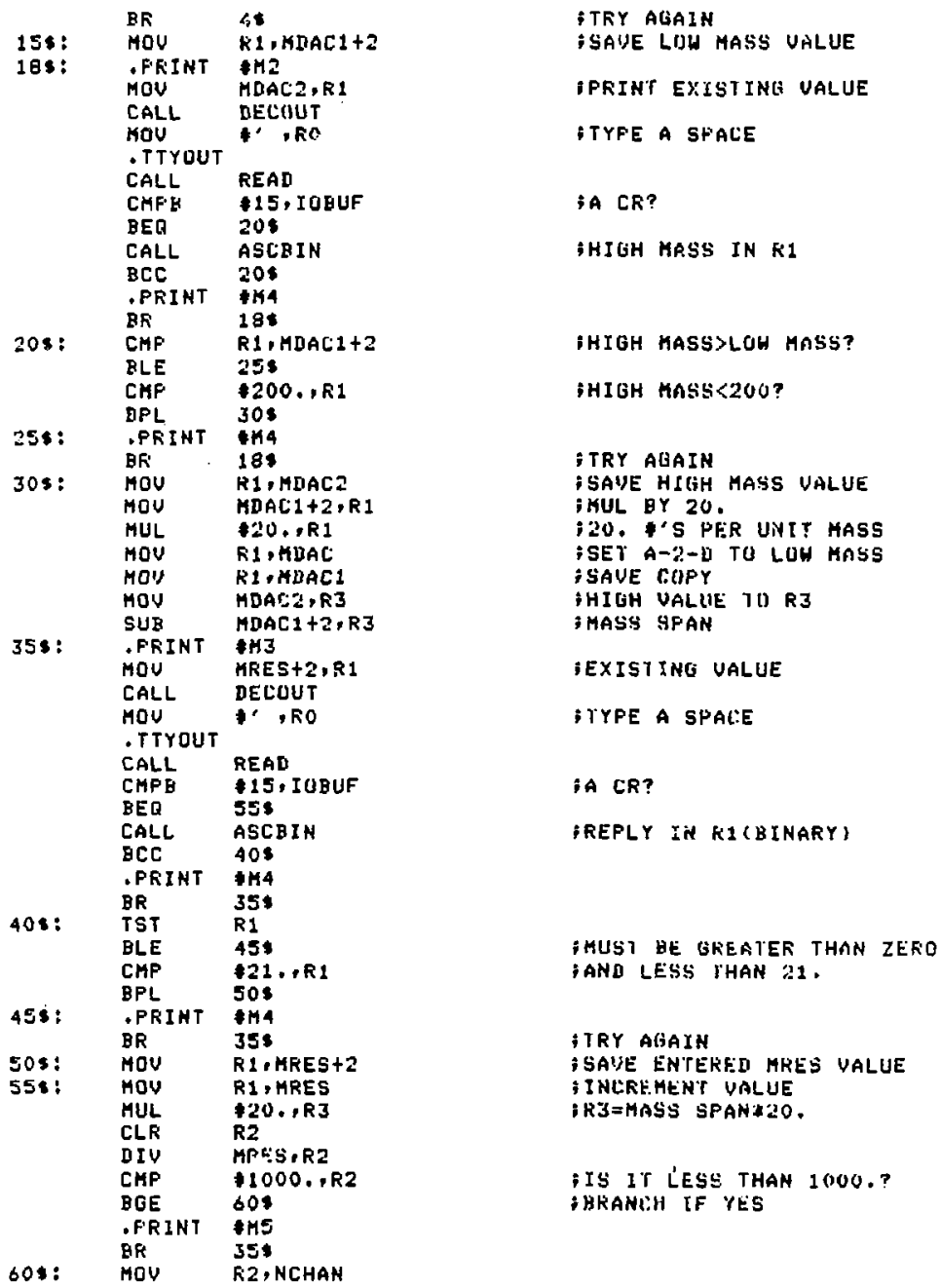




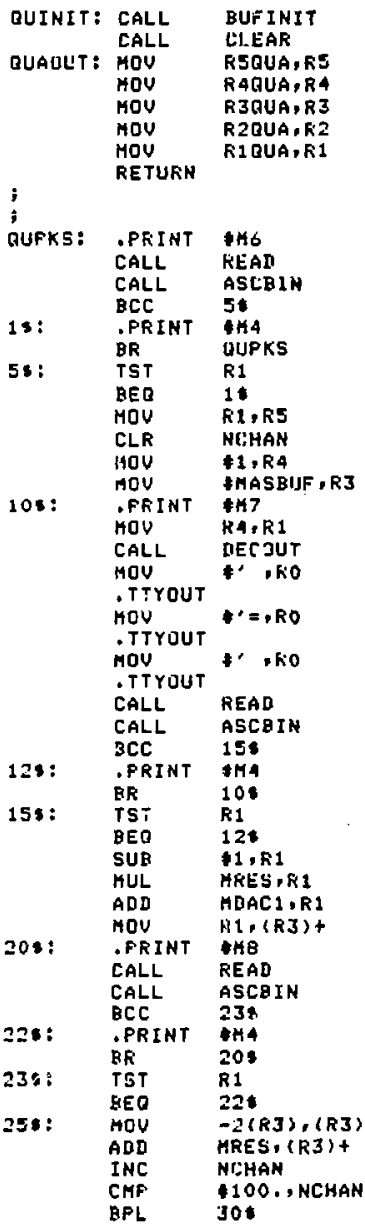

; GENERATE FRUHEK GHFFER PUINTEKS ICLEAR UAYA HUFFËRS †RESTUKE RE.GISTEKS

IASK FUR NUABER OF SEGHENTS IISET RESPIJHSE -CONUERT TU BINARY i GRANEH IF NU ERKOR

IZERO?

IL OUP COUNTER iclear chanNEL coIJNTER ISEGMENT COIJNTER M MASS SUFFER STARIING LDLATION IASK FUR STARTIHG EHAHAEL HUAHEKS

ITÝPE A SPACE

ITYPE =

I TYPE AMUIHEK SFACE

;GET REPLY

ILUNUERT YO AINARY

iBRANCH IF" NQ ERKUR

; TRY Alinin

IZERO?

:CHANNEL 1 = ZERO OFFGET

"MRES" UNITS PER CHANHEL ; STARTINU A-2-D UALUE iflaee In hass bufFer ;NUMBER OF LHANNELS IN SEGAHENT? †GET REPLY SCDNUERT TI) BINARY (REFLY IN R1) IBKANLH IF HO ERRIR

itry again D.EKO?

fCREaTE sigan akRay ; CUUNT NUHT.ER JJF CHANHELS FALLOW OHLY 100 CHANNELS 


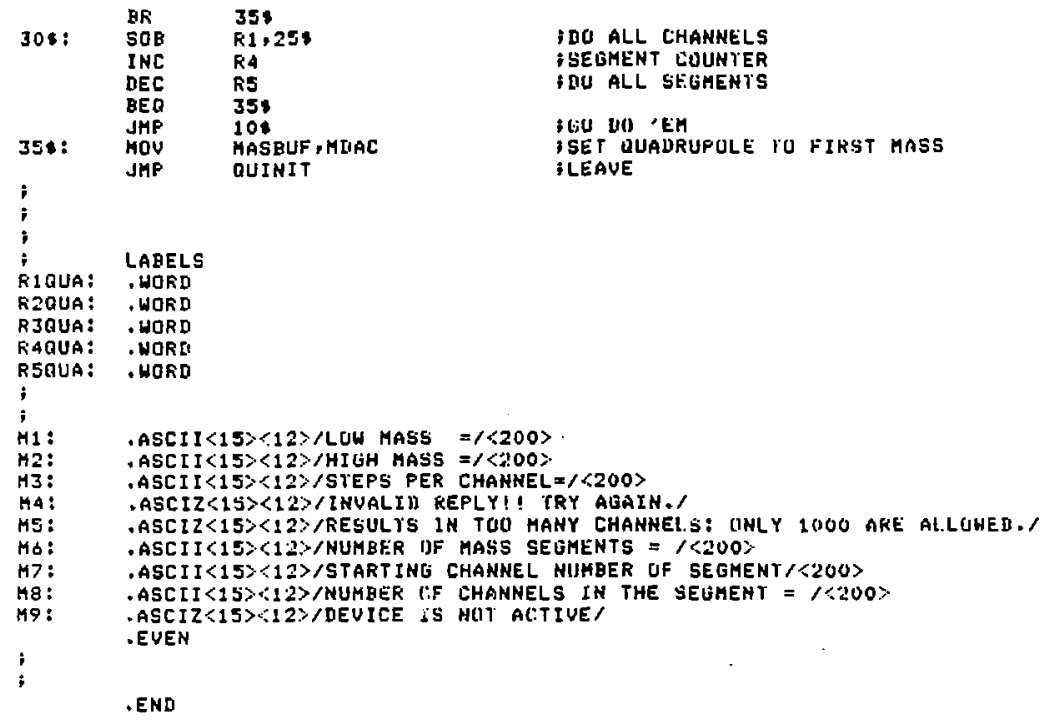




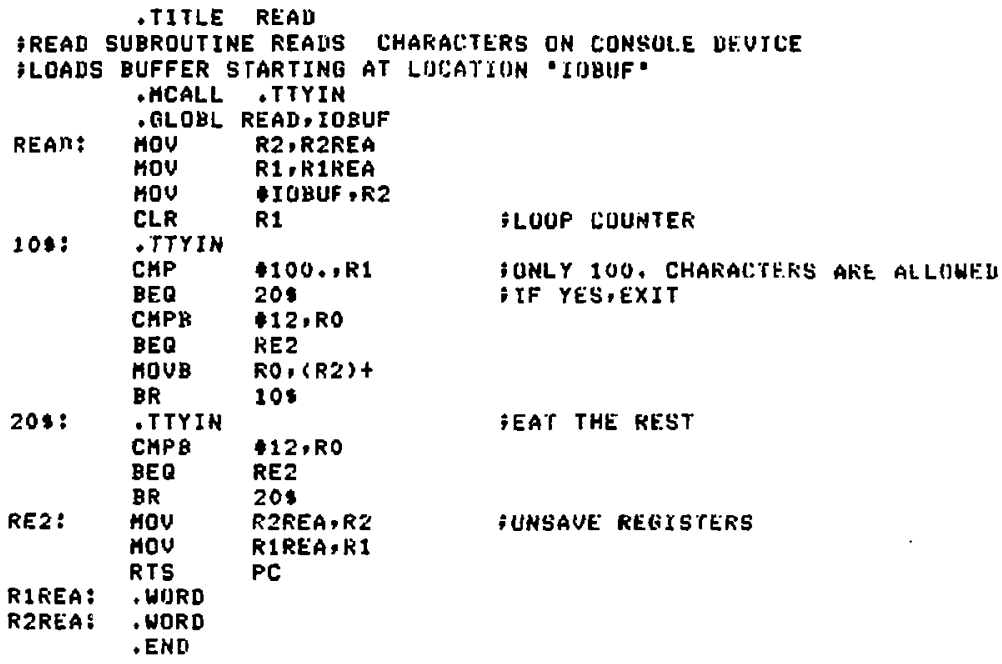


SUEFJUTINE PLOTTR SPLCTRL, FLCHAR, FLLINE, IISIR", HYCHNS,STCHAN, PL.HIU, (YMAX)

INTEGER PLCTRL, UISTRT, DICHNS, STCHAN

INTEGER PLLINE, PLLHAR, PLMOU,CTRLL, PI.MOUE

EXTERNAL RUN

INTEGERE 4 YHAX

REAL $\$ 8$ DJFLT

DIMENSION ITOCK( 9 )

C
C
C
C
C
!
l:

C DEFINE SFECIAL CHARACTERS

$C T R L C=3$

TURN PLOTTER UN.

CALL ON

CALL DNMODE

CALL XONOFF

INI T IALIZE. TYPE 100

FORHAT ("INAPUIIP704,1630,10306,8103\%")

IF(PLLTRL .EU.' 'PP' .OR. PLETKL .EO. 'PH') GU TO H5O

IF (FLCTRL ,EQ. 'PC') GO TO 1510

IF (PLCTRL .EQ. ' $P H$ ')

IF (PLETRL ,EQ. ' $F U$ ') GO TO 2200

IF (PLCTRL .EQ. 'PA') 10192300

C

C

C

DRAW THE BOX,

TYFE 200

200 FOKMAT ('US10:PA10306,6:03:FU;')

TYPE 250

250

C

FORMAT ("PA10306,1135,704,1135,704,8103,10306,8103;FU,USi')

C

C

i

300

350

360

450

500

550

CHANGE SCALE--IIFAH THE Y-AXIS TICKS.

TYPE 300

FORHAT ('SCO,101,0,105;PAU,-10iTL1,0;')

TYPE 3SW, LTRLC

FORHAT (? YT;EF-3.5,-.25iLE-10, A1)

DO $500,1=0,100,10$

TYPE AEO,I,I,CTRLC

FORHAT ?, PAO,'I3,',YTICP-3,3,-.2SILE, I3,A1

CONT INUE

TYPE 550

FORMAT ('TLO,1;')

IO $600 I=-10,100,10$

TYPE $575, I$

575 FORHAT ('PALOL,,IJ,'MTF') 


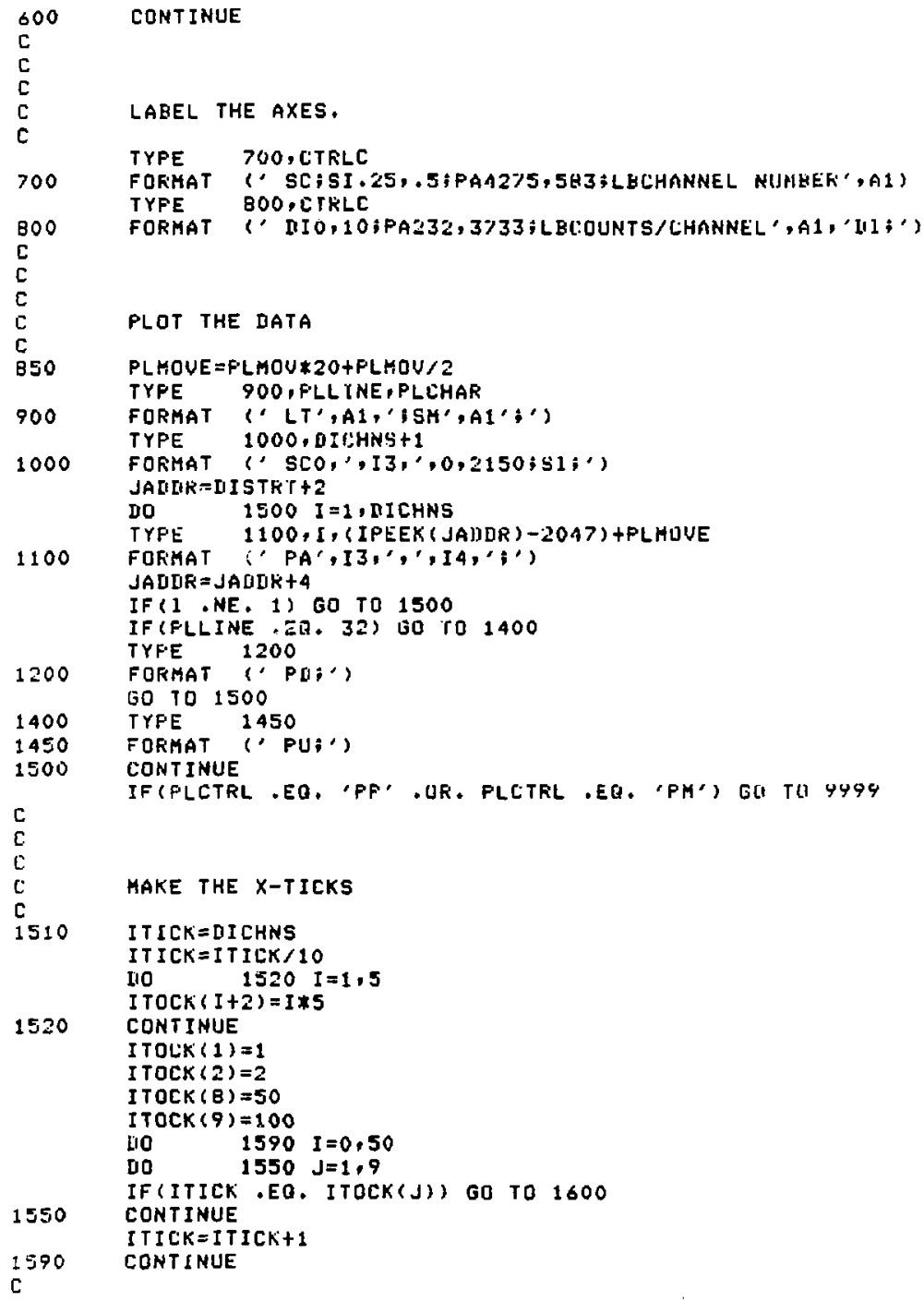




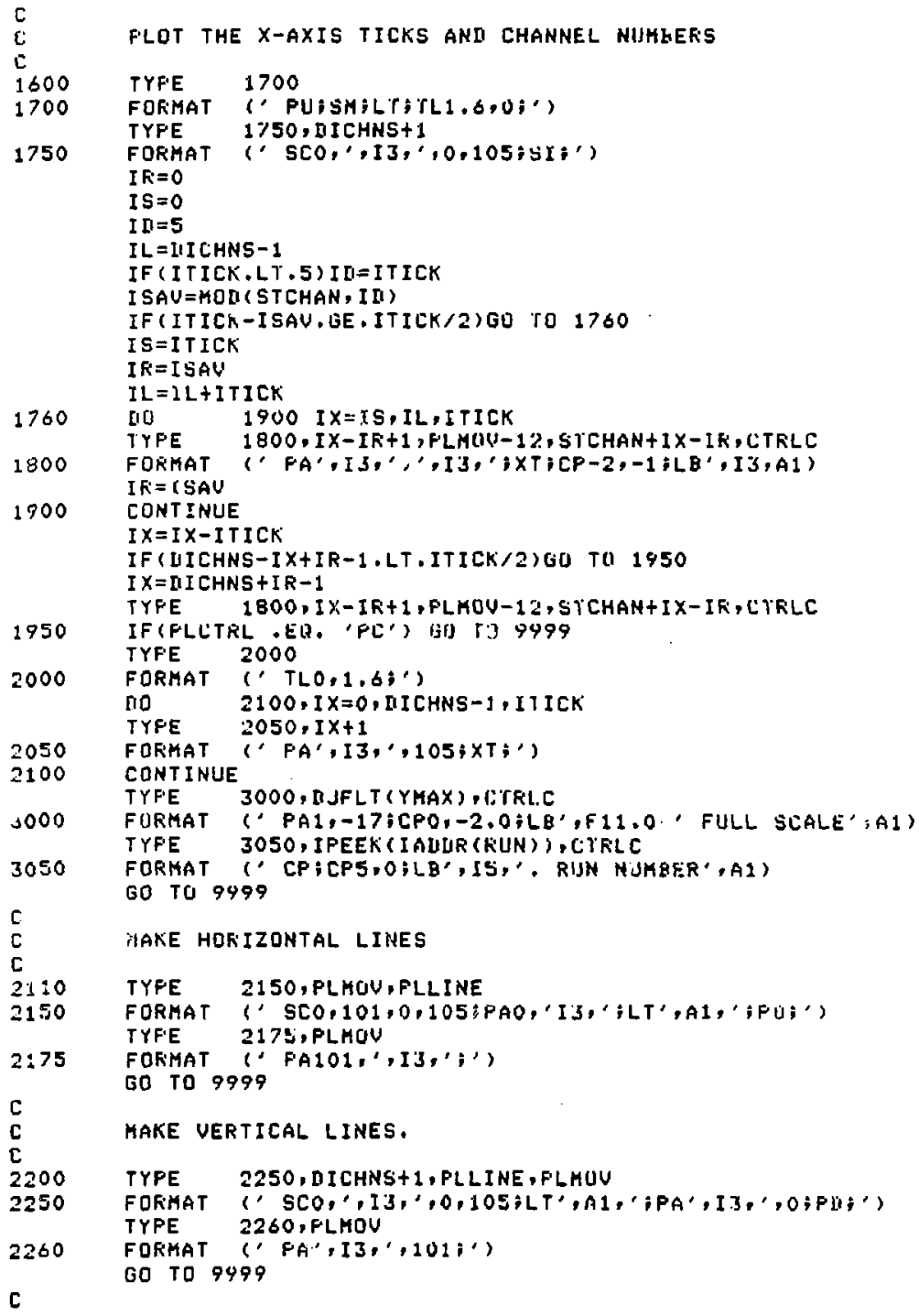




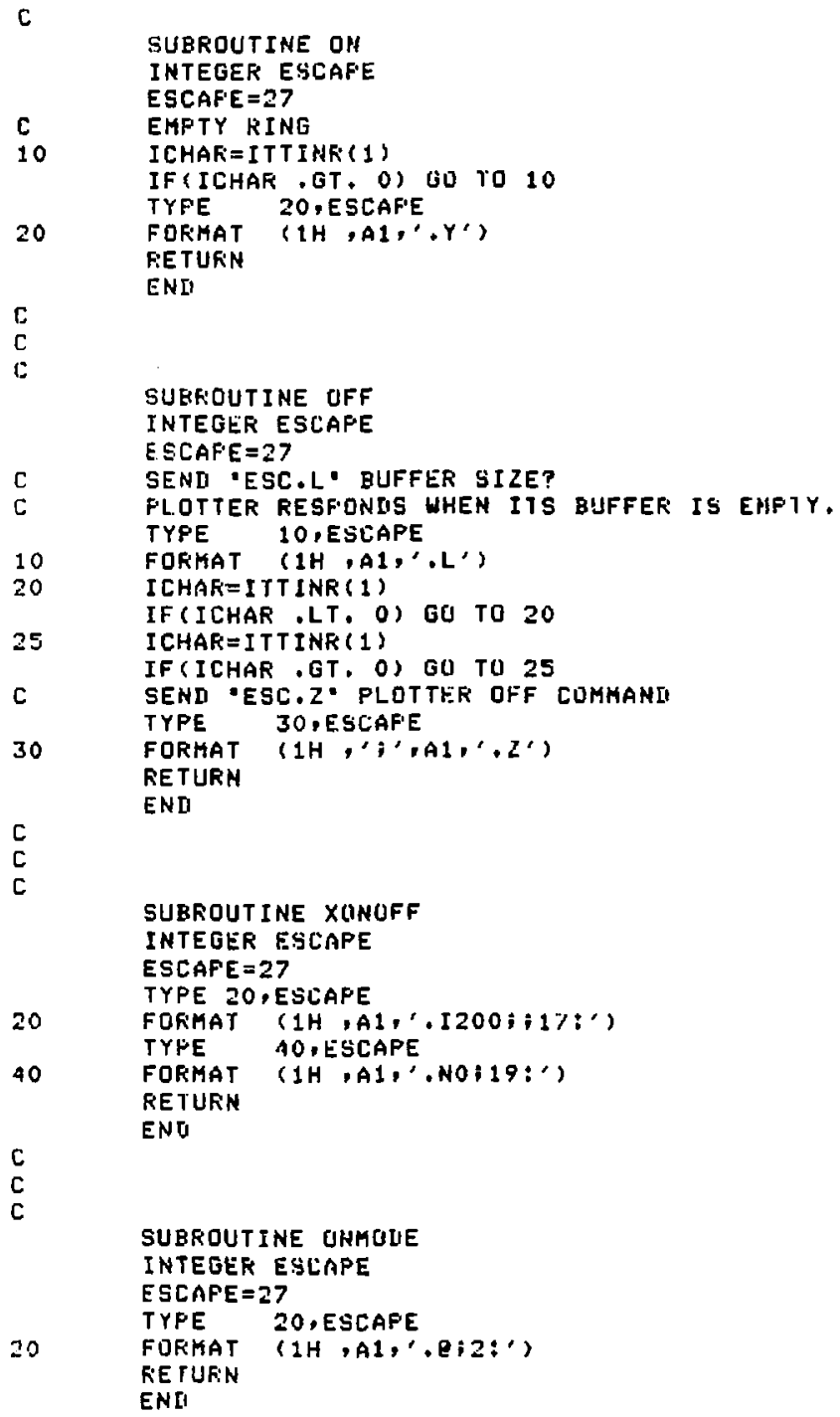

c

c

c

SUBROUTINE UNMQUE

INTEGER ESLAPE

ESCAPE $=27$

TYPE 2O,ESCAFE

20 FORKAT (1H,A1,', RI2:')

ENII 


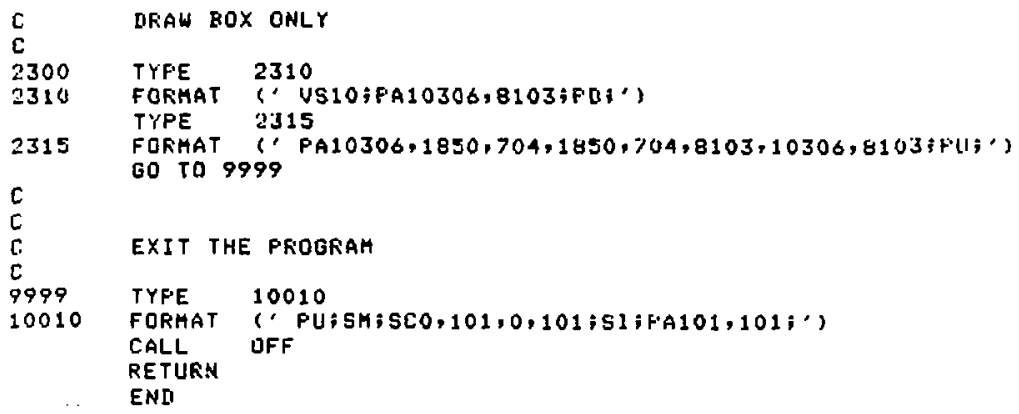

